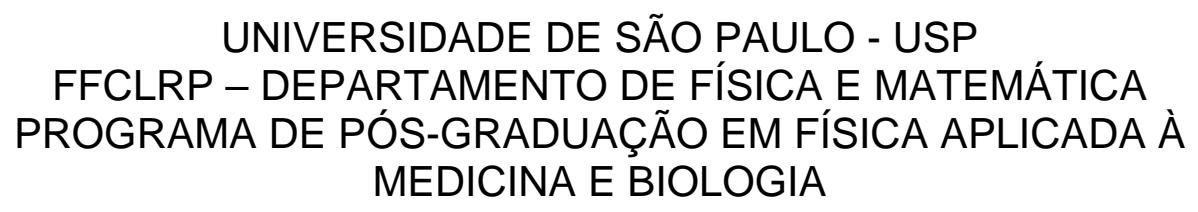

MEDICINA E BIOLOGIA

\title{
Materiais micro e nanoestruturados para sensores de íons do tipo EGFET
}

\section{Gláucio Ribeiro Silva}

Tese apresentada ao Departamento de Física e Matemática da Faculdade de Filosofia, Ciências e Letras de Ribeirão Preto da Universidade de São Paulo, como parte das exigências para a obtenção do título de doutor em Ciências.

Área de Concentração: Física Aplicada à Medicina e Biologia.

\section{RIBEIRÃO PRETO - SP}




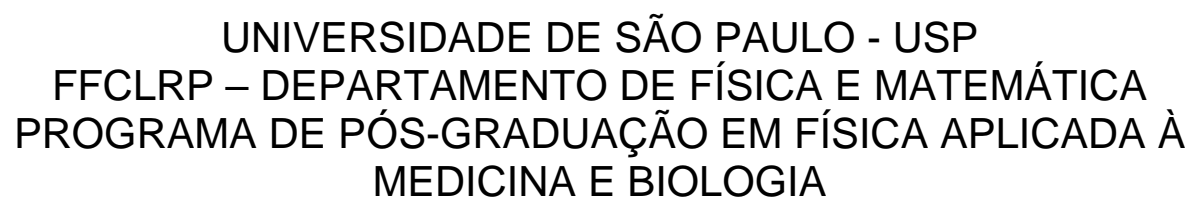

MEDICINA E BIOLOGIA

\section{Materiais micro e nanoestruturados para sensores de íons do tipo EGFET}

\section{Gláucio Ribeiro Silva}

Tese apresentada ao Departamento de Física e Matemática da Faculdade de Filosofia, Ciências e Letras de Ribeirão Preto da Universidade de São Paulo, como parte das exigências para a obtenção do título de doutor em Ciências.

Área de Concentração: Física Aplicada à Medicina e Biologia.

\section{RIBEIRÃO PRETO - SP}




\section{FICHA CATALOGRÁFICA}

AUTORIZO A REPRODUÇÃO E DIVULGAÇÃO TOTAL OU PARCIAL DESTE TRABALHO, POR QUALQUER MEIO CONVENCIONAL OU ELETRÔNICO, PARA FINS DE ESTUDO E PESQUISA, DESDE QUE CITADA A FONTE.

Silva, Gláucio Ribeiro

Materiais micro e nanoestruturados para sensores de íons do tipo EGFET.

Ribeirão Preto, 2009

144 p.;il.;30cm

Tese de Doutorado, apresentada ao Departamento de Física e Matemática da Faculdade de Filosofia, Ciências e Letras de Ribeirão Preto da Universidade de São Paulo. Área de concentração: Física Aplicada à Medicina e Biologia.

Orientador: Mulato, Marcelo

1. EGFET. 2. Sensor de Íons. 3. Nanotubos de Carbono.

4. Feltro de Carbono. 
Gláucio Ribeiro Silva

\title{
Materiais micro e nanoestruturados para sensores de íons do tipo EGFET
}

\author{
Tese para obtenção do grau de Doutor
}

Departamento de Física e Matemática da Faculdade de Filosofia, Ciência e Letras de Ribeirão Preto - USP

Área: Física Aplicada à Medicina e Biologia

Comissão Julgadora

Orientador:

$2^{\circ}$ Examinador:

$3^{\circ}$ Examinador:

$4^{\circ}$ Examinador:

$5^{\circ}$ Examinador:

Ribeirão Preto, de de 2009 
A minha esposa Mônica, pelo amor, carinho, paciência, compreensão e incentivo;

Aos meus filhos: Ana Clara, presente de Deus e mais uma benção que está por vir;

A minha mãe Cenide, pelo carinho e orações;

Ao meu irmão Leandro pelo apoio e incentivo e pela ajuda incondicional;

Em especial à memória de meu pai Elio, que se faz presente em todos os momentos de minha vida e principalmente por ter acreditado em minha capacidade. O senhor faz muita falta, meu "velho" 


\section{Agradecimentos}

A realização deste trabalho, só foi possível graças à colaboração direta e muitas pessoas. Manifesto minha gratidão a todas elas;

A Deus, presença forte em minha vida, por ter me possibilitado e conduzido a chegar até aqui;

Ao meu orientador, Prof. Dr. Marcelo Mulato, pela orientação, compreensão, paciência e pelos ensinamentos transmitidos;

Ao Prof. Dr. José Maurício Rosolen, pela co-orientação e contribuições para a realização deste trabalho;

Aos funcionários do Departamento, pelo esforço e colaboração;

Aos Técnicos Aziane e Elcio, pela ajuda e pelo suporte técnico durante a fabricação dos equipamentos. Valeu mesmo;

Aos colegas e amigos, que fazem ou que fizeram parte, do Laboratório por tornar um ambiente de trabalho divertido e pela ajuda quando precisei, em especial a Thaís, Nathália, Elídia, Júlio, José Fernando, Tobias e Marcílio.

Aos colegas e amigos do Departamento, que comigo trilham o mesmo caminho, pela prontidão nos momentos em que precisei. Em especial ao Rond, Jorge, Ernando, Cássia e Tiago.

Aos amigos da casa da pós e agregados, pela compreensão, apoio e amizade. Vocês não sabem o quanto vocês são importantes, pela acolhida e por facilitar a adaptação e tornaram parte da minha vida. Em especial à Gláucia, Juliana, Jaqueline, Luciana, Ricardo (pancinha), Camilo, João Paulo, Alvinho, Roberto Ruller (Bob), Ademar, Pablo (não saía de lá). "Valeu Moçada". Gostaria de não citar nomes para não esquecer alguém, mas fui obrigado. Sei que vou esquecer alguém. Peço perdão, aceite é verdadeiro.

Aos amigos de Araxá, que entendem a distância que nos separam. Em especial ao Fernando e Renata, pelo apoio e incentivo. A Prof. Rosa Villaça que contribuiu para que houvesse menos erros.

Ao Prof. Robson do IFMG, por possibilitar que esse trabalho se realizasse, dando-me condições para terminá-lo. Muito obrigado, Robson. E também aos amigos do IFMG que seguraram as "pontas" quando estive ausente.

Em especial à Mônica por estar sempre ao meu lado, suportando tudo junto comigo. Você se fez companheira e cúmplice em todo o percurso da minha vida, inclusive do trabalho. Não poderia ficar de fora do mérito. Ele também é seu. Obrigado por cuidar tão bem dos nossos filhos, na minha ausência. Obrigado pelo apoio incondicional em todos os momentos. Sacrificando a sua vida em favor da minha. Muito obrigado; 
Mãe, obrigado pelo carinho e orações. Continue sempre assim. Leandro, obrigado pelo apoio e ajuda quando precisei. A minha família de modo geral, por tornar o fim de semana agradável e pela compreensão da "bagunça" em casa. Muito obrigado.

Ao Luciano Montoro, pela ajuda fundamental no desenvolvimento deste trabalho.

A todas as outras pessoas que de alguma forma contribuíram para a realização deste trabalho e que por falha da minha memória não foram citadas.

A CAPES, CNPQ e FAPESP pelo apoio financeiro;

A USP, por toda a infraestrutura. 
"Eu quase nada sei, mas desconfio de muita coisa"

(Guimarães Rosa)

"invoca-me, e te respondereis, revelando-te grandes coisas misteriosas que ignoras"

(JR 33,3) 


\section{Sumário}

Resumo

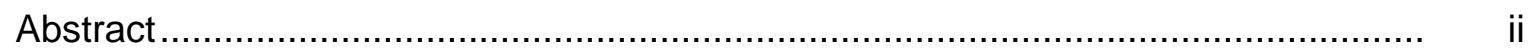

Índice de Figuras ......................................................................................... iii

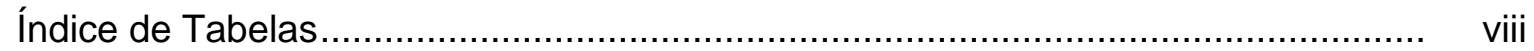

Lista de Abreviaturas e Siglas...................................................................... ix

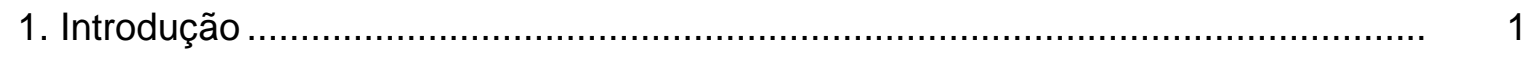

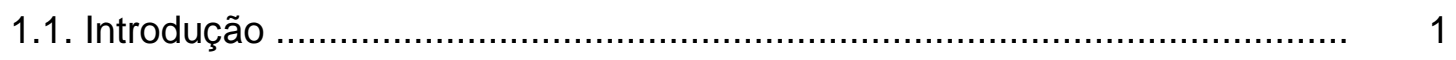

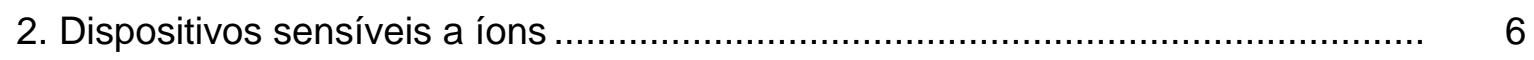

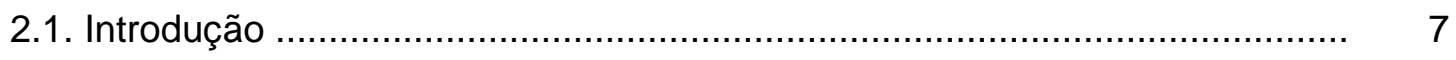

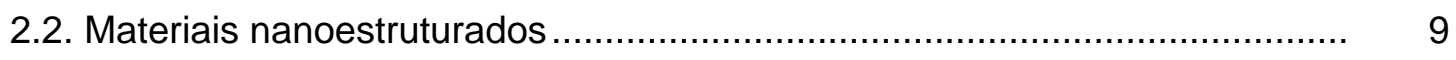

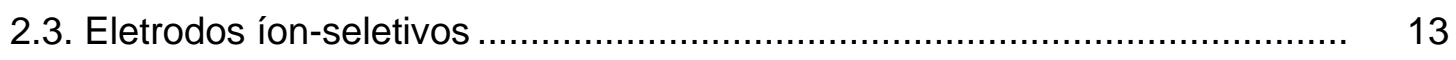

2.4. Princípio de Funcionamento do ISFET .................................................. 15

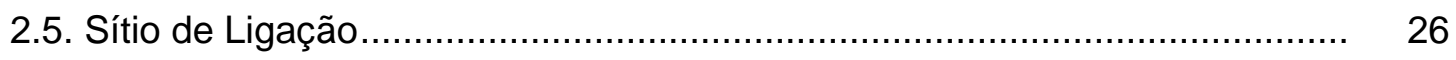

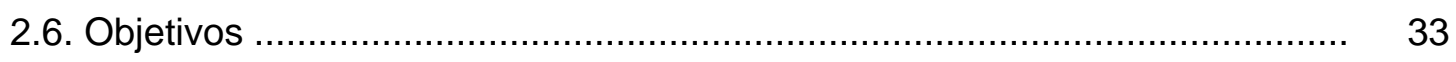

3. EGFET com óxido de manganês............................................................. 35

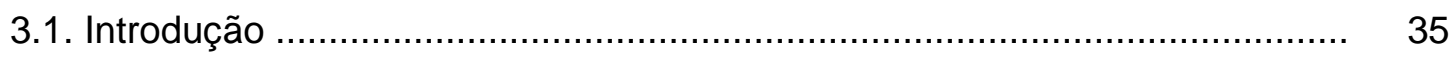

3.1.1. Óxido de manganês nanoestruturados .............................................. $\quad 35$

3.1.2. Método hidrotérmico ................................................................... $\quad 37$

3.1.3. Produção do óxido de manganês e dos filmes finos........................... 37

3.2. Caracterização no infravermelho (FTIR) ………………………............ 38

3.3. Caracterização estrutural (DRX) ....................................................... 40

3.4. Caracterização da superfície (MEV) .................................................... 43

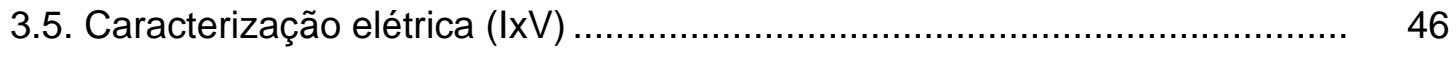

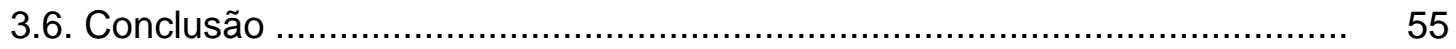

4. EGFET com nanotubos de carbono.......................................................... 58

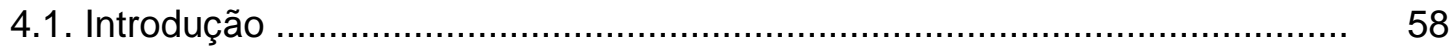

4.2. Preparação dos filmes finos de nanotubos de carbono .............................. 61

4.2.1. Produção dos nanotubos de carbono e dos filmes finos ..................... 61

4.3. Caracterização no infravermelho (FTIR) .................................................. 63 


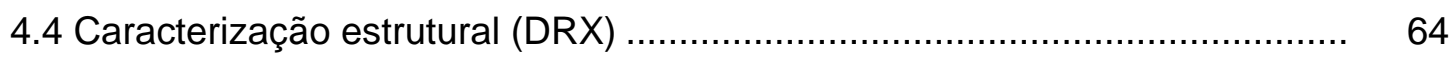

4.5. Caracterização da superfície (MEV) ................................................ 67

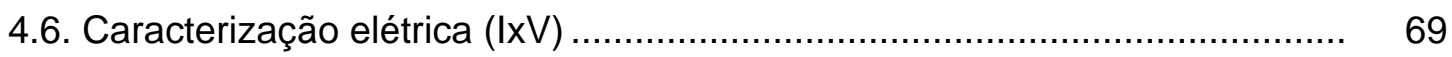

4.6.1. Substrato de vidro liso (VL) ................................................ 69

4.6.2. Substrato de vidro rugoso (VR) ............................................. 78

4.7. Conclusão ….................................................................................... 86

5. EGFET com feltro de carbono …............................................................ 88

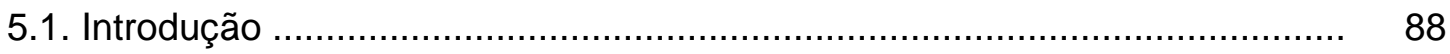

5.1.1. Polímeros ............................................................................. 90

5.1.2. Polímeros condutores .............................................................. 90

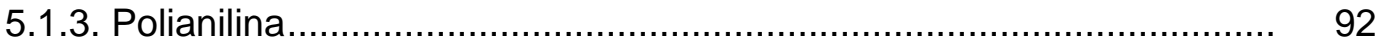

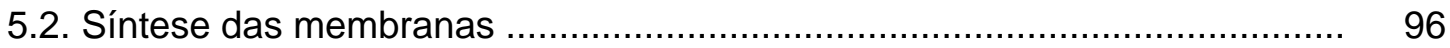

5.3. Caracterização da superfície (MEV) ................................................ 98

5.4. Caracterização no infravermelho (FTIR) ............................................ 107

5.5. Caracterização elétrica (IXV) .......................................................... 109

5.5.1. Influência dos nanotubos ....................................................... 112

5.5.2. Influência da polianilina ............................................................ 117

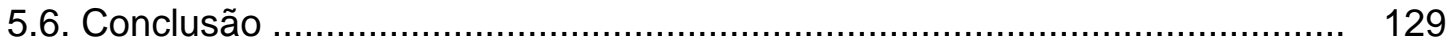

6. Conclusão …............................................................................................. 132

7. Referências bibliográficas ....................................................................... 137 


\section{Resumo}

Silva, G. R.; Materiais micro e nanoestruturados para sensores de íons do tipo EGFET, Tese de Doutorado - Departamento de Física de Matemática, Faculdade de Filosofia Ciências e Letras, Universidade de São Paulo, Ribeirão Preto.

Palavras Chaves: EGFET, Sensor de íons, Nanotubos de carbono, Feltro de Carbono,.

Este trabalho descreve os resultados do estudo de materiais como óxido de manganês, nanotubos de carbono e feltro de carbono (puro e recoberto com nanotubos ou polianilina-Pani), assim como do desenvolvimento de dispositivos. Os dispositivos estudados estão relacionados a sensores de $\mathrm{pH}$, utilizando esses materiais como membranas seletivas de $\mathrm{H}^{+}$. Essas membranas funcionam como parte de dispositivos denominados EGFETs, cujo princípio de funcionamento é semelhante ao ISFET. Inicialmente utilizamos o óxido de manganês produzido através do método hidrotérmico com posterior fabricação de filmes finos desse material através da técnica de spray-pyrolysis. Esses filmes foram depositados variando a temperatura de deposição, a concentração da solução e o tipo de superfície do substrato de vidro, com o objetivo de investigar a resposta elétrica do EGFET em função da concentração de íons de $\mathrm{H}^{+}$. As melhores sensibilidades foram de $50,1 \mathrm{mV} / \mathrm{pH}$ e $75 \mathrm{mV} / \mathrm{pH}$ no filmes produzidos no substrato de vidro rugoso e vidro liso, respectivamente, com $2 \mathrm{~g} / \mathrm{l}$ de concentração e temperatura de $80^{\circ} \mathrm{C}$ em ambos os filmes. Num segundo momento, trabalhamos com a produção de nanotubos de carbono e posterior fabricação de filmes finos também pela técnica de spray-pyrolysis, tendo como parâmetros, os mesmos utilizados na primeira parte. Os filmes finos que melhor responderam foram aqueles produzidos a $80^{\circ} \mathrm{C}$ no vidro rugoso e $100^{\circ} \mathrm{C}$ no vidro liso, com sensibilidades de $51,6 \mathrm{mV} / \mathrm{pH}$ e $53,1 \mathrm{mV} / \mathrm{pH}$, respectivamente, ambos com $3 \mathrm{~g} / \mathrm{l}$ de concentração. Finalmente, utilizamos os feltros de carbono ( $F C$ ) como membrana seletiva e também como substrato para os nanotubos de carbono (NTC) e a polianilina (Pani). Como membrana, os feltros tiveram uma sensibilidade de $65,47 \mathrm{mV} / \mathrm{pH}$. NTC purificados e não purificados foram também depositados utilizando FC como substrato. NTC não purificados apresentaram pior resposta, enquanto que a parte que foi purificada teve um ligeiro aumento na sensibilidade, sendo de $67,7 \mathrm{mV} / \mathrm{pH}$. Houve ainda o recobrimento dos FC e dos FC/NTC com a Pani. As membranas que contém Pani, são mais estáveis do que as outras amostras, sendo que a Pani no estado deprotonado tem melhor sensibilidade e estabilidade do a Pani no estado protonado. A melhor sensibilidade obtida com a participação da Pani foi de 46,4 $\mathrm{mV} / \mathrm{pH}$, que mesmo assim não supera a das demais amostras. Esses materiais se mostram como potenciais para uso de sensores de $\mathrm{pH}$ e posteriormente para uso como biossensores. 


\section{Abstract}

Silva, G. R.; Micro and nanostructured materials for EGFET ion sensor, Tese de Doutorado - Departamento de Física de Matemática, Faculdade de Filosofia Ciências e Letras, Universidade de São Paulo, Ribeirão Preto.

Keywords: EGFET, Ion sensor, Carbon nanotubes, Carbon felt,.

This work presents the results related to the study of materials such as manganese oxide, carbon nanotubes and carbon felt (pure and with deposition of nanotubes and polyaniline-Pani). The development of devices related to $\mathrm{pH}$ sensors is also presented. The materials are used as $\mathrm{H}^{+}$selective membranes in sensors based on the EGFET configuration, almost similar to the ISFET. We produced manganese oxide by the hydrothermal method with subsequent deposition of thin films using spray pyrolysis. We varied the deposition temperature, concentration of solution and glass substrates surface with the aim of studying the electrical response of the EGFET as a function of the concentration of $\mathrm{H}^{+}$ions. The best sensitivities were $50.1 \mathrm{mV} / \mathrm{pH}$ and $75 \mathrm{mV} / \mathrm{pH}$ for films grown on rough and flat substrates, respectively, with a concentration of $2 \mathrm{~g} / \mathrm{l}$ and substrate temperature of $80^{\circ} \mathrm{C}$ for both films. In the sequence, carbon nanotubes were investigated with the production of thin films also using the spray pyrolysis technique with the same deposition parameters. Films produced at $80^{\circ} \mathrm{C}$ on rough substrates and at $100^{\circ} \mathrm{C}$ on flat substrates presented sensitivities of $51.6 \mathrm{mV} / \mathrm{pH}$ and $53.1 \mathrm{mV} / \mathrm{pH}$, respectively. Both were produced with a concentration of $3 \mathrm{~g} / \mathrm{l}$. Finally, carbon felts (FC) were used as selective membranes and also as substrates for the deposition of NTC and Pani. As single membrane FC presented a sensitivity of $65.47 \mathrm{mV} / \mathrm{pH}$. Purified and non-purified NTC were deposited on FC. Non-purified NTC presented the worst response, while purified NTC presented an increase in sensitivity to about $67.7 \mathrm{mV} / \mathrm{pH}$. Pani was then deposited over FC and FC/NTC. Membranes that contain Pani were more stable than other samples. Pani was used either protonated or deprotonated. Deprotonated samples presented a better response. The best response with Pani was about $46.4 \mathrm{mV} / \mathrm{pH}$, which is not as good as the one corresponding to other samples. These materials are promising candidates for a future use as $\mathrm{H}+$ sensors, and also as biosensors. 


\section{Índices de Figuras}

Figura 2.1: Representações das regiões do MOSFET

Figura 2.2: Representação de um MOSFET em (a) onde aparece a porta metálica que por sua vez foi substituído por uma membrana seletiva e o eletrodo de referencia no ISFET em (b) enquanto que a representação do circuito equivalente de ambos estão representados em (c)

Figura 2.3: Representação do sistema de medida. O EGFET consiste em uma membrana seletiva conectada a um MOSFET

Figura 3.1: Análise de FTIR da amostra do óxido de manganês em forma de pó obtido pelo método hidrotérmico que posteriormente foi usado na produção dos filmes finos .... 39 Figura 3.2: Espectro de difração de raios-X do óxido de manganês, na forma de pó, sintetizado pelo método hidrotérmico e utilizado para a produção dos filmes finos 41

Figura 3.3: Espectro de difração de raios- $X$ dos fimes finos de óxido de manganês feito pela técnica de spray pyrolysis com concentração de $2 \mathrm{~g} / \mathrm{l}$ nos substratos de vidro liso e rugoso 42

Figura 3.4: Imagens de microscopia eletrônica de varredura do óxido de manganês sintetizados pelo método hidrotérmico e utilizados para a produção dos filmes finos.......44 Figura 3.5: Imagens de microscopia eletrônica de varredura dos filmes de óxido de manganês depositado sobre o vidro liso à $80^{\circ} \mathrm{C}$ com concentração de $2 \mathrm{~g} / \mathrm{l}$ 45

Figura 3.6: Curva da resposta do filme fino de óxido de manganês EGFET depositado com concentração de $1 \mathrm{~g} / \mathrm{l}$ a $80^{\circ} \mathrm{C}$. Em (a) o EGFET operando na região de saturação e (b) na região linear, filmes depositados sobre VR. Em (c) o EGFET operando na região de saturação e (d) na região linear, filmes depositados sobre VL

Figura 3.7: Curva da resposta do filme fino de óxido de manganês EGFET depositado com concentração de $3 \mathrm{~g} / \mathrm{l}$ a $80^{\circ} \mathrm{C}$. Em (a) o EGFET operando na região de saturação e (b) na região linear, filmes depositados sobre VR. Em (c) o EGFET operando na região de saturação e (d) na região linear, filmes depositados sobre VL

Figura 3.8: Curva de resposta do filme fino de óxido de manganês EGFET depositada a $80^{\circ} \mathrm{C}$ com concentração de $2 \mathrm{~g} / \mathrm{l}$ em substrato rugoso (VR). Em (a) apresenta o EGFET operando na região de saturação, em (b) na região linear enquanto que em (c) mostra a relação da raiz quadrada da corrente função do pH e em (d) a sensibilidade do dispositivo ..... 50 
Figura 3.9: Comportamento da corrente de dreno em função do tempo, depositado a $80^{\circ} \mathrm{C}$ com concentração de $2 \mathrm{~g} / \mathrm{l}$ em substrato rugoso (VR)

Figura 3.10: Curva de resposta do filme fino de óxido de manganês EGFET depositada a $80^{\circ} \mathrm{C}$ com concentração de $2 \mathrm{~g} / \mathrm{l}$ em substrato liso (VL). Em (a) apresenta o EGFET operando na região de saturação, em (b) na região linear enquanto que em (c) mostra a relação da raiz quadrada da corrente função do pH e em (d) a sensibilidade do dispositivo .53

Figura 3.11: Comportamento da corrente de dreno em função do tempo, depositado a $80^{\circ} \mathrm{C}$ com concentração de $2 \mathrm{~g} / \mathrm{l}$ em substrato liso (VL) 54

Figura 4.1: A ilustração da construção de um nanotubo, enrolando uma folha de grafite na direção do vetor chiral C.. Se o enrolamento fosse na direção das linhas pontilhadas, teríamos tubos armchair e zigzag. Todos os outros tubos chiral, são gerados pelo ângulo de helicidade $\phi$ medido a partir da direção armchair, ou pelo ângulo $\theta$ medido a partir da direção zigzag .

Figura 4.2: Análise de FTIR do pó de nanotubos de carbono obtido pela técnica de CVD....63 Figura 4.3: Espectros de DRX das amostras produzidas sobre o vidro liso (VL) em diferentes concentrações e temperaturas e também do pó usado na produção dos filmes finos

Figura 4.4: Espectros de DRX das amostras produzidas sobre o substrato de vidro rugoso (VR) em diferentes concentrações e temperaturas

Figura 4.5: Imagens de microscopia eletrônica de varredura da amostra produzida a $80^{\circ} \mathrm{C}$ sobre o substrato de vidro rugoso com concentração de $3 \mathrm{~g} / \mathrm{l}$ 68

Figura 4.6: Imagens de microscopia eletrônica de varredura do filme fino produzido sobre o substrato de vidro liso a $100^{\circ} \mathrm{C}$ com concentração de $3 \mathrm{~g} / \mathrm{l}$ 68

Figura 4.7: Curva de resposta do filme fino de NTC EGFET depositado sobre substrato de vidro liso à $80^{\circ} \mathrm{C}$ com concentração de $1 \mathrm{~g} / \mathrm{l}$. Em (a) apresenta o EGFET operando nas regiões de saturação e em (b) na região linear, enquanto que em (c) o comportamento da raiz quadrada da corrente em função da variação do $\mathrm{pH}$ e (d) a sensibilidade. 71

Figura 4.8: Curva de resposta do filme fino de NTC EGFET depositada sobre substrato de vidro liso à $80^{\circ} \mathrm{C}$ com concentração de $3 \mathrm{~g} / \mathrm{l}$. Em (a) apresenta o EGFET operando nas região de saturação e em (b) na região linear, enquanto que em (c) o comportamento da raiz quadrada da corrente em função da variação do pH e (d) a sensibilidade 72 Figura 4.9: Curva de resposta dos filmes finos de NTC EGFET depositados sobre substrato de vidro liso à $80^{\circ} \mathrm{C}$ com concentração de $3 \mathrm{~g} / \mathrm{l}(\mathrm{a})$ e $1 \mathrm{~g} / \mathrm{l}$ em (b). 73 
Figura 4.10: Curva de resposta do filme fino de NTC EGFET depositada sobre substrato de vidro liso à $100^{\circ} \mathrm{C}$ com concentração de $1 \mathrm{~g} / \mathrm{l}$. Em (a) apresenta o EGFET operando nas região de saturação e em (b) na região linear, enquanto que em (c) o comportamento da raiz quadrada da corrente em função da variação do $\mathrm{pH}$ e (d) a sensibilidade 74

Figura 4.11: Curva de resposta do filme fino de NTC EGFET depositada sobre substrato de vidro liso à $100^{\circ} \mathrm{C}$ com concentração de $3 \mathrm{~g} / \mathrm{l}$. Em (a) apresenta o EGFET operando na região de saturação e em (b) na região linear, enquanto que em (c) o comportamento da raiz quadrada da corrente em função da variação do $\mathrm{pH}$ e (d) a sensibilidade. 76

Figura 4.12: Curva de resposta dos filmes finos de NTC EGFET depositados sobre substrato de vidro liso à $100^{\circ} \mathrm{C}$ com concentração de $3 g / l$ (a) e 1g/l em (b) 77

Figura 4.13: Curva de resposta do filme fino de NTC EGFET depositada sobre substrato de vidro rugoso à $80^{\circ} \mathrm{C}$ com concentração de $1 \mathrm{~g} / \mathrm{l}$. Em (a) apresenta o EGFET operando nas região de saturação e em (b) na região linear, enquanto que em (c) o comportamento da raiz quadrada da corrente em função da variação do pH e (d) a sensibilidade. 78

Figura 4.14: Curva de resposta do filme fino de NTC EGFET depositada sobre substrato de vidro rugoso à $80^{\circ} \mathrm{C}$ com concentração de $3 \mathrm{~g} / \mathrm{l}$. Em (a) apresenta o EGFET operando nas região de saturação e em (b) na região linear, enquanto que em (c) o comportamento da raiz quadrada da corrente em função da variação do $\mathrm{pH}$ e (d) a sensibilidade..... 80

Figura 4.15: Curva de resposta dos filmes finos de NTC EGFET depositados sobre substrato de vidro rugoso à $80^{\circ} \mathrm{C}$ com concentração de $3 \mathrm{~g} / \mathrm{l}$ (a) e $1 \mathrm{~g} / \mathrm{l}$ em (b) .....

Figura 4.16: Curva de resposta do filme fino de NTC EGFET depositada sobre substrato de vidro rugoso à $100^{\circ} \mathrm{C}$ com concentração de $1 \mathrm{~g} / \mathrm{l}$. Em (a) apresenta o EGFET operando nas região de saturação e em (b) na região linear, enquanto que em (c) o comportamento da raiz quadrada da corrente em função da variação do $\mathrm{pH}$ e (d) a sensibilidade

Figura 4.17: Curva de resposta do filme fino de NTC EGFET depositada sobre substrato de vidro rugoso à $100^{\circ} \mathrm{C}$ com concentração de $3 \mathrm{~g} / \mathrm{l}$. Em (a) apresenta o EGFET operando nas região de saturação e em (b) na região linear, enquanto que em (c) o comportamento da raiz quadrada da corrente em função da variação do $\mathrm{pH}$ e (d) a sensibilidade

Figura 4.18: Curva de resposta dos filmes finos de NTC EGFET depositados sobre substrato de vidro rugoso à $80^{\circ} \mathrm{C}$ com concentração de $3 \mathrm{~g} / \mathrm{l}(\mathrm{a})$ e $1 \mathrm{~g} / \mathrm{l}$ em (b) .....

Figura 5.1: Ilustração da estrutura da Pani, mostrando os estados possíveis de protonação

Figura 5.2: Imagens de microscopia eletrônica de varredura do feltro de carbono (FC) derivado da poliacrilonitrica e utilizado para a produção das membranas 98 
Figura 5.3: Imagens de microscopia eletrônica de varredura da membrana de feltro de carbono com crescimento de nanotubos em suas fibras onde houve purificação da membrana para eliminação de catalisadores (FC/NTC-pur)

Figura 5.4: Imagens de microscopia eletrônica de varredura da membrana de feltro de carbono com crescimento de nanotubos em suas fibras onde não houve purificação da membrana para eliminação de catalisadores (FC/NTC-npur) 101

Figura 5.5: Imagens de microscopia eletrônica de varredura da membrana de feltro de carbono com crescimento de nanotubos, com purificação da membrana e também com polimerização da polianilina no seu estado protonado (FC/NTC-pur/Pani-pro).............. 102

Figura 5.6: Imagens de microscopia eletrônica de varredura da membrana de feltro de carbono com crescimento de nanotubos, sem purificação da membrana e também com polimerização da polianilina no seu estado protonado (FC/NTC-npur/Pani-pro)............. 103

Figura 5.7: Imagens de microscopia eletrônica de varredura da membrana de feltro de carbono com crescimento de nanotubos, com purificação da membrana e também com polimerização da polianilina no seu estado deprotonado (FC/NTC-pur/Pani-depro)....... 104

Figura 5.8: Imagens de microscopia eletrônica de varredura da membrana de feltro de carbono com crescimento de nanotubos, sem purificação da membrana e também com polimerização da polianilina no seu estado deprotonado (FC/NTC-npur/Pani-depro)..... 105

Figura 5.9: Imagens de microscopia eletrônica de varredura da membrana de feltro de carbono com polimerização da polianilina no seu estado protonado (FC/Pani-pro)........ 106

Figura 5.10: Imagens de microscopia eletrônica de varredura da membrana de feltro de carbono com polimerização da polianilina no seu estado deprotonado (FCt/Pani-depro)..... 106

Figura 5.11: Análise de FTIR da amostra de feltro e seus compostos que posteriormente foram usados como membrana seletiva ..... 108

Figura 5.12: Curva da resposta do FC como EGFET. Na figura é visto o EGFET operando na região de saturação (a) e na direita na região linear (b), com comportamento da raiz quadrada em funçao do $\mathrm{pH}$ (c) e da sensibilidade (d)

Figura 5.13: Curva da estabilidade das correntes de dreno em função do tempo, da amostra de FC

Figura 5.14: Curva da resposta do FC/NTC-pur como EGFET. Na figura é visto o EGFET operando na região de saturação (a) e na direita na região linear (b), com comportamento da raiz quadrada em funçao do $\mathrm{pH}$ (c) e da sensibilidade (d) 
Figura 5.15: Curva da resposta do FC/NTC-npur como EGFET. Na figura é visto o EGFET operando na região de saturação (a) e na direita na região linear (b), com comportamento da raiz quadrada em funçao do $\mathrm{pH}$ (c) e da sensibilidade (d)

Figura 5.16: Curva da estabilidade do FC/NTC-pur (a) e do FC/NTC-npur (b)como EGFET 116

Figura 5.17: Curva da resposta do FC/NTC-pur/Pani-pro como EGFET. Na figura é visto o EGFET operando na região de saturação (a) e na direita na região linear (b), com comportamento da raiz quadrada em funçao do $\mathrm{pH}$ (c) e da sensibilidade (d) 118

Figura 5.18: Curva da resposta do FC/NTC-pur/Pani-depro como EGFET. Na figura é visto o EGFET operando na região de saturação (a) e na direita na região linear (b), com comportamento da raiz quadrada em funçao do $\mathrm{pH}$ (c) e da sensibilidade (d) 119

Figura 5.19: Curva da estabilidade do FC/NTC-pur/Pani-pro (a) e do FC/NTC-pur/Panidepro (b)como EGFET. 120

Figura 5.20: Curva da resposta do FC/NTC-npur/Pani-pro como EGFET. Na figura é visto o EGFET operando na região de saturação (a) e na direita na região linear (b), com comportamento da raiz quadrada em funçao do $\mathrm{pH}$ (c) e da sensibilidade (d) 121

Figura 5.21: Curva da resposta do FC/NTC-npur/Pani-depro como EGFET. Na figura é visto o EGFET operando na região de saturação (a) e na direita na região linear (b), com comportamento da raiz quadrada em funçao do $\mathrm{pH}$ (c) e da sensibilidade (d) 123

Figura 5.22: Curva da estabilidade do FC/NTC-npur/Pani-pro (a) e do FC/NTC-npur/Panidepro (b)como EGFET. 123

Figura 5.23: Curva da resposta do FC/Pani-pro como EGFET. Na figura é visto o EGFET operando na região de saturação (a) e na direita na região linear (b), com comportamento da raiz quadrada em funçao do $\mathrm{pH}$ (c) e da sensibilidade (d)

Figura 5.24: Curva da resposta do FC/Pani-depro como EGFET. Na figura é visto o EGFET operando na região de saturação (a) e na direita na região linear (b), com comportamento da raiz quadrada em funçao do $\mathrm{pH}$ (c) e da sensibilidade (d) 125

Figura 5.25: Curva da estabilidade do FC/Pani-depro (a) e do FC/Pani-pro (b)como EGFET 126 


\section{Índices de Tabelas}

Tabela 2.1: Materiais utilizados como membranas para EGFETs

Tabela 4.1: Desempenho dos dispositivos depositados sobre o vidro liso

Tabela 4.2: Desempenho dos dispositivos depositados sobre o vidro rugoso.

84

Tabela 4.3: Desempenho dos dispositivos depositados sobre o VL e VR 85

Tabela 5.1: Desempenho dos dispositivos em relação a sua constituição 127 


\section{Lista de Abreviaturas e Siglas}

\section{ChemFET}

CTAB

CVD

DRX

EGFET

EIS

EnFET

FC

FC/NTC

FC/NTC/Pani

FET

FTIR

ID

IGFET

ISE

ISFET

JCPDS

MEV

MOSFET

MWNT

NTC

PAN

SDS

SWNT

$\mathrm{V}_{\mathrm{DS}}$

$V_{G S}$

$\mathrm{V}_{\mathrm{th}}$
Chemical field effect transistor

Brometo de cetiltrimetilamônio

Chemical vapor deposition

Difratometria de raios- $X$

Extended gate field effect transistor

Electrolyte-insulator-semiconductor

Enzyme field effect transistor

Feltros de carbono

Feltro/Nanotubos de carbono

Feltros/Nanotubos de carbono/Pani

Field effect transistor

Espectrometria no infravermelho com transformada de Fourier

Corrente de dreno

Insulated gate field effect transistor

Íon-sensitive electrode

Íon-sensitive field effect transistor

Joint committee on power difraction standarts

Microscopia eletrônica por varredura

Metal-oxide-semiconductor field effect transistor

Multi-wall carbon nanotubes

Nanotubos de carbono

Poliacrilonitrila

Dodecil sulfato de sódio

Single-wall carbon nanotubes

Tensão entre dreno e a fonte

Tensão entre gate e fonte

Tesão de limiar (threshold) 


\section{Introdução}

\section{1-Introdução}

O estudo e o desenvolvimento da ciência dos materiais são considerados hoje uma das linhas de pesquisa de maior interesse, tanto do ponto de vista acadêmico quanto tecnológico. A literatura científica apresenta uma vasta produção de temas relacionados à área de ciências dos materiais, o que reflete um interesse pela descoberta de novos materiais ou novas aplicações dos materiais já existentes.

Possivelmente, uma das habilidades mais desejáveis em um cientista moderno, e que atue na área específica do conhecimento de ciências dos materiais, não seja a de inventar/descobrir novos materiais, mas sim, a competência de unir (agregar/misturar) os materiais já existentes, com propriedades (físicas, químicas, etc.) bem estabelecidas, resultando no desenvolvimento de materiais com propriedades diferentes e específicas. 
Por se tratar de uma área de conhecimento que envolve vários campos de atuação da ciência, tais como 'física, química, engenharia, entre outras, a ciências dos materiais é considerada uma área inter/multidisciplinar. Por certo, esta é uma prática utilizada aqui, no programa de pós-graduação de Física Aplicada à Medicina e Biologia (FAMB), do departamento de Física e Matemática, da Faculdade de Filosofia, Ciências e Letras de Ribeirão Preto (FFCLRP) da Universidade de São Paulo (USP).

O desenvolvimento de novos materiais como parte da física dos dispositivos têm despertado interesses dos pesquisadores nas últimas décadas, o que se observa pela evolução de todas as áreas da ciência no meio acadêmico, assim como na indústria. Esse fato também pode ser verificado pelo aumento em número de publicações de artigos com o tema relacionado a novos materiais.

Um dos maiores avanços na utilização de novos materiais está na indústria eletrônica, onde descobertas na área de física dos dispositivos semicondutores resultaram na transição dos tubos de vácuo para diodos e transistores e posteriormente para chips miniaturizados.

Os primeiros dispositivos semicondutores remontam a 1947, quando W. Schockley, W. Brattain e J. Bardeen, nos EUA tiveram sucesso ao fabricarem o primeiro transistor de estado sólido. No inicio, as dimensões dos transistores eram de alguns centímetros. Com a evolução tecnológica nos anos seguintes, os dispositivos semicondutores passaram a ser produzidos com dimensões de milímetros e de alguns micrômetros.

A revolução da miniaturização possibilitou a fabricação de dispositivos e circuitos integrados digitais contendo componentes com dimensões sub- 
micrométricas. A partir da segunda metade dos anos 80 e até os dias de hoje, há pesquisas para o desenvolvimento de dispositivos semicondutores na escala nanométrica.

Dessa forma, verificamos o desenvolvimento e aplicações de materiais, chegando em nanoestruturas e nanodispositivos, que se utilizam das propriedades físicas, químicas, elétricas e óticas dessa nova fronteira da ciências dos materiais.

Entretanto, a nanociência e a nanotecnologia não se restringem apenas aos materiais e dispositivos semicondutores, envolvem, também, materiais plásticos (polímeros), cerâmicos, materiais isolantes, materiais metálicos, materiais biológicos, entre outros.

Dentro do contexto exposto anteriormente, foi que surgiu a motivação e o intuito para a realização do presente trabalho na busca de encontrar uma membrana que respondesse de forma satisfatória com relação à detecção de $\mathrm{H}^{+}$, fazendo uso de micro e nanoestruturas para confecção dos dispositivos. Foram produzidos e estudados três principais materiais: o feltro de carbono, o oxido de manganês e os nanotubos de carbono. Todos eles foram utilizados como membranas seletivas para desenvolvimentos de dispositivos que funcionassem como sensores de $\mathrm{pH}$, operando como porta estendida do transistor de efeito de campo.

Este trabalho foi realizado sob a orientação do Prof. Dr. Marcelo Mulato e contou com a co-orientação do Prof. Dr. José Maurício Rosolen e a apresentação do trabalho está divido em três partes principais, que são divididos em função dos materiais utilizados. No próximo capítulo faz-se uma pequena introdução contextualizando a importância de se medir o pH e o uso de um dispositivo 
alternativo ao transistor de efeito de campo sensível a íons. Faz-se também uma abordagem teórica do funcionamento do dispositivo. Nos capítulos seguintes, capítulos 3, 4 e 5, são discutidos os materiais utilizados como membranas seletivas.

No capítulo 2 será apresentada uma breve revisão sobre os eletrodos íonseletivos (ISE - íon-sensitive electrode), passando pela descrição de funcionamento do transistor de efeito de campo sensível a ions (ISFET - íonsensitive field effect transistor) que é uma derivação do ISE. É feito também a representação do modelo teórico da variação do potencial em função da variação do $\mathrm{pH}$, sentido pela membrana, através do modelo de sítios de ligação (Sitebinding Model), assim como a discussão do transistor de efeito de campo de porta estendida (EGFET - Extended gate field effect transistor) como uma alternativa para fabricação de sensores a partir do efeito de campo.

No capítulo 3, são apresentados os resultados relacionados ao sensor de pH utilizando o óxido de manganês. Esses materiais foram crescidos pelo método hidrotérmico e os filmes finos depositados pela técnica de spray-pyrolysis.

No capítulo 4, mostramos e discutimos a utilização dos nanotubos de carbono como membrana seletiva. Esses nanotubos de carbono foram crescidos pelo método de deposição química a vapor (CVD - Chemical Vapor Deposition) e feitos filmes finos pela técnica de deposição de spray-pyrolysis.

No capitulo 5, serão discutidos a contribuição dos feltros de carbono (FC), derivado da poliacrilonitrila (PAN) e a contribuição dos nanotubos de carbono crescidos em suas fibras, feltro/nanotubos de carbono (FC/NTC) e também o comportamento desse sensor sob a influência da polianilina em suas fibras, 
feltros/nanotubos de carbono/Pani (FC/NTC/Pani) como membranas sensíveis a ions $\mathrm{H}^{+}$. Nos capítulos 3, 4 e 5 são descritas as sínteses e as propriedades dos materiais estudados como membranas seletivas.

Por fim, no capitulo 6, as conclusões deste trabalho são apresentados com as perspectivas futuras relacionadas aos dispositivos desenvolvidos. 


\section{Dispositivos sensíveis a íons}

Nesse capitulo, será feita uma contextualização da importância de se medir o pH e também o princípio de funcionamento dos dispositivos sensíveis a íons. Começaremos por uma descrição dos sensores químicos, a utilização de nanoparticulas como sensores e chegando ao dispositivo eletrodo sensível a íons. Desse último tipo de dispositivo, mostramos um em especial, o transistor de efeito de campo sensível a íons, que é a base de funcionamento do transistor de efeito de campo de porta estendida. Será apresentado o modelo de sítios de ligação, como o modelo que represente o aparecimento do potencial de superfície, que irá modelar a corrente de dreno do MOSFET, em função da variação do pH da solução. 


\section{1-Introdução}

A ciências dos materiais possibilita uma gama de aplicações que vem contribuindo para o desenvolvimento da ciência e tecnologia. Uma dessas aplicações consiste em utilizar os materiais como sensores.

Um sensor é um dispositivo que manifesta informação quantitativa ou qualitativa sobre um estímulo externo, através de um transdutor de um evento ou sinal que pode ser medido[1]. Uma representação desse sensor é o sensor químico. Um sensor químico é um dispositivo que pode gerar um sinal mensurável quando exposto a componentes químicos (analitos). Com isso, ele pode ser usado para detectar uma variedade de gases, vapores, $\mathrm{pH}$, etc, além de uma larga aplicação em campos variados como na indústria, na área médica, em segurança, entre outras $[1,2]$

Os sensores químicos/eletroquímicos são dispositivos que não necessitam da adição contínua de reagentes para a sua operação podendo fornecer informações confiáveis continuamente. Observamos o crescimento da utilização dos sensores químicos/eletroquímicos pelo fato da necessidade de testes simples, rápidos e de baixo custo para determinação de importantes compostos químicos e biológicos em concentrações baixas [3].

No campo da medicina, devido a crescente necessidade de identificação e quantificação de metabólicos de forma rápida, específica e em quantidades muito pequenas, ocorreu o desenvolvimento dos biossensores. Os biossensores podem

ser definidos como um sensor químico cujo reconhecedor é um componente biológico, onde o processo bioquímico é a fonte do sinal analítico [1,4,5]. 
Assim uma das características dos biossensores é a sua alta seletividade com relação a um determinado alvo [4,5]. A construção de um biossensor baseiase na comunicação de suas partes: o componente biológico ativo (o reconhecedor) e um transdutor. A primeira parte faz o reconhecimento de uma determinada substância por meio de uma reação bioquímica específica, podendo gerar diferentes resultados como: variação na concentração de prótons; liberação de gases; emissão ou absorção de luz; emissão de calor; variação de massa; alteração no estado de oxidação do analito, entre outras. A segunda parte, por sua vez, converte a energia destes eventos numa forma mensurável, como uma variação de corrente, potencial, temperatura e outros [6-14].

Biossensores são simples sistemas de medidas que usam moléculas biológicas, usualmente enzimas, anticorpos, ou ácido nucléico para recombinar moléculas de interesse por meio de pontes de hidrogênio, interação de carga e outras interações bioquímicas para prover informações moleculares[6]. A aplicação desses biossensores em laboratórios clínicos ocorreu devido à demanda por métodos rápidos, confiáveis e de baixo custo para a determinação de substâncias tais como glicose, colesterol, uréia entre outros [7-13].

Uma das maneiras de medir a atividades de algumas dessas substâncias biológicas seria por meio indireto, através da medida de pH [12,15-17].

Nos biossensores, a medida de $\mathrm{pH}$ é uma das tarefas requeridas em análise clínica, ambiental e em alguns controles de processos. Tanto a solubilidade de biomoléculas quanto a velocidade da reação bioquímica são dependentes do pH. O pH também é importante para otimizar a reação desejada e adquirir a reação previamente definida. A medida do $\mathrm{pH}$ é requerida em quase 
todo ramo do conhecimento, porque é essencial para controle de reações químicas [18-20].

$\mathrm{Na}$ busca de novos materiais que possam ser utilizados como sensores ou parte deles (membranas por exemplo), com propriedades e funções específicas, novos campos estão sendo explorados, entre eles, a fronteira do tamanho dos materiais que irão compor essas membranas. Tem sido demonstrado que a redução na dimensão das partículas de determinados compostos e materiais influencia profundamente nos seus comportamentos físicos e/ou químicos, mais especificamente, quando se atinge a escala nanométrica. Esta abordagem tem despertado interesse no estudo das metodologias de preparação e propriedades de materiais nanoestruturados [21-30].

\section{2-Materiais nanoestruturados}

O estudo de materiais, cujos tamanhos das partículas que os constituem encontram-se na faixa de nanômetros (nanomateriais), ganhou importância significativa no final do século XX, levando ao aparecimento e consolidação de uma área do conhecimento, hoje conhecida como "Nanociência e Nanotecnologia" [23]. Assim, a nanociência e nanotecnologia visam, de maneira genérica, a compreensão e o controle da matéria na escala nanométrica.

A nanociência apresenta-se como uma das áreas mais atraentes e promissoras para o desenvolvimento tecnológico neste século. Analisando em periódicos de alcance internacional, pode-se confirmar esta tendência dos centros de pesquisas, onde se pode verificar um aumento gradativo de trabalhos 
envolvendo nanoestruturas e nanotecnologia. Na literatura científica, são encontrados diversos termos relacionados a esta recente área, dentre os quais podemos citar nanoparticulas, nanofios, nanofitas, nanotubos, nanocompósitos, entre outros [25-30]. O que se pode concluir é que todos esses termos estão, de algum modo, relacionados com materiais nanoestruturados, que apresentam características bem definidas.

Para futuras aplicações tecnológicas, tornam-se de grande interesse as propriedades físicas e químicas de materiais nanoestruturados. Estes materiais apresentam propriedades bem diferenciadas com relação aos materiais de outras dimensões [22, 25-30]. Estas propriedades são resultantes do tamanho reduzido e da forma do material obtido. O domínio das propriedades, proveniente do controle da morfologia e constituição dos materiais, pode ser de grande utilidade, resultando em novas tecnologias.

Os avanços tecnológicos recentes têm fornecido meios e processos de fabricação que permitem reproduzir e estudar sistemas dimensionalmente reduzidos, para obtenção do controle na produção, visando aplicações diversas. Estudos recentes de materiais nanoestruturados têm projetado grande potencial em direção ao desenvolvimento de novos dispositivos e sensores com capacidades únicas e específicas [25-30].

Para tal propósito, esses estudos levam em consideração as características elétricas e/ou químicas, a capacidade de alteração das propriedades eletrônicas do sistema em questão, se são quimicamente inertes ou não, se são biocompatíveis - quando usado como biossensores -, enfim o comportamento desses materiais nanoestruturados, no sistema a ser medido em questão. 
A etapa fundamental do desenvolvimento de sensores/detectores, está no processo de produção dos materiais que irão compor esses sensores/detectores, além de algumas estratégias como a funcionalização e imobilização de espécies químicas na superfície. Para facilitar ou melhorar/otimizar as aplicações, esses materiais são produzidos de diversas formas como nanotubos, nanoguias, nanofios, nanopartículas, nanofitas, nanobastões, entre outras.

A nanociência e nanotecnologia podem contribuir para o desenvolvimento das indústrias farmacêutica, eletrônica, automobilística e têxtil, entre tantas outras. Uma estimativa é que nos próximos 15 anos, a nanotecnologia movimente um mercado de US\$ 1 trilhão, cabendo ao Brasil 1\% desse faturamento [22]. Nesse contexto se justificam as pesquisas no estudo dos processos de produção de nanoestruturas de materiais, buscando o entendimento de seus mecanismos e aplicações.

Dentre os novos materiais que vem despertando o interesse dos pesquisadores e que se enquadram como nanomateriais, estão os nanotubos de carbono (NTC), que foram sintetizados pela primeira vez por S.lijima [31] em 1991, usando o processo de pirólise de grafite em plasma sob atmosfera controlado por hélio.

A diversidade de aplicações, diferenciadas e singulares, dos nanotubos de carbono, podendo ser utilizados em um grande número de sistemas, entre eles como sensores, fazem desse material um objeto de estudo multidisciplinar $[23,32,33]$. As aplicações dos nanotubos de carbono dependem, de fatores como síntese, composição com outros materiais, funcionalização, a forma e o tipo de produção do dispositivo, entre outros.[23,32-37]. Os nanotubos de carbono 
apresentam vantagens como grande área superficial com relação ao seu volume, a propriedade de imobilizar proteínas sem que as mesmas percam suas atividades, indicando ser um bom material com potencial para ser utilizado como sensores e/ou biossensores $[32,35,36]$.

Pela importância de se medir pH e de se utilizar materiais nanoestruturados como sensores de $\mathrm{pH}$, e posteriormente com a possibilidade de sua utilização como biossensores, como exposto anteriormente, esse campo de atuação mostrase importante e promissor, devido aos variados ramos de aplicação, podendo ser produzidos com micro ou nanoestruturas.

Uma das formas de medir o pH é através dos sensores químicos/eletroquímicos. Esses sensores são classificados de acordo com as diferentes propriedades durante a detecção do objeto de estudo. Os principais sensores químicos/eletroquímicos, dependendo da propriedade a ser medida e o modo de detecção, podem ser classificados como: potenciométricos, amperométricos, voltamétricos e condutométricos $[3,4]$. Os sensores condutométricos medem a variação da condutância entre um par de eletrodos, enquanto que sensores amperométricos medem a variação da corrente no eletrodo devido à oxidação de produtos de uma reação química/bioquímica, ao passo que, os voltamétricos medem a variação de tensão. $O$ termo potenciométrico está relacionado com a técnica de medida utilizada, caracterizada pelo potencial entre os eletrodos $[3,4]$.

Esta última família de sensores, os potenciométricos, além de ser antiga é uma das mais empregadas, sendo um dos seus representantes os eletrodos íonseletivos, ISEs (do inglês íon-sensitive electrode) [4,20]. 


\section{3-Eletrodos íon-seletivos}

Os eletrodos íon-seletivos podem ser definidos como sensores eletroquímicos que permitem a determinação potenciométrica da atividade de uma espécie iônica, na presença de outros íons. Nesse tipo de sensor, a membrana seletiva é a parte mais importante do dispositivo [21]. A potenciometria é uma técnica bem conhecida dos químicos. A base da potenciometria foi estabelecida por Nernst em 1888 [20]. O primeiro sensor potenciométrico usado para medir a acidez de uma solução aquosa foi o eletrodo de hidrogênio, proposto por Nernst em 1897, mas devido a sua complexidade, não tinha finalidade prática [20]. Cremer, em 1906, desenvolveu o eletrodo de vidro, que foi posteriormente aperfeiçoado por Haber e Klemensiewicz [20]. Entretanto, havia problemas com a definição da escala de acidez e também com o melhoramento da instrumentação para se ter reprodutibilidade [20]. O aperfeiçoamento do eletrodo de vidro surgiu da comunidade acadêmica, enquanto que a definição da escala de $\mathrm{pH}$, da indústria, por Sörensen [39]. Apesar de a potenciometria ter surgido no século XIX, os ISEs tiveram seu maior desenvolvimento em 1957, com os trabalhos de Eisenman e Nikolski [20]. A primeira grande revolução na construção do ISE pode ser atribuída a Ross [20] que, em 1966, propôs um novo conceito de eletrodo para cálcio, o de membrana líquida, e que posteriormente, em conjunto com Frant, desenvolveu o eletrodo a base de cristal de $\mathrm{LaF}_{3}$, que seria o ISE mais empregado depois do eletrodo de vidro. A segunda revolução ocorreu com Moody, Oke e Thomas, que usaram eletrodo de membrana liquida na base do PVC, em 1970 [40]. Dentro desse contexto, a terceira revolução foi o ISE-Enzimático, [20] 
permitindo que os sensores potenciométricos pudessem ser utilizados como medida de substâncias biológicas, onde comumente são chamados de biossensores. Finalmente, pode-se considerar que uma das últimas revoluções dos ISEs seja o desenvolvimento do transistor de efeito de campo sensível a íon (ISFET - íon-sensitive field effect transistor)[9]. Maiores detalhes sobre a história e desenvolvimento dos ISEs podem ser vistos na referência [20].

Durante os últimos trinta anos, os eletrodos ion-seletivos (ISE) têm sido um dos mais ativos e promissores em eletroquímica, haja vista a literatura com esse objetivo. O desenvolvimento e aplicação dos ISEs continuam sendo promissores e tem tido expansão em diversas áreas da química analítica e outras afins, por oferecer vantagens como simplicidade, baixo custo de produção, análises não destrutivas da amostra e possibilidade de automação [41-48].

Na aplicação de sensores iônicos, alguns parâmetros precisam ser levados em consideração tais como seletividade, sensibilidade, estabilidade, reprodutibilidade, tempo de respostas e tempo de vida do dispositivo, entre outros. Membranas íon-seletivas não são completamente satisfatórias em todos os requisitos mencionados anteriormente. Um dos problemas com os eletrodos íonseletivos é a interferência devido ao aparecimento de outros íons, dificultando ou impedindo a análise correta da amostra desejável [20].

O conhecimento fundamental do mecanismo de resposta das membranas íon-seletivas é necessário. O mecanismo de trabalho das membranas íonseletivas tem sido alvo de pesquisas acadêmicas desde a primeira década do século passado, quando o primeiro eletrodo de vidro foi desenvolvido [20]. Alguns estudos teóricos das membranas íon-seletivas têm sido desenvolvidos, para 
explicar o comportamento das espécies, levando em consideração em algumas delas, o gradiente de concentração iônica ou gradiente de potencial, entre outros. Entretanto, há uma certa dificuldade para distinguir e aplicar essas teorias, além do fato de que, o meio onde se faz a medida também influencia na miscividade e solvatação das membranas. Portanto, há uma quantidade de dados que precisam ser avaliados sobre o entendimento que se faz de cada componente envolvido.

A teoria empregada aqui, para explicar a interação da membrana em contato com o eletrólito, é aquela que leva em consideração o comportamento eletrólito-isolante-semicondutor (EIS - electrolyte-insulator-semiconductor) [20, 48-51]. Esta teoria é a base do funcionamento do ISFET, onde o comportamento EIS irá contribuir com termos (tensões) na tensão de limiar ISFET. Nessa teoria, está contemplada a contribuição da dupla camada formada pelos íons que se ligam nos sítios de ligação, levando em consideração o raio iônico e a solvatação desses íons. Essa dupla camada, também é conhecida como dupla camada de Gouy-Chapman-Stern [48-51].

A importância do uso do ISFET pode ser atribuída a sua capacidade de miniaturização e a possibilidade de usar processos de microfabricação. Outro fato importante é que eles representam uma família de ISE moderno.

\section{4-Principio de funcionamento do ISFET}

No caso de se trabalhar com sensores através do método potenciométrico uma das alternativas, para torná-los viáveis em aplicações diversas, seria o uso do transistor de efeito de campo (FET - Field effect transistor). O transistor de efeito 
de campo (FET) tem esta designação porque o seu princípio de funcionamento é determinado em maior ou menor grau pelo campo elétrico no seu interior. A corrente, nesse dispositivo, é devida a um só tipo de portadores de carga (elétrons ou buracos) dependendo do tipo de FET (canal $\mathrm{n}$ ou canal $\mathrm{p}$, respectivamente), o que da ao FET um outro nome, transistor unipolar. Um dos representantes dos transistores de efeito de campo é o transistor de efeito de campo sensível a íon (ISFET - íon-sensitive field effect transistor).

Os sensores de $\mathrm{pH}$ desenvolvidos a partir dos FETs, detectam o campo elétrico criado pelos íons $\mathrm{H}^{+}$da solução. A mudança do potencial entre o eletrólito e a membrana seletiva, resultante da mudança da concentração de pH no eletrólito, modula a intensidade da corrente no MOSFET.

O transistor de efeito de campo metal-óxido-semicondutor (MOSFET Metal-oxide-semiconductor) é um tipo de transistor que é controlado por tensão. Ele é um dispositivo também conhecido como transistor de efeito de campo de porta isolada (IGFET - insulated gate field effect transistor). A operação do MOSFET se baseia no controle da corrente do canal em função da tensão da porta, um eletrodo metálico depositado sobre uma camada de óxido isolante sob o qual se encontra o canal de condução. Uma diferença de potencial $V_{D S}$ (entre dreno e a fonte), produz uma corrente I IS (conhecida como corrente de dreno) no canal formado por elétrons (no caso do MOSFET ser do tipo $n$ ). O valor dessa corrente é determinado pela tensão $\bigvee_{D S}$ e também pela resistência do canal, que por sua vez, depende da concentração de impurezas, do comprimento e da área efetiva da seção reta do canal. Uma tensão positiva $V_{G S}$ entre a porta e fonte, atrai elétrons para o canal. Se existir um número de elétrons suficientes nesse canal, 
ao se aplicar uma tensão $V_{D S}$ entre o dreno e fonte, fluirá uma corrente nessa região. $O$ valor de $V_{G S}$ suficiente para que haja uma corrente nesse canal é chamada de tesão de limiar (threshold), representada por $V_{\text {th }}$. Se continuarmos aumentando a tensão $\bigvee_{D S}$, chegará um ponto onde não haverá mais um aumento da corrente de dreno $I_{D}$, numa região conhecida como região de saturação, devido ao estrangulamento do canal. A região onde a tensão $V_{D S}$ é menor que o $V_{D S}$ de saturação, a corrente varia de maneira linear com a tensão. Essa região é chamada de região linear [52,53]. Abaixo as curvas características desse dispositivo.

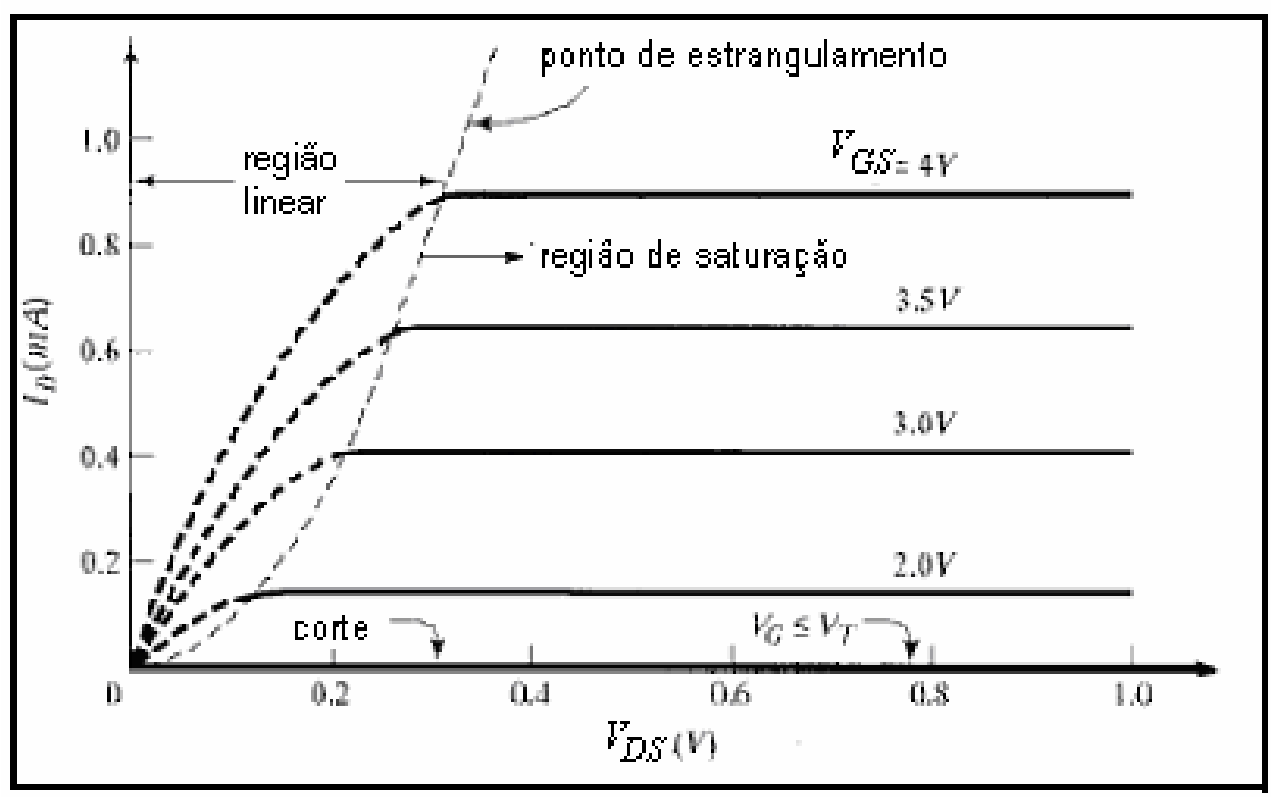

Figura 2.1: Representações das regiões do MOSFET

O ISFET pode ser considerado como um tipo especial do MOSFET $[52,53]$ sem a porta metálica, onde a porta metálica foi substituída por uma membrana seletiva diretamente em contato com o eletrólito da solução. O ISFET por sua vez 
combina a detecção seletiva de íons através da membrana seletiva e a transformação do potencial sentido na superfície pela membrana, alterando o campo elétrico na interface isolante-semicondutor, tendo como conseqüência, a modulação da corrente.

Nos anos 70, teve início a era do transistor de efeito de campo para detecção de espécie química (ChemFET- Chemical field effect transistor), como uma derivação do ISE. A idéia para usar o transistor de tecnologia MOS, com a porta feita de uma membrana sensível a íons, como um sensor químico em ambiente líquido, foi proposto por um cientista holandês P.Bergveld [54]. Desde então, muitos artigos são dedicados ao desenvolvimento de tipos diferentes de ChemFETs: transistor de efeito de campo sensível a íons (ISFET - íon-sensitive field effect transistor); transitor de efeito de campo enzimático (EnFET - enzyme field effect transistor); e suas derivações de acordo com a aplicação como ImmunoFET, BioFET, entre outros $[44,46,55,56]$.

O ISFET é um dos mais comuns transistores de efeito de campo sensível a espécies químicas (ChemFET). Ele foi proposto, primeiramente por Bergveld em 1970 [54], seguindo-se, depois, por uma publicação mais completa em 1972 [55]. A inclusão do eletrodo de referência em contato com o eletrólito, fazendo parte do sistema de medida, foi proposto em 1974 por Matsuo [56] e desde então, faz parte do sistema do ISFET. A figura 2.1 mostra um diagrama MOSFET e do ISFET, assim como um circuito equivalente de ambos. 

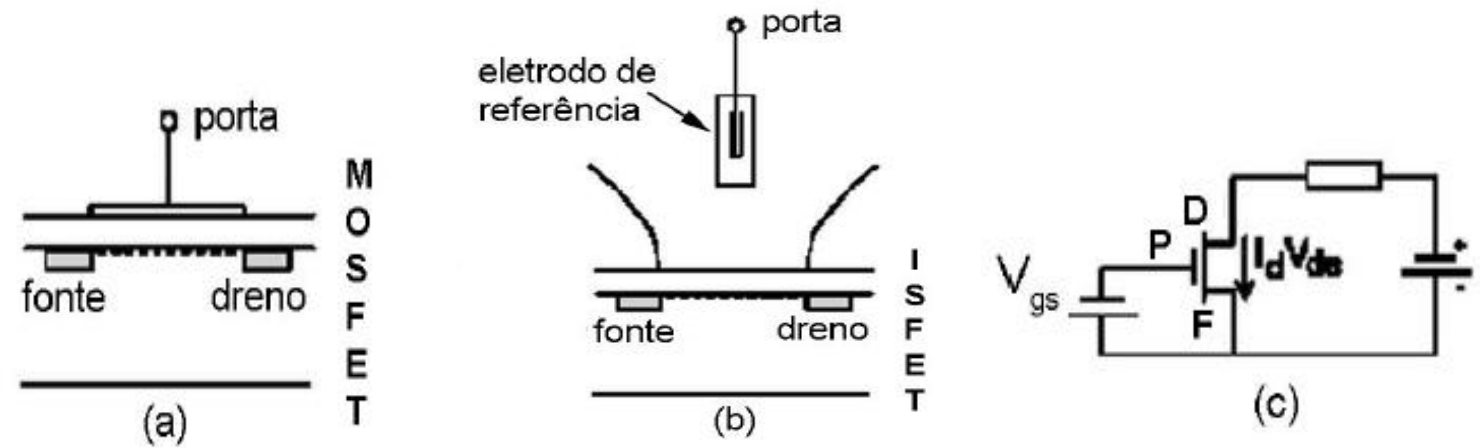

(c)

Figura 2.2: Representação de um MOSFET em (a) onde aparece a porta metálica que por sua vez foi substituído por uma membrana seletiva e o eletrodo de referencia no ISFET em (b) enquanto que a representação do circuito equivalente de ambos estão representados em (c)[ ].

As propriedades do ISFET são afetadas por vários materiais dependendo das diferentes reações desse material com o eletrólito. Muitos materiais sensíveis foram e continuam sendo investigados como sensor de $\mathrm{pH}$. O óxido de silício $\left(\mathrm{SiO}_{2}\right)$ foi o primeiro material a ser utilizado como membrana sensível a pH no ISFET. Depois disso, outros materiais como $\mathrm{Al}_{2} \mathrm{O}_{3}, \mathrm{Si}_{3} \mathrm{~N}_{4}, \mathrm{Ta}_{2} \mathrm{O}_{5}$ também foram usados como membranas sensíveis a pH, entre outros $[59,60]$. Esses materiais, normalmente, são depositados com técnicas um pouco dispendiosas e não muito simples.

Os sensores do tipo ISFET ganham uma atenção especial pelo fato de que podem ser fabricados em larga escala, porém não é uma tecnologia barata. Uma abordagem para a fabricação industrial de sensores e/ou biossensores baseados no ISFET encontra uma dificuldade, o encapsulamento. Essa dificuldade consiste na necessidade para assegurar uma isolação elétrica do sensor, evitando assim que nenhuma região do ISFET, exceto a área de contato, fique exposta a solução. 
O isolamento do ISFET, exceto a área de contato, é feito com filmes dielétricos com uma baixa permeabilidade a íons.

Uma derivação desse tipo de sensor é o transistor de efeito de campo com porta estendida (EGFET - extended gate field effect transistor). Esse tipo de dispositivo consiste de uma membrana seletiva conectada a um MOSFET comercial [52,53]. A figura 2.2 apresenta a estrutura do sistema de medida.

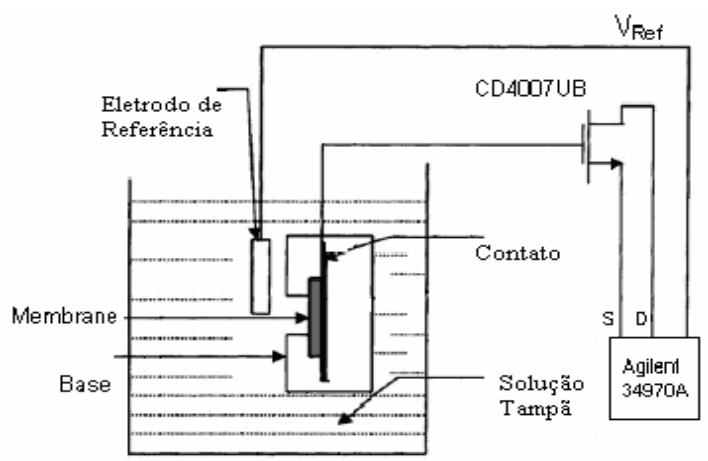

Figura 2.3: Representação do sistema de medida . O EGFET consiste em uma membrana seletiva conectada a um MOSFET

Esse dispositivo oferece vantagens, possibilitando a pesquisa $\mathrm{e}$ desenvolvimento de sensores e biossensores, sendo um dos atrativos a simplicidade do sensor, a reutilização do MOSFET, o não encapsulamento do sistema de medida e o baixo custo de produção, já que não necessita de etapas de produção utilizada na fabricação do MOSFET. O sistema de medida, permite o seu uso variado como sensores e/ou biossensores, de detecção de diversas espécies químicas, necessitando apenas trocar a membrana, reutilizando inclusive o mesmo MOSFET. A principal linha de pesquisa quando se utiliza o EGFET está 
na otimização do processo de fabricação da membrana e a pesquisa de novas camadas sensíveis, ou seja, novas membranas.

Depois do surgimento dos sensores de efeito de campo, como sensores de $\mathrm{pH}$, algumas características desejáveis vem sendo discutidas a respeito das membranas seletivas a íons de hidrogênio. Algumas dessas características seriam os comportamentos anfotéricos das membranas e se respondem em uma ampla faixa de $\mathrm{pH}$ (de 2 a 12).

Muitos materiais foram estudados por tentativa e erro, e ainda continuam sendo estudados, em alguns casos, dessa mesma forma. Uma outra característica desse dispositivo é que, eles respondem apenas em determinadas faixas de $\mathrm{pH}$, dependendo da técnica de produção dos materiais utilizados como membranas seletivas. Um dos exemplos é o $\mathrm{SnO}_{2}$, produzido pela técnica sol-gel que não responde (danifica-se) a pH maiores que 9 [60], comportamento não observado quando esse mesmo material é produzido por sputtering [61,62]. Mas apenas a técnica não define o comportamento. $\mathrm{O} \mathrm{W}_{3} \mathrm{O}_{2}$ produzido por sputtering se estraga quando imerso em pH maior que 7 [63], enquanto que o $\mathrm{Pb}_{2} \mathrm{O}_{3}$ produzido por solgel, apresenta um bom comportamento [64,65]. Outro fato observado foi que os materiais que comumente são utilizados no ISFET para membranas sensíveis a $\mathrm{H}^{+}$, não apresentam respostas ao $\mathrm{pH}$ quando utilizados em EGFETs. Como dito anteriormente, a pesquisa continua ainda em alguns casos por tentativa e erro.

Entre as propriedades do sensor de $\mathrm{pH}$, a sensibilidade é uma das mais importantes. Teoricamente, espera-se que dispositivos que trabalhem por efeito de campo, tenham máxima sensibilidade da ordem de $59 \mathrm{mV} / \mathrm{pH}$ e que respondam linearmente na faixa de $\mathrm{pH}$ de 2 a 12 . Modelos teóricos e alguns experimentos 
vem correlacionando algumas propriedades do material com a sensibilidade dos dispositivos [66-68]. Uma dessas propriedades diz respeito à estrutura, ou melhor, a cristalinidade. Vários pesquisadores fizeram trabalhos buscando novos materiais e métodos que respondessem de forma satisfatória que pudessem ser utilizados como sensores de pH em EGFETs. Alguns desses materiais são mostrados na tabela abaixo.

Tabela 2.1: Materiais utilizados como membranas para EGFETs.

\begin{tabular}{|c|c|c|c|c|c|}
\hline Material & $\begin{array}{c}\text { Técnica de } \\
\text { deposição }\end{array}$ & Substrato & Faixa de pH & Sensibilidade & Ano \\
\hline $\mathrm{SnO}_{2}$ & Sputtering & Al/Vidro & $2-12$ & $50 \mathrm{mV} / \mathrm{pH}$ & $2000^{[69]}$ \\
\hline $\mathrm{SnO}_{2}$ & Sputtering & Al/Silício & $2-12$ & $58 \mathrm{mV} / \mathrm{pH}$ & $2000^{[61]}$ \\
\hline $\mathrm{ITO}$ & Sputtering & Vidro & $2-12$ & $57 \mathrm{mV} / \mathrm{pH}$ & $2001^{[62]}$ \\
\hline $\mathrm{TiN}$ & Sputtering & Silício & $2-10$ & $57 \mathrm{mV} / \mathrm{pH}$ & $2001^{[70]}$ \\
\hline $\mathrm{SnO}{ }_{2}$ & Sol-gel & Silício & $2-9$ & $59 \mathrm{mV} / \mathrm{pH}$ & $2003^{[60]}$ \\
\hline a-BCxNy & Sputtering & Silício & $2-11$ & $46 \mathrm{mV} / \mathrm{pH}$ & $2004^{[71]}$ \\
\hline $\mathrm{SiNWs}$ & CVD & Silício & $2-11$ & $58 \mathrm{mV} / \mathrm{pH}$ & $2005^{[73]}$ \\
\hline $\mathrm{ZnO}$ & Sol-gel & Alumínio & $2-12$ & $38 \mathrm{mV} / \mathrm{pH}$ & $2005^{[74]}$ \\
\hline
\end{tabular}

O comportamento da corrente em função da tensão é praticamente o mesmo do MOSFET. A diferença está na tensão de limiar do ISFET que tem a contribuição de tensões que aparecem devido à interface entre o eletrólito e o isolante de um lado, e o eletrólito e o eletrodo de referência do outro. 
Seguindo o comportamento da corrente de dreno $I_{D}$ em função da tensão entre dreno e a fonte $V_{D S}$, baseado nas características do MOSFET, em duas regiões, da seguinte forma $[49,52,53,74]$ :

Na região de não saturação

$$
I_{D}=\mu_{n} C_{o x} \frac{W}{L}\left[\left(V_{G S}-V_{t h}\right) V_{D S}-\frac{1}{2} V_{D S}^{2}\right]
$$

Na região de saturação

$$
I_{D}=\frac{1}{2} \mu_{n} C_{o x} \frac{W}{L}\left(V_{G S}-V_{t h}\right)^{2}
$$

com a tensão limiar dada por

$$
V_{t h}(M O S F E T)=V_{F B}+2 \phi_{F}-\frac{Q_{B}}{C_{o x}}
$$

com a tensão de banda plana (flatband) dada por:

$$
V_{F B}=\frac{\Phi_{M}-\Phi_{S}}{q}-\frac{Q_{s s}+Q_{o x}}{C_{o x}}
$$

Com $I_{D}$ representando a corrente de dreno, $\mu_{n}$ a mobilidade do portador, no caso aqui exemplificado, do tipo n, $C_{o x}$ a capacitância do óxido e $W$ e $L$ representam a largura e o comprimento do canal, respectivamente. A tensão entre a porta e a fonte é representada por $V_{G S}$ enquanto que a tensão de limiar (threshold) e a tensão entre o dreno e a fonte são representados por $V_{t h}$ e $V_{D S}$ respectivamente. A expressão que mostra a tensão de limiar, $V_{F B}$ representa o potencial de banda plana, enquanto que $\Phi_{M}$ e $\Phi_{S}$ representam a função trabalho da porta metalizada e função trabalho do silício, respectivamente, enquanto que $Q_{s s}$ a carga na 
superfície do silício, $Q_{o x}$ carga fixa no oxido, $Q_{B}$ a carga na região de depleção no silício e $\phi_{F}$ é o potencial de Fermi. A tensão de limiar nos dispositivos semicondutores depende da tensão de banda plana, que é a tensão verificada pela variação ("entortamento") da banda de energia causada pela separação das cargas na região de contato entre dois materiais diferentes. Todos esses termos mencionados acima são termos relativos e característicos do MOSFET.

Nas equações do ISFET, há contribuições de tensões para a tensão de limiar. Uma dessas contribuições é aquela devida a interação entre o eletrólito e o eletrodo de referência, com o aparecimento do potencial do eletrodo de referência $E_{\operatorname{Re} f}$. Uma outra contribuição é o potencial de dipolo da superfície devida a solução $\chi^{\text {sol }}$. A interação entre o eletrólito e a membrana resulta em um outro potencial, aquele devido a interação na interface (adsorção) entre o eletrólito/membrana, $\psi_{0}$, que resulta da reação química, usualmente governado pela dissociação dos grupos de superfície do material utilizado como membrana.

Dessa forma a variação da tensão de limiar que está incluída no novo valor de $V_{\text {th }}$ do ISFET, passa a ter a contribuição de todas as partes dos sistema: eletrodo de referência/eletrólito/membrana e o MOSFET. O valor da variação da tensão de limiar é da seguinte forma[...].

$$
\Delta V_{\text {th }}=E_{\operatorname{Re} f}-\psi_{0}+\chi^{\mathrm{sol}}-\Phi_{S} / q
$$

O eletrodo de referência é descrito como $E_{\mathrm{Re} f}$, onde está incluído o potencial da junção líquido-líquido no caso de o eletrodo de referência ser preenchido com liquido, como $\mathrm{Ag} / \mathrm{AgCl}$. 
No sentido de ordenar as Equações 1 e 2, para a estrutura do ISFET, novas expressões para $V_{G S}$ e $V_{\text {th }}$ devem ser estabelecidas. Se todos os termos do potencial, devido à variação da tensão de limiar introduzida pelo ISFET, estiverem incluídos na definição da tensão de limiar do ISFET $\left(V_{\text {th }}\right)$, o potencial de interface entre o eletrólito e a membrana que varia em função do $\mathrm{pH}$ da solução, também estará incluído no novo valor da tensão de limiar do ISFET, da seguinte forma:

$$
V_{t h}(\text { ISFET })=V_{t h}(M O S F E T)+\Delta V_{t h}
$$

Onde o $V_{\text {th }}($ ISFET) representa o novo valor da tensão de limiar do sistema ISFET, $V_{\text {th }}$ (MOSFET) representa a tensão de limiar do MOSFET e o ultimo termo representa a variação causada pela interação eletrodo de referencia/eletrolito/membrana.

$$
V_{t h}(I S F E T)=E_{\operatorname{Re} f}-\psi_{0}+\chi^{s o l}-\frac{\Phi_{S}}{q}-\left(\frac{Q_{s s}+Q_{s c}}{C_{o x}}\right)-\frac{Q_{B}}{C_{o x}}+2 \phi_{F}
$$

A operação do dispositivo do ISFET pode ser resultado da combinação da equação 7, e daquelas que descrevem o comportamento do MOSFET, equações 1 e 2.

O resultado da expressão para a corrente de dreno do ISFET na região linear é escrito como:

$$
I_{D}=\mu_{n} C_{o c} \frac{W}{L}\left\{\left[V_{G S}-\left(E_{\mathrm{Re} f}-\psi_{0}+\chi^{s o l}-\frac{\Phi_{s}}{q}-\frac{Q_{s s}+Q_{s c}}{C_{o x}}+2 \phi_{F}\right)\right] V_{D S}-\frac{1}{2} V_{D S}^{2}\right\}
$$

e na região de saturação 


$$
I_{D}=\frac{\mu_{n} C_{o x}}{2} \frac{W}{L}\left[V_{G S}-\left(E_{\mathrm{Re} f}-\psi_{0}+\chi^{s o l}-\frac{\Phi_{s}}{q}-\frac{Q_{s S}+Q_{s c}}{C_{o x}}+2 \phi_{F}\right)\right]^{2}
$$

Essas são as novas relações da corrente em função do potencial do ISFET, que levam em consideração a variação do potencial devido à variação do $\mathrm{pH}$ da solução, ou seja, depende da acidez da solução. Todos os parâmetros nas equações são fixos, à exceção do potencial eletrostático $\psi_{0}$. O potencial $\psi_{0}$ depende do $\mathrm{pH}$ e influencia no comportamento da corrente de fonte-dreno. Este potencial se desenvolve na interface da membrana/eletrólito.

\section{5-Sitio de ligação (site-binding model).}

O modelo que representa, o mecanismo responsável pelo aparecimento do potencial de superfície na membrana, segundo a variação do pH da solução, pode ser descrito pelo modelo de sítio de ligação (site-binding-model). Esse modelo descreve o equilíbrio entre os sítios chamados anfóteros e os íons $\mathrm{H}^{+}$em solução. Este modelo foi proposto pela primeira vez em 1974 por Yates e colaboradores sendo posteriormente generalizada por Fung e colaboradores em 1986 para caracterizar o ISFET com a porta feita com óxido isolante $[51,75]$. No modelo do sítio de ligação, a superfície óxida, superfície sensível à variação de pH, contêm sítios em três formas: $\mathrm{A}-\mathrm{O}^{-}, \mathrm{A}-\mathrm{OH}$, e $\mathrm{A}-\mathrm{OH}_{2}{ }^{+}$. O comportamento ácido ou básico do sítio neutro A-OH são caracterizados pelas constantes de equilíbrio $K_{a}$ e $K_{b}$ respectivamente. Utilizando a notação $A$ para representar o material sensível da 
membrana que se ligará ao íon a ser medido, esse modelo pode ser descrito como seguinte:

$$
\begin{aligned}
& \mathrm{AOH}_{2}^{+} \stackrel{K_{a}}{\longleftrightarrow} \mathrm{AOH}+\mathrm{H}_{s}^{+} \\
& \mathrm{AOH} \stackrel{K_{b}}{\longleftrightarrow} \mathrm{AO}^{-}+H_{s}^{+}
\end{aligned}
$$

As reações acima indicam que o sítio, originalmente neutro, pode se associar a um próton da solução e tornar-se um sítio positivo, assim como, cedendo um próton à solução, tornando-se um sítio negativo. Onde $\mathrm{H}_{\mathrm{s}}{ }^{+}$representa os prótons da solução.

O potencial que modula a corrente de dreno $\psi_{0}$, em função da variação do $\mathrm{pH}$, pode ser escrito com a diferença entre o potencial da superfície da membrana $\psi_{S}$ e o potencial da solução $\psi_{B}$.

$$
\psi_{0}=\psi_{S}+\psi_{B}
$$

Com a equação de Boltzmann, a atividade do próton da solução $a_{\mathrm{HB}^{+}}$pode ser relacionada à atividade do próton na vizinhança direta da superfície do oxido, $a_{H S}$, e os termos correspondentes, $\left[\mathrm{H}^{+}\right]_{\mathrm{S}}\left[\mathrm{H}^{+}\right]_{\mathrm{s}}$ que representam as concentrações de prótons na superfície e na solução, respectivamente, assim como o valor do $\mathrm{pH}$.. Suas equações correspondentes, acordo com as equações 12,13 e 14.

$$
a_{H_{S}}=a_{H_{B}} \exp \left(-\frac{q \psi_{0}}{k T}\right) \text { ou }
$$




$$
\begin{aligned}
& {\left[H^{+}\right]_{S}=\left[H^{+}\right]_{B} \exp \left(-\frac{q \psi_{0}}{k T}\right) \text { ou }} \\
& p H_{S}=p H_{B}+\frac{q \psi_{0}}{2,3 k T}
\end{aligned}
$$

Sendo as constantes de equilíbrio das equações anteriormente dadas por:

$$
\begin{gathered}
K_{a}=\frac{[\mathrm{AOH}]\left[\mathrm{H}^{+}\right]_{s}}{\left[A O H_{2}^{+}\right]} \\
K_{b}=\frac{\left[A O^{-}\right]\left[\mathrm{H}^{+}\right]_{s}}{[\mathrm{AOH}]}
\end{gathered}
$$

Onde $\mathrm{A}-\mathrm{OH}_{2}{ }^{+}, \mathrm{A}-\mathrm{OH}$ e A-O são os sitos de superfície positivo, neutro e negativo respectivamente, com $\mathrm{K}_{a}$ e $\mathrm{K}_{b}$ são constantes de equilíbrio e $\left[\mathrm{A}-\mathrm{OH}_{2}{ }^{+}\right],[\mathrm{A}-\mathrm{OH}]$ e [A-O] são o número de sítios por unidade de área. Note-se que a atividade $\mathrm{H}_{\mathrm{s}}{ }^{+}$ resulta na concentração $\left[\mathrm{H}^{+}\right]_{s}$. O coeficiente da atividade está incluído na constante de dissociação. A relação entre $\left[\mathrm{H}^{+}\right]_{S}$ e a concentração de $\mathrm{H}^{+}$na solução $\left(\left[\mathrm{H}^{+}\right]_{\mathrm{b}}\right)$ é obtido pela equação de Boltzmann acima. Com q sendo a carga elementar, $\mathrm{K}$ a constante de Boltzmann, $\mathrm{T}$ a temperatura absoluta, e $\psi_{0}$ é o potencial de superfície dependente do $\mathrm{pH}$.

Pelo fato de o potencial ser gerado pela densidade de carga, a densidade de carga superficial, $\sigma_{0}$, é dado por:

$$
\sigma_{0}=q\left(\left\lfloor A O H_{2}^{+}\right\rfloor-\left\lfloor A O^{-}\right\rfloor\right)
$$

O termo entre parênteses representa a diferença entre o número de grupos carregados positivamente e negativamente, em mol por unidades de área. $\mathrm{O}$ 
número total de sítios por unidade de área, que serão aqueles de ligação com os íons desejados, Ns, é dado por:

$$
N_{S}=[A O H]+\left[\mathrm{AOH}_{2}^{+}\right]+\left[A \mathrm{O}^{-}\right]
$$

A relação entre $\Psi, \sigma_{0} \mathrm{e}\left[\mathrm{H}^{+}\right]_{\mathrm{b}}$ pode ser determinada através das equações 15 a 18 em termos de $K_{a}, K_{b}$ e $N_{s}$, que são os parâmetros que caracterizam a superfície óxida.

O efeito da atividade do próton superficial na densidade de carga superficial pode ser expresso da seguinte maneira:

$$
\frac{\partial \sigma_{0}}{\partial p H_{S}}=-q \frac{\partial B}{\partial p H_{S}}=-q \beta_{\text {int }}
$$

Onde constata-se que a carga é expressa em seu correspondente $\mathrm{pH}$, e a carga resultante em $\sigma_{0}$ no número de grupos em $\beta_{\text {int }}$. Por definição $\beta_{\text {int }}$ representa a capacidade de acumular informação de cargas na superfície (buferizar). Por razões de neutralidade, a carga superficial $\sigma_{0}$ está balanceada por uma carga equivalente $\sigma_{d l}$ oposta no eletrólito.

Essa densidade de carga $\sigma_{d l}$, se encontra na dupla camada (plano interno e externo de Helmholtz). Os planos interno e externo de Helmholts, são as distâncias em que os íons da solução se aproximam da superfície. Essas densidades de carga paralelas formam a capacitância de dupla camada $C_{d l}$. A diferença de potencial sobre essa capacitância é igual à diferença entre o potencial da superfície do óxido e da solução. A relação entre essas densidades 
de carga, a capacitância da dupla camada e a tensão de superfície é dada a seguir.

$$
\sigma_{0}=-\sigma_{d l}=C_{d l} \psi_{0}
$$

Essa capacitância pode ser calculada através do modelo de GouyChapman-Stern. A habilidade da dupla camada para armazenar carga em resposta a uma pequena carga de superfície é definida como capacitância diferencial da dupla camada $C_{\text {dif }}$ e é dada seguinte forma:

$$
C_{d i f}=-\frac{\partial \sigma_{d l}}{\partial \psi_{0}}=\frac{\partial \sigma_{0}}{\partial \psi_{0}}
$$

Combinando as relações onde aparece a densidade superficial de carga, têm-se as equações a seguir:

$$
\frac{\partial \psi_{0}}{\partial p H_{S}}=\frac{\partial \psi_{0}}{\partial \sigma_{0}} \frac{\partial \sigma_{0}}{\partial p H_{S}}=-\frac{q \beta_{\text {int }}}{C_{\text {dif }}}
$$

combinando essa relação com a relação de Boltzmann, obtém-se a atividade do próton na superfície e a diferença entre o valor do pH na superfície e na solução, dados por:

$$
a_{H_{S}}=a_{H_{B}} \exp \left(-\frac{q \psi_{0}}{k T}\right) \text { e }\left(p H_{S}-p H_{B}\right)=\frac{q \psi_{0}}{k T}
$$

o que resulta na expressão geral para a sensibilidade ao pH para o ISFET:

$$
\frac{\partial \psi_{0}}{\partial p H_{S}}=-2,3 \frac{k T}{q} \alpha \text { onde } \alpha=\frac{1}{\frac{2,3 k T C_{d i f}}{q^{2} \beta_{\text {int }}}+1}
$$


O parâmetro $\alpha$ é um parâmetro que representa a sensibilidade que varia entre 0 e 1, dependendo da capacidade de acumular informação de cargas na superfície $\beta_{\text {int }}$ da superfície do óxido e da capacidade diferencial de dupla camada $C_{\text {dif }}$. Se $\alpha=1$, o ISFET apresenta uma sensibilidade Nernstiana, que é igual a $59,2 \mathrm{mV} / \mathrm{pH}$ a temperatura ambiente.

Aqui, podemos definir um ponto de referência na escala de $\mathrm{pH}$. O valor de $\mathrm{pH}$ no qual $\psi_{0}=0$, é obtido como a seguir

$$
p H_{p z c}=-\log _{10}\left(k_{a} k_{b}\right)^{1 / 2}=\frac{1}{2}\left(p k_{a}+p k_{b}\right)
$$

Este valor é denominado $\mathrm{pH}$ no ponto de carga zero $\left(\mathrm{pH}_{\mathrm{pzc}}\right)$. Onde $K_{a}$ e $K_{b}$ são as constantes de equilíbrio, $\mathrm{pK}_{\mathrm{a}}=-\log _{10}\left(\mathrm{~K}_{\mathrm{a}}\right), \mathrm{pK}_{\mathrm{b}}=-\log _{10}\left(\mathrm{~K}_{\mathrm{b}}\right)$. O fato de $\psi_{0}=0$ implica $\sigma_{0}=0$, ou, em outras palavras, $\mathrm{pH}_{\mathrm{pzc}}$ representa o valor no qual a concentração de íons de hidrogênio resulta em uma superfície eletricamente neutra. O potencial de superfície, levando em consideração esse fato torna-se:

$$
2,3\left(p H_{p z c}-p H\right)=\frac{q \psi_{0}}{k T}+\sinh ^{-1}\left(\frac{q \psi_{0}}{k T \beta}\right)
$$

De acordo com a equação acima os únicos parâmetros que determinam a relação $\frac{\Psi_{0}}{\mathrm{pH}}$ são $\mathrm{pH}_{\mathrm{pzc}}, \beta$. Estes parâmetros dependem principalmente das características da superfície expressas por $K_{a}, K_{b}$ e a densidade de sites, $\mathrm{N}_{\mathrm{s}}$. A equação 26 é uma aproximação para superfícies, tais como óxidos, onde o número de sítios é suficientemente alto para assegurar que a densidade de carga nunca se aproxima do máximo valor na faixa de $\mathrm{pH}$ utilizada. Assuma-se que $\Delta \mathrm{pK}=\mathrm{pK}_{\mathrm{a}}-\mathrm{pK}_{\mathrm{b}}$ é 
grande para assegurar que $\mathrm{K}_{\mathrm{a}} / \mathrm{K}_{\mathrm{b}} \ll<1$. Próximo ao ponto de carga zero, a equação 26 pode ser analisada separadamente em duas regiões da curva $\frac{\psi_{0}}{p H}$, resultando nas seguintes relações:

Quando $\frac{\mathrm{q} \Psi_{0}}{\mathrm{KT}}<<\beta$, resulta em:

$$
\psi_{0}=2,3 \frac{k T}{q} \frac{\beta}{\beta+1}\left(p H_{p z c}-p H\right)
$$

Quando $\frac{\mathrm{q} \Psi_{0}}{\mathrm{KT}} \gg>\beta$, resulta em

$$
2,3\left(p H_{p z c}-p H\right)=\frac{q \psi_{0}}{k T}+\ln \frac{2 q \psi_{0}}{\beta k T} \approx \ln \frac{2 q \psi_{0}}{\beta k T}
$$

onde $\beta=\frac{2 q^{2} N_{S}}{C_{d l} k T\left(\frac{k_{a}}{k_{b}}\right)^{1 / 2}}$

A sensibilidade em termos do parâmetro $\beta$, um parâmetro que caracteriza a sensibilidade do óxido em função do pH da solução pode ser escrito da seguinte forma:

$$
S=\frac{\partial \psi_{0}}{\partial\left(p H_{p z c}-p H\right)}=2,3\left(\frac{k T}{q}\right) \frac{\beta}{\beta+1}
$$

$\operatorname{com} \alpha=\frac{\beta}{\beta+1}$

Em membranas onde a interação com os íons da solução forem descritos pelo método de associação e dissociação do grupo anfótero, essas equações são válidas. 
Em resumo, o EGFET pode ser tratado como uma diversificação dos sensores iônicos onde uma membrana depositada sobre um substrato é conectada a um MOSFET comercial.

Umas das principais vantagens do EGFET em relação ao ISFET, é que o ISFET necessita da fabricação da estrutura do MOSFET, enquanto que no EGFET, essa etapa é dispensada. Por isso, o custo para fabricação do EGFET é reduzido e pode facilitar a produção de sensores de $\mathrm{pH}$, já que etapas envolvidas no desenvolvimento do ISFET não serão necessárias. Vale ressaltar que, medidas de metabólitos podem ser feitas de forma indireta através do $\mathrm{pH}$, dessa forma, esse dispositivo serviria como biossensor. Outra vantagem é que o MOSFET não é imerso na solução, o que ocorre com o ISFET, com isso o dispositivo não é danificado, além de o fato de encapsulamento do ISFET não ser necessário no EGFET.

Dentro do contexto exposto anteriormente, foi que surgiu a motivação e a intuito para a realização do presente trabalho na busca de encontrar uma membrana que respondesse de forma satisfatória com relação à detecção de $\mathrm{H}^{+}$.

\section{6-Objetivos}

Os objetivos desse trabalho são constituídos essencialmente pela pesquisa e desenvolvimento de dispositivos, através da produção de membranas, que possam ser utilizadas como sensores de $\mathrm{H}^{+}$. As diversas amostras foram fabricadas em nano (nanotubos de carbono e óxidos de manganês) e 
microestruturas (feltros de carbono $(F C)$ ) com a finalidade de avaliar 0 desempenho desses materiais como possíveis candidatos a aplicação como membranas íon seletivas. Foi verificada também, a influência dos nanotubos de carbono e da polianilina depositadas nas fibras de carbono e testadas como membranas seletivas. Essas diversas amostras foram estudadas como membranas seletivas da estrutura do EGFET. A idéia principal consiste em desenvolver sensores de pH a partir da fabricação de EGFETs. Pretende-se com isso, dar continuidade a uma linha de pesquisa para o desenvolvimento de biossensores, ou seja, dar o passo inicial da aplicação dessas membranas, como parte dos biossensores. 


\section{EGFET com óxido de manganês}

Nesse capitulo, serão apresentados os resultados relacionados à utilização de filmes finos de óxido de manganês depositados em substratos de vidros, como membranas seletivas. Esses filmes foram caracterizados como membranas sensíveis a $\mathrm{H}^{+}$, conectadas ao MOSFET para o desenvolvimento de sensores de pH funcionando como EGFET.

\section{1-Introdução}

\subsection{1- Óxido de manganês nanoestruturados}

Nanoestruturas de óxidos metálicos têm despertado um grande interesse dos pesquisadores devido à potenciais aplicações como componentes funcionais para a fabricação de dispositivos eletrônicos, ópticos, optoeletrônicos, 
eletroquímicos e sensores em escala nanométricas [76-78]. Entre os óxidos estão $\mathrm{MgO}, \mathrm{ZnO}, \mathrm{CdO}, \mathrm{Ga}_{2} \mathrm{O}_{3}, \mathrm{In}_{2} \mathrm{O}_{3}, \mathrm{TiO}_{2}, \mathrm{SnO}_{2}$, entre outros.

O óxido de manganês tem sido alvo de estudo em várias aplicações em dispositivos eletroquímicos, eletrocromismo, células combustíveis, em catálise, adsorção molecular, biossensor, estocagem de energia em baterias secundárias. Além disso, é um semicondutor onde a diferença entre a energia da banda de condução e a de valência ("gap") é baixo, ainda exibe propriedades ferroelétricas, entre outras aplicações. O óxido de manganês é sintetizado em diferentes rotas entre elas técnicas como redução, copreciptação, sol-gel, decomposição térmica, entre outras [79-83].

A síntese hidrotérmica é uma outra técnica de produção, que tem sido aplicada e se mostra interessante para o preparo de materiais com diferentes nanoarquiteturas, tais como nanoguias, nanofios, entre outras [79-83].

A principal vantagem da rota hidrotérmica sobre as outras rotas químicas é a habilidade de controlar as nanoestruturas mudando suas conformações, ou seja, passar de nanoparticulas para nanobastão ou de nanoparticulas para nanotubos, como exemplo, pela mudança da temperatura, tempo de reação, pressão ou solvente. Dentre as estruturas possíveis, as aplicações variam, sendo empregadas para fotocatálise, eletrodos de recarga de baterias, supercapacitores, eletrocatálise de células combustíveis, entre outras [79-83].

Dentre as várias morfologias de nanoestruturas do óxido de manganês, o trabalho em questão retrata a produção de oxihidróxido de manganês do tipo Y$\mathrm{MnOOH}$, que foi sintetizado pelo método hidrotérmico com controle da temperatura e de tempo de reação. 


\subsection{2-Método hidrotérmico}

O método hidrotérmico vem cada vez mais sendo utilizado para a produção de materiais com estruturas nanométricas. A obtenção desses materiais por esse método apresenta vantagens quando comparadas a outros métodos devido ao fato de que ele é autoconsistente, ou seja, mediante a escolha dos reagentes, da temperatura e tempo de reação, chega-se à formação dessas novas estruturas pela auto regulagem da pressão que é fornecida ao sistema através do controle da temperatura. Chega-se, a uma pressão considerável, com baixa temperatura, favorecendo a organização estrutural do produto que seria conseguido com essa mesma pressão a uma alta temperatura por outros métodos.

O processo hidrotérmico pode ser dividido em duas etapas: a primeira etapa seria a preparação do precursor do óxido desejado e a segunda etapa, a preparação do óxido propriamente em questão.

\subsection{3-Produção do óxido de manganês e dos filmes finos}

Para a produção do óxido, segue como dito anteriormente, dividido em duas partes. A primeira parte segue com a preparação do precursor que irá originar o óxido de manganês. Esse precursor é conseguido, dissolvendo 14,5g de Cetil-trimetil brometo de amônio (CTAB) em $100 \mathrm{ml}$ de $\mathrm{H}_{2} \mathrm{O}$. Em outro recipiente, 6,3g de permanganato de potássio é dissolvido em outros $100 \mathrm{ml}$ de $\mathrm{H}_{2} \mathrm{O}$. As soluções são misturadas, filtradas e deixadas para secar em um dessecador. O produto formado será o precursor do óxido de manganês. A segunda parte se faz misturando $40 \mathrm{mM}$ 
desse precursor, em 50ml de acetona. Depois de dissolver o precursor em acetona, é acrescentado $50 \mathrm{ml}$ de $\mathrm{H}_{2} \mathrm{O}$ nessa solução, sob agitação. Mantendo a agitação, essa nova solução é aquecida por aproximadamente $24 \mathrm{~h}$ a uma temperatura de $90^{\circ} \mathrm{C}$, no autoclave de Teflon (reator). Depois de frio, o produto dessa reação é filtrado e secado.

A produção dos filmes finos de manganês é feita com o pó seco, disperso em uma solução de etanol nas concentrações de $1 \mathrm{~g} / \mathrm{l}, 2 \mathrm{~g} / \mathrm{l}$ e $3 \mathrm{~g} / \mathrm{l}$. Essa solução é mantida sob agitação e no banho de ultra-som por 30min. Os filmes finos são depositados nos substratos de vidro nas temperaturas de $80^{\circ} \mathrm{C}$ e $100^{\circ} \mathrm{C}$ pela técnica de deposição de spray-pyrolysis, em cada uma das concentrações mencionadas anteriormente. Os substratos de vidro são de dois tipos: um deles é o corning-glass 7059 , lixado com lixa $n^{0} 1600$, que a partir de agora será chamado vidro rugoso (VR) e o vidro usado como lâmina de microscópio, que a partir de agora será chamado de vidro liso (VL). $\mathrm{O}$ uso dessas temperaturas foi para verificar a diferença na formação dos filmes finos em duas temperaturas superiores a temperatura de evaporação do etanol, solução usada para dispersar o oxido de manganês. Entretanto, os filmes depositados a $100^{\circ} \mathrm{C}$ não tiveram uma boa aderência nos substratos, comprometendo o desempenho como sensores. Acreditamos que mesmo assim, não é descartada essa temperatura de deposição, necessitando uma análise mais detalhada do procedimento de deposição.

\section{2-Caracterização no infravermelho (FTIR)}

As medidas de espectroscopia no infravermelho com transformada de Fourier (FTIR) foram realizadas em um espectrofotometro Bomem MB 100. As 
amostras estavam em forma de pastilhas misturadas com $\mathrm{KBr}$. As análises foram realizadas no modo de transmissão, na faixa de $4000 \mathrm{~cm}^{-1}$ a $400 \mathrm{~cm}^{-1}$.

A figura 3.1, mostra o espectro de transmitância na região do infravermelho da amostra do pó do óxido de manganês que foi posteriormente depositada a $80^{\circ} \mathrm{C}$ sobre o VL. Não foi possível obter o espectro do filme fino de manganês depositado sobre $\mathrm{VL}$ a $80^{\circ} \mathrm{C}$ com concentração de $2 \mathrm{~g} / \mathrm{l}$, porque a instrumentação utilizada estava disposta para utilização apenas no modo de transmissão, não conseguindo um espectro do filme depositado sobre VL.

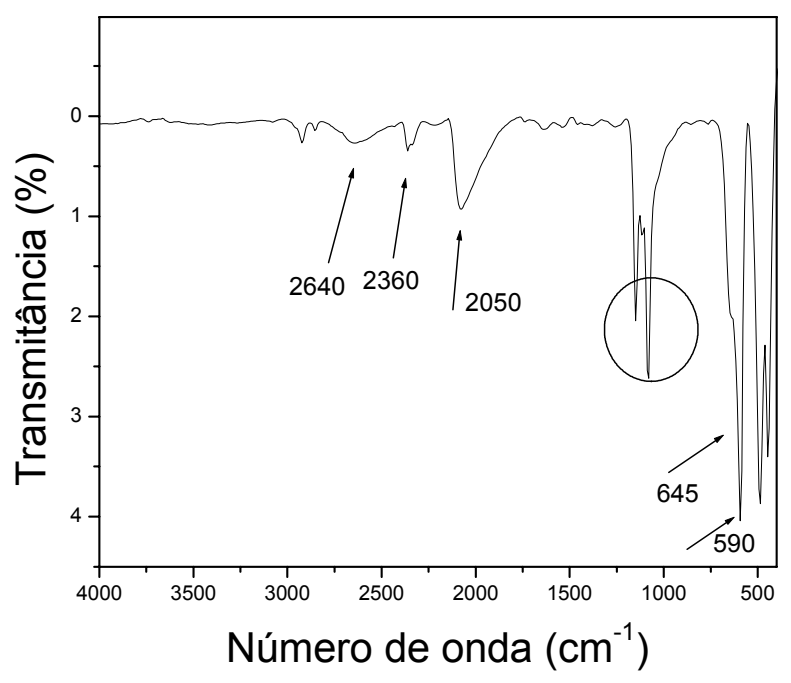

Figura 3.1: Análise de FTIR da amostra do óxido de manganês em forma de pó obtido pelo método hidrotérmico que posteriormente foi usado na produção dos filmes finos.

Através do resultado, podemos observar no espectro de infravermelho a existência de um pico em $2360 \mathrm{~cm}^{-1}$ que é causado pela absorção de água e dióxido de carbono, segundo Zhang et al [80]. Os picos que estão circulados são típicos do modo de ligação $\mathrm{OH}$. A banda em torno de 2050 era também observada 
em outros estudos feitos com esse oxido [80,82]. Essa banda pode ser considerada como uma combinação da banda no modo estiramento ("stretching") $\mathrm{OH}$ - em 2640 com o modo de rede excitado Mn-O em 590, como reportado em Zhang e colaboradores[80,82]. O pico em 645 corresponde à vibração Mn-O [80]. O grupo $\mathrm{OH}$ presente pode, segundo o modelo do sitio de ligação, funcionar como um sítio de interação para os íons $\mathrm{H}^{+}$.

\section{3-Caracterização estrutural}

As estruturas dos filmes de óxido de manganês depositados sobre os substratos de vidro (VL e VR) foram caracterizadas pela difratometria de Raios-X (DRX), realizadas em um difratômetro SIEMENS D5005, com radiação $\mathrm{K} \alpha$ do $\mathrm{Cu}$ $(\lambda=1,5418 \AA)$, operando a $40 \mathrm{KV}$ e $40 \mathrm{~mA}$. Os padrões de raios-X foram obtidos na faixa compreendida entre $2^{\circ}$ e $50^{\circ}(2 \theta)$ e em um passo de $0,2^{\circ}$ a cada segundo.

Com a técnica de DRX, estudamos a estrutura do pó que foi usado para produção dos filmes finos de óxido de manganês feitos por spray-pyrolysis.

As análises aqui mostradas são dos filmes feitos com concentração de $2 \mathrm{~g} / \mathrm{l}$. Os filmes feitos com concentração de $1 \mathrm{~g} / \mathrm{l}$ e $3 \mathrm{~g} / \mathrm{l}$ não aderiram aos substratos. $\mathrm{O}$ primeiro com concentração de $1 \mathrm{~g} / \mathrm{l}$, ficou com pouco material. Não foi possível fazer a DRX desse filme, nem mesmo o teste como membrana seletiva. Os filmes feitos com concentração de 3g/l também não ficaram bons. Esses filmes ficaram espessos e soltos sobre os substratos, além de não responderem também como membranas seletivas. Apenas os filmes com concentração de $2 \mathrm{~g} / \mathrm{l}$ que se 
aderiram nos substratos. O resultado para o pó do óxido usado para fabricação do dispositivo é apresentado na figura 3.2.

Como a difração foi até $50^{\circ} \mathrm{C}$, apenas os picos compreendidos abaixo desse ângulo foram analisados e confrontados com a literatura.

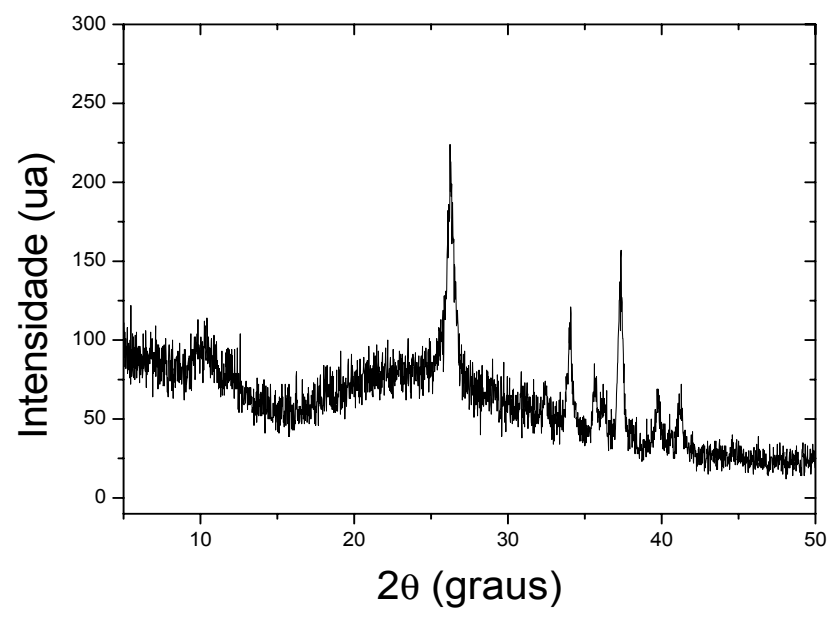

Figura 3.2: Espectro de difração de raios-X do óxido de manganês, na forma de pó, sintetizado pelo método hidrotérmico e utilizado para a produção dos filmes finos.

Assim sendo, esses picos identificaram a estrutura do óxido de manganês na forma $\mathrm{Y}-\mathrm{MnOOH}$. Segundo Zhang e colaboradores [52,54,57], $\mathrm{Y}-\mathrm{MnOOH}$ apresenta constantes de rede $a=5,2793 \AA$, b=5,2671 $\mathrm{A}$ e $c=5,3242 \AA$, compatível aos valores do banco de dados JCPDS $n^{\circ} 41-1379$. Zhang e colaboradores [80] reportam que esse material é precursor de uma outra estrutura quando submetido ao aquecimento, a do tipo $\beta-\mathrm{MnO}_{2}$. Na literatura $[80,82]$ a estrutura $\beta-\mathrm{MnO}_{2}$ é conseguida mediante aquecimento a $280^{\circ} \mathrm{C}$ por $5 \mathrm{~h}$ de $\mathrm{y}-\mathrm{MnOOH}$. 
Na figura 3.3 podem ser vistos os filmes finos de manganês, feitos pela técnica de spray-pyrolysis à $80^{\circ} \mathrm{C}$ com concentração de $2 \mathrm{~g} / \mathrm{l}$ nos substratos de vidro, (VR e VL).

Observa-se que os filmes com concentração de $2 \mathrm{~g} / \mathrm{l}$ no substrato VL apresenta uma estrutura com picos mais proeminentes do que aquele feito no substrato VR.

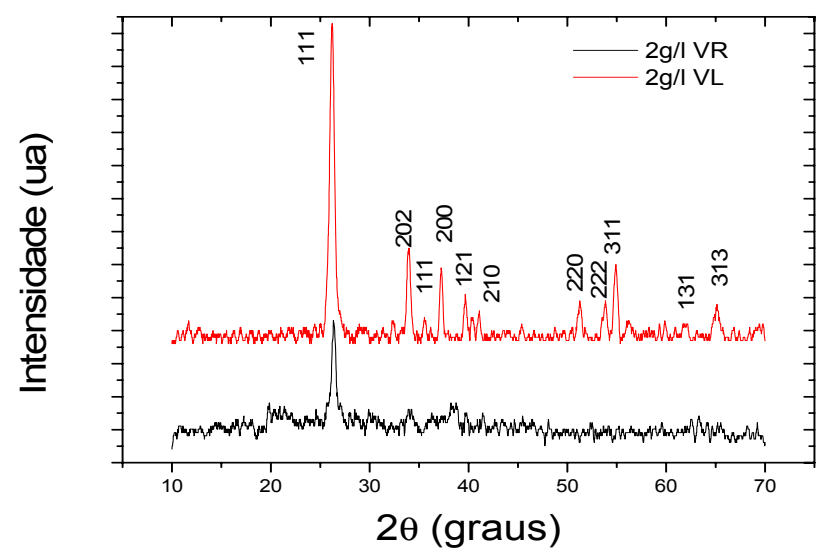

Figura 3.3: Espectro de difração de raios-X dos fimes finos de óxido de manganês feito pela técnica de spray pyrolysis com concentração de $2 \mathrm{~g} / \mathrm{l}$ nos substratos de vidro liso e rugoso.

Os picos do filme fino crescido sobre o substrato $\mathrm{VL}$ correspondem ao $\mathrm{y}-\mathrm{MnOOH}$ identificado na literatura segundo Zhang e colaboradores [79-82]. Nessa estrutura o pico $26,2^{\circ}$ tem o crescimento preferencial em (111). Os filmes crescidos na temperatura de $80^{\circ} \mathrm{C}$ nos substratos $\mathrm{VL}$, também foram aqueles que responderam melhor à variação do $\mathrm{pH}$, como será discutido posteriormente. 


\section{4-Caracterização da superfície}

A superfície do pó e do filme de manganês depositado por spray-pyrolysis à $80^{\circ} \mathrm{C}$ sobre o VL foi analisada através da técnica de microscopia eletrônica por varredura (MEV), utilizando um microscópio ZEISS DSM - 960 (Departamento de Química - FFCLRP - USP). As amostras analisadas por microscopia eletrônica de varredura foram fixadas sobre um porta-amostra com o auxílio de uma fita dupla de carbono. Uma cobertura fina de ouro $(\approx 20 \AA)$ foi aplicada sobre as amostras utilizando-se um Sputter Coater - Balzers SCD 050, quando necessário. Esta camada é responsável por conferir condutividade elétrica suficiente para a geração de boas imagens. O interesse em utilizar o MEV é a capacidade de identificar a morfologia quanto ao aparecimento de buracos e à homogeneidade dos filmes produzidos que interferem no desempenho do dispositivo

A imagem do pó, utilizado para a deposição do filme pode ser vista na figura 3.4.

A figura 3.4 mostra os nanofios de manganês, como se fossem agulhas em ampliações de 4000 e 20000 vezes. Nota-se que o pó se aglomera em blocos e cada bloco com feixes de nanofios. Pode-se notar nessa imagem, que os blocos compreendem uma larga quantidade de nanofios. Os diâmetros desses nanofios podem ser estimados na faixa de 10-60 nm, e de comprimento da ordem de microns, o que está de acordo com a literatura [57]. 

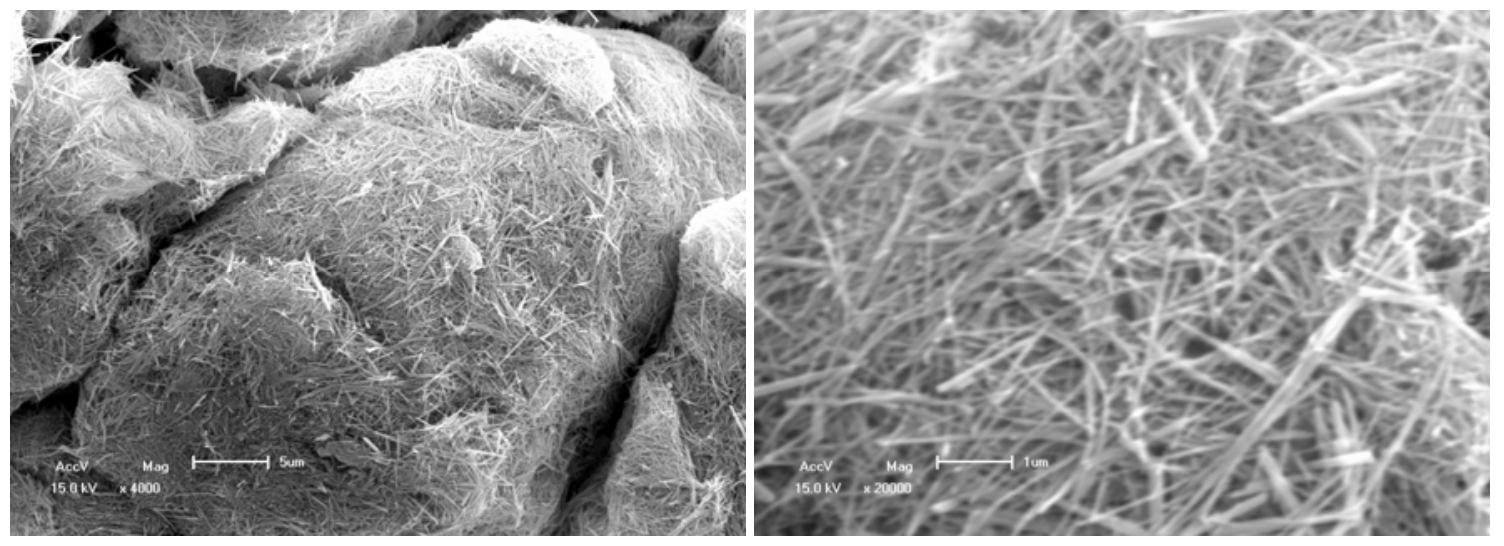

Figura 3.4: Imagens de microscopia eletrônica de varredura do óxido de manganês sintetizados pelo método hidrotérmico e utilizados para a produção dos filmes finos.

Pelas imagens, pode-se inferir que eles são de alta qualidade. Da imagem, da pra notar que os nanofios não têm uma morfologia especifica, ou seja, de mesmo tamanho ou forma, sendo variada essa estrutura. Como esse material tem grande área superficial, facilitaria a interação desses nanofios com os íons a serem medidos, já que sua razão área-volume é grande.

$\mathrm{Na}$ figura 3.4, fica claro que eles estão agrupados em feixes sem nenhuma orientação. Na preparação dos filmes finos, a deposição no substrato VL foi feita a $80^{\circ} \mathrm{C}$ com concentração de $2 \mathrm{~g} / \mathrm{l}$.

Na figura 3.5, a série de imagens com ampliações de 1000, 5000, 10000 e 30000 vezes, mostra a estrutura superficial do filme depositado sobre o VL.

A deposição ocorreu quase que por completo sobre todo o substrato. Além disso, o filme apresenta aglomerado de nanofios de manganês, uma característica importante para aplicações envolvendo sensores, porque influencia na área superficial onde ocorrerá o contato com os íons da solução. 

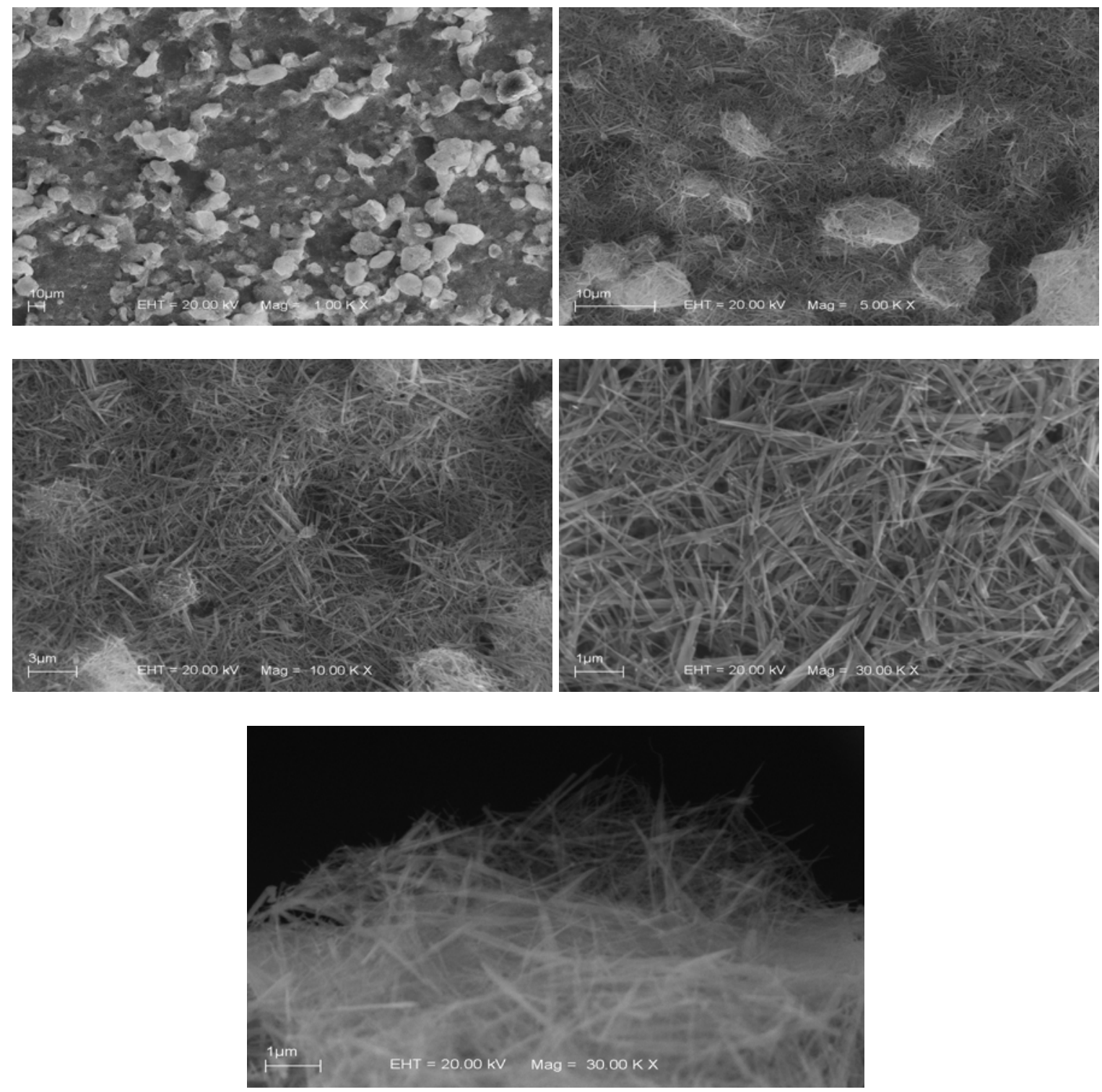

Figura 3.5: Imagens de microscopia eletrônica de varredura dos filmes de óxido de manganês depositado sobre o vidro liso à $80^{\circ} \mathrm{C}$ com concentração de $2 \mathrm{~g} / \mathrm{l}$.

Uma análise cuidadosa foi feita, com ampliação das imagens para certificarse de que o filme foi realmente todo recoberto, não evidenciando poros que, de certa forma, influenciam no sinal. Nas imagens, podemos notar alguns pontos escuros. Esses pontos escuros por sua vez, não nos permitem concluir que seja o substrato. Esses pontos escuros podem ser que o filme depositado nessa região 
esteja com menor espessura. Por outro lado, detalhes da superfície podem ser vistos com uma ampliação maior, mostrando que a estrutura do filme é composta por um emaranhado de nanofios de manganês com tamanho estimado entre 1060 nanômetros. Não foi possível determinar a espessura do filme, já que o mesmo não apresentou um contraste com o substrato. Essa fato aconteceu, possivelmente, porque havia material depositado na superfície lateral do filme.

\section{5-Caracterização elétrica}

Nessa seção, serão apresentados os resultados referentes ao comportamento dos filmes feitos sobre os substratos de VL e VR. O sistema de EGFET consiste em uma parte sendo a membrana sensível, ou seja, os filmes finos e outra parte um MOSFET comercial CD4007UB, onde a membrana sensível está acoplada. A membrana está em contato com o MOSFET através de uma garra metálica. A resposta elétrica do dispositivo era medida usando um multímetro Agilent 34970A. As curvas de corrente em função da tensão foram obtidas com o dispositivo imerso em soluções com pH entre 2 e 12. Em todas as amostras, esperou-se o tempo necessário para a estabilização da corrente de dreno, antes de fossem realizadas as demais curvas de caracterização.

A melhor resposta do EGFET foi sobre o substrato de vidro liso (VL) que foi depositado a $80^{\circ} \mathrm{C}$ com concentração $2 \mathrm{~g} / \mathrm{l}$. Outras concentrações, $1 \mathrm{~g} / \mathrm{l}$ e $3 \mathrm{~g} / \mathrm{l}$, foram testadas mas nenhuma respondeu satisfatoriamente, como pode ser visto na figura 3.6 com concentrações de $1 \mathrm{~g} / \mathrm{l}$ e na figura 3.7 com concentrações de $3 \mathrm{~g} / \mathrm{l}$. Nessas figuras apenas o $\mathrm{pH} 2$ respondeu diferente dos demais. Não há como 
saber se o problema de não responder à variação do $\mathrm{pH}$ é porque as membranas se estragam após o contato com o pH 2 ou se a má qualidade do filme formado seja o responsável. Entretanto, os comportamentos são distintos.
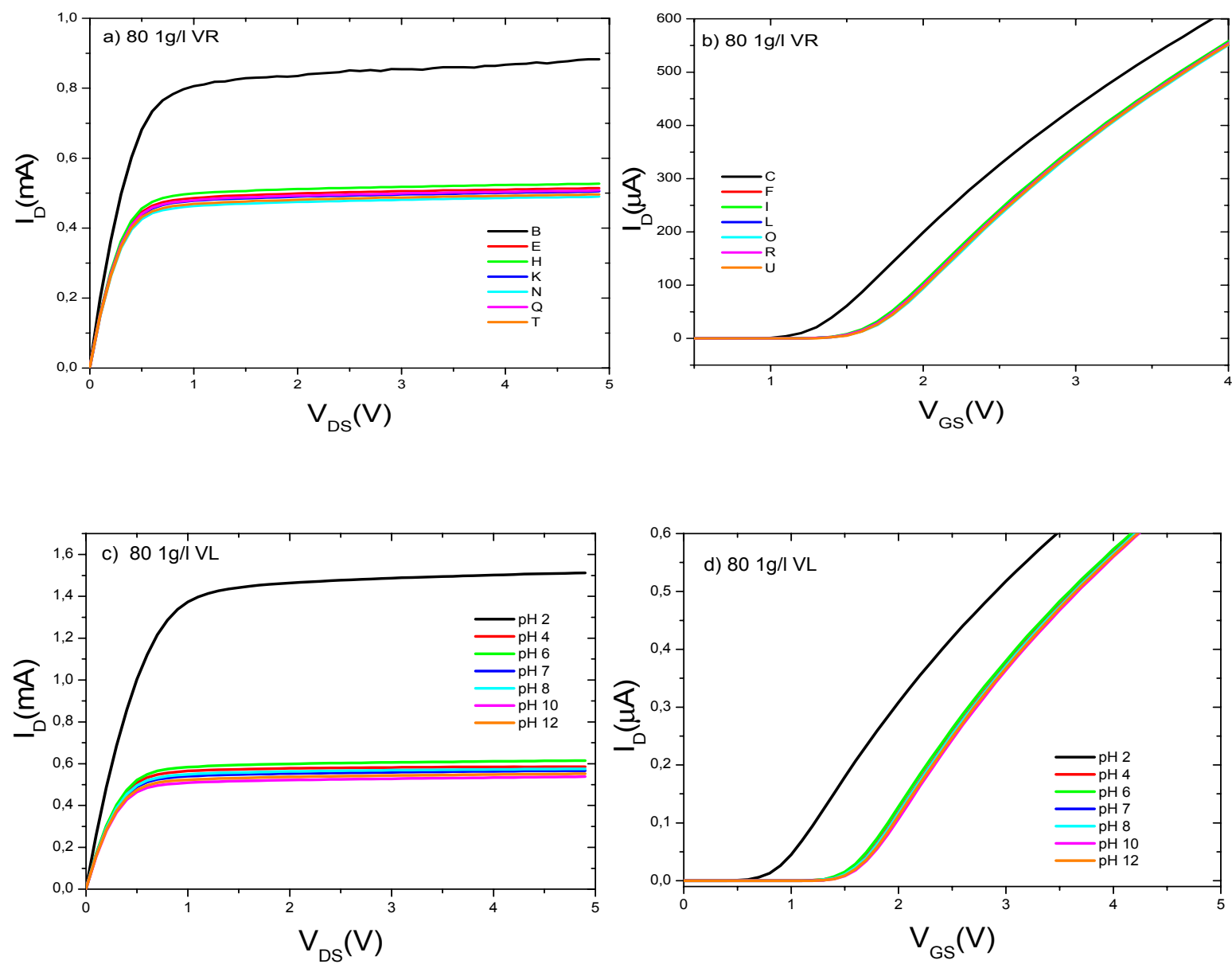

Figura 3.6: Curva da resposta do filme fino de óxido de manganês EGFET depositado com concentração de $1 \mathrm{~g} / \mathrm{l}$ a $80^{\circ} \mathrm{C}$. Em (a) o EGFET operando na região de saturação e (b) na região linear, filmes depositados sobre VR. Em (c) o EGFET operando na região de saturação e (d) na região linear, filmes depositados sobre VL. 
Quando a concentração nos filmes é 3g/l, aparecem outras curvas. Porem, elas não têm os mesmos comportamentos nos dois substratos.
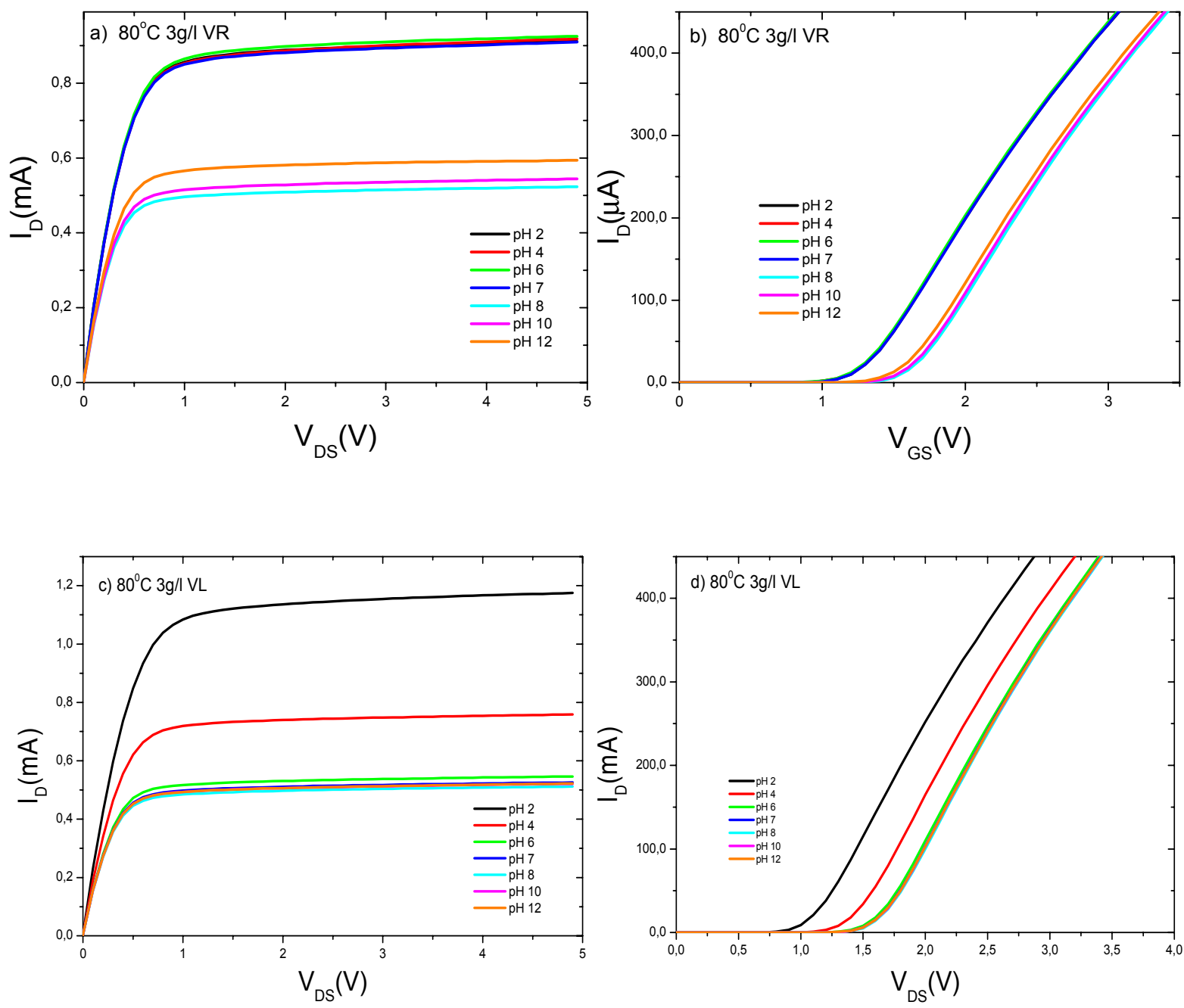

Figura 3.7: Curva da resposta do filme fino de óxido de manganês EGFET depositado com concentração de $3 \mathrm{~g} / \mathrm{l}$ a $80^{\circ} \mathrm{C}$. Em (a) o EGFET operando na região de saturação e (b) na região linear, filmes depositados sobre VR. Em (c) o EGFET operando na região de saturação e (d) na região linear, filmes depositados sobre VL. 
No substrato de vidro liso (VL) há separação entre os pHs 2 e 4, com os demais $\mathrm{pHs}$ se misturando. Enquanto que no substrato de vidro rugoso (VR) não há separação entre os pHs nas soluções ácidas (2 e 4), há um princípio de separação nas soluções com pHs maiores (10 e 12).

Pelos resultados apresentados, não é possível chegar a nenhuma conclusão sobre esse comportamento, necessitando de uma análise mais cuidadosa.

Nas figuras 3.6 e 3.7, os gráficos (a) e (c), os EGFET estão operando na região de saturação com $\mathrm{V}_{\mathrm{GS}}$ igual a $2,5 \mathrm{~V}$ e $\mathrm{V}_{\mathrm{DS}}$ variando de 0 a $5 \mathrm{~V}$, enquanto que em (b) e (d) o EGFET está operando na região linear com $V_{D S}$ igual a $0,17 \mathrm{~V} e$ $V_{G S}$ variando de 0 a $5 \mathrm{~V}$. Nessas figuras, pode ser visto que, tanto os filmes depositados sobre o substrato VL quanto os depositados sobre o substrato VR com concentrações de $1 \mathrm{~g} / \mathrm{l}$ quanto $3 \mathrm{~g} / \mathrm{l}$, a corrente não mais depende da variação do $\mathrm{pH}$, ou seja, não sofre variação com a mudança do $\mathrm{pH}$, permanecendo constantes próximas de um mesmo valor. Pode-se, pois, inferir que esse comportamento esteja relacionado à qualidade dos filmes formados. Os filmes com concentração de 1g/l tiveram uma deposição ruim, pobre homogeneização e que dificulta a adsorção de carga na superfície e também o transporte de carga até o contato elétrico, onde este está conectado ao MOSFET. Com o mesmo comportamento, os filmes com concentrações de 3g/l também não conseguiram uma correspondência, ou seja, uma separação entre a corrente de dreno e os pHs. Nesse caso, houve problemas de aderência do material nos substratos. Esse material quando imerso na solução, desprendia do substrato, dificultando a medida. Para otimizar o processo de deposição em função da concentração, foi 
feita a deposição à $80^{\circ} \mathrm{C}$ com concentração de $2 \mathrm{~g} / \mathrm{l}$. De acordo com a caracterização superficial (figura 3.5) apresentada na seção anterior, os filmes depositados com concentração de $2 \mathrm{~g} / \mathrm{l}$ foram aqueles que responderam melhor a variação do $\mathrm{pH}$. Esses filmes apresentaram boa aderência com uma boa homogeneização. Na figura 3.8 é apresentado o comportamento elétrico do filme feito sobre o substrato rugoso (VR).
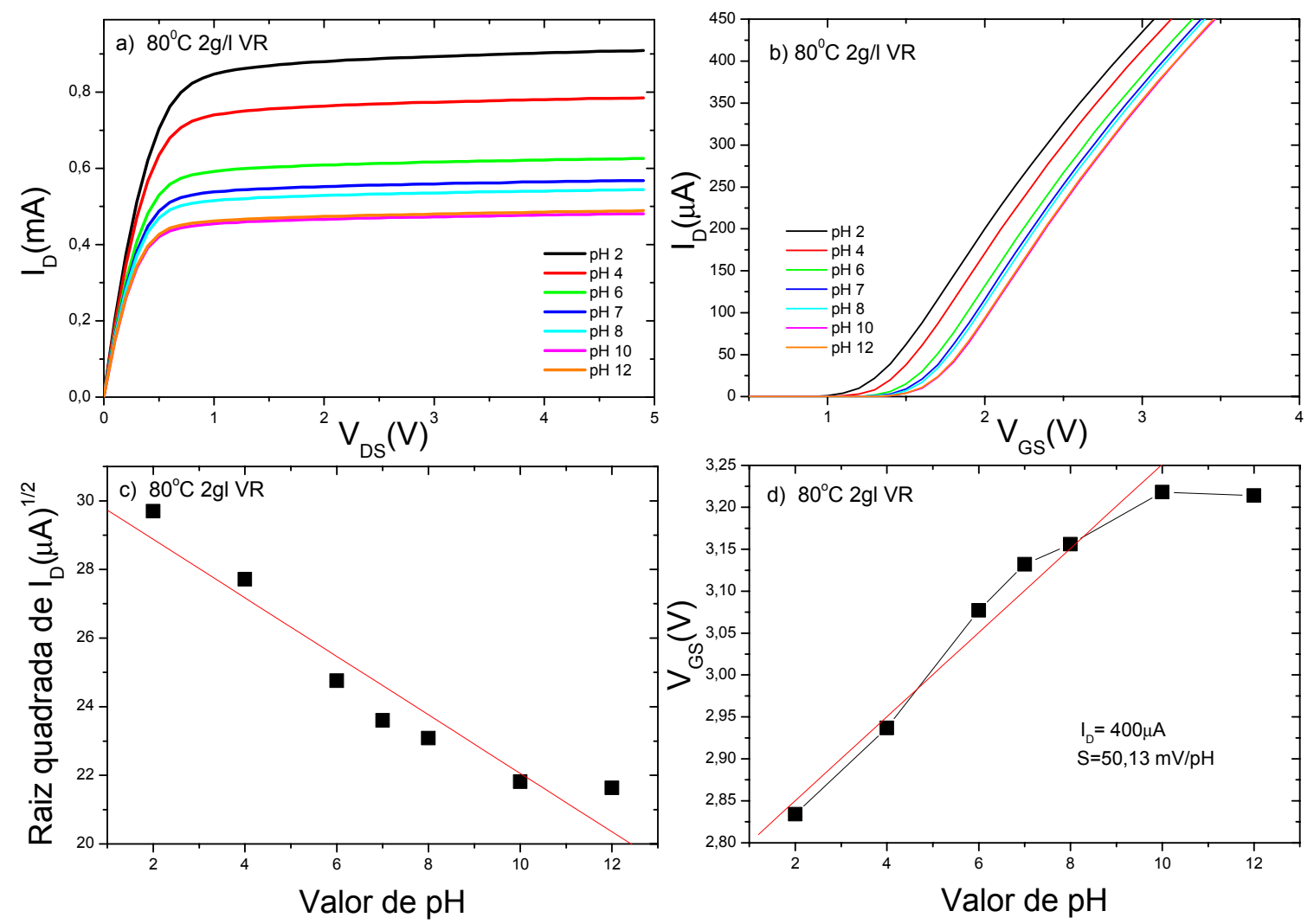

Figura 3.8: Curva de resposta do filme fino de óxido de manganês EGFET depositada a $80^{\circ} \mathrm{C}$ com concentração de $2 \mathrm{~g} / \mathrm{l}$ em substrato rugoso (VR). Em (a) apresenta o EGFET operando na região de saturação, em (b) na região linear enquanto que em (c) mostra a relação da raiz quadrada da corrente função do $\mathrm{pH}$ e em (d) a sensibilidade do dispositivo. 
A figura 3.8 apresenta as medidas de $I_{D S}$ em função de $V_{D S}(a)$ quando a membrana é imersa em diferentes valores de pH. Pode ser observado que há uma separação da corrente quando submetidas a diferentes pHs. Entretanto, a separação da corrente $I_{D s}$ nos pHs 10 e 12 não ocorreu. Isso faz com que as curvas que relacionam, a raiz quadrada de $\mathrm{I}_{\mathrm{DS}} \mathrm{com} \circ \mathrm{pH}$, figura 3.8-c, como a curva que mostra relação da $V_{\text {Ref }} \operatorname{com} \circ \mathrm{pH}$, figura 3.8-d, não fiquem linear em todos os pHs. Acreditamos que o filme tenha perdido a sensibilidade depois de imerso em solução de pH igual a 10, fato esse que se mostrou repetitivo em todas as amostras testadas.

Quando o pH da solução está básico, há maior concentração de íons $\mathrm{OH}$ do que $\mathrm{H}^{+}$. O oxido utilizado nesse caso, $\mathrm{y}-\mathrm{MnOOH}$, pela sua constituição, ou seja, com $\mathrm{OH}$ em sua estrutura, apresenta maior possibilidade de se unir com íons $\mathrm{H}^{+}$ do que com $\mathrm{OH}$. Sendo assim, seria uma possibilidade das curvas referentes aos pHs 10 e 12 não terem sido separadas. Mas isso seria exclusivo do filme produzido no substrato rugoso (VR), porque, como será visto mais adiante, para o filme produzido no substrato liso (VL) esse comportamento não é observado. Outra hipótese possível, seria o fato de que o substrato rugoso, por ter sido lixado, comprometeria a formação do filme, reduzindo o número de sítios efetivos. Com a solução estando básica, a concentração de $\mathrm{H}^{+}$seria menor e com o número de sítios efetivos também menor, a separação de pHs básicos ficaria prejudicada.

A partir dos dados figura 3.8-a, pode-se obter a relação entre a raiz quadrada de $\mathrm{I}_{\mathrm{DS}}$ e o valor de $\mathrm{pH}$, figura 3.8-c, em que uma variação de aproximadamente 8 mA é observada quando o pH da solução varia entre 2 a 12 . 
A partir da figura 3.8-b, obtemos a sensibilidade do filme fino. A sensibilidade desse filme, a partir dos dados de $I_{D S}$ pela tensão $V_{G S}$ para $V_{D S}=$ 0,17 volts, pode ser vista na figura $3.8-d$. Escolhendo uma corrente $I_{D S}=0,4 \mathrm{~mA}$, na figura 3.8-b, a curva de $\mathrm{V}_{\mathrm{GS}}$ em função do $\mathrm{pH}$ pode ser adquirida, observandose uma sensibilidade de $50,1 \mathrm{mV} / \mathrm{pH}$.

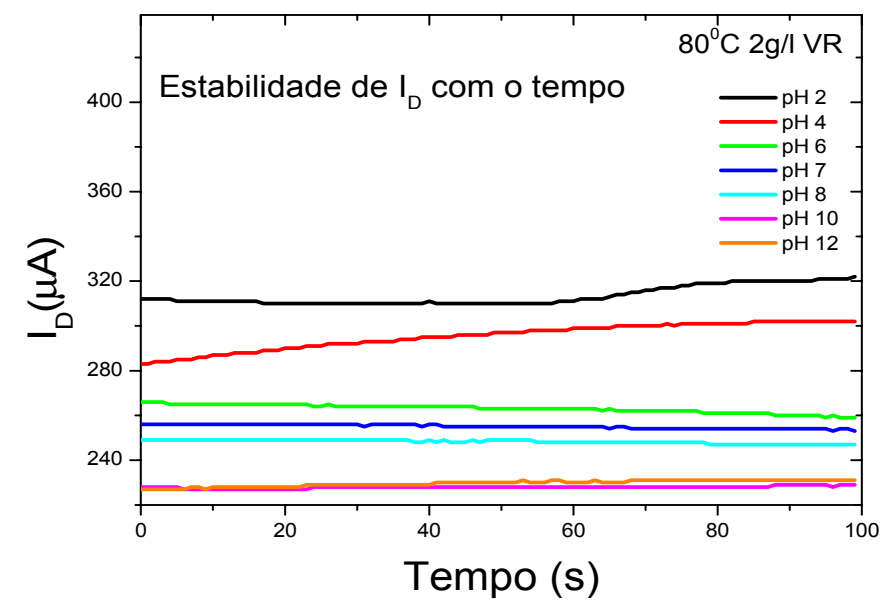

Figura 3.9: Comportamento da corrente de dreno em função do tempo, depositado a $80^{\circ} \mathrm{C}$ com concentração de $2 \mathrm{~g} / \mathrm{l}$ em substrato rugoso (VR).

Na figura 3.9, vemos a estabilidade da corrente $I_{D}$ com o tempo. Pode-se notar nessa figura que as correntes correspondentes aos pHs 10 e 12 estão juntas e permanecem assim por todo o tempo medido. Nessa figura, é observado também, que as correntes correspondentes aos pHs 2 e 4 variam com tempo de um modo ascendente, mas dando indícios de que estabilizariam. Enquanto que as correntes relacionadas, aos demais pHs, permanecem praticamente estáveis.

Analisando o filme depositado sobre o substrato liso (VL), figura 3.10, constatamos que ocorreu um fato semelhante àquele filme depositado sobre o 
substrato rugoso. A corrente $I_{D S}$ nos pHs 6 e 7 não se diferenciaram. Entretanto, os outros pHs responderam de maneira linear com uma variação de aproximadamente em 0,9 mA na curva de $I_{D S}$ versus $V_{D S}$, figura3.10-a. Enquanto que a relação entre a raiz quadrada de $\mathrm{I}_{\mathrm{DS}}$ versus $\mathrm{pH}$, figura $3.10-\mathrm{c}$, com comportamento praticamente linear, exceto nos pHs 6 e 7, houve uma variação da corrente de aproximadamente 15,1 mA entre os pHs 2 e 12 .
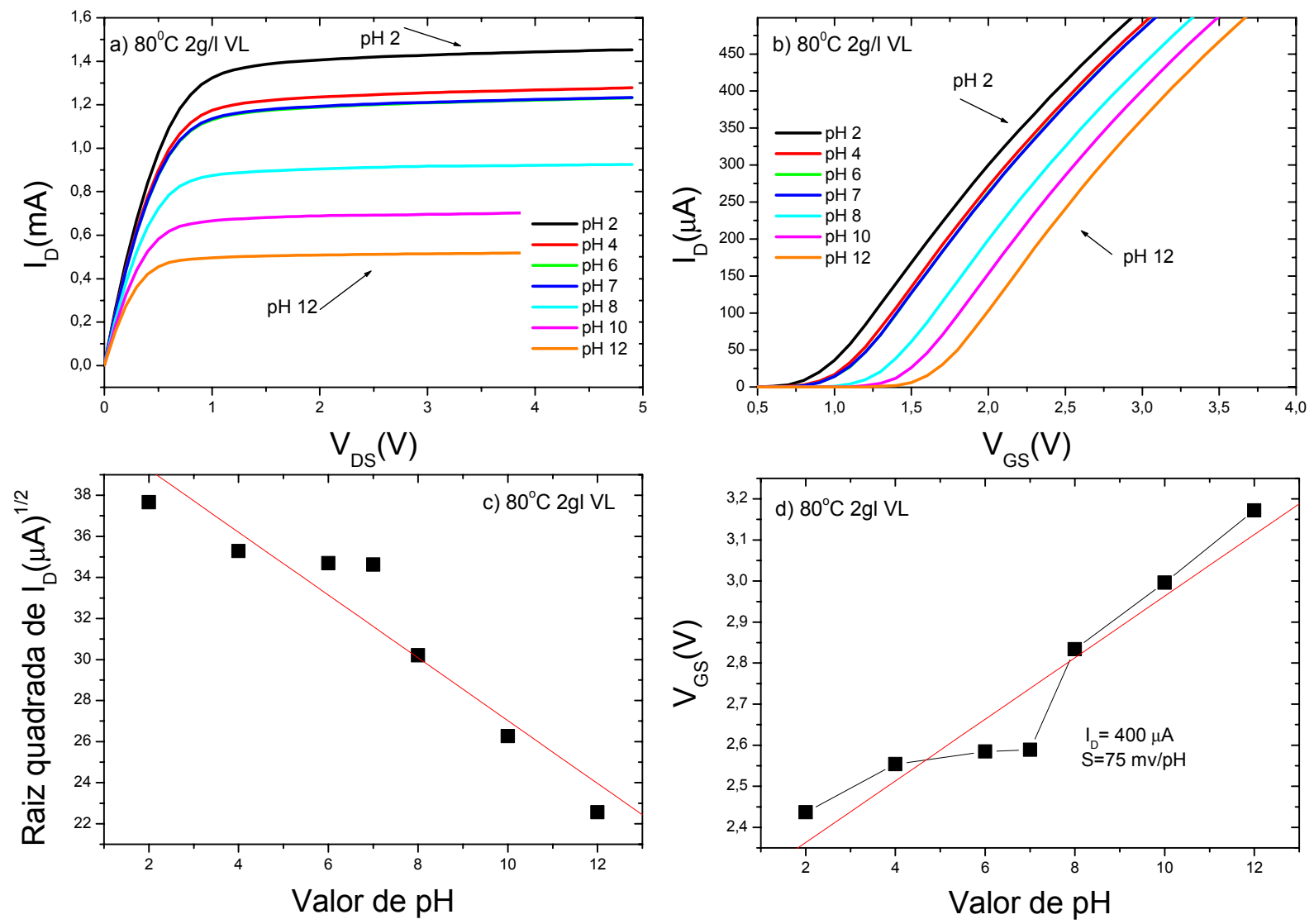

Figura 3.10: Curva de resposta do filme fino de óxido de manganês EGFET depositada a $80^{\circ} \mathrm{C}$ com concentração de $2 \mathrm{~g} / \mathrm{l}$ em substrato liso (VL). Em (a) apresenta o EGFET operando na região de saturação, em (b) na região linear enquanto que em (c) mostra a relação da raiz quadrada da corrente função do $\mathrm{pH}$ e em (d) a sensibilidade do dispositivo 
A sensibilidade pode ser obtida da curva $\mathrm{V}_{\mathrm{GS}}$ pelo $\mathrm{pH}$, figura 3.10-d. O valor da corrente usado para determinação da sensibilidade, determinada pelos dados de $I_{D S}$ versus $V_{G S}$, da figura 3.10-b, foi a corrente $I_{D S}=0,4 \mathrm{~mA}$.

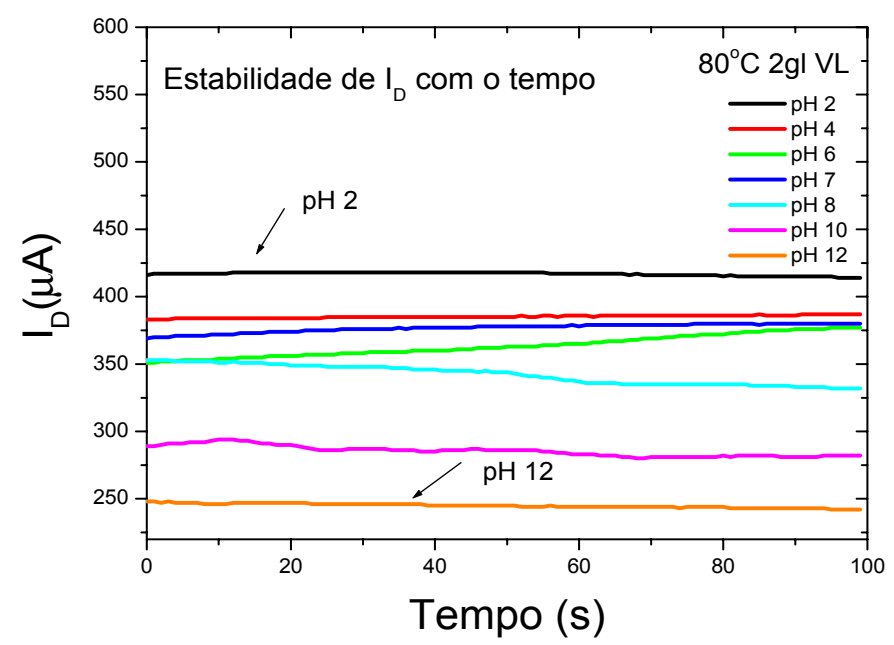

Figura 3.11: Comportamento da corrente de dreno em função do tempo, depositado a $80^{\circ} \mathrm{C}$ com concentração de $2 \mathrm{~g} / \mathrm{l}$ em substrato liso (VL).

Com essa corrente de dreno, uma sensibilidade de $75 \mathrm{mV} / \mathrm{pH}$ é observada. Esse comportamento extrapola o valor de $59,2 \mathrm{mV} / \mathrm{pH}$ que é teoricamente a maior sensibilidade que se possa ter, ou seja, um comportamento Nernstiano, segundo a relação de Nernst. O resultado que tivemos foi supernernstiano. A teoria prediz que o valor da sensibilidade está relacionado à capacitância entre o eletrólito e a membrana e também com o número de sítios efetivos. Assim, mesmo quando se tem um grande número de sítios, o máximo de sensibilidade que se consegue é 59, $2 \mathrm{mV} / \mathrm{pH}$. Uma hipótese, para sensibilidade de $75 \mathrm{mV} / \mathrm{pH}$ é que a capacitância entre o eletrólito e o filme tenha mudado para que o valor da sensibilidade também pudesse mudar. Uma outra hipótese seria uma mistura de mecanismos de 
interação acontecendo, além daquele de adsorção, como uma dissociação e/ou reação do manganês com a solução. Uma terceira, mas não excludente das anteriores, seria a interferência de outros íons na medida da membrana. Fog e Buck [59] reportaram em 1983, que alguns óxidos sofriam a interferência de alguns íons, mudando o drift desse material, que por sua vez, tinha uma sensibilidade maior que $59,2 \mathrm{mV} / \mathrm{pH}$.

A estabilidade dessa amostra, figura 3.11, mostrou-se praticamente constante com o tempo nas soluções de pHs 2, 4, 7, 10 e 12. A corrente de dreno, relacionada com os pHs 6 e 8 modificaram muito com o tempo. A partir desses dados, é aconselhável esperar estabilizar os pHs antes de fazer a medida, o que vimos pela figura, que o tempo de 100 segundos seria suficiente.

\section{6-Conclusão}

Inicialmente, foi desenvolvido o pó do óxido de manganês que foi posteriormente usado para desenvolvimento das membranas, sob a forma de filmes finos, de óxido de manganês depositados em substratos de vidro liso e rugoso, em temperaturas de $100^{\circ} \mathrm{C}$ e $80^{\circ} \mathrm{C}$ com concentrações de $1 \mathrm{~g} / /$ e $3 \mathrm{~g} / \mathrm{l}$. Os filmes foram propostos como sensores utilizando o EGFET. Entretanto, não foi possível a utilização de nenhum desses materiais como sensores. Os filmes com concentrações de $1 \mathrm{~g} / \mathrm{l}$ e $3 \mathrm{~g} / \mathrm{l}$ depositados à $80^{\circ} \mathrm{C}$, em ambos substratos, respondem sempre da mesma maneira (figuras 3.6 e 3.7), ou seja, independentes da variação do $\mathrm{pH}$. Acreditamos que a má formação dos filmes seja o principal 
motivo pelo seu mau funcionamento. Os filmes depositados com concentração de 1g/l apresentava pouca quantidade de material depositado e pobre homogeneização, enquanto que os filmes depositados com concentração de 3g/l apresentavam uma maior quantidade de filme depositado, porém com pouca aderência. Tentou-se então uma concentração intermediaria, 2g/l. Filmes com concentração de $2 \mathrm{~g} / \mathrm{l}$ produzidos a $80^{\circ} \mathrm{C}$ sobre os substratos de vidro liso e rugoso, apresentaram um comportamento linear com a variação do $\mathrm{pH}$. O filme depositado sobre o substrato rugoso não conseguiu diferenciar os pH 10 e 12 (figura 3.8), porém, responderam bem aos demais pHs, com uma sensibilidade de $50,1 \mathrm{mV} / \mathrm{pH}$. Filmes produzidos sobre o vidro liso também responderam de maneira linear com o pH, com exceção dos pHs 6 e 7 (figura 3.10) com uma sensibilidade de $75 \mathrm{mV} / \mathrm{pH}$. Não há uma resposta satisfatória, por que alguns materiais tenham um comportamento supernernstiano. As hipóteses para esse comportamento, poderiam ser o aumento da capacitância entre o eletrólito e a membrana sensível, uma mistura de mecanismo na detecção dos íons $\mathrm{H}^{+}$, e a interferência de outros íons na membrana durante a medida, ou ainda uma parcela de todos eles. Ainda não é possível apontar uma explicação para a sensibilidade do material.

Vale ressaltar que, de acordo com nosso conhecimento, o óxido de manganês não têm sido estudado como sensor de pH pelo processo EGFET. Vale ressaltar ainda, que a otimização deste material como sensor de $\mathrm{pH}$, abre um leque de aplicações como biossensores. Outros experimentos necessitam ser feitos para uma investigação mais sistemática dos fatores que podem estar afetando o funcionamento do dispositivo. 
Entretanto, mostra-se interessante o estudo de óxido de manganês feito pelo método hidrotérmico para futuras aplicações, devido ao fato de que por esse processo de produção, pode-se produzir material com diversas estruturas, possivelmente com propriedades diferentes, e também pelo fato do uso de técnicas simples de produção de filmes finos, resultando em uma alta sensibilidade.

Mediante o trabalho com o oxido de manganês, foi interessante o resultado de se trabalhar com nanoestruturas. Dessa forma tentou-se um outro material que se apresentam também estrutura com grande relação área-volume que apresentasse grande número de sítios de ligação. $O$ material proposto foi o nanotubo de carbono (NTC). O fato de usar os nanotubos seria a possibilidade de sua aplicação futura como biossensores. No próximo capítulo será feito o estudo dos nanotubos de carbono como EGFET. 


\section{4}

\section{EGFET com nanotubos de carbono}

Nesse capitulo, serão apresentados os resultados relacionados à utilização dos filmes finos de nanotubos de carbono como membrana seletiva. Esses filmes foram caracterizados como membranas sensíveis a $\mathrm{H}^{+}$, para o desenvolvimento de sensores de $\mathrm{pH}$ como EGFET.

\section{1-Introdução}

Nesse capítulo, continuaremos com a utilização de materiais nanoestruturados como membrana seletiva. O material utilizado nesse capítulo são os nanotubos de carbono. Nas últimas décadas, diversas descobertas têm estimulado a pesquisa científica na área de carbonos. No entanto, uma das descobertas mais significativas, seria a descoberta dos fulerenos, em 1985[84 ] e dos nanotubos de carbono em 1991[85]. Essas novas estruturas de carbono são 
bastante versáteis para se integrarem às diferentes áreas do conhecimento e promover uma inter/multidisciplinaridade.

Os nanotubos de carbono podem ser classificados em dois tipos considerando-se o número de camadas: nanotubos de carbono de paredes múltiplas (MWNT - multi-wall carbon nanotubes) e nanotubos de carbono de paredes simples (SWNT - single-wall carbon nanotubes). [32,33]. Dependendo da aplicação, um tipo é mais desejado que o outro.

Os nanotubos de carbono de paredes múltiplas (MWNT) foram observados pela primeira vez por ljima[85] em 1991. Em 1993 ljima e colaboradores[86] no Japão e Bethume e colaboradores[87] nos EUA publicaram a descoberta dos nanotubos de paredes simples (SWNT). Os nanotubos são conceitualmente construídos como sendo formados a partir de arranjos hexagonais de carbono que originam pequenos cilindros. Os nanotubos de paredes simples podem ser considerados como uma única folha de grafite enrolada sobre si mesma para formar o tubo cilíndrico, enquanto que os nanotubos de paredes múltiplas compreendem um conjunto de nanotubos concêntricos. A forma como os nanotubos estão enrolados determinam as suas estruturas e suas propriedades.

A maioria das suas propriedades depende do diâmetro e ângulo quiral, também chamado de helicidade[32,33]. O ângulo quiral é definido por parâmetros chamados índice de Hamada. Os índices de Hamada(n,m) e a helicidade definem três tipos de nanotubos: armchair $(n=m)$, zig-zag $(n, m=0)$ ou quiral $(n \neq 0, m \neq 0)$ e estão definidos pelo ângulo de helicidade $\Phi$. Se $\Phi$ varia de 0 a $30^{\circ}$ podem ser gerados tubos partindo do tipo zig-zag até o armachair como limites, passando pelos tubos, sem nome especifico, conhecido como quiral[32,33]. Em função dos 
índices de Hamada, um nanotubo pode ser metálico quando n-m é múltiplo de 3, caso contrário é semicondutor, assim, todos os nanotubos do tipo armachair são metálicos, enquanto os zig-zag e quiral podem ser metálicos ou semicondutores.

Essas considerações são válidas para os nanotubos de parede simples. Mas os nanotubos perfeitos de paredes múltiplas, assemelham-se aos de nanotubos de paredes simples, por causa do fraco acoplamento entre os cilindros de carbono concêntricos [32,33]. Abaixo uma ilustração dos nanotubos de carbono.

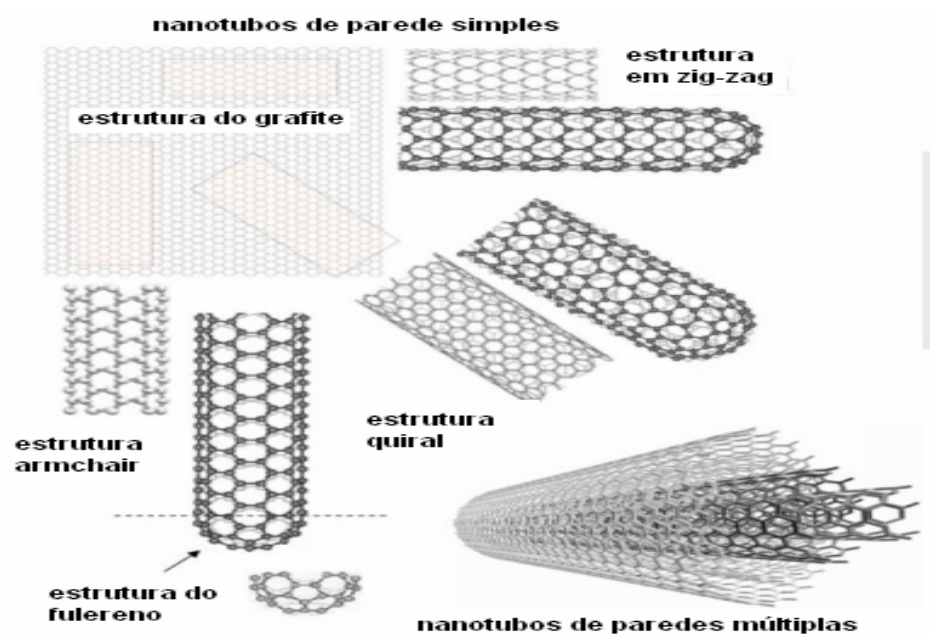

Figura 4.1: A ilustração da construção de um nanotubo, enrolando uma folha de grafite na direção do vetor quiral C.. Se o enrolamento fosse na direção das linhas pontilhadas, teríamos tubos armchair e zigzag. Todos os outros tubos chiral, são gerados pelo ângulo de helicidade $\phi$ medido a partir da direção armchair, ou pelo ângulo $\theta$ medido a partir da direção zigzag. 
Do ponto de vista das investigações teóricas, os nanotubos de paredes simples representam sistemas mais adequados em relação aos nanotubos de paredes múltiplas devido à maior facilidade computacional. Por outro lado, os nanotubos de paredes múltiplas são produzidos com mais facilidade e com menor custo que os nanotubos de paredes simples [33].

Os nanotubos de carbono apresentam propriedades eletrônica, ótica e mecânica muito interessantes, sendo assim, utilizados na confecção de diferentes tipos de dispositivos, como emissores de elétrons, sensores de gás, sensores biológicos, e outras aplicações quando combinados com outros materiais [32,33,35-37]. Para uma análise completa e um entendimento melhor das características, propriedades e aplicações,sugerimos a referência[35-37,88,89].

Nesse trabalho, vamos nos deter apenas no desenvolvimento de filmes finos com aplicação especial como membrana seletiva a íons de $\mathrm{H}^{+}$, sem nos atermos à discussão sobre a síntese, e caracterização específica sobre a mesma.

\section{2-Preparação dos Filmes Finos de nanotubos de carbono}

\subsection{1-Produção dos Nanotubos de Carbono e dos Filmes Finos.}

Os nanotubos de carbono são sintetizados pelo método de Deposição Química a Vapor (CVD - Chemical Vapor Deposition), a partir da mistura de 6ml de etanol e $8 \mathrm{ml}$ de água, com $1,25 \mathrm{~g}$ de acetato de Manganês II [Mn $\left.\left(\mathrm{OOCH}_{3}\right)_{3} \cdot 2 \mathrm{H}_{2} \mathrm{O}\right]$ e $1,25 \mathrm{~g}$ de acetato de Cobalto II [Co( $\left.\left(\mathrm{OOCCH}_{3}\right)_{2} .4 \mathrm{H}_{2} \mathrm{O}\right]$ da Alfa Aesar, sendo esses sais utilizados como catalisadores e 1,5g de zeólita, como 
suporte para os sais, utilizando-se um banho de ultra-som para misturar. A solução é aquecida, sob agitação, para a evaporação do solvente para depois ser levado ao forno para secagem por $2 \mathrm{~h}$ a $150^{\circ} \mathrm{C}$. Depois de seco, o pó é colocado sobre um suporte de titânio e levado ao forno à $600^{\circ} \mathrm{C}$ por $30 \mathrm{~min}$, com rampa de $10^{\circ} \mathrm{C} / \mathrm{min}$. Nesse sistema, é fornecido um fluxo de Nitrogênio $\left(150 \mathrm{~cm}^{3} / \mathrm{min}\right)$, por $5 \mathrm{~min}$. Após esse tempo, a temperatura é elevada à $650^{\circ} \mathrm{C}$. Nessa temperatura de $650^{\circ} \mathrm{C}$, o fluxo de Nitrogênio permanece ativo por mais $5 \mathrm{~min}$, sendo desligado logo em seguida e com abertura do Etileno com mesmo fluxo utilizado anteriormente pelo Nitrogênio. Após uma hora, são trocados os fluxos de Etileno pelo Nitrogênio com o desligamento do forno. Permanece o fluxo de Nitrogênio até que a temperatura do forno chegue a $200^{\circ} \mathrm{C}$, sendo desligado o fluxo logo em seguida.

Após o resfriamento, o produto é retirado e triturado, sendo misturado em seguida com $50 \mathrm{ml}$ de ácido fluorídrico (HF), sob agitação, permanecendo nessa situação por aproximadamente $18 \mathrm{~h}$. Após esse tempo, são colocados $30 \mathrm{ml}$ de ácido nítrico nessa solução, com uma porção de dodecil sulfato de sódio (SDS), mantendo sob agitação em um banho de ultra-som, por aproximadamente 1h. Em seguida, a mistura foi diluída com aproximadamente $200 \mathrm{ml}$ de água, filtrada e lavada. A seguir, o material resultante foi misturado a uma solução $1,0 \mathrm{~mol} / \mathrm{L}$ de ácido clorídrico e aquecido a $100^{\circ} \mathrm{C}$ sob refluxo por 5 h. Após a filtração, são feitas as lavagens com água e acetona, sendo logo em seguida, seco em estufa a $80^{\circ} \mathrm{C}$.

Depois de filtrados e secos, os nanotubos são dispersos em uma solução de etanol na concentração de $1 \mathrm{~g} / \mathrm{l}$ e $3 \mathrm{~g} / \mathrm{l}$, concentrações idênticas ao capítulo anterior para fins de comparação. Mantém-se essa solução sob agitação e em banho de ultra-som. Depois de algum tempo nessa condição os filmes são 
depositados nos substratos de vidro liso (VL) e rugoso (VR) pela técnica de spraypyrolysis nas temperaturas de $80^{\circ} \mathrm{C}$ e $100^{\circ} \mathrm{C}$.

\section{3-Caracterização no infravermelho (FTIR)}

A figura 4.2 mostra o espectro de transmitância na região do infravermelho dos nanotubos de carbono em forma de pó. Para a análise de FTIR a amostra foi misturada a $\mathrm{KBr}$ e prensada para formar pastilhas.

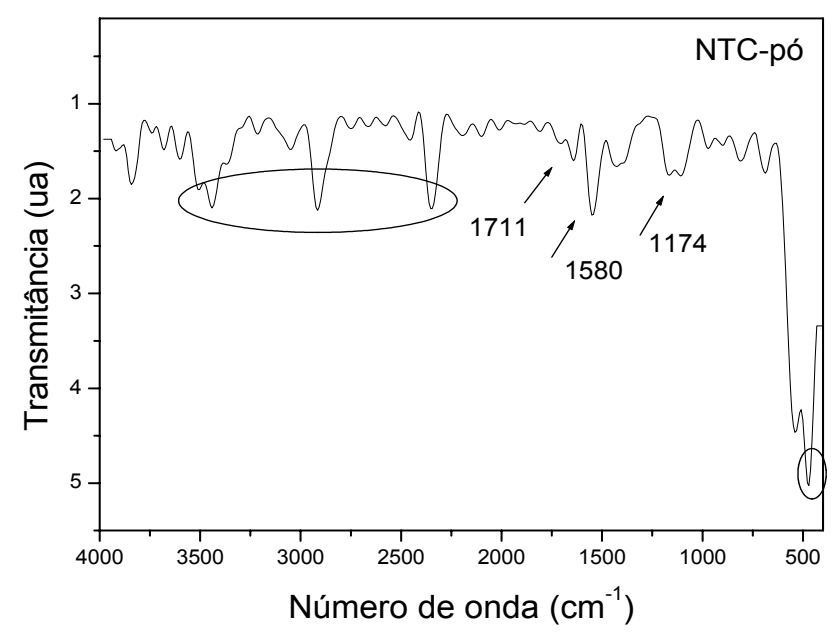

Figura 4.2: Análise de FTIR do pó de nanotubos de carbono obtido pela técnica de CVD.

No espectro de IR do pó de nanotubos de carbono, aparecem picos numa (circulados) numa banda próxima a $469 \mathrm{~cm}^{-1}$ que possivelmente estão relacionados ao estiramento do grupo $\mathrm{C}-\mathrm{O}$, enquanto que as bandas em 3500 $2324 \mathrm{~cm}^{-1}$, relacionadas ao estiramento $\mathrm{O}-\mathrm{H}$ [90]. Os picos indicados com setas, segundo $\mathrm{D}$. Sobhi, e colaboradores [90], representam o estiramento $\mathrm{C}=\mathrm{O}$ do grupo ácido, estiramento $\mathrm{C}=\mathrm{C}$ dos nanotubos e a existência de grupos de ácidos 
carboxílicos em $1174 \mathrm{~cm}^{-1}, 1580 \mathrm{~cm}^{-1}$ e $1711 \mathrm{~cm}^{-1}$, respectivamente. Com os resultados de DRX e FTIR, os nanotubos produzidos estão em concordância com aqueles apresentados na literatura [90].

\section{4-Caracterização estrutural}

As estruturas dos filmes de NTC, depositados sobre os substratos de vidro liso e rugoso, foram caracterizadas por difratometria de Raios-X (DRX).

A figura 4.3 apresenta os resultados dos espectros de raios-X das amostras fabricadas por spray-pyrolysis sobre o vidro liso (VL) e também do pó utilizado para a produção dos filmes finos.

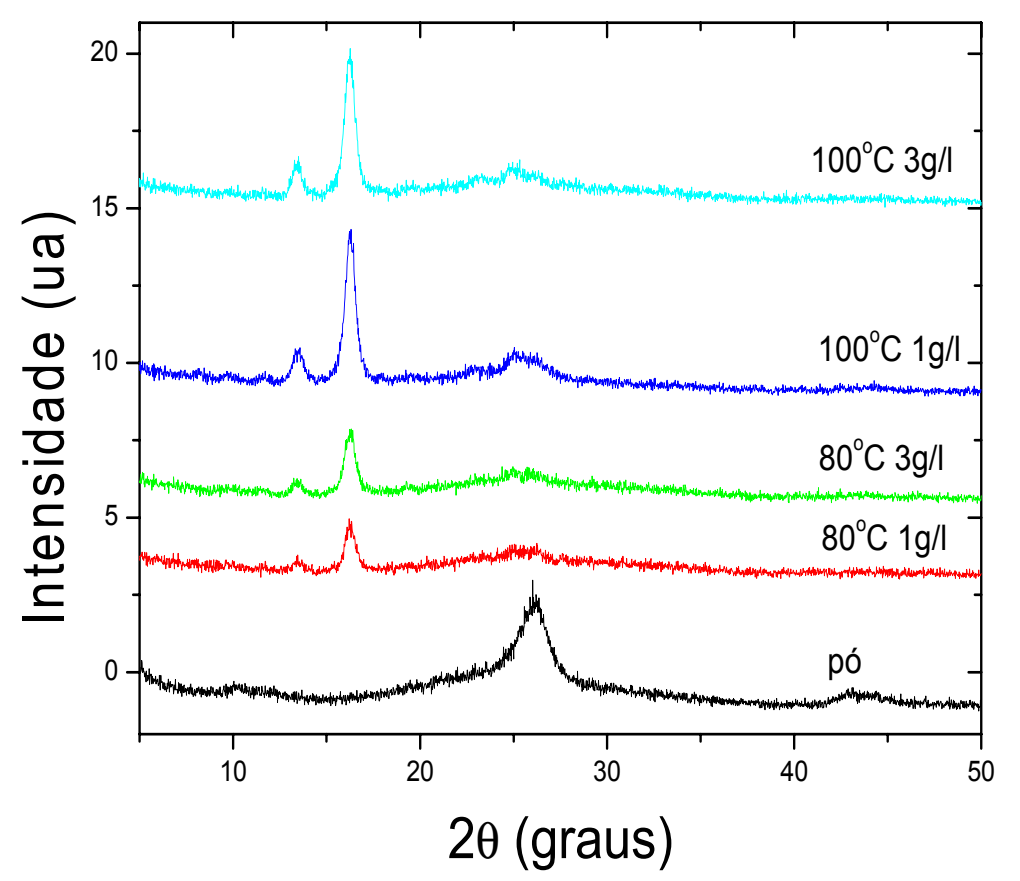

Figura 4.3: Espectros de DRX das amostras produzidas sobre o vidro liso (VL) em diferentes concentrações e temperaturas e também do pó usado na produção dos filmes finos. 
Os resultados de DRX mostram que os filmes produzidos em temperaturas de $80^{\circ} \mathrm{C}$ e $100^{\circ} \mathrm{C}$, com concentrações de $1 \mathrm{~g} / /$ e $3 \mathrm{~g} / \mathrm{l}$, são semelhantes em si no que diz respeito à posição dos picos.

Pode-se notar, nessa figura, que a intensidade dos picos aumenta com o aumento da temperatura de deposição e com pouca variação quando varia a concentração na mesma temperatura de deposição dos filmes finos. Os picos identificados estão localizados em $13,4^{\circ}$ e $16,3^{\circ}(2 \theta)$, sendo a razão entre as áreas, a área integrada do pico maior em relação ao pico menor em cada amostra, de aproximadamente 6,5. Não foi encontrada na literatura nenhuma referência à estrutura desses filmes, mas estimamos a separação entre planos, que segundo a Lei de Bragg, são $6,6 \hat{A}$ e $5,4 \AA$ referentes aos picos difratados em $13,4^{\circ}$ e $16,3^{\circ}(2 \theta)$, respectivamente.

Foi feito a DRX do pó dos NTC, onde se observou apenas um pico com maior intensidade $\left(26,1^{\circ}\right)$ e outro de menor intensidade $\left(43,2^{\circ}\right)$, identificados segundo o banco de dados como picos do carbono na forma de grafite. O pico em $26,1^{\circ}$, também está presente nos filmes finos, em todas as amostras, porém com menor intensidade. Liu e colaboradores [91], reportaram os mesmos picos e os identificaram como $2 \mathrm{H}-\mathrm{C}(002)$ segundo o banco de dados (JCPDS $\mathrm{n}^{\circ} 41-1487$ ).

A figura 4.4 apresenta os resultados dos espectros de raios-X das amostras fabricados por spray-pyrolysis sobre o vidro rugoso (VR).

Os resultados da difração de raios- $X$ dos filmes finos sobre o substrato de vidro rugoso (VR), mostram que a posição dos picos e a razão entre as áreas, área integrada sob o pico maior com relação ao pico menor, são semelhantes aos resultados dos filmes finos feitos no substrato de vidro liso. Os picos identificados 
estão em $13,4^{\circ}$ e $16,3^{\circ}(2 \theta)$, sendo a razão entre as áreas de aproximadamente 6,5 .

Pode-se notar, nessa figura, que a intensidade dos picos diminuem com o aumento da temperatura de deposição. Essa característica mostrada aqui, apresenta um comportamento oposto àquele que acontece nos filmes feitos no substrato de vidro liso.

Por sua vez, a intensidade dos picos tem pouca variação quando varia a concentração na mesma temperatura de deposição dos filmes finos.

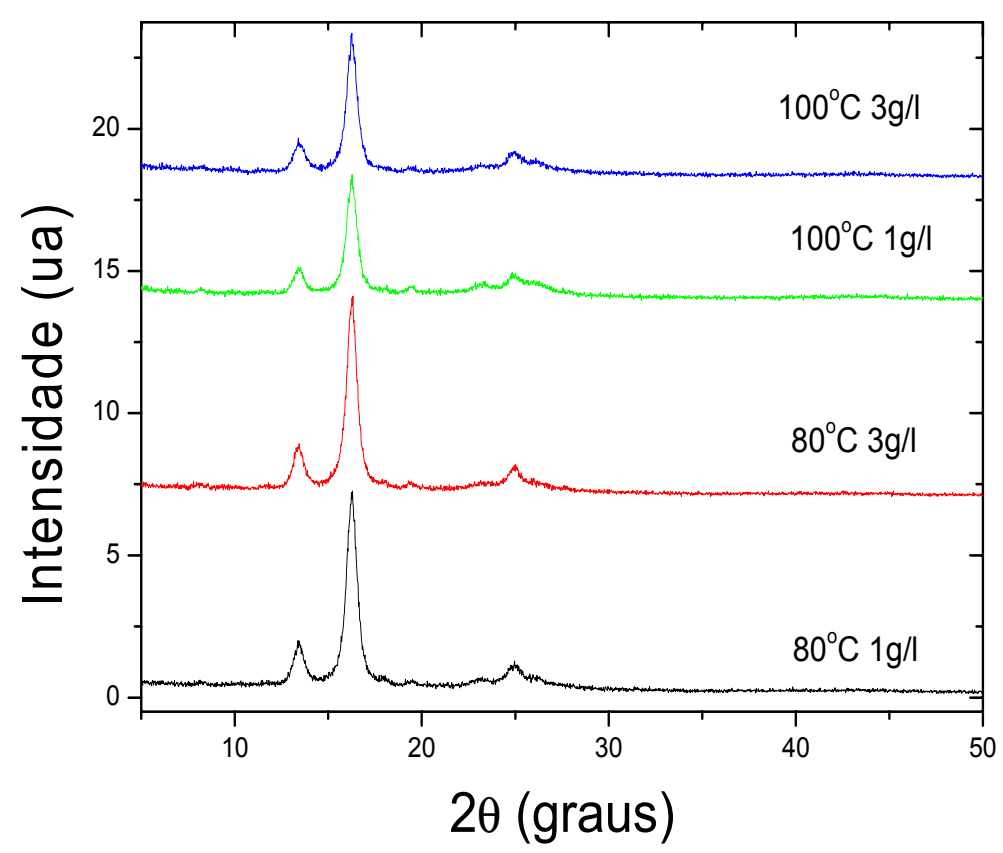

Figura 4.4: Espectros de DRX das amostras produzidas sobre o substrato de vidro rugoso (VR) em diferentes concentrações e temperaturas.

A intensidade dos picos dos filmes produzidos no substrato de vidro rugoso é maior do que aqueles produzidos no substrato de vidro liso. Esse 
comportamento pode estar relacionado com o fato do substrato ter sido lixado. $\mathrm{O}$ fato de substrato ter sido lixado favorece a adesão dos nanotubos em sua superfície, favorecendo o crescimento orientado do filme fino.

A cristalinidade dos filmes finos de alguns materiais pode influenciar o comportamento do dispositivo usado como sensor de $\mathrm{pH}$ na estrutura EGFET. Trabalhos a esse respeito dizem que materiais amorfos são melhores do os cristalinos devido ao fato de possuir maior número de sítios efetivos. Fato oposto ao observado aqui, como será visto mais adiante.

\section{5-Caracterização da superfície}

A superfície dos filmes de nanotubos de carbono depositados sobre os substratos de vidro liso e rugoso, foi caracterizada através da técnica de microscopia eletrônica de varredura (MEV). O interesse em utilizar o MEV é a capacidade de identificar a morfologia quanto ao aparecimento de buracos e à homogeneidade dos filmes produzidos que interferem no desempenho do dispositivo.

A figura 4.5 apresenta as micrografias do filme fino de NTC depositado sobre o substrato de vidro rugoso a $80^{\circ} \mathrm{C}$ com concentração de $3 \mathrm{~g} / \mathrm{l}$, enquanto que a figura 4.6 apresenta as imagens dos filmes de NTC depositados sobre os substratos de vidro liso a $100^{\circ} \mathrm{C}$ com concentração de $3 \mathrm{~g} / \mathrm{l}$.

A escolha dessas duas amostras se deu pelo fato de que foram as duas amostras que melhor responderam como membranas sensíveis a medida de $\mathrm{pH}$. As amostras depositadas com concentração de $1 \mathrm{~g} / \mathrm{l}$, ficaram com pouco material depositado e algumas delas apresentaram falhas. 

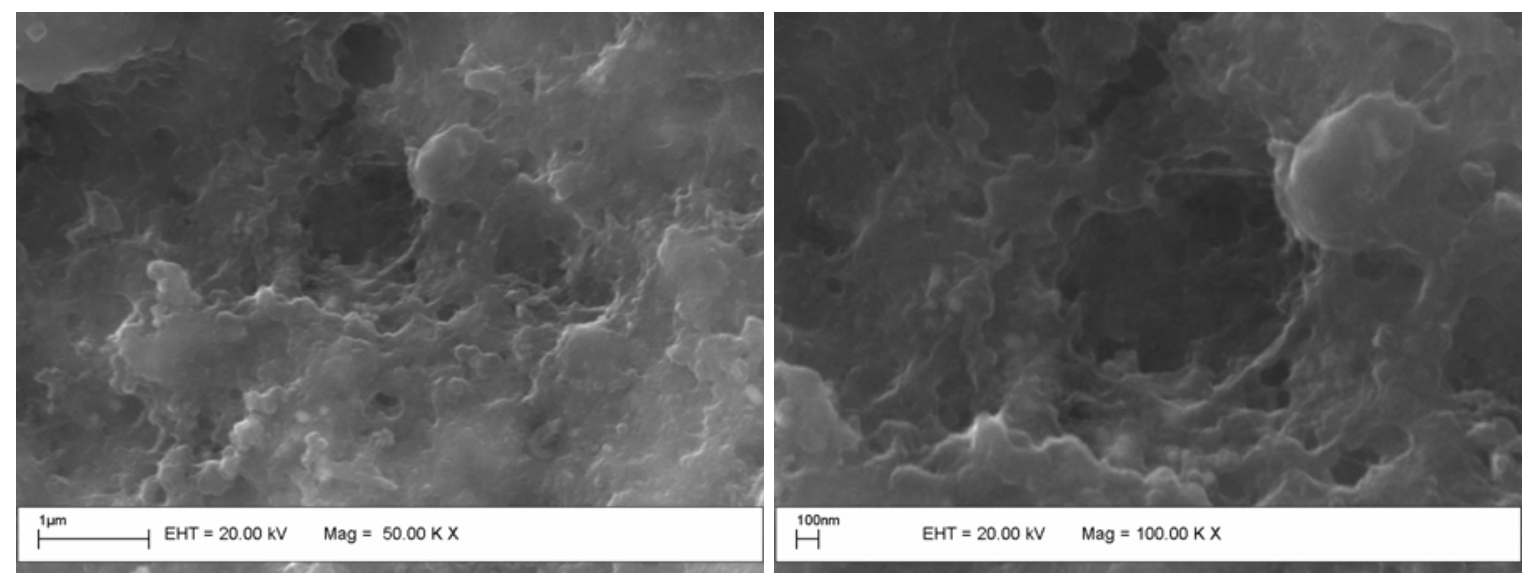

Figura 4.5: Imagens de microscopia eletrônica de varredura da amostra produzida a $80^{\circ} \mathrm{C}$ sobre o substrato de vidro rugoso com concentração de $3 \mathrm{~g} / \mathrm{l}$.
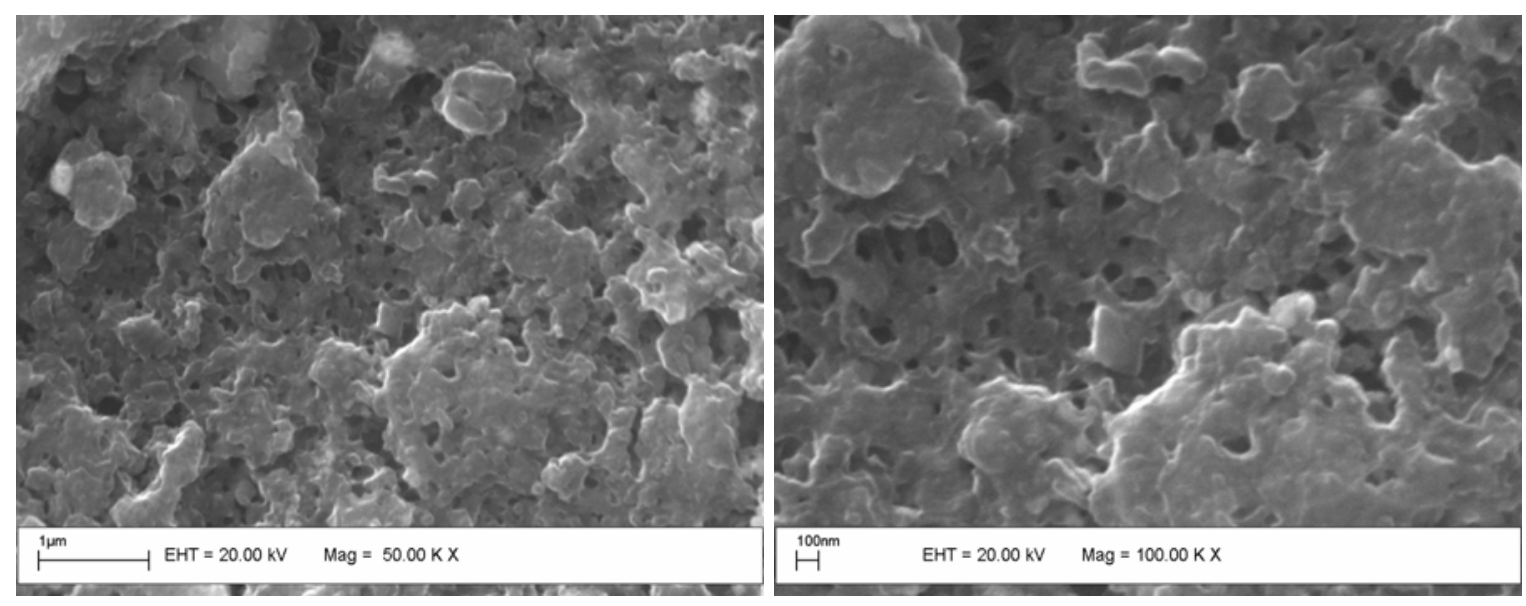

Figura 4.6: Imagens de microscopia eletrônica de varredura do filme fino produzido sobre o substrato de vidro liso a $100^{\circ} \mathrm{C}$ com concentração de $3 \mathrm{~g} / \mathrm{l}$.

São apresentadas ampliações de 50000 e 100000 vezes em relação ao tamanho normal. O filme depositado no substrato de vidro rugoso, figura 4.5 , apresenta alguns poros ("buracos"), ou seja, pouca uniformidade. Isso, possivelmente se deve ao substrato pelo fato desse substrato ter sido lixado antes da deposição do filme. A superfície resultante é nada uniforme. Outra hipótese 
seria as sujeiras presentes no substrato após terem sido lixados e uma limpeza não tão eficiente para eliminar essas sujeiras foi efetuada. Dessa forma, os filmes podem ter crescidos em torno dessas impurezas (sujeiras) "deixadas" no substrato.

Por outro lado, o filme crescido no substrato de vidro liso, a $100^{\circ} \mathrm{C}$, apresenta pequenas aglomerações, "ilhas", que possivelmente, se deve à não uniformidade térmica no substrato, favorecendo com isso o crescimento desigual, ou melhor, não uniforme. Contudo, através desses resultados não é possível identificar se esses buracos se estendem até o substrato e se o mesmo, juntamente com a não uniformidade é o fato principal de interferência nos

resultados como membrana seletiva. Além disso, não foi possível obter a espessura do filme, através de medidas laterais, pois não houve bom contraste lateral com o substrato, porque possivelmente havia material depositado na lateral do filme. A espessura esperada, mediante outros trabalhos por nos executados, era em torno de alguns micrometros.

\section{6-Caracterização Elétrica}

\subsection{1- Substrato de vidro liso (VL)}

Esses dispositivos foram imersos em soluções tampão com diferentes valores de $\mathrm{pH}$ e caracterizados eletricamente em função da concentração dos íons de $\mathrm{H}^{+}$. As curvas de corrente em função da tensão foram avaliadas pela variação do $\mathrm{pH}$ de 2 a 12. 
O sistema de EGFET consiste em uma parte sendo a membrana sensível, ou seja, os filmes finos e outra parte um MOSFET comercial CD4007UB, onde a membrana sensível está conectada ao MOSFET por uma garra metálica, como apresentado no capítulo anterior.

A figura 4.7 apresenta as curvas de caracterização elétrica do dispositivo de NTC depositado em substrato de vidro liso a $80^{\circ} \mathrm{C}$ com concentração de $1 \mathrm{~g} / \mathrm{l}$.

A figura 4.7-a mostra o comportamento do dispositivo operando com $V_{G S}$ igual a $2,5 \mathrm{~V}$ e $\mathrm{V}_{\mathrm{DS}}$ variando de 0 a $5 \mathrm{~V}$, operando na região de saturação, enquanto que na figura 4.7-b, é mostrado o comportamento do dispositivo operando com $\mathrm{V}_{\mathrm{DS}}$ igual $0,17 \mathrm{~V}$ e $\mathrm{V}_{\mathrm{GS}}$ variando de 0 a $5 \mathrm{~V}$, ou seja, operando na região de não saturação, região linear.

A figura 4.7-c mostra o comportamento da raiz quadrada do dispositivo em função da variação do $\mathrm{pH}$, enquanto que a figura 4.7-d, mostra o comportamento linear da tensão em função da variação do $\mathrm{pH}$, ou seja, a sensibilidade.

Observa-se que EGFET feito à $80^{\circ} \mathrm{C}$ com uma concentração de $1 \mathrm{~g} / \mathrm{l}$ possui uma relação linear da raiz quadrada de $\mathrm{I}_{\mathrm{DS}}$ em função do $\mathrm{pH}$.

lém disso, a sensibilidade desse dispositivo pode ser determinada a partir dos resultados da figura 4.7-b, a parte linear, com a corrente do dispositivo IDS igual a $400 \mu \mathrm{A}$. 

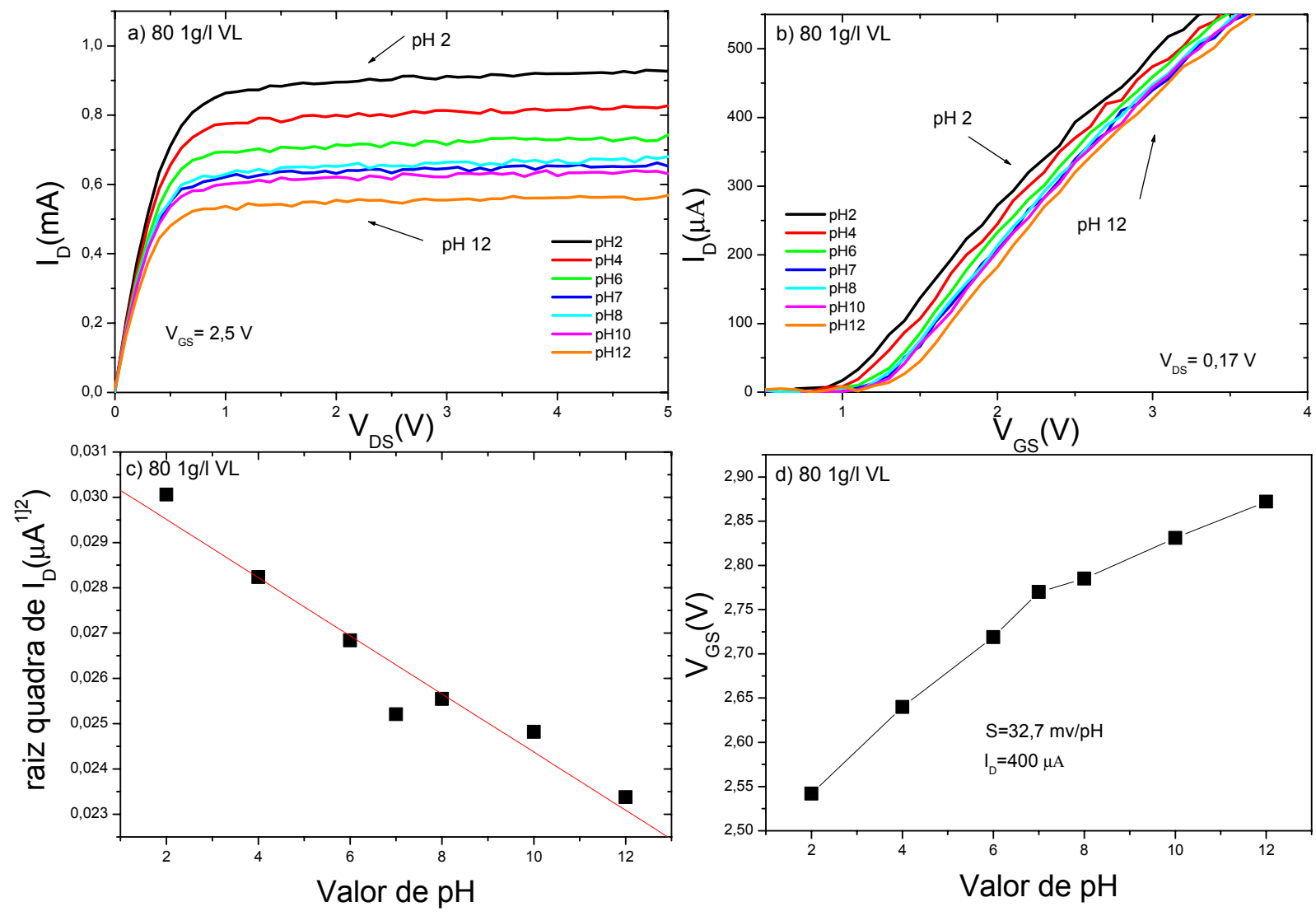

Figura 4.7: Curva de resposta do filme fino de NTC EGFET depositado sobre substrato de vidro liso à $80^{\circ} \mathrm{C}$ com concentração de $1 \mathrm{~g} / \mathrm{l}$. Em (a) apresenta o EGFET operando nas regiões de saturação e em (b) na região linear, enquanto que em (c) o comportamento da raiz quadrada da corrente em função da variação do $\mathrm{pH}$ e (d) a sensibilidade.

Com essa corrente de $400 \mu \mathrm{A}$ podemos obter uma relação entre a tensão de referência e o pH da solução, mostrada na curva de $V_{G S}$ em função do $\mathrm{pH}$ na figura 4.7-d. Segundo a figura 4.7-d, obtemos uma sensibilidade de $32,7 \mathrm{mV} / \mathrm{pH}$.

A figura 4.8, por sua vez, apresenta as curvas de caracterização elétrica do dispositivo de NTC depositados em substratos de vidro liso a $80^{\circ} \mathrm{C}$ com concentração de $3 \mathrm{~g} / \mathrm{l}$. As correntes e tensões usadas, ou seja, as configurações 
elétricas para a aquisição dos dados foram iguais àquelas depositadas a $80^{\circ} \mathrm{C}$ com concentração de 1g/l.

Assim, figura 4.8-a mostra o comportamento do dispositivo operando na região de saturação, enquanto que na figura 4.8-b, mostra-se o comportamento do dispositivo operando na região linear. Enquanto que na figura 4.8-c é mostrado o comportamento da raiz quadrada da corrente função do $\mathrm{pH}$ e a figura 4.8-d, a sensibilidade do dispositivo.
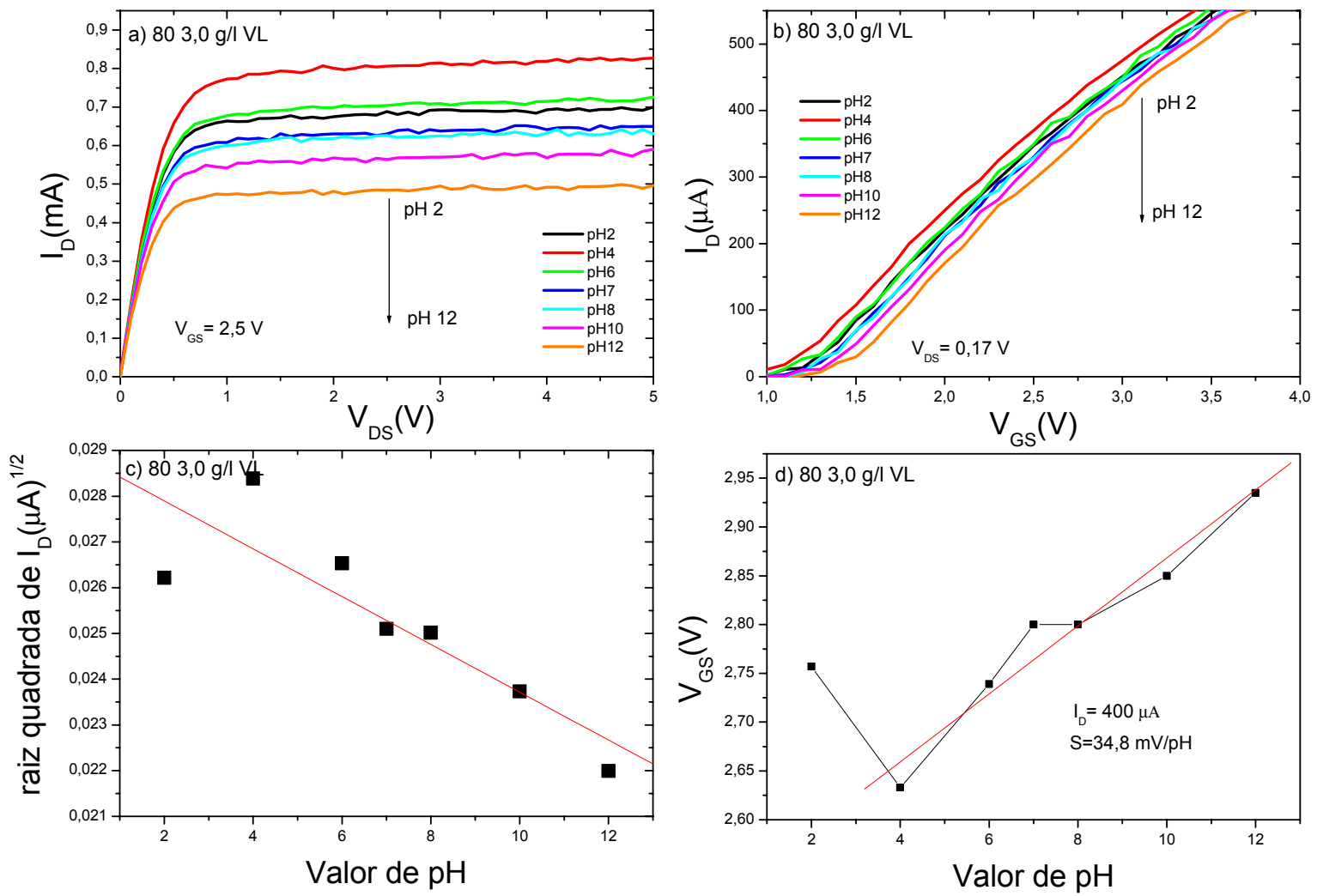

Figura 4.8: Curva de resposta do filme fino de NTC EGFET depositada sobre substrato de vidro liso à $80^{\circ} \mathrm{C}$ com concentração de $3 \mathrm{~g} / \mathrm{l}$. Em (a) apresenta o EGFET operando nas região de saturação e em (b) na região linear, enquanto que em (c) o comportamento da raiz quadrada da corrente em função da variação do pH e (d) a sensibilidade. 
Pode ser visto na figura 4.8 que o pH 2 não teve um comportamento linear com relação aos demais pHs. Pode ser visto também que esse dispositivo não apresentou uma boa relação linear da raiz quadrada de $I_{D S}$ em função do $\mathrm{pH}$, figura 4.8-c. A sensibilidade dos demais $\mathrm{pHs}(4-12)$ foi de $34,8 \mathrm{mV} / \mathrm{pH}$.

A figura 4.9 apresenta os resultados da estabilidade da corrente em função do tempo, dos filmes depositados nos substratos de vidro liso a $80^{\circ} \mathrm{C}$ com concentrações de $1 \mathrm{~g} / \mathrm{l}$ e $3 \mathrm{~g} / \mathrm{l}$. Essas variações das correntes de dreno com o tempo, foram realizadas com uma tensão $V_{D S}$ igual a $0,17 \mathrm{~V}$ e $V_{G S}$ igual a $2,5 \mathrm{~V}$ por um período de 300 segundo (5 min).
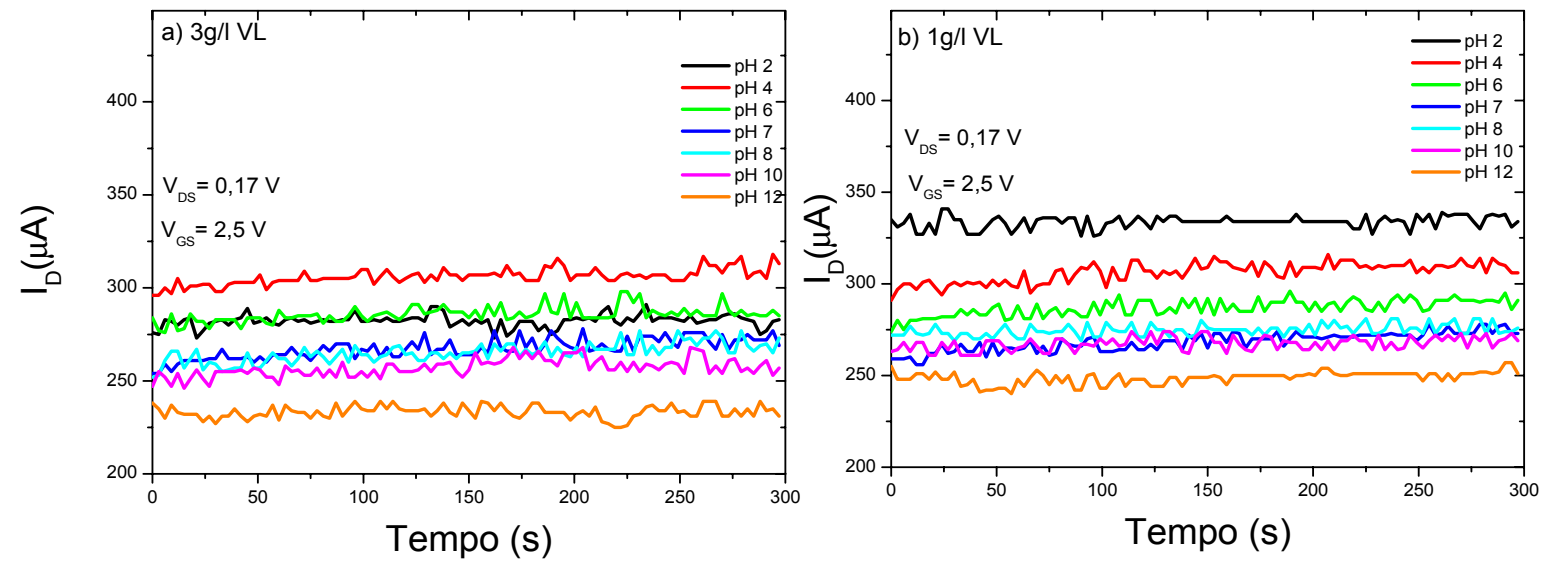

Figura 4.9: Curva de resposta dos filmes finos de NTC EGFET depositados sobre substrato de vidro liso à $80^{\circ} \mathrm{C}$ com concentração de $3 \mathrm{~g} / \mathrm{l}(\mathrm{a})$ e $1 \mathrm{~g} / \mathrm{l}$ em (b).

Pode ser visto da figura 4.9, que há sobreposições de algumas correntes com o tempo, o que representa uma separação ruim, além do fato de não se ter uma boa estabilidade, ou seja, oscila muito. 
As correntes relacionadas com os pHs 7 e 8 em ambas as concentrações foram as que mais se misturaram, de forma mais proeminente na concentração de $3 g / l$.

A figura 4.10 apresenta os resultados para as membranas feitas nos substratos de vidro liso, agora à $100^{\circ} \mathrm{C}$ com concentrações de $1 \mathrm{~g} / \mathrm{l}$.
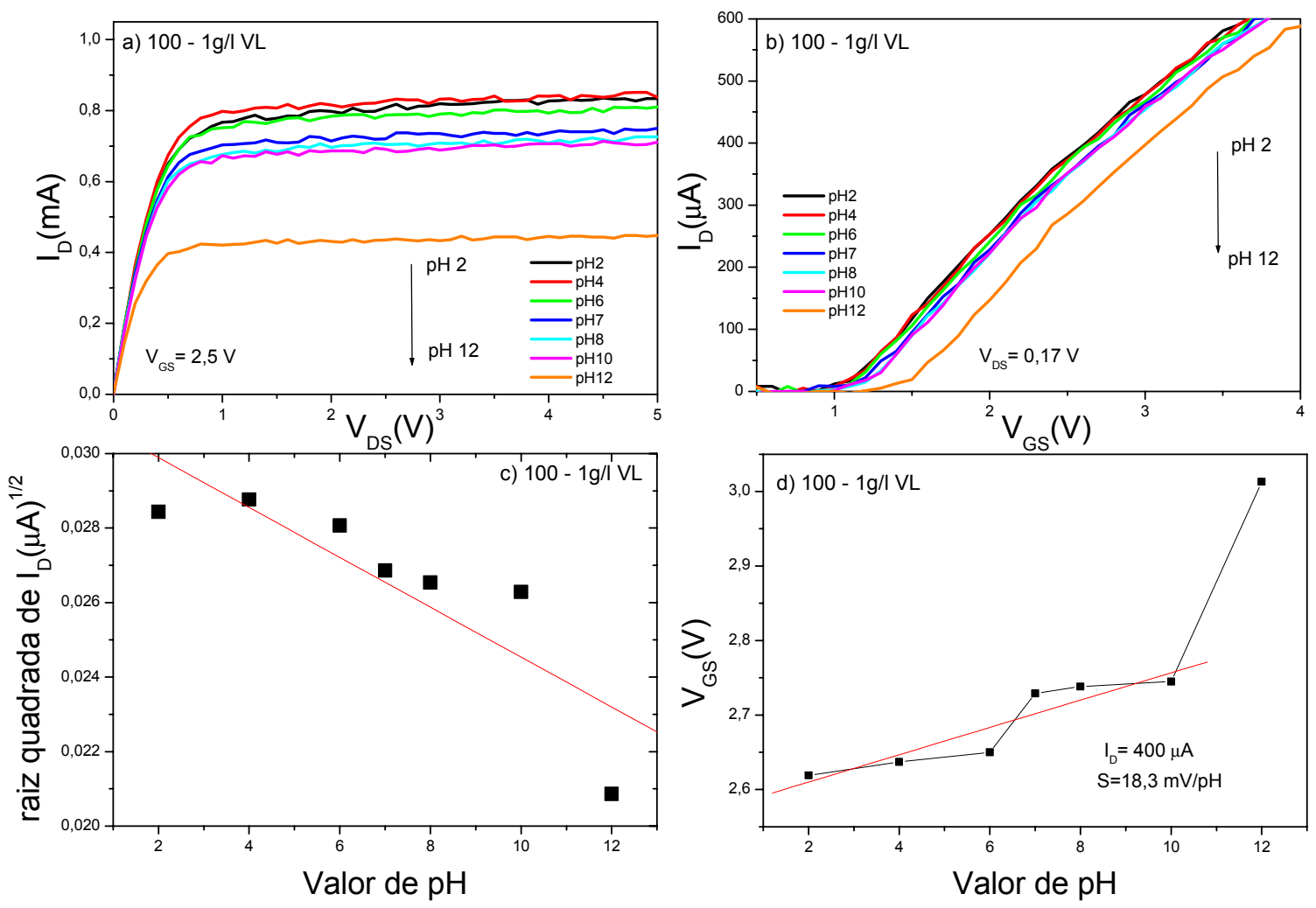

Figura 4.10: Curva de resposta do filme fino de NTC EGFET depositada sobre substrato de vidro liso à $100^{\circ} \mathrm{C}$ com concentração de $1 \mathrm{~g} / \mathrm{l}$. Em (a) apresenta o EGFET operando nas região de saturação e em (b) na região linear, enquanto que em (c) o comportamento da raiz quadrada da corrente em função da variação do pH e (d) a sensibilidade. 
As correntes e tensões usadas para a caracterização elétrica dos filmes depositados a $100^{\circ} \mathrm{C}$ foram às mesmas daquelas usadas no filme depositado a $80^{\circ} \mathrm{C}$.

Na figura 4.10, vemos que há pouca separação entre as correntes de dreno em função da variação do $\mathrm{pH}$, além do fato de que há algumas sobreposições de correntes, figura 4.10-a e 4.10-b.

A relação da raiz quadrada com o $\mathrm{pH}$, figura 4.10-c, mostrou que apenas o pH 12 teve uma separação maior em relação aos demais, mesma característica observada com a sensibilidade, figura 4.10-d, mostrando que o pH 12 destoou dos demais $\mathrm{pHs}$ e uma baixa sensibilidade de $18,3 \mathrm{mV} / \mathrm{pH}$ foi obtida em uma faixa de $\mathrm{pH}$ de 2-10.

Na figura 4.11, pode ser visto que há uma boa separação das correntes de dreno em função da variação do pH.

Outro fato observado é que as intensidades das correntes de dreno dessa amostra, figura 4.11-a, são altas em comparação aos dispositivos apresentados anteriormente.

A figura 4.11-c mostra que o EGFET possui uma relação linear da raiz quadrada de $I_{D S}$ em função do $\mathrm{pH}$. Alem disso, a sensibilidade, figura 4.11-d, foi de $53,1 \mathrm{mV} / \mathrm{pH}$.

$\mathrm{Na}$ figura 4.12 vemos a estabilidade da corrente com o tempo nos filmes depositados a $100^{\circ} \mathrm{C}$ com concentrações de $1 \mathrm{~g} / \mathrm{l}$ e $3 \mathrm{~g} / \mathrm{l}$. 

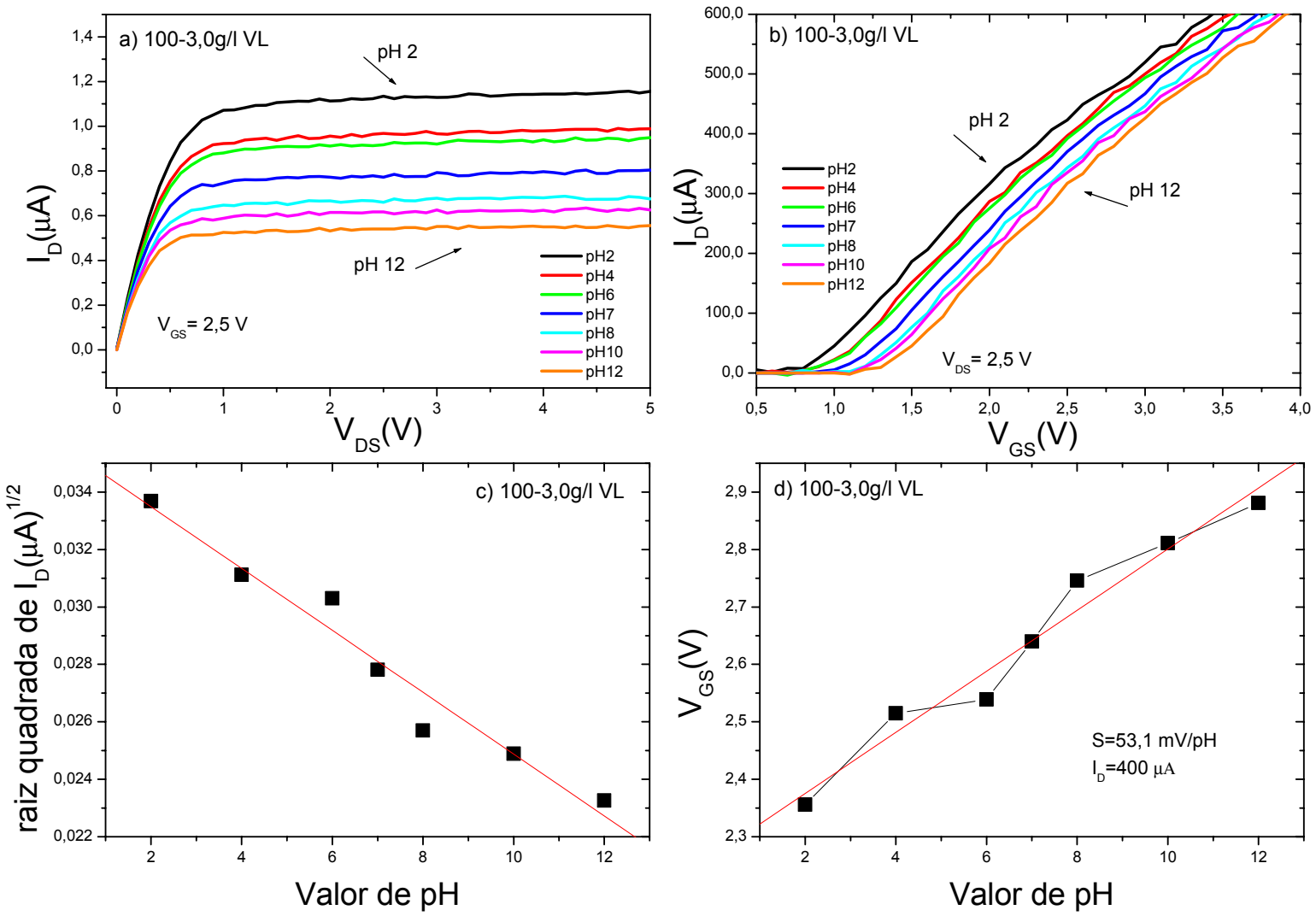

Figura 4.11: Curva de resposta do filme fino de NTC EGFET depositada sobre substrato de vidro liso à $100^{\circ} \mathrm{C}$ com concentração de 3g/l. Em (a) apresenta o EGFET operando na região de saturação e em (b) na região linear, enquanto que em (c) o comportamento da raiz quadrada da corrente em função da variação do $\mathrm{pH}$ e (d) a sensibilidade.

Na figura 4.12, vemos que as correntes variam com o tempo, mas com uma tendência a se estabilizar na amostra com concentração de $3 \mathrm{~g} / \mathrm{l}$. No inicio, essa amostra, figura 4.12-a, não tinha boa separação, se misturavam, mas com o tempo as correntes de dreno se separaram e com indício de se estabilizarem. 

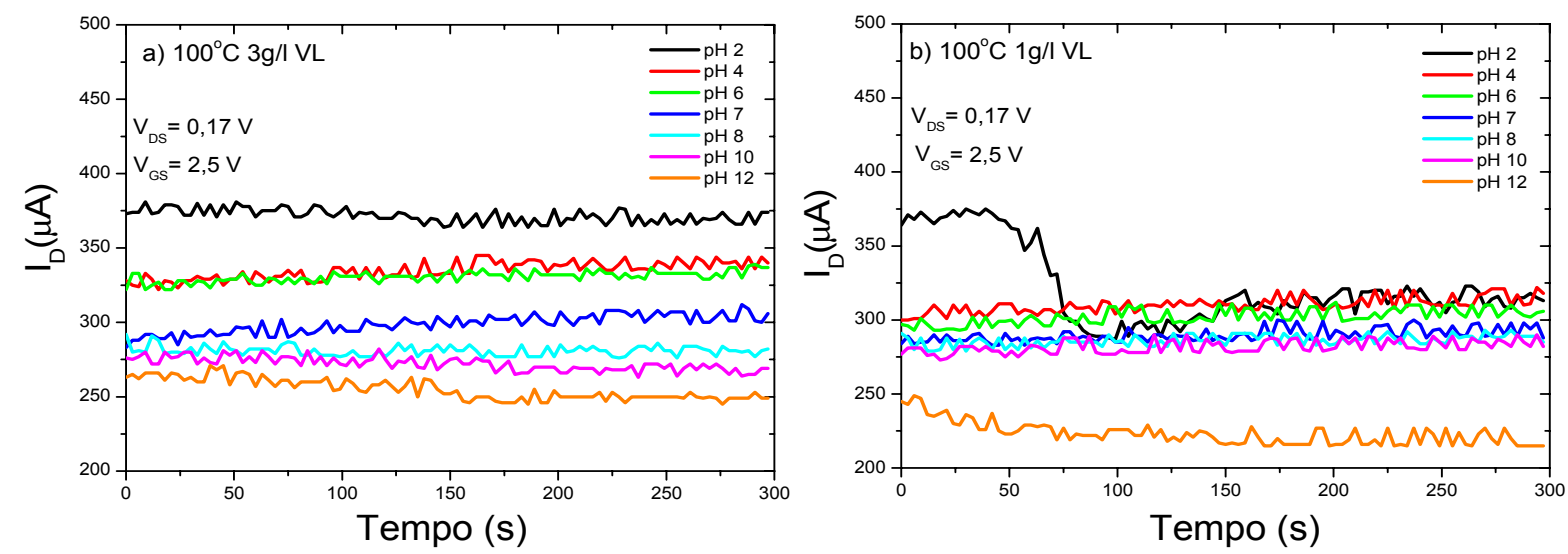

Figura 4.12: Curva de resposta dos filmes finos de NTC EGFET depositados sobre substrato de vidro liso à $100^{\circ} \mathrm{C}$ com concentração de $3 \mathrm{~g} / \mathrm{l}(\mathrm{a})$ e $1 \mathrm{~g} / \mathrm{l}$ em (b).

A resposta da sensibilidade foi de $53,1 \mathrm{mV} / \mathrm{pH}$. Por outro lado, a amostra com concentração de 1g/l, figura 4.12-b, começou com as correntes de dreno sem separação e continuou assim, tendo como conseqüência uma sensibilidade baixa de $18,3 \mathrm{mV} / \mathrm{pH}$.

Abaixo, é apresentado um quadro com o resumo do desempenho do filme fino depositado sobre o substrato de vidro liso, em função da concentração e da temperatura de deposição.

Tabela 4.1: Desempenho dos dispositivos depositados sobre o vidro liso.

\begin{tabular}{|c|c|c|c|}
\hline $\begin{array}{c}\text { Temperatura de } \\
\text { deposição }\end{array}$ & Concentração & Sensibilidade & $\begin{array}{c}\text { Faixa de resposta } \\
\text { valor de } \mathrm{pH}\end{array}$ \\
\hline \multirow{2}{*}{$80^{\circ} \mathrm{C}$} & $1 \mathrm{~g} / \mathrm{l}$ & $32,7 \mathrm{mV} / \mathrm{pH}$ & $2-12$ \\
\cline { 2 - 4 } & $3 \mathrm{~g} / \mathrm{l}$ & $34,8 \mathrm{mV} / \mathrm{pH}$ & $4-10$ \\
\hline \multirow{2}{*}{$\mathbf{1 0 0 ^ { \circ } \mathrm { C }}$} & $1 \mathrm{~g} / \mathrm{l}$ & $18,3 \mathrm{mV} / \mathrm{pH}$ & $2-10$ \\
\cline { 2 - 4 } & $\mathbf{3} \mathbf{g} / \mathbf{I}$ & $\mathbf{5 3 , 1} \mathbf{~} \mathbf{V V H}$ & $\mathbf{2 - 1 2}$ \\
\hline
\end{tabular}




\subsection{2- Substrato de vidro rugoso (VR)}

Foi feita a caracterização elétrica também dos filmes depositados nos substratos de vidro rugoso, nas mesmas condições daqueles depositados no substrato de vidro liso.

O resultado do desempenho da amostra depositada a $80^{\circ} \mathrm{C}$ com concentração de $1 \mathrm{~g} / \mathrm{l}$ pode ser visto na figura 4.13.
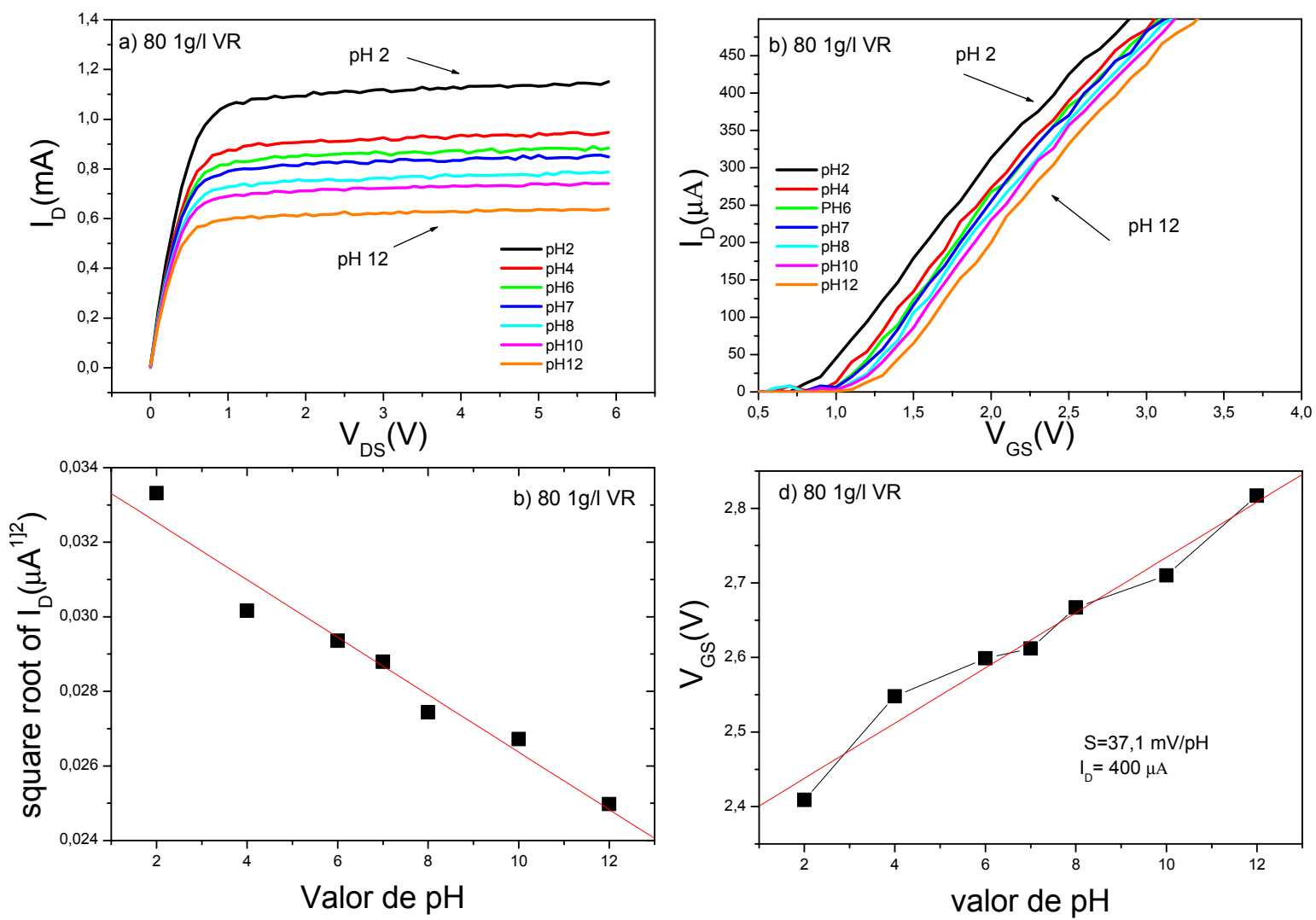

Figura 4.13: Curva de resposta do filme fino de NTC EGFET depositada sobre substrato de vidro rugoso à $80^{\circ} \mathrm{C}$ com concentração de $1 \mathrm{~g} / \mathrm{l}$. Em (a) apresenta o EGFET operando nas região de saturação e em (b) na região linear, enquanto que em (c) o comportamento da raiz quadrada da corrente em função da variação do $\mathrm{pH}$ e (d) a sensibilidade. 
Na figura 4.13-a, pode ser visto que há uma boa separação das correntes de dreno com a variação do $\mathrm{pH}$, na região saturada. Esse comportamento se repete também na região linear, figura 3.13-b.

Outro fato observado, é que a intensidade da corrente de dreno é alta. A raiz quadrada da corrente variou praticamente de forma linear com o $\mathrm{pH}$, figura 4.13-c. Apesar da intensidade da corrente ter sido alta e ter uma correspondência linear entre os pHs, a sensibilidade foi baixa, com $37,1 \mathrm{mV} / \mathrm{pH}$, figura 4.13-d.

Os filmes depositados à $80^{\circ} \mathrm{C}$ com uma concentração de $3 \mathrm{~g} / \mathrm{l}$, figura 4.14 , apresenta uma sensibilidade muita maior do que aquela apresentada com os filmes sendo depositados no mesmo substrato e mesma temperatura, porém com concentração de $1 \mathrm{~g} / \mathrm{l}$.

Enquanto o dispositivo com concentração de $1 \mathrm{~g} / \mathrm{l}$ apresentou uma intensidade de corrente de dreno alta (figura 4.13-a), com sensibilidade de 37,1 $\mathrm{mV} / \mathrm{pH}$ (figura 4.13-d), o dispositivo com concentração de 3g/l apresentou uma intensidade de corrente de dreno menor (figura 4.14-a), mas com uma sensibilidade de $51,6 \mathrm{mV} / \mathrm{pH}$.(figura 4.14-d).

Na figura 4.15 é mostrada a estabilidade dos dispositivos depositados a $80^{\circ} \mathrm{C}$ com concentrações de $1 \mathrm{~g} / \mathrm{l}$ e $3 \mathrm{~g} / \mathrm{l}$.

Pode ser visto na figura 4.15 , que as correntes são praticamente estáveis com poucas oscilações.

No dispositivo com concentração de $3 \mathrm{~g} / \mathrm{l}$ vemos o mesmo problema que nos outros dispositivos apresentados aqui, as correntes de dreno relacionadas com os pHs 7 e 8 , se misturam. 
No dispositivo com concentração de $1 \mathrm{~g} / \mathrm{l}$ por sua vez, começa sem diferenciação nas correntes de dreno, porem com o tempo elas se separam, porem não muito.
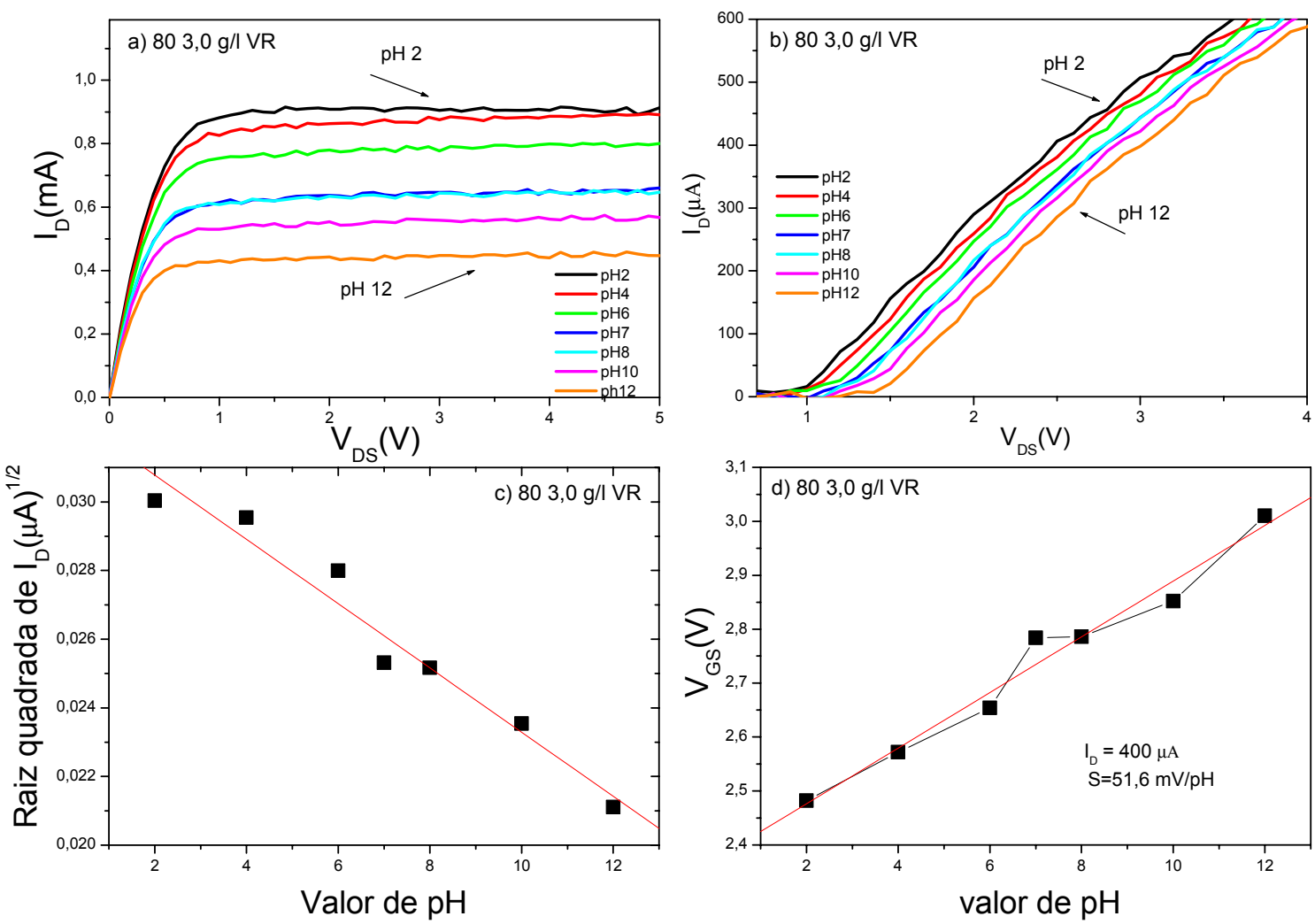

Figura 4.14: Curva de resposta do filme fino de NTC EGFET depositada sobre substrato de vidro rugoso à $80^{\circ} \mathrm{C}$ com concentração de $3 \mathrm{~g} / \mathrm{l}$. Em (a) apresenta o EGFET operando nas região de saturação e em (b) na região linear, enquanto que em (c) o comportamento da raiz quadrada da corrente em função da variação do $\mathrm{pH}$ e (d) a sensibilidade.

Assim como foi feito para o filme depositado no substrato de vidro liso, a temperatura de deposição, aqui também foi alterada. Os resultado a seguir correspondem aos dispositivos depositados em substratos de vidro rugoso a $100^{\circ} \mathrm{C}$ nas concentrações de $1 \mathrm{~g} / \mathrm{l}$ e $3 \mathrm{~g} / \mathrm{l}$. 

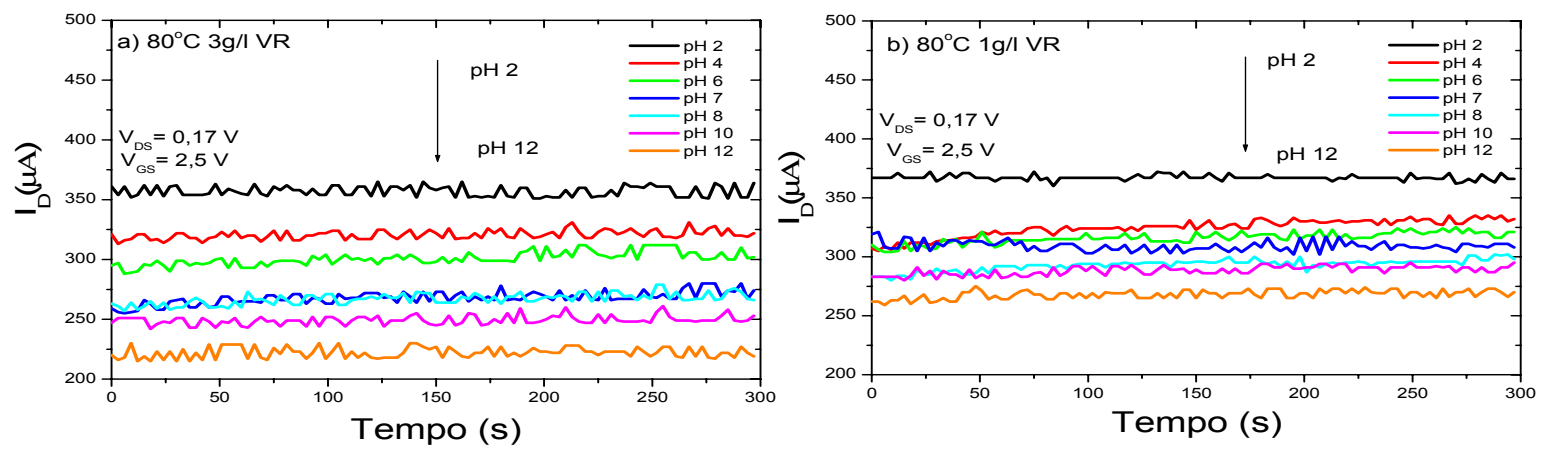

Figura 4.15: Curva de resposta dos filmes finos de NTC EGFET depositados sobre substrato de vidro rugoso à $80^{\circ} \mathrm{C}$ com concentração de $3 \mathrm{~g} / \mathrm{l}(\mathrm{a})$ e $1 \mathrm{~g} / \mathrm{l}$ em (b).
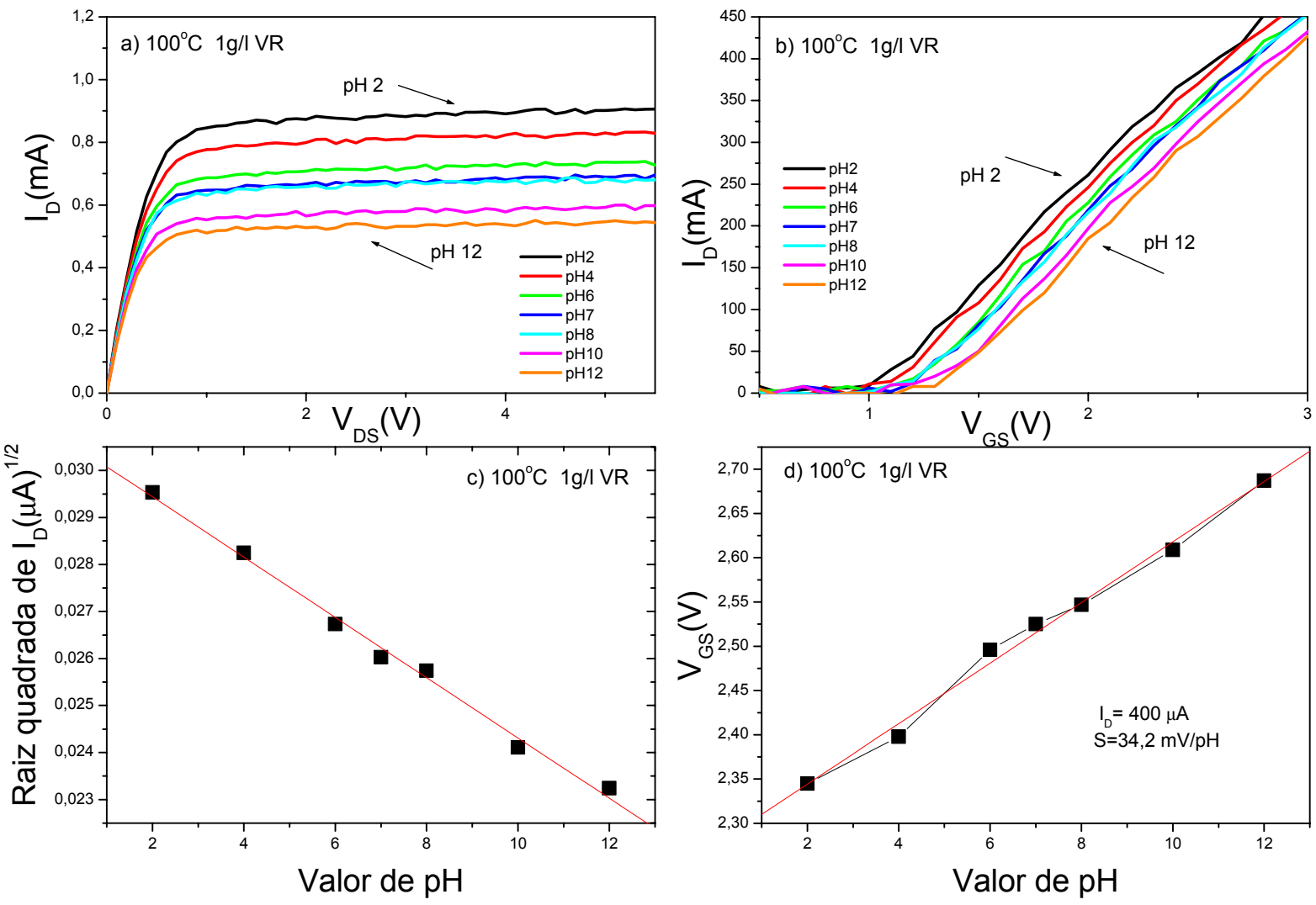

Figura 4.16: Curva de resposta do filme fino de NTC EGFET depositada sobre substrato de vidro rugoso à $100^{\circ} \mathrm{C}$ com concentração de $1 \mathrm{~g} / \mathrm{l}$. Em (a) apresenta o EGFET operando nas região de saturação e em (b) na região linear, enquanto que em (c) o comportamento da raiz quadrada da corrente em função da variação do pH e (d) a sensibilidade 
Na figura 4.16, observamos o comportamento do dispositivo depositado a $100^{\circ} \mathrm{C}$ com concentração de $1 \mathrm{~g} / \mathrm{l}$. Pode-se observar que houve a separação das correntes de dreno em função da variação de pH (figura 4.16-a e 4.16-b).

Observa-se também que o EGFET possui uma relação linear da raiz quadrada de $\mathrm{I}_{\mathrm{DS}}$ em função do $\mathrm{pH}$, figura 4.16-c. Apesar de todo esse comportamento, a sensibilidade do dispositivo foi de apenas $34,2 \mathrm{mV} / \mathrm{pH}$, mesmo sendo linear em todos os pHs.

A figura 4.17 , mostra o dispositivo depositado a $100^{\circ} \mathrm{C}$, com concentração de $3 g / l$.
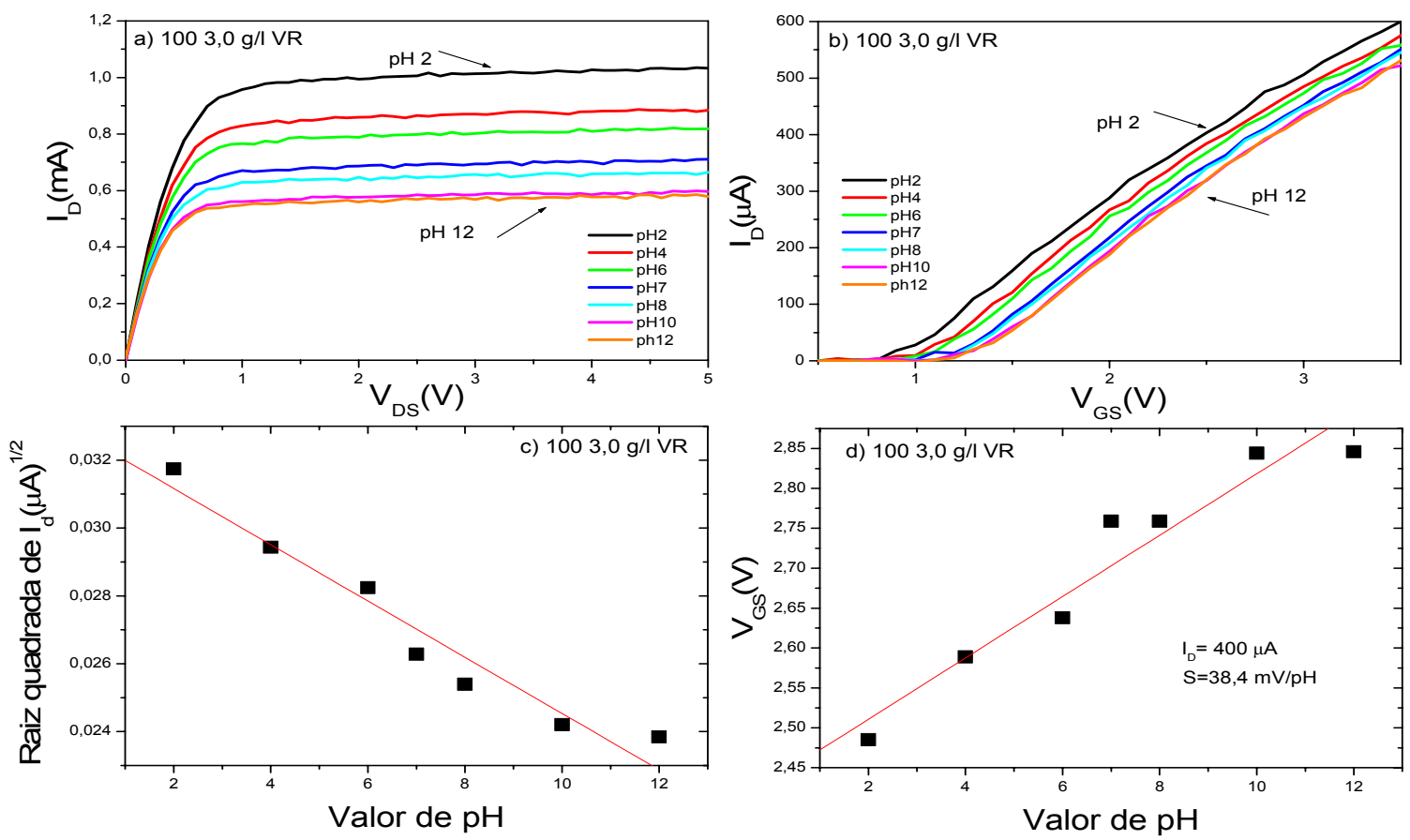

Figura 4.17: Curva de resposta do filme fino de NTC EGFET depositada sobre substrato de vidro rugoso à $100^{\circ} \mathrm{C}$ com concentração de 3g/l. Em (a) apresenta o EGFET operando nas região de saturação e em (b) na região linear, enquanto que em (c) o comportamento da raiz quadrada da corrente em função da variação do $\mathrm{pH}$ e (d) a sensibilidade 
Observamos na figura 4.17-a e 4.17-b, que há separação das correntes de dreno em função do pH, exceto os pHs 10 e 12, o que pode ser confirmado nas figuras 4.17-c e 4.17-d.

O comportamento da raiz quadrada em função da variação do $\mathrm{pH}$ foi menos linear do que aquela com concentração de $1 \mathrm{~g} / \mathrm{l}$ nessa mesma temperatura. Fato esse observado também na sensibilidade, embora a sensibilidade tenha sido um pouco maior, de $38,4 \mathrm{mV} / \mathrm{pH}$, figura 4.17-d.

A estabilidade dos filmes depositados a $100^{\circ} \mathrm{C}$ com concentrações de $1 \mathrm{~g} / \mathrm{l} \mathrm{e}$ $3 \mathrm{~g} / \mathrm{l}$ podem ser vistos na figura 4.18 .
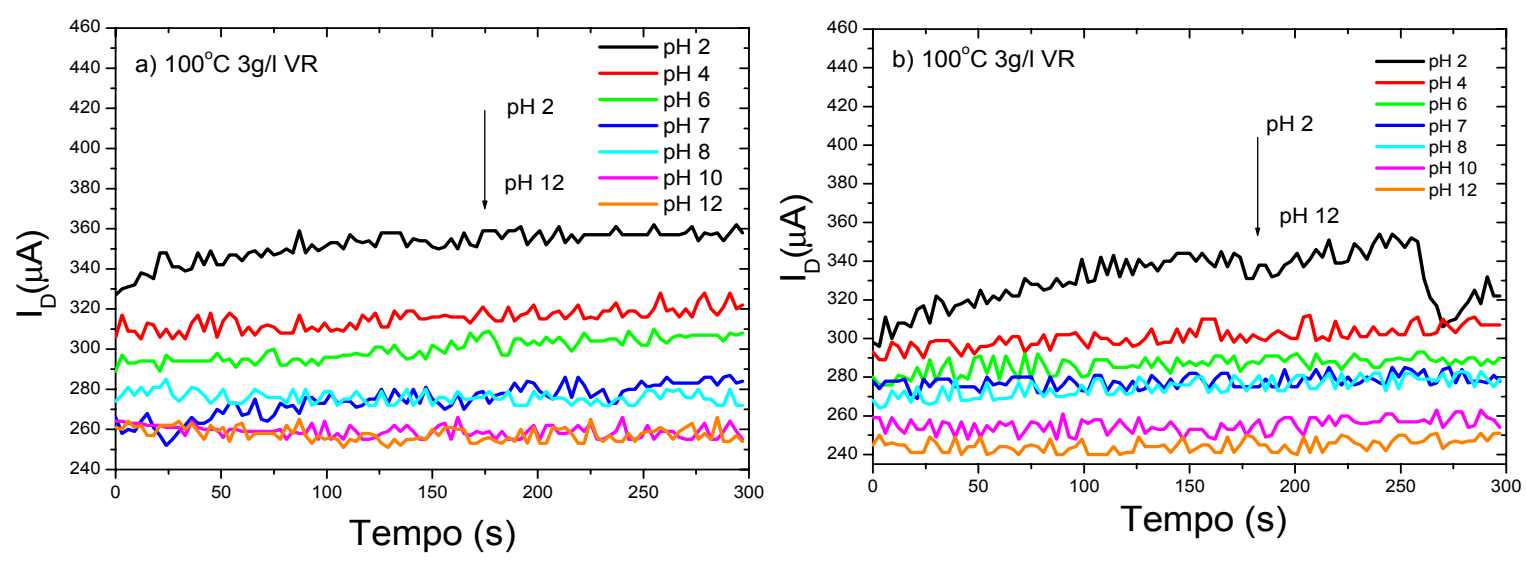

Figura 4.18: Curva de resposta dos filmes finos de NTC EGFET depositados sobre substrato de vidro rugoso à $80^{\circ} \mathrm{C}$ com concentração de $3 \mathrm{~g} / \mathrm{l}(\mathrm{a})$ e $1 \mathrm{~g} / \mathrm{l} \mathrm{em} \mathrm{(b).}$

A figura 4.18, apresenta o comportamento das correntes de dreno em função do tempo, nas concentrações $3 \mathrm{~g} / \mathrm{l}$ e $1 \mathrm{~g} / \mathrm{l}$.

Pode ser observado que as correntes de dreno no inicio da medida não são estáveis, oscilam muito, além do fato de se misturarem. Porém, com o passar do 
tempo, as correntes de dreno no dispositivo com a concentração de $3 \mathrm{~g} / \mathrm{l}$ tende a se estabilizar.

Enquanto que o dispositivo com concentração de $1 \mathrm{~g} / \mathrm{l}$, esse fato não acontece. Mesmo assim, em ambas as concentrações as sensibilidades são baixas.

Abaixo, a tabela 2 mostra o resumo do comportamento do dispositivo depositado no substrato de vidro rugoso.

Tabela 4.2: Desempenho dos dispositivos depositados sobre o vidro rugoso

\begin{tabular}{|c|c|c|c|}
\hline $\begin{array}{c}\text { Temperatura de } \\
\text { deposição }\end{array}$ & Concentração & Sensibilidade & $\begin{array}{c}\text { Faixa de resposta } \\
\text { valor de } \mathrm{pH}\end{array}$ \\
\hline \multirow{2}{*}{$\mathbf{8 0}^{\circ} \mathbf{C}$} & $1 \mathrm{~g} / \mathrm{l}$ & $37,1 \mathrm{mV} / \mathrm{pH}$ & $2-12$ \\
\cline { 2 - 4 } & $\mathbf{3} \mathbf{~ g / l}$ & $\mathbf{5 1 , 6} \mathbf{~ m V} / \mathbf{p H}$ & $\mathbf{2 - 1 2}$ \\
\hline \multirow{2}{*}{$100^{\circ} \mathrm{C}$} & $1 \mathrm{~g} / \mathrm{l}$ & $34,2 \mathrm{mV} / \mathrm{pH}$ & $2-10$ \\
\cline { 2 - 4 } & $3 \mathrm{~g} / \mathrm{l}$ & $38,4 \mathrm{mV} / \mathrm{pH}$ & $2-12$ \\
\hline
\end{tabular}

Apresentamos os resultados preliminares com relação à utilização dos NTC como material sensível a íons $\mathrm{H}^{+}$.

Os filmes finos feitos a partir dos NTC foram testado como sensores utilizando o EGFET.

A sensibilidade, que é a propriedade de maior interesse, nesse estágio preliminar, foi estudada em função de três parâmetros principais: A temperatura, a concentração e o substrato.

A seguir, um quadro resumo dos três parâmetros envolvidos no trabalho. 
Tabela 4.3: Desempenho dos dispositivos depositados sobre o VL e VR.

\begin{tabular}{|c|c|c|c|c|}
\hline Substrato & $\begin{array}{l}\text { Temperatura } \\
\text { de deposição }\end{array}$ & Concentração & Sensibilidade & $\begin{array}{c}\text { Faixa de } \\
\text { resposta valor } \\
\text { de } \mathrm{pH}\end{array}$ \\
\hline \multirow{4}{*}{ Vidro Liso } & \multirow{2}{*}{80} & $1 \mathrm{~g} / \mathrm{l}$ & $32,7 \mathrm{mV} / \mathrm{pH}$ & $2-12$ \\
\hline & & $3 \mathrm{~g} / \mathrm{l}$ & $34,8 \mathrm{mV} / \mathrm{pH}$ & $4-10$ \\
\hline & \multirow{2}{*}{$100^{\circ} \mathrm{C}$} & $1 \mathrm{~g} / \mathrm{l}$ & $18,3 \mathrm{mV} / \mathrm{pH}$ & $2-10$ \\
\hline & & $3 \mathrm{~g} / \mathrm{l}$ & $53,1 \mathrm{mV} / \mathrm{pH}$ & $2-12$ \\
\hline \multirow{4}{*}{ Vidro Rugoso } & \multirow{2}{*}{80} & $1 \mathrm{~g} / \mathrm{l}$ & $37,1 \mathrm{mV} / \mathrm{pH}$ & $2-12$ \\
\hline & & $3 \mathrm{~g} / \mathrm{l}$ & $51,6 \mathrm{mV} / \mathrm{pH}$ & $2-12$ \\
\hline & \multirow{2}{*}{$100^{\circ} \mathrm{C}$} & $1 \mathrm{~g} / \mathrm{l}$ & $34,2 \mathrm{mV} / \mathrm{pH}$ & $2-12$ \\
\hline & & $3 \mathrm{~g} / \mathrm{l}$ & $38,4 \mathrm{mV} / \mathrm{pH}$ & $2-12$ \\
\hline
\end{tabular}

Foram desenvolvidas membranas de NTC variando a concentração, a temperatura de deposição e o substrato.

Pelo quadro resumo acima, é observado, que nas membranas, quando a concentração é $1 \mathrm{~g} / \mathrm{l}$, seja qual for o substrato ou a temperatura de deposição, a sensibilidade é baixa. Uma hipótese seria que a má qualidade do filme seja o responsável por isso, já que quando a concentração é de 3g/l, a sensibilidade é maior. Pode não ser tão melhor a sensibilidade, mas é maior em todos os casos.

Com relação à temperatura de deposição, não há uma tendência geral em todas as amostras. Vemos que as duas melhores sensibilidades aconteceram uma com a temperatura de $80^{\circ} \mathrm{C}$ e outra com temperatura de $100^{\circ} \mathrm{C}$. Ambas com concentrações de $3 \mathrm{~g} / \mathrm{l}$. Não podemos afirmar que uma temperatura favorece a formação de um filme com melhor sensibilidade, mas sim que há um efeito combinado da temperatura e da rugosidade especifica do substrato onde o filme 
será crescido. Cada superfície/substrato possui uma temperatura ideal como mostrado.

Outro fato observado é que a evolução temporal dos filmes com concentração de $1 \mathrm{~g} / \mathrm{l}$ é menos estável do que aqueles com concentração $3 \mathrm{~g} / \mathrm{l}$. Pode ser que a qualidade do filme seja o principal fator, visto que, os filmes com $1 \mathrm{~g} / \mathrm{l}$ são menos espessos e apresentam falhas, com isso, ela pode estragar mais fácil, prejudicando a medida da amostra.

Outro fato interessante é que quando se aumenta a temperatura de deposição, no substrato de vidro rugoso, as intensidades dos picos difratados (DRX) diminuem. Oposto daquilo que acontece no substrato de vidro liso. Portanto, quanto mais orientado for o filme, mais cristalino será, e melhor a sensibilidade observada nesse caso.

\section{7-Conclusão}

Por fim, para concluir, o melhor filme produzido no vidro rugoso foi aquele depositado a $80^{\circ} \mathrm{C}$ com $3 \mathrm{~g} / \mathrm{l}$, que apresentou maior intensidades dos picos difratados, enquanto que, o melhor filme produzido no vidro liso foi aquele depositado a $100^{\circ} \mathrm{C}$ com $3 \mathrm{~g} / \mathrm{l}$, que também apresentou maior intensidade dos picos difratados, com sensibilidades de $51,6 \mathrm{mV} / \mathrm{pH}$ e $53,1 \mathrm{mV} / \mathrm{pH}$, respectivamente.

Os resultados apresentados pelos nanotubos não nos credenciam a dizer como isso acontece de uma forma definitiva. Uma hipótese para explicar a sensibilidade, quando os nanotubos são utilizados como membranas seletivas, é 
que eles oferecem larga área superficial que facilita a adsorção de íons e também o fato de que, para purificar os nanotubos, utiliza-se produtos que introduzem defeitos nesse material e esses defeitos podem contribuir para que haja adsorção dos íons com esse filme.

Entretanto, mesmo não tendo uma resposta satisfatória a respeito de como a sensibilidade muda ou aconteça, os nanotubos de carbono se apresentam como candidatos a serem utilizados como sensores de íon e posteriormente como biossensores, porque responderam bem aos testes iniciais.

Dessa forma, como biossensores, o uso de nanotubos de carbono pode ser extremamente vantajoso, uma vez que permite funcionalização de materiais em suas "paredes". O outro ponto forte é que foi obtida uma sensibilidade relativamente alta como EGFET, além de ser um método para produção de membranas seletivas de baixo custo.

Com o objetivo de tentar outro substrato para os nanotubos de carbono, foi utilizado o feltro de carbono. Esses feltros não foram utilizados apenas como substratos para os nanotubos, eles foram utilizados também como membranas seletivas. No próximo capitulo, vamos discutir a utilização dos feltros e a inserção dos nanotubos, juntamente com a polianilina em suas fibras como EGFETs. 


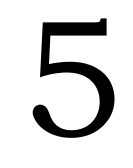

\title{
EGFET com feltros de carbono
}

\author{
(e os seus compostos: com nanotubos de carbono e Pani)
}

Nesse capitulo, serão apresentados os resultados relacionados à utilização do feltro de carbono e também da membrana feita de feltro com crescimento de nanotubos de carbono em suas fibras. Nessa membrana, veremos além da influência dos nanotubos de carbono no feltro para a detecção de $\mathrm{H}^{+}$, a influência da Pani como membrana seletiva, para o desenvolvimento de sensores de $\mathrm{pH}$ como EGFETs.

\section{1-Introdução}

Materiais baseados em carbono, em suas diferentes alotropias, têm sido largamente estudados devido as suas singulares propriedades para importantes aplicações tecnológicas. Fibras de carbono (feltros) representam uma nova geração 
de materiais de alta resistência, e tem sido descrita como uma fibra que contém, pelo menos, $90 \%$ de carbono, obtida pela pirólise controlada de fibras adequadas. Muitos materiais são utilizados como precursores na obtenção dos feltros de carbono, entre eles o algodão, linho entre outros. No entanto, um dos três principais precursores utilizados para produção em larga escala de fibra de carbono é a poliacrilonitrila (PAN)[92,93]. Fibras baseadas na PAN, apresentam propriedades físicas superiores, como por exemplo, resistência mecânica em comparação com as demais fibras. Outro fato é que, o processo de fabricação é mais fácil e mais econômico, devido à maior produção de carbono, que é de $50 \%$ contra $30 \%$ para o outro principal precursor, "rayon". Muitas propriedades das fibras feitas a base da PAN podem ser afetadas pelo seu processo de produção. A taxa de carbonização e, conseqüentemente, a produção de gases, devem ser controladas para evitar defeitos. Poros são criados nessas fibras devido à formação e à perfeição do carbono nas camadas estruturais. A alta temperatura no processo de carbonização aumenta a cristalinidade das fibras e se tornam mais perfeitos os planos da camada de carbono, gerando uma grande estrutura de poros fechados. A condutividade elétrica é fortemente afetada pela temperatura do tratamento térmico[94-100].

Nesse trabalho utilizamos os feltros de carbono como membrana sensível a íons $\mathrm{H}^{+}$. Algumas modificações nessa membrana foram feitas, entre elas o crescimento de NTC e/ou a adesão da Polianilina (Pani) em suas fibras. A membrana obtida, depois de cada um desses processos, também foi utilizada como dispositivo.

Os motivos principais em utilizar os feltros foram dois. Primeiro, é que os feltros são materiais usados como capacitores, assim como outros materiais que 
por sua vez, são usados como membranas seletivas, e o feltro não havia sido testado ainda. O segundo motivo foi a possibilidade de utilização dos feltros como suporte para os nanotubos de carbono. A utilização da polianilina surgiu devido a possibilidade dela poder ser carregada positivamente e também negativamente, além do fato de que os feltros poderiam servir de suporte para ela.

\subsection{1-Polímeros}

Dentre os vários tipos de sensores químicos que trabalham com variação de condutividade, estão os sensores baseados em semicondutores e os filmes poliméricos, como a polianilina (Pani) [101-105]. Os filmes poliméricos apresentam algumas vantagens sobre os tradicionais sensores baseados em materiais inorgânicos, que é a de fácil manuseio e reversibilidade na dopagem, além do fato, de que alguns deles tem a propriedade de serem carregados positivamente e negativamente, como dito anteriormente. Dentre esses polímeros, está a polianilina que é um polímero condutor.

\subsection{2-Polímeros condutores}

Polímeros são macromoléculas formadas por unidades químicas que se repetem, denominadas monômeros. Os monômeros são geralmente hidrocarbonetos, ou seja, constituídos por ligações de carbono e hidrogênio, ou derivados, que formam a cadeia polimérica [101-105]. Diversos polímeros são 
encontrados na natureza e têm origem animal ou vegetal, como por exemplo, as proteínas, o DNA e a madeira. Outros são obtidos sinteticamente como o PVC e o PET, que são amplamente utilizados devido as suas características mecânicas.

Os polímeros apresentam características elétricas isolantes. A idéia de associar propriedades elétricas dos metais às propriedades mecânicas dos polímeros ocorreu por volta de 1950 através da incorporação de cargas condutoras. Entretanto, as tentativas de alcançar uma condutividade somente teve êxito na década de 70 [102-108].

A descoberta dos polímeros conjugados deu-se, no fim da década de 70 com Shirakawa trabalhando em colaboração com MacDiarmid[105-110]. Esta descoberta criou um novo campo de pesquisas e desafios entre físicos e químicos com um número cada vez maior de oportunidades para novas aplicações e uma maior variedade de materiais condutores [ ].

As propriedades de condução elétrica destes polímeros surgem do caráter conjugado das cadeias poliméricas, ou seja, a alternância de ligações simples e duplas entre os átomos de carbono ao longo da cadeia principal [107-109]. Dessa forma os elétrons da dupla ligação podem ser removidos ou adicionados para formar um íon. Quando um elétron é removido da cadeia, forma-se um radical cátion. Isto pode ser interpretado como uma redistribuição eletrônica que polariza a cadeia polimérica apenas localmente, produzindo uma modificação de curto alcance na distribuição espacial dos átomos.

A oxidação/redução da cadeia polimérica é efetuada por agentes de transferência de carga, aceitadores e doadores de elétrons, convertendo o polímero de isolante para condutor ou semicondutor. Estes agentes são chamados 
de dopantes em analogia ao processo de dopagem dos semicondutores inorgânicos. Entretanto são adicionados em quantidades muito superiores, ao contrário do que ocorre nos semicondutores inorgânicos. Nestes polímeros as reações de dopagem são reversíveis.

A característica de combinar propriedades mecânicas e processabilidade dos polímeros com comportamentos elétrico, ótica, entre outros, equivalentes ao dos metais e semicondutores inorgânicos fez com que os polímeros intrinsecamente condutores se enquadrassem na categoria de metais sintéticos. Os polímeros condutores intrínsecos possuem uma vasta área de aplicação alem dos sensores, como em baterias recarregáveis , coberturas antiestáticas, eletrocatalisadores, proteção contra radiação eletromagnética, anticorrosivos, células solares, dispositivos eletrônicos, entre outros [ 105-113].

\subsection{3-Polianilina}

A polianilina é um polímero condutor, integrante da classe dos chamados metais sintéticos. Esta classe de materiais tem sido objeto de diversas pesquisas, pois suas aplicações são promissoras em áreas como sensores, diodos emissores de luz, biossensores e bateriais entre outras [105-109]. Diversos polímeros condutores tem sido objeto de estudos como o polipirrol, o politiofeno, pofenileno, além da polianilina.

A polianilina (Pani) é um dos polímeros que vem sendo amplamente estudado, pois apresenta facilidade na preparação e dopagem, boa estabilidade química em temperatura ambiente e baixo custo. Desta maneira, varias aplicações 
tecnológicas e científicas tem se utilizado deste material pra produzir sensores, entre outros dispositivos. A figura 5.1 ilustra a Pani em suas formas possíveis, de sal de esmeraldina, quando é condutora e também quando na forma de base de pernigralina, não condutora. A Polianilina é derivada da anilina, e o produto de sua oxidação foi preparado pela primeira vez em 1862, porém suas propriedades como polímero condutor intrínseco foram reconhecidos somente a partir da década de $80[105,109,111]$.
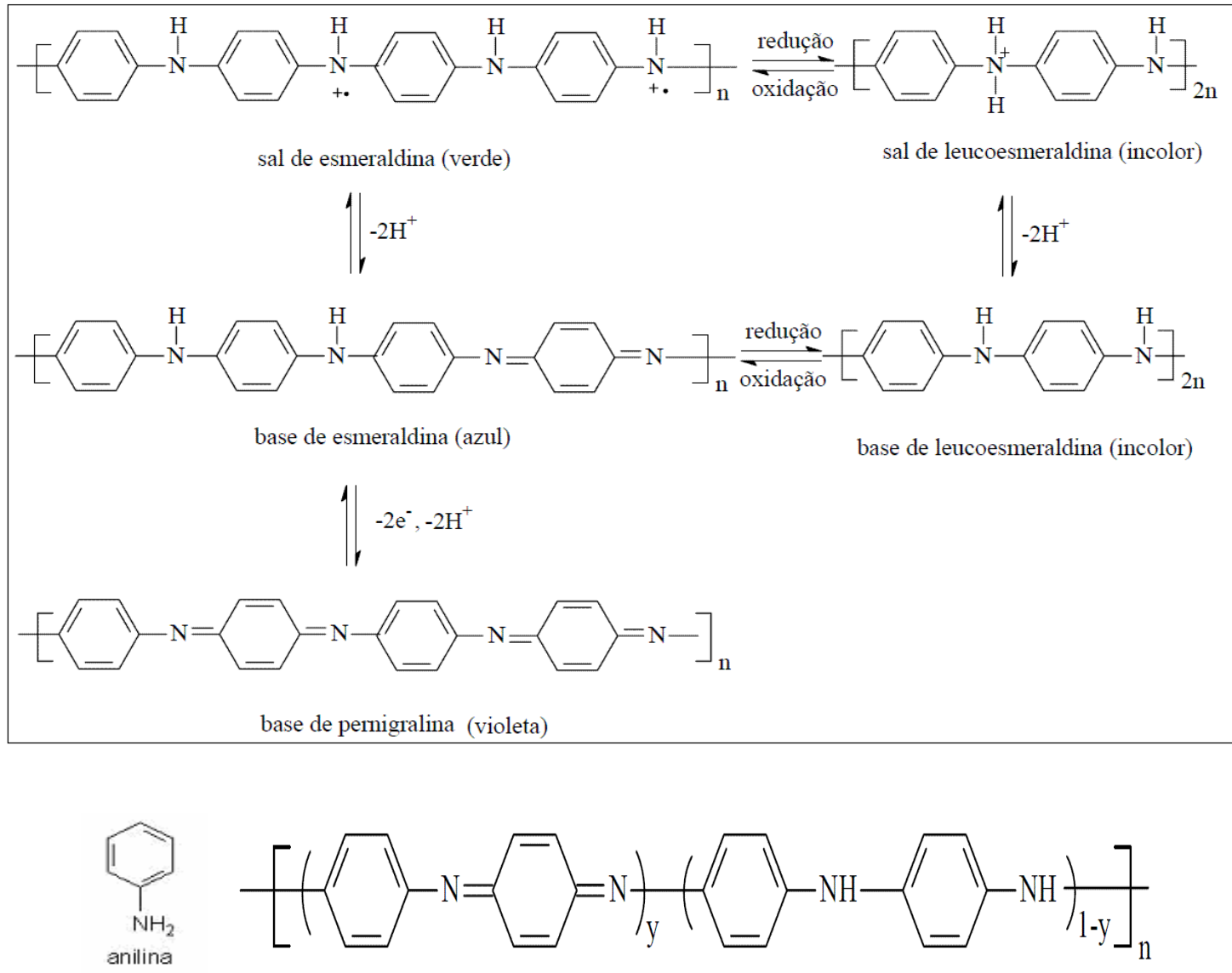

Figura 5.1: Ilustração da estrutura da Pani, mostrando os estados possíveis de protonação. 
A Polianilina pode ser descrita como uma cadeia composta de unidades constituídas de um grupo - $\mathrm{NH}$ - que contém em ambos os lados um agrupamento fenil, cuja composição química na forma de base (não dopada) é dada pela fórmula geral ilustrada na figura 5.1.

Esta estrutura geral é composta por (y) unidades repetidas de espécies reduzidas (as chamadas aminas, ou seja, os grupos $-\mathrm{NH}-$ ) e (1-y) unidades repetidas de espécies oxidadas (as chamadas iminas, ou seja, os grupos $-\mathrm{N}=$ ). Esse estado de oxidação pode variar de acordo com $(y)$ que pode assumir valores entre 0 a 1 [105,108]. Na situação de totalmente reduzido y=1, o polímero possui apenas nitrogênios amina, sendo conhecido como leucoesmeraldina. Na forma totalmente oxidada, ou seja, $y=0$, o polímero possui apenas nitrogênios imina ($\mathrm{N}=$ ), sendo conhecido como pernigranilina [107].

No estado de oxidação, onde o polímero encontra-se parcialmente oxidado, em que o número de unidades reduzidas e oxidadas são iguais, a polianilina apresenta os átomos de nitrogênios distribuídos em igual porcentagem de unidades imina e amina, conhecida como esmeraldina, sendo a mais estável dentre os diferentes estados.

Como em muitos outros polímeros conjugados, a condutividade elétrica da Polianilina é função do estado de oxidação, ou seja, do número de elétrons adicionados na estrutura polimérica ou dela removidos. A diferença deste polímero em relação aos demais está relacionada ao seu processo de dopagem. Assim, a condutividade depende de duas variáveis: o estado de oxidação e o grau de protonação dos átomos de nitrogênio na estrutura. Isso implica na inserção de 
cargas sem que resulte em alterações no número de elétrons associados à cadeia polimérica.

O estado de oxidação intermediário (esmeraldina) pode ser obtido sob a forma neutra (base de esmeraldina) pela oxidação da base de leucoesmeraldina, ou através de protonação por meio da dopagem com ácidos, obtendo-se assim o sal de esmeraldina[105]. A reação de protonação ocorre principalmente nos nitrogênios imina da Polianilina $(-\mathrm{N}=)$ de forma parcial ou total, para se obter o polímero na forma de sal (forma protonada). O grau de protonação da base depende do grau de oxidação que o polímero foi sintetizado e do pH da solução dopante.

A polianilina pode ser sintetizada por uma grande variedade de métodos que induzem ao mecanismo de polimerização da anilina através de sua oxidação, sendo o mais comum, o método químico por apresentar o melhor rendimento, além da vantagem de permitir o ajuste da produção para quantidades maiores, ou seja, melhor adaptação para escala piloto ou industrial.

A síntese química da polianilina precisa de três reagentes: a anilina, um meio ácido e um oxidante [105,107]. Uma variedade de ácidos inorgânicos, assim como de agentes oxidantes podem ser utilizados, sendo o mais utilizado o ácido clorídrico $(\mathrm{HCl})$ e o perssulfato de amônio $\left[\left(\mathrm{NH}_{4}\right)_{2} \mathrm{~S}_{2} \mathrm{O}_{8}\right]$, como ácido e agente oxidante, respectivamente.

Com o objetivo de contribuir para um melhor desempenho de sensores de $\mathrm{pH}$, e com possibilidade de aplicação em biossensores futuramente, o presente trabalho visa estudar o comportamento elétrico de sensores fabricados com filmes onde a polianilina foi agregada nos feltros de carbono. 


\section{2-Síntese das Membranas}

Os feltros de carbono foram produzidos a partir da carbonização da PAN na temperatura de $1000^{\circ} \mathrm{C}$. A PAN permaneceu nessa temperatura por 30 min e após sofrem resfriamento à temperatura ambiente. Os feltros de carbono foram cortados com uma dimensão de $0,15 \mathrm{~cm}$ de espessura, $1 \mathrm{~cm}$ de comprimento e 0,6 cm de largura. Estas amostras não foram produzidas em nosso laboratório. Estas amostras foram adquiridas do Laboratório do Prof.Dr. José Maurício Rosolen, que faz parte do Departamento de Química, da Faculdade de Filosofia, Ciências e Letra de Ribeirão Preto.

Posteriormente, nesses feltros que serviram como membrana sensível a $\mathrm{H}^{+}$, foram crescidos nanotubos de carbono em suas fibras. Essa nova membrana também serviu como dispositivo sensível a $\mathrm{H}^{+}$. $\mathrm{O}$ compósito feltro de carbono/nanotubos de carbono (FC/NTC) foi obtido pelo crescimento dos nanotubos via decomposição de metanol utilizando como catalisadores o acetato de cobalto e acetato de manganês na proporção de 1:1.

A metodologia desse crescimento se processa colocando os feltros de carbono em um eppendorf com $0,1 \mathrm{~g}$ de acetatos para $10 \mathrm{ml}$ etanol durante 3 horas, sob agitação a cada intervalo de 30 min. Após esse período, o líquido remanescente é eliminado e o eppendorf é levado à estufa à $80^{\circ} \mathrm{C}$ durante $15 \mathrm{~min}$, com os tubos do eppendorfs abertos. Após a aderência química dos catalisadores, os nanotubos são crescidos pelo método CVD, em rampa de $20^{\circ} \mathrm{C} / \mathrm{min}$ até $650^{\circ} \mathrm{C}$. Quando o forno atinge a temperatura de $650^{\circ} \mathrm{C}$ é injetado metanol. Algumas amostras, após o crescimento são purificadas com $\mathrm{HCl}$ concentrado (em 
temperatura ambiente por $30 \mathrm{~min}$ ). Este procedimento é usado para a remoção das partículas excedente do catalisador.

Os nanotubos formados são do tipo-bamboo. Por fim, a Pani foi sintetizada nos feltros de carbono (FC/Pani) e também em feltros de carbono com nanotubos de carbono (FC/NTC/Pani).

O processo usado para a polimerização da Pani consistia em colocar 100mg de anilina e 61,6 $\mathrm{g}$ de persulfato de amônia por feltro com uma relação de 4:1 (mmol) de anilina/oxidante. É gotejado $98 \mu \mathrm{l}$ de anilina e $5 \mathrm{ml}$ de uma solução preparada de $\mathrm{HCl}(1 \mathrm{M})$ com persulfato de amônia em cada feltro. A polimerização procede com a solução se tornando azul, primeiramente, e depois verde escura, característica da polianilina no seu estado protonado (Pani-ES, sal de esmeraldina). Após a polimerização, os feltros são lavados com uma solução de $\mathrm{HCl}(1 \mathrm{M})$. No caso de polianilina em estado deprotonado, a membrana sofre um tratamento com $0,50 \mathrm{~mL}$ de $\mathrm{NH}_{4} \mathrm{OH}(1 \mathrm{M})$. $\mathrm{Na}$ discussão das caracterizações realizadas, as amostras serão identificadas da seguinte forma: FC - representa a membrana de feltro puro; FC/NTC - representa a membrana de feltro, onde cresceram os nanotubos, que pode ser denominados de duas formas FC/NTC-pur e FC/NTC-npur, que representam as membranas que sofreram purificação e aquelas que não sofreram purificação, respectivamente; FC/Pani - representam o feltro onde houve a polimerização da polianilina em suas fibras, podendo ser na forma protonada e deprotonada identificadas como FC/Pani-pro e FC/Pani-depro; e por fim a combinação com os nanotubos e a polianilina na fibras do feltro podendo ocorrer em quatro variações FC/NTC-pur/Pani-pro e FC/NTC-pur/Panidepro; FC/NTC-npur/Pani-pro e FC/NTC-npur/Pani-depro. 


\section{3-Caracterização de superfície (MEV)}

A morfologia das amostras usadas como dispositivo sensível a $\mathrm{H}^{+}$foi analisada através da microscopia eletrônica de varredura (MEV). Na figura 5.2 podem ser observadas as imagens da amostra feita com o feltro puro -FC-, ou seja, sem impregnação de nenhum composto.
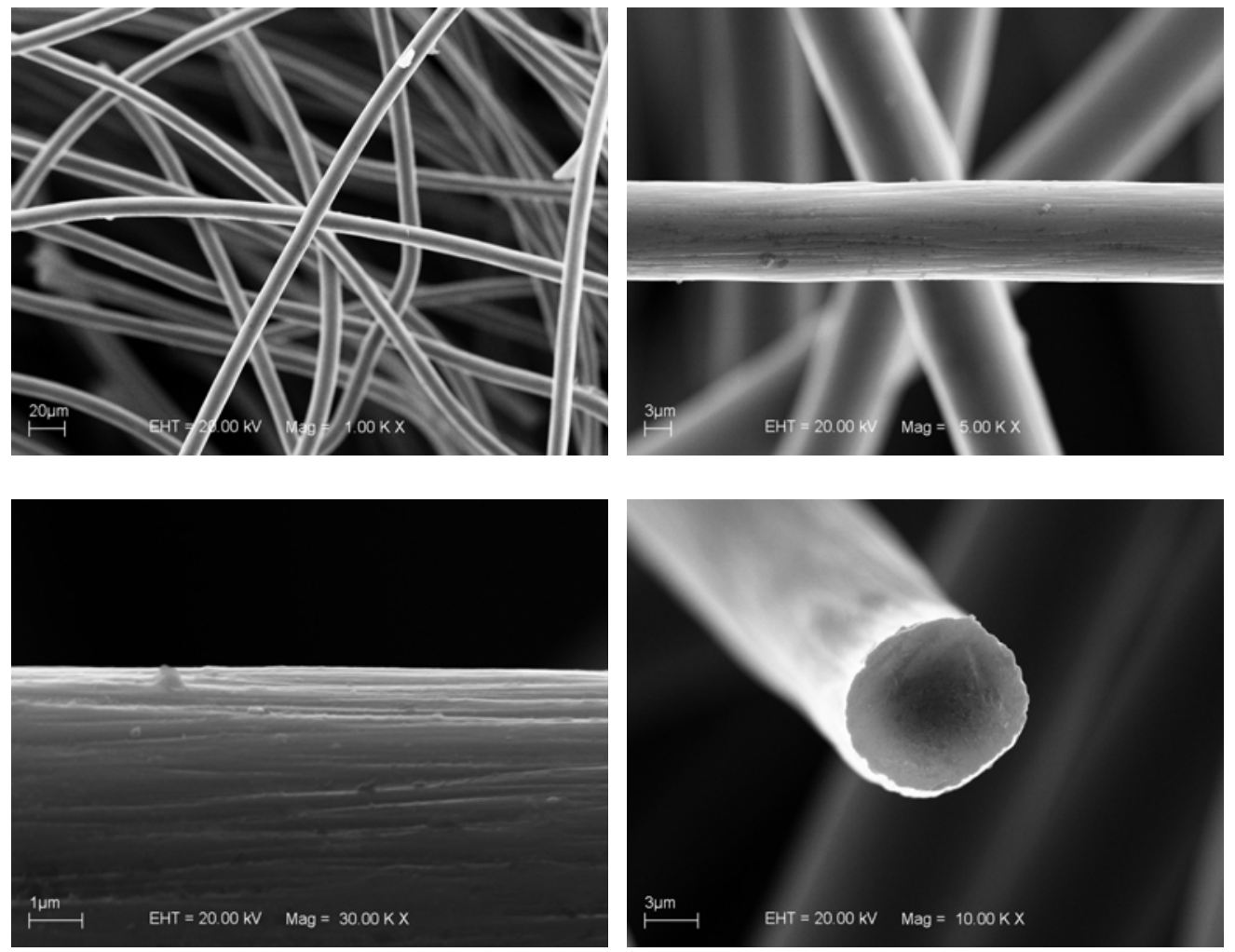

Figura 5.2: Imagens de microscopia eletrônica de varredura do feltro de carbono (FC) derivado da poliacrilonitrica e utilizado para a produção das membranas.

São apresentadas nessa figura, quatro ampliações diferentes. Pode ser visto que as fibras não têm orientação preferencial e que por isso, ocorre um 
emaranhado dessas fibras em todas as direções. Pode ser observado, também, que ao longo do corte longitudinal as fibras apresentam algumas ranhuras, o que é de alguma forma interessante, pelo fato de aumentar a rugosidade das fibras, favorecendo a aderência de íons ou outro composto desejável. Segundo o corte transversal, pode ser observado que o diâmetro médio das fibras está em torno de $10 \mu \mathrm{m}$, o que está de acordo com a literatura[ ].

A figura 5.3, por sua vez, mostra a membrana FC/NTC-pur, onde os nanotubos foram crescidos em suas fibras e após o crescimento houve o processo de purificação para a retirada dos catalisadores, que foram necessários para o crescimento dos nanotubos.

Pode ser visto, nesta figura, que mesmo com a purificação, ainda há partículas que podem ser dos catalisadores, e em torno dessas partículas, algum material sugerindo ser os nanotubos. Seria necessária a microscopia eletrônica de transmissão para confirmar essa hipótese, mas não há outra que não seja esta, porque o processo é o mesmo utilizado por outros pesquisadores que fizeram análises e confirmaram essa hipótese como no laboratório do Prof. Dr. José Maurício Rosolen [ ].

Observa-se, nessa figura, que não há um crescimento uniforme em todas as fibras, entretanto, observa-se que, onde os nanotubos cresceram (circulados em branco) nestas fibras eles foram uniformes. Entretanto, aparecem catalisadores (circulados em preto). 

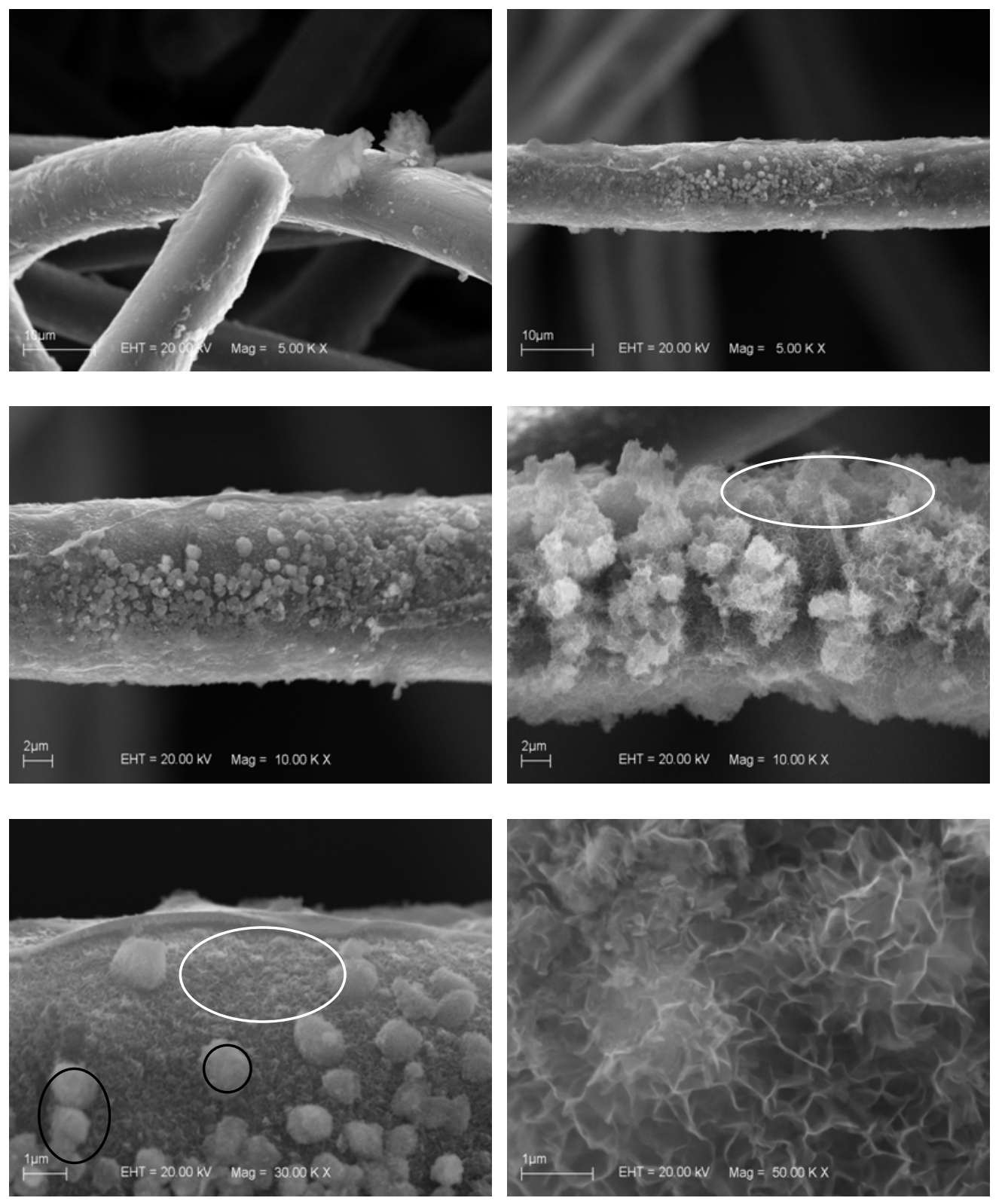

Figura 5.3: Imagens de microscopia eletrônica de varredura da membrana de feltro de carbono com crescimento de nanotubos em suas fibras onde houve purificação da membrana para eliminação de catalisadores (FC/NTC-pur).

A figura 5.4 mostra a membrana semelhante à anterior, diferenciando-se apenas pelo fato de a membrana não ter sido purificada. Pode ser observado que 
há um maior número de partículas de catalisadores (circulados em preto). Com um crescimento desigual de nanotubos entre as fibras (circulados em brancos).

Veremos na caracterização elétrica que a purificação melhora a sensibilidade da membrana.
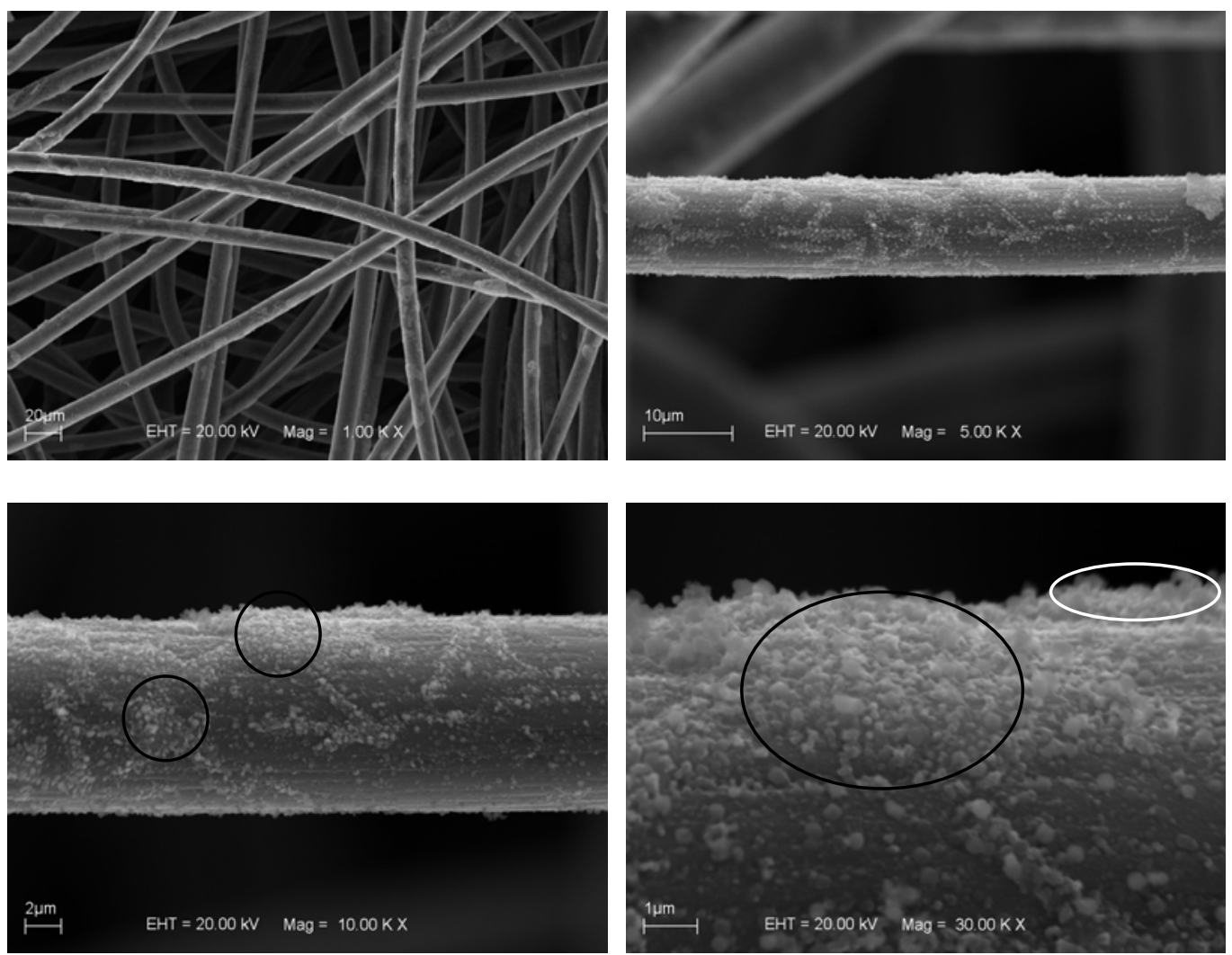

Figura 5.4: Imagens de microscopia eletrônica de varredura da membrana de feltro de carbono com crescimento de nanotubos em suas fibras onde não houve purificação da membrana para eliminação de catalisadores (FC/NTC-npur). 

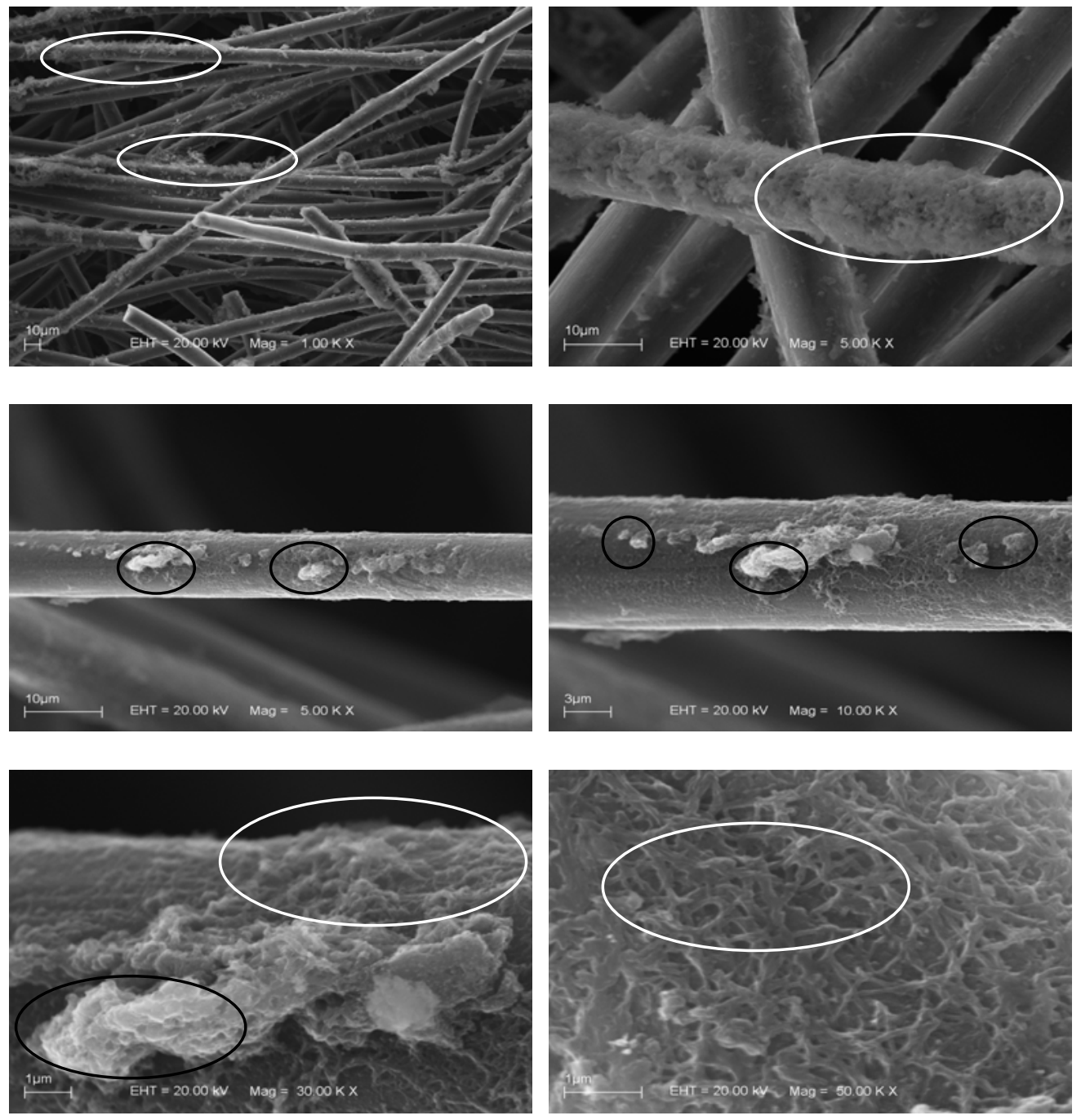

Figura 5.5: Imagens de microscopia eletrônica de varredura da membrana de feltro de carbono com crescimento de nanotubos, com purificação da membrana e também com polimerização da polianilina no seu estado protonado (FC/NTC-pur/Pani-pro).

Na figura 5.5, vemos a membrana FC/NTC-pur/Pani-pro. Nessa figura, é observado que a polianilina se agrega nas fibras do feltro (circulados em branco). Não há como saber o alcance da influência da presença dos nanotubos. Pode-se notar que a polianilina sofreu a influência da presença dos catalisadores (circulados em pretos), mostrando que onde estes estão presentes, o 
recobrimento não ocorreu uniformemente, mas na fibra onde não havia muito catalisador, apenas nanotubos ou somente o feltro, o crescimento foi uniforme e completo em torno da fibra.
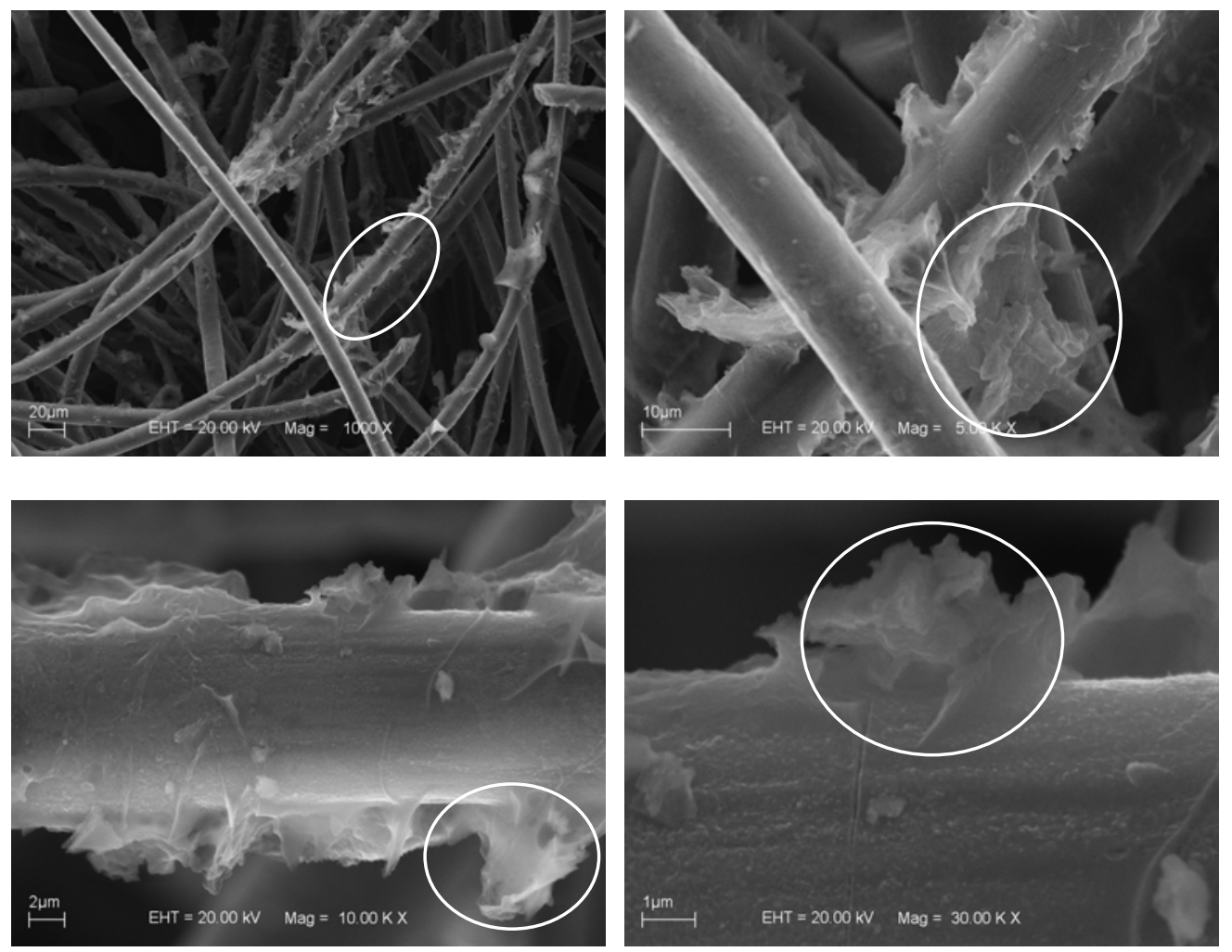

Figura 5.6: Imagens de microscopia eletrônica de varredura da membrana de feltro de carbono com crescimento de nanotubos, sem purificação da membrana e também com polimerização da polianilina no seu estado protonado (FC/NTC-npur/Pani-pro).

A influência dos catalisadores, seria uma hipótese, figura 5.6, para responder, porque que o recobrimento da polianilina (circulados em branco) não foi uniforme nas fibras, onde ele ocorre, além do fato de não se observar todo o envolvimento da fibra. 
Foi feito o recobrimento da polianilina deprotonada nas membranas para detecção de $\mathrm{H}^{+}$. Na figura 5.7 e 5.8 , podem ser visto as membranas FC/NTCpur/Pani-depro e FC/NTC-npur/Pani-depro, respectivamente. Observa-se que o recobrimento não foi homogêneo em nenhuma das amostras, porém na amostra que não sofreu a purificação dos nanotubos, a cobertura foi pior além do fato de se observar que há muitas partículas de catalisadores (circulados em preto) naquela onde não houve a purificação.

Como no caso anterior, esses catalisadores, podem ter atrapalhado, a sensibilidade da amostra.
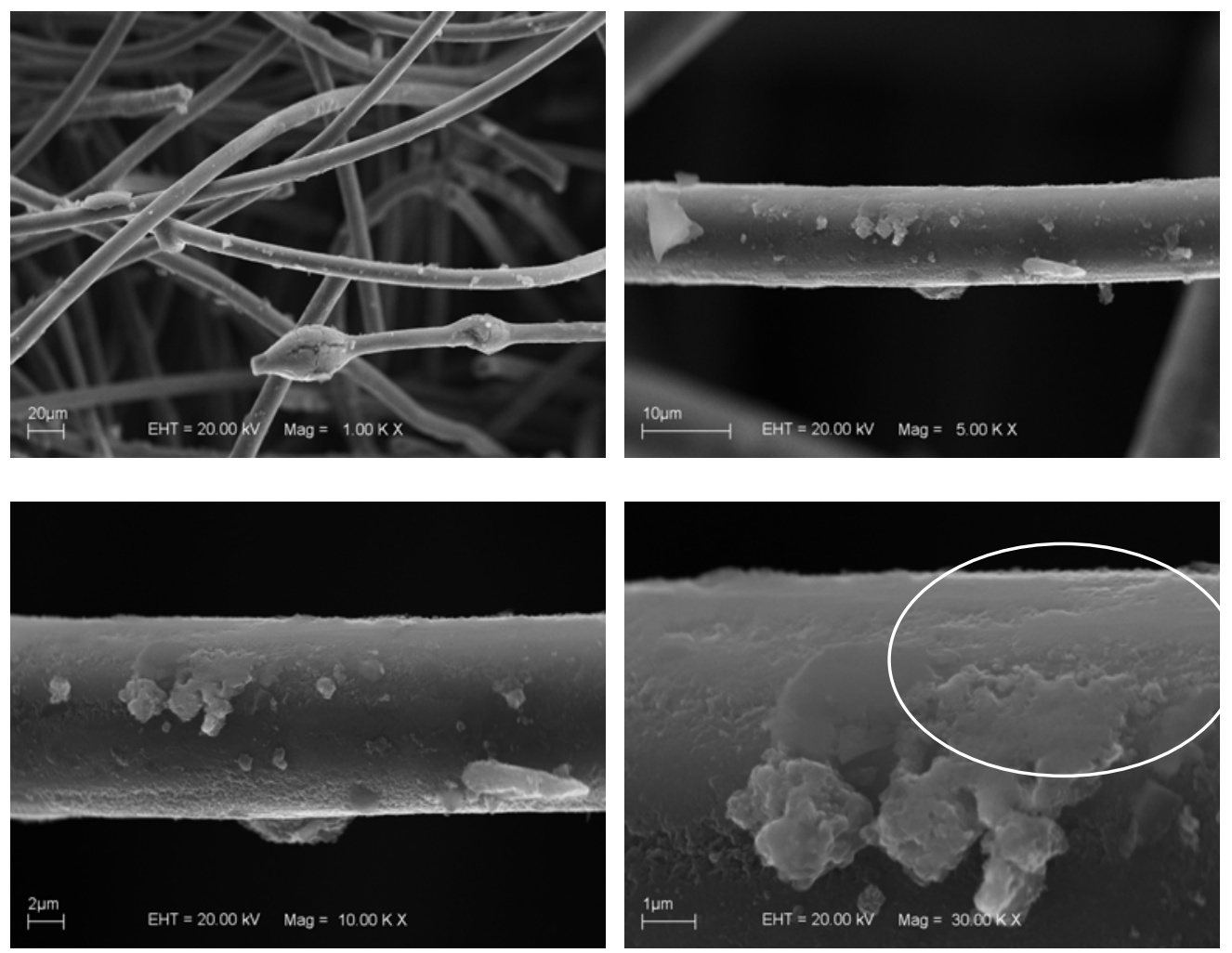

Figura 5.7: Imagens de microscopia eletrônica de varredura da membrana de feltro de carbono com crescimento de nanotubos, com purificação da membrana e também com polimerização da polianilina no seu estado deprotonado (FC/NTC-pur/Pani-depro). 
Por fim, foi feito o recobrimento da polianilina nos feltros puros. A figura 5.9 mostra a membrana FC/Pani-pro enquanto que a figura 5.10 mostra a membrana FC/Pani-depro.
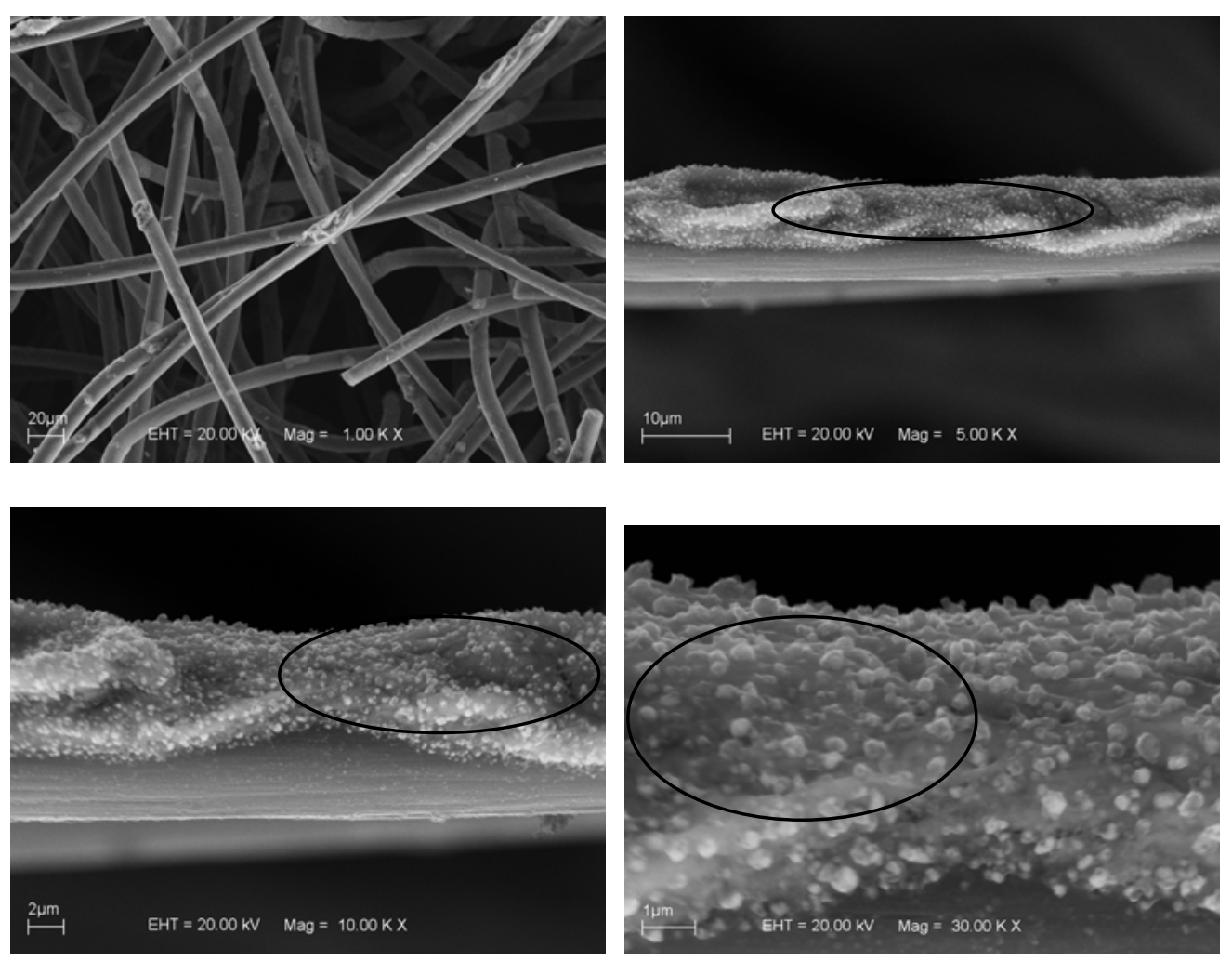

Figura 5.8: Imagens de microscopia eletrônica de varredura da membrana de feltro de carbono com crescimento de nanotubos, sem purificação da membrana e também com polimerização da polianilina no seu estado deprotonado (FC/NTC-npur/Pani-depro).

Pode-se observar nessas micrografias que o recobrimento da Pani (circulados em branco) nas fibras do feltro no estado protonado foi melhor, ocorrendo de forma mais homogênea do que o recobrimento no estado deprotonado. 

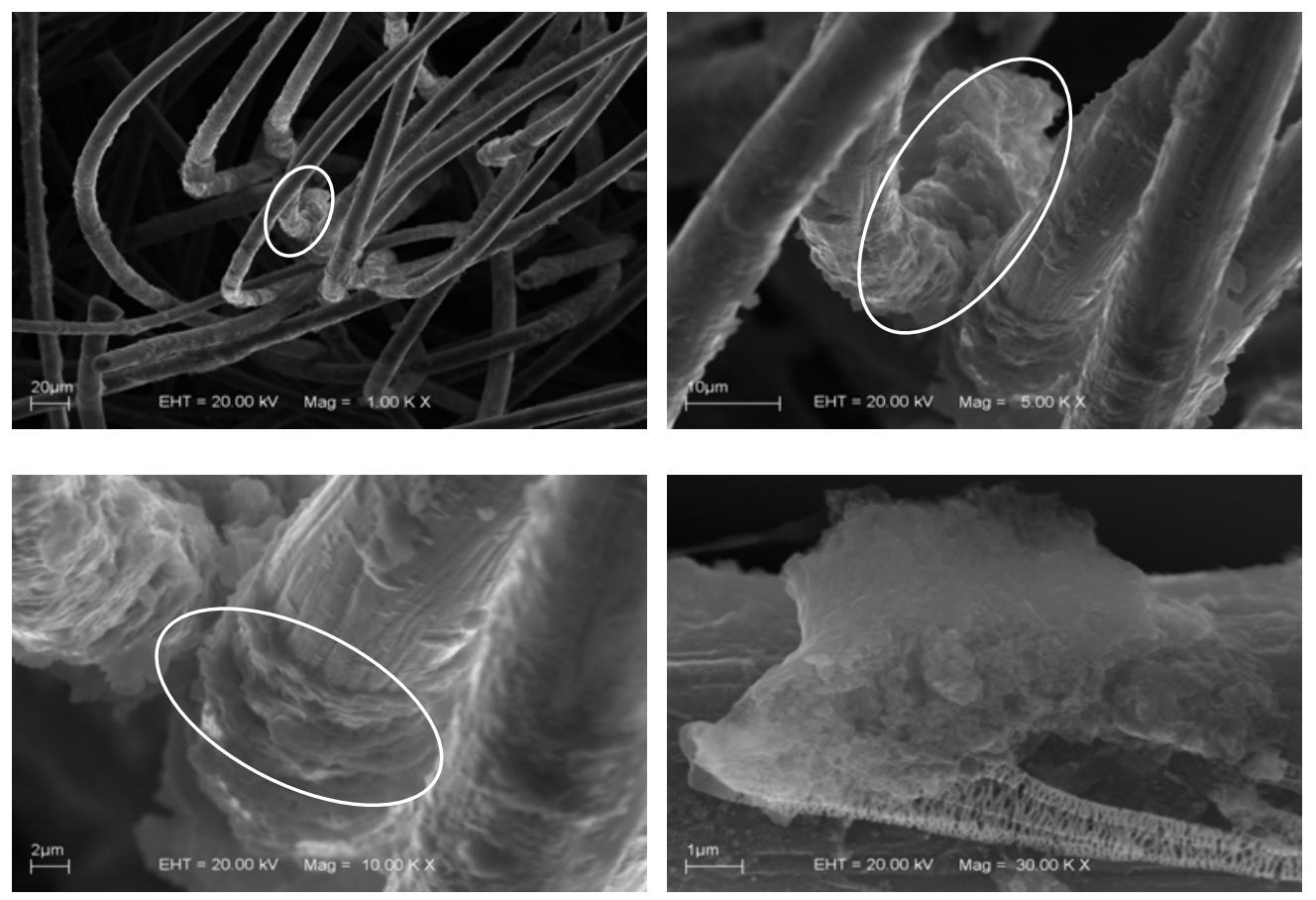

Figura 5.9: Imagens de microscopia eletrônica de varredura da membrana de feltro de carbono com polimerização da polianilina no seu estado protonado (FC/Pani-pro).
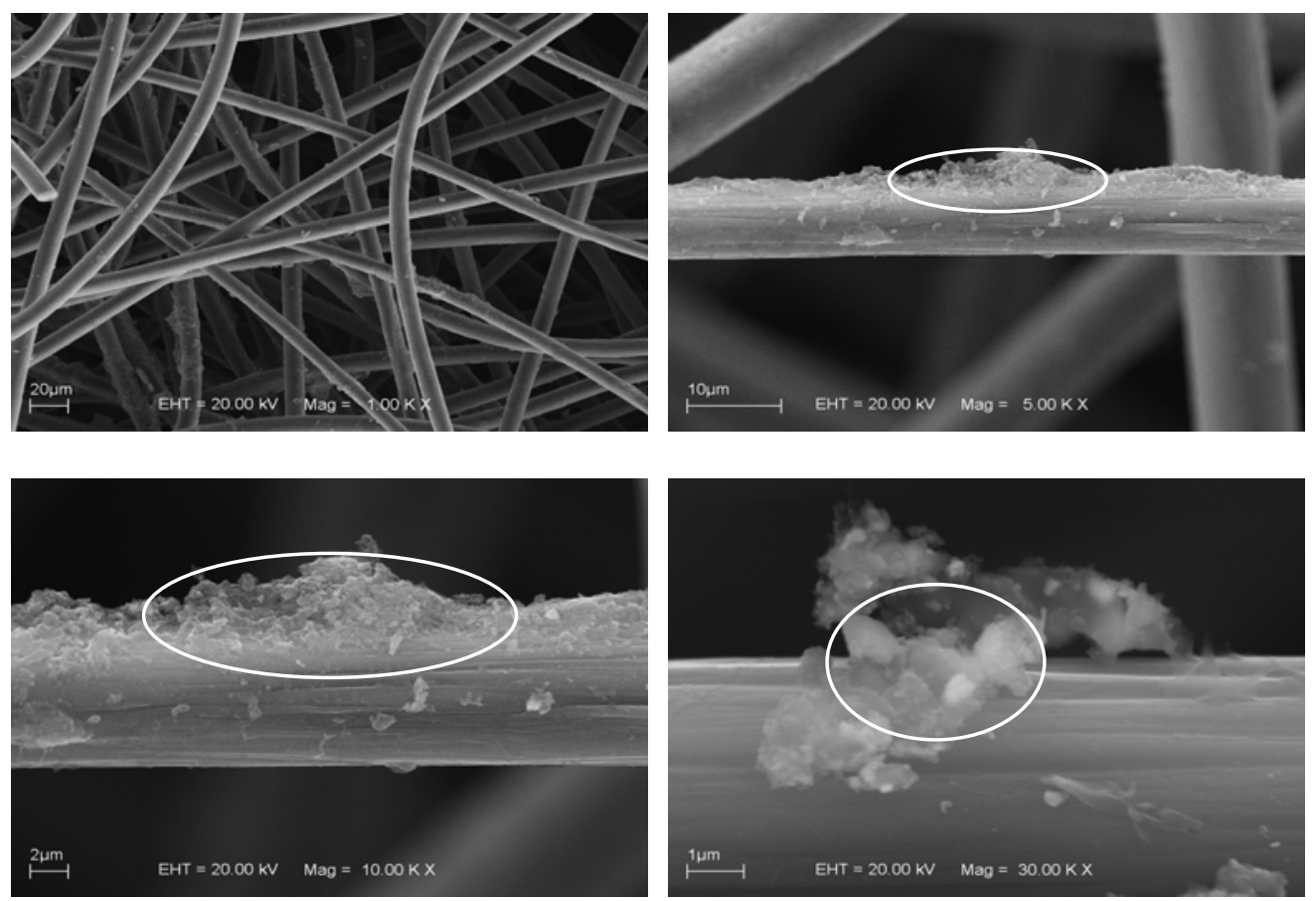

Figura 5.10: Imagens de microscopia eletrônica de varredura da membrana de feltro de carbono com polimerização da polianilina no seu estado deprotonado (FCt/Pani-depro). 
Na primeira membrana, FC/Pani-pro, figura 5.9, há maior número de fibras recobertas enquanto que no estado deprotonado, houve intervalos, ou seja, fibras sem ser recoberta pela Pani.

Nessas imagens, podemos ver que os feltros crescem de forma

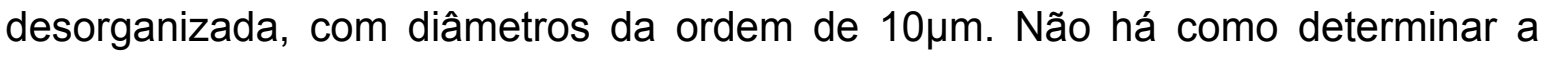
influência dos nanotubos sobre o recobrimento da Pani. Sabemos que nas amostras onde os nanotubos não foram purificados, uma maior quantidade de catalisadores era esperado. Também, podemos sugerir que os catalisadores atrapalham o recobrimento da Pani nos feltros de carbono. Isso pode ser notado em quase todas as amostras onde havia catalisador. A diferença entre o estado de protonação da Pani sobre o recobrimento dos feltros, é que quando ela está no estado protonado, o recobrimento é melhor do que quando ela está no estado deprotonado. Foi feita uma medida de condutividade do feltro, apenas por curiosidade, e ele se mostrou ser um condutor. $O$ feltro é considerado um condutor, com cargas negativas em excesso, e a Pani no estado protonado, tem carga positiva para se ligar com o feltro. Por isso a Pani no estado protonado recobre melhor as fibras do feltro.

\section{4-Caracterização no infravermelho (FTIR)}

Todas as amostras utilizadas, foram caracterizadas pela técnica de espectroscopia de FTIR. A caracterização por FTIR foi realizada por transmitância, onde as amostras foram misturadas com $\mathrm{KBr}$ e prensadas para formar pastilhas. 


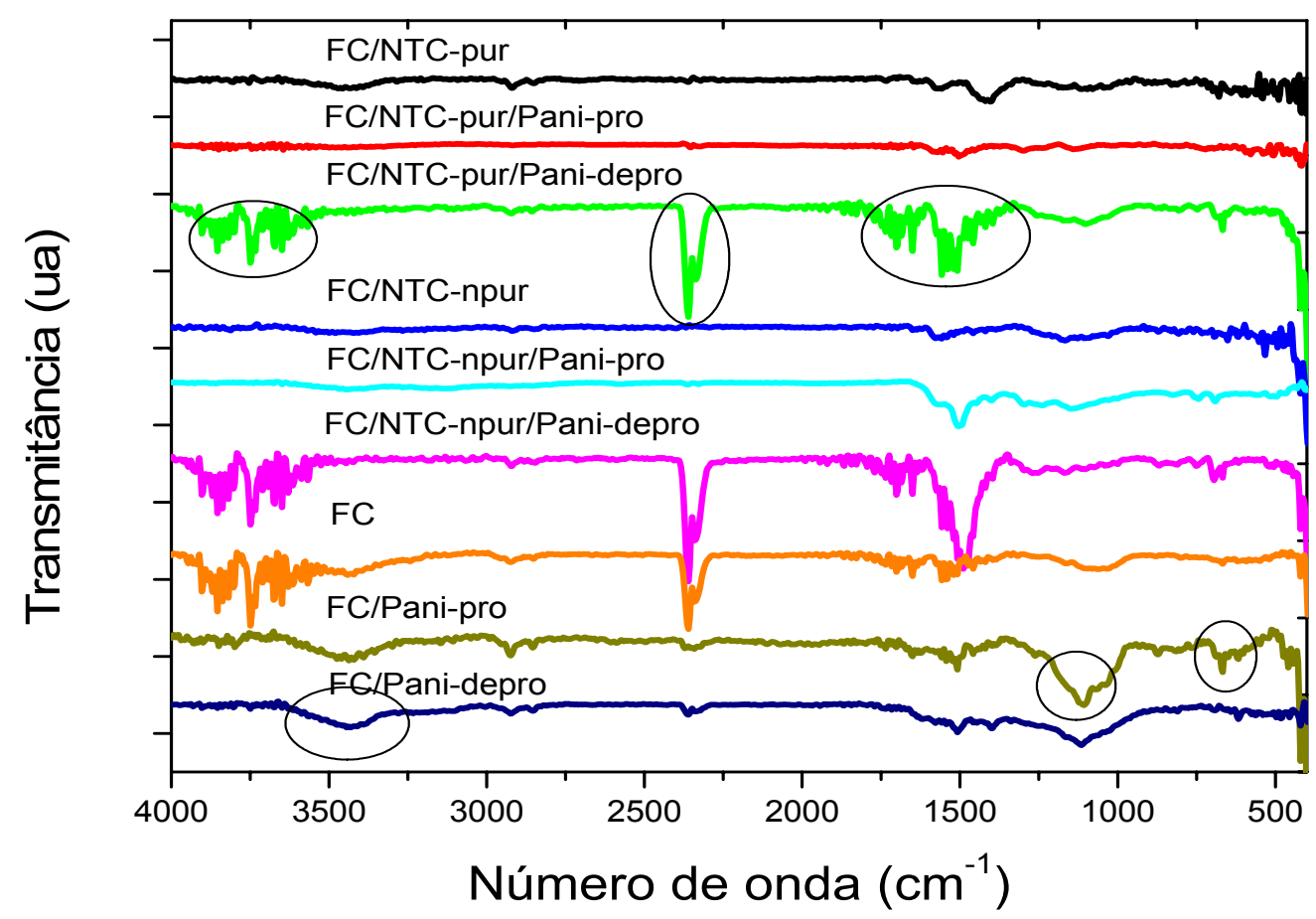

Figura 5.11: Análise de FTIR da amostra de feltro e seus compostos que posteriormente foram usados como membrana seletiva.

A figura 5.11 mostra o espectro das nove amostras utilizadas. Comparandose os espectros obtidos, nota-se que há semelhança nos espectros das amostras de feltro e feltro com crescimento de nanotubos e com recobrimento da Pani na sua forma deprotonada, ou seja, as amostras FC/NTC-pur/Pani-depro, FC/NTCnpur/Pani-depro e FC apenas.

Outra semelhança são as amostras onde há apenas nanotubos e feltros, ou seja, FC/NTC-pur e FC/NTC-npur. Há algumas bandas que puderam ser identificadas. As bandas próximas a $3400 \mathrm{~cm}^{-1}$ estão relacionadas ao estiramento $\mathrm{N}-\mathrm{H}$ da polianilina, a banda localizada próxima a $2900 \mathrm{~cm}^{-1}$ está relacionada ao 
estiramento $\mathrm{C}-\mathrm{H}$ do feltro feito a partir da poliacrilonitrila. Em $1493 \mathrm{~cm}^{-1}$ há uma possível sobreposição do estiramento do anel benzênico da Pani com a deformação da ligação $-\mathrm{CH}_{2}$ do feltro. Modos de ligação $\mathrm{C}-\mathrm{H}$ no plano são usualmente observados na região em $1147 \mathrm{~cm}^{-1}$, que está relacionado com a Pani, que em alguns casos, serve para medir o grau de dopagem. A região em $680 \mathrm{~cm}^{-1}$ aproximadamente, está relacionada à ligação C-H da Pani[113]. Há alguns autores que relacionam a região próxima a $2250 \mathrm{~cm}^{-1}$ com estiramento $\mathrm{C} \equiv \mathrm{N}$, o grupo acrilonitrila, visto em apenas três amostras (FC/NTC-pur/Pani-depro; FC/NTC-npur/Pani-depro e no FC) enquanto que nas outras amostras há apenas um indício dessa manifestação.

O FTIR serve para identificar o composto. Mediante o espectro de FTIR, pode-se inferir, que existam sítios em que os íons que se queira medir possam se unir a esses sítios. Uma hipótese para utilizar os feltros e os compostos feltro/nanotubos e Pani, é porque esses materiais apresentam pontos (sítios) onde o íon a ser medido possa se adsorver. Como a Pani tem, no nosso caso, dois estados, protonados e deprotonados, seria de grande utilidade para se unir a $\mathrm{OH}$ e $\mathrm{H}^{+}$, respectivamente.

\section{5-Caracterização Elétrica}

Nesse capítulo serão mostradas as membranas feitas a partir do feltro de carbono e aquelas com crescimento de nanotubos e com o recobrimento da polianilina nas fibras do feltro. Sem conhecer antecipadamente a característica ideal de uma membrana feita de feltro para ser usada como membrana sensível a 
íons $\mathrm{H}^{+}$, qual seria a quantidade otimizada de nanotubos em suas fibras e também a quantidade de polianilina recoberta nos feltro, essas membranas foram testadas e caracterizadas, sendo escolhidos todos os parâmetros utilizados por uma questão empírica.

A sugestão em utilizar o feltro, como membrana seletiva, partiu da hipótese que outros materiais que eram utilizados como capacitores, inclusive o feltro, também eram utilizados como membranas seletivas $\left(\mathrm{SnO}_{2}, \mathrm{ZnO}\right)$.

O feltro não tinha sido testado ainda como membrana seletiva. Surgiu a hipótese de utilizá-lo com essa finalidade.

Além disso, ele possui muitos sítios de ligação e pontos suficientes para que se possam agregar outros materiais em sua superfície. Outro fato é que os feltros também são feitos de carbono e, já que havia-se testado os nanotubos, ter outro material de carbono seria de grande valor.

Começando dos resultados pelo feltro, a figura 5.12 apresenta as curvas de caracterização desse sensor em função da variação do $\mathrm{pH}$ da solução. $\mathrm{O}$ dispositivo EGFET é caracterizado pela curva operando na região de saturação, com $\mathrm{V}_{\mathrm{GS}}$ igual a $2,5 \mathrm{~V}$ e $\mathrm{V}_{\mathrm{DS}}$ variando de 0 a $5 \mathrm{~V}$. A outra curva apresenta a resposta do dispositivo operando na região de não saturação, com $\bigvee_{D S}$ igual 0,17 $\mathrm{V}$ e $\mathrm{V}_{\mathrm{GS}}$ variando de 0 a $5 \mathrm{~V}$. Em todas as amostras, a configuração elétrica para a aquisição dos dados será a mesma.

Pode ser observada nessa figura, que há a separação das correntes quando há variação dos pHs e que a intensidade da corrente é alta. 

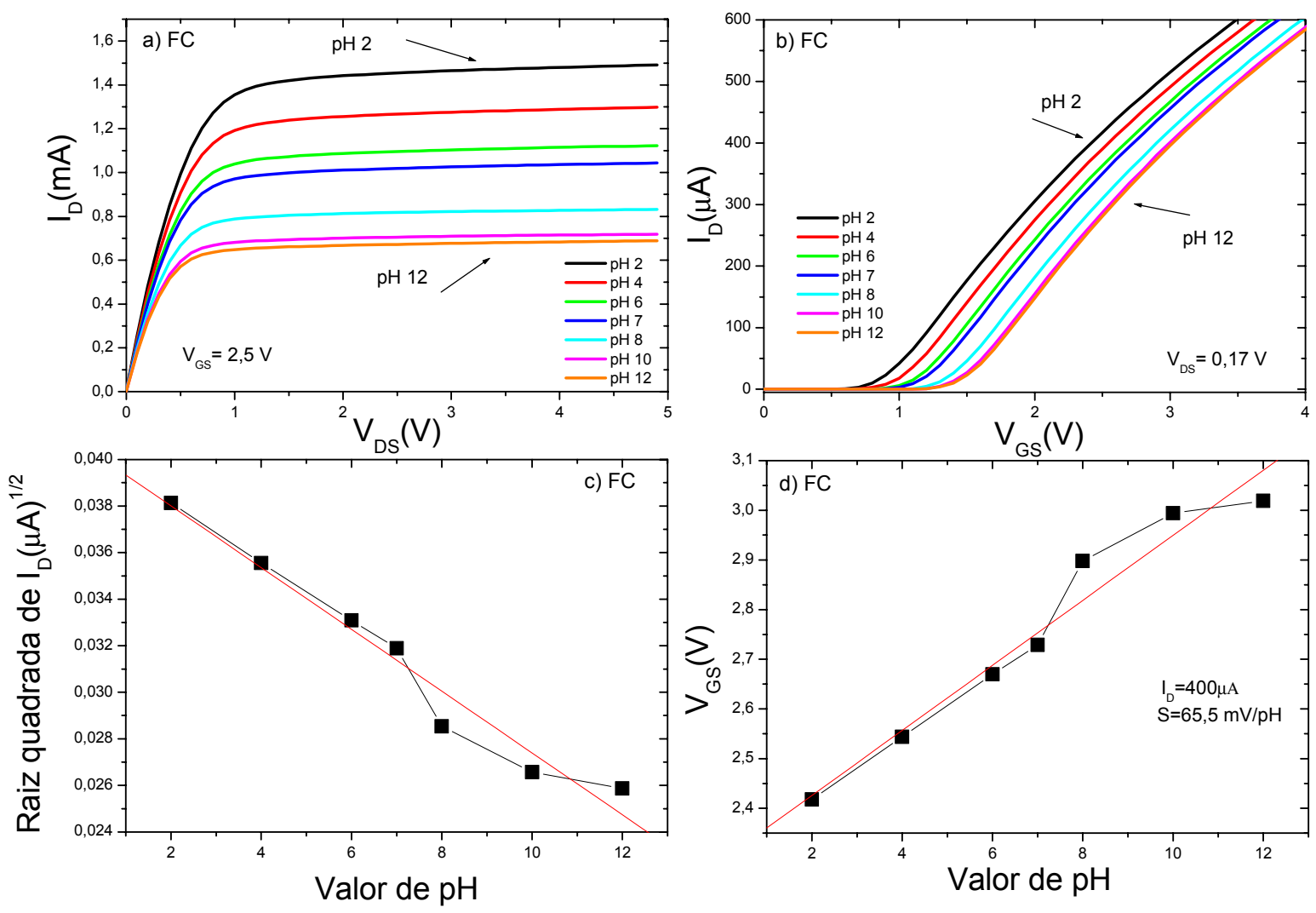

Figura 5.12: Curva da resposta do FC como EGFET. Na figura é visto o EGFET operando na região de saturação (a) e na direita na região linear (b), com comportamento da raiz quadrada em funçao do $\mathrm{pH}$ (c) e da sensibilidade (d).

Através dos dados fornecidos da figura 5.12, mostramos o comportamento praticamente linear da raiz quadrada da corrente em função do pH, figura 5.12-c, e também a sensibilidade, figura $5.12-\mathrm{d}$, de $65,5 \mathrm{mV} / \mathrm{pH}$, calculado com uma corrente de $400 \mu \mathrm{A}$. Vemos que a sensibilidade dessa membrana está acima da sensibilidade apresentada por outros materiais, além do fato de se ter uma boa separação entre os pHs. 
Pode ser observada a figura 5.13 , que há a separação das correntes quando da variação dos pHs começam e permanecem separadas e estáveis ao longo do tempo.

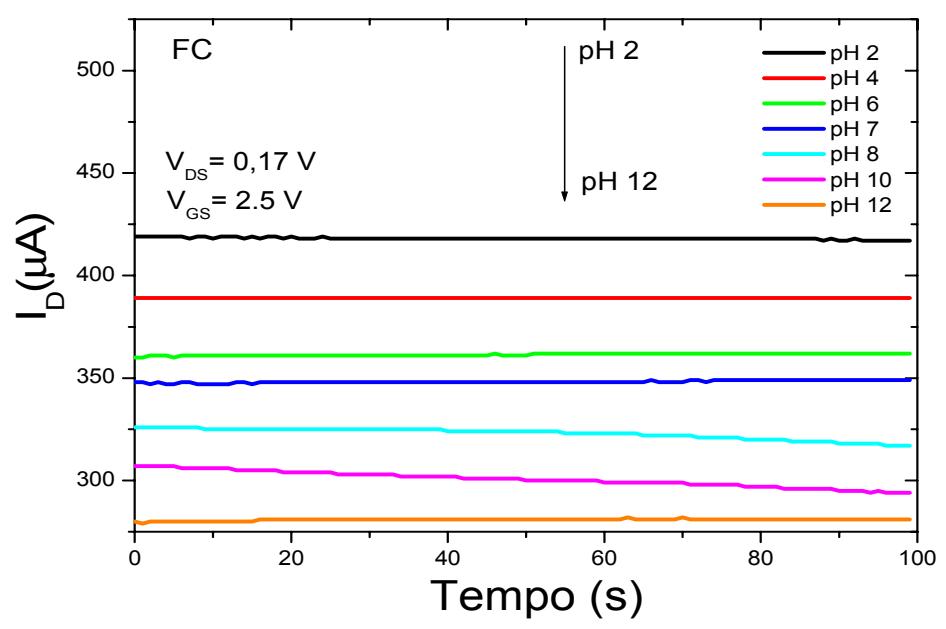

Figura 5.13: Curva da estabilidade das correntes de dreno em função do tempo, da amostra de FC.

As correntes de dreno quase não oscilam, permanecendo constante o tempo todo, ou seja com muita estabilidade.

Esse comportamento do feltro se deve pelo fato do feltro conter muitos sítios de ligação, favorecendo a adsorção dos íons $\mathrm{H}^{+}$em pontos de suas fibras.

\subsection{1-A influência dos nanotubos}

Os nanotubos de carbono foram crescidos nas fibras dos feltros de carbono. Numa primeira amostra, houve a purificação desses nanotubos. A figura 5.14 mostra o comportamento do dispositivo FC/NTC-pur. 

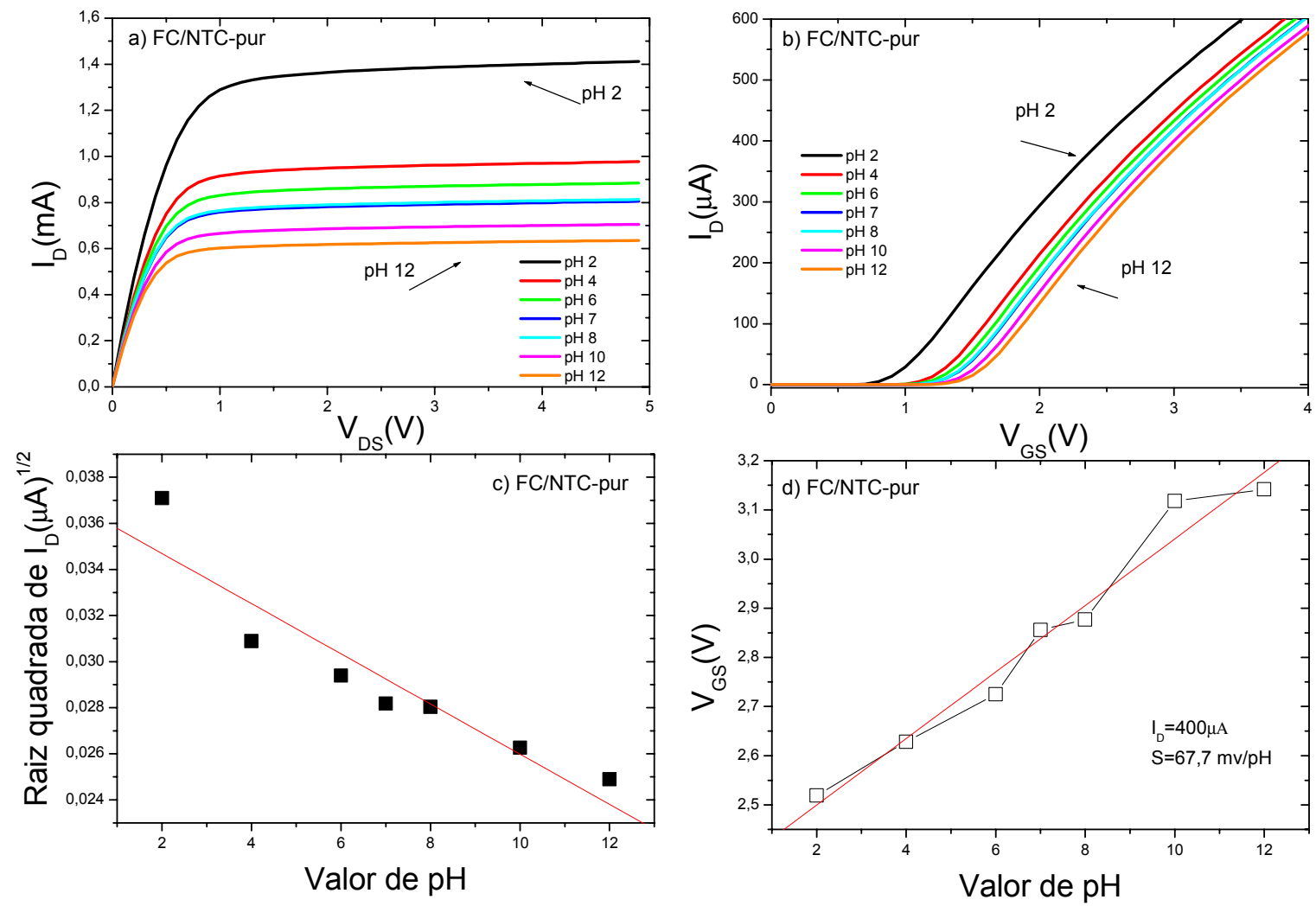

Figura 5.14: Curva da resposta do FC/NTC-pur como EGFET. Na figura é visto o EGFET operando na região de saturação (a) e na direita na região linear (b), com comportamento da raiz quadrada em funçao do $\mathrm{pH}$ (c) e da sensibilidade (d).

Observa-se nessa na figura 5.14 que a corrente relacionada ao $\mathrm{pH} 7 \mathrm{e} \mathrm{pH} 8$ praticamente se sobrepõe, ou seja, o dispositivo não consegue separar esses valores de pHs. Vemos que as correntes de dreno são separadas tendo o pH 2 com maior relevância.

A partir dos resultados apresentados por esses gráficos, podemos mostrar o comportamento linear da raiz quadrada da corrente em função do $\mathrm{pH}$, figura 
5.14-c, quando o dispositivo está operando na região saturação e a sensibilidade em função do $\mathrm{pH}$, figura 5.14-d.

É observado que a variação da raiz quadrada não se apresenta de forma muito linear, entretanto, a sensibilidade apresenta-se praticamente linear com um valor de $67,7 \mathrm{mV} / \mathrm{pH}$.

Esse resultado indica que os nanotubos crescidos nos feltros de carbono, colaboram de forma a aumentar a quantidade de sítios efetivos disponíveis para a interação com íon a ser medido.

Outra hipótese seria o fato da utilização de produtos químicos utilizados para remover os catalisadores, terem causado defeitos nas fibras de carbono e até mesmo nos nanotubos, favorecendo a interação com os íons a serem medidos.

A sensibilidade dessa amostra, $67,7 \mathrm{mV} / \mathrm{pH}$, está acima da sensibilidade apresentada por outros materiais utilizados como membranas sensíveis a íons de $\mathrm{H}^{+}$.

Numa outra amostra, não houve a purificação. A figura 5.15, mostra os resultados para os feltros de carbono, com nanotubos de carbonos crescidos em suas fibras, porem sem purificação.

É observado na figura 5.15, que há separação das correntes, sendo que a corrente relativa ao $\mathrm{pH} 4$ se superpôs ao $\mathrm{pH}$ 2. A separação entre as correntes também não foi suficiente para garantir uma boa sensibilidade. 

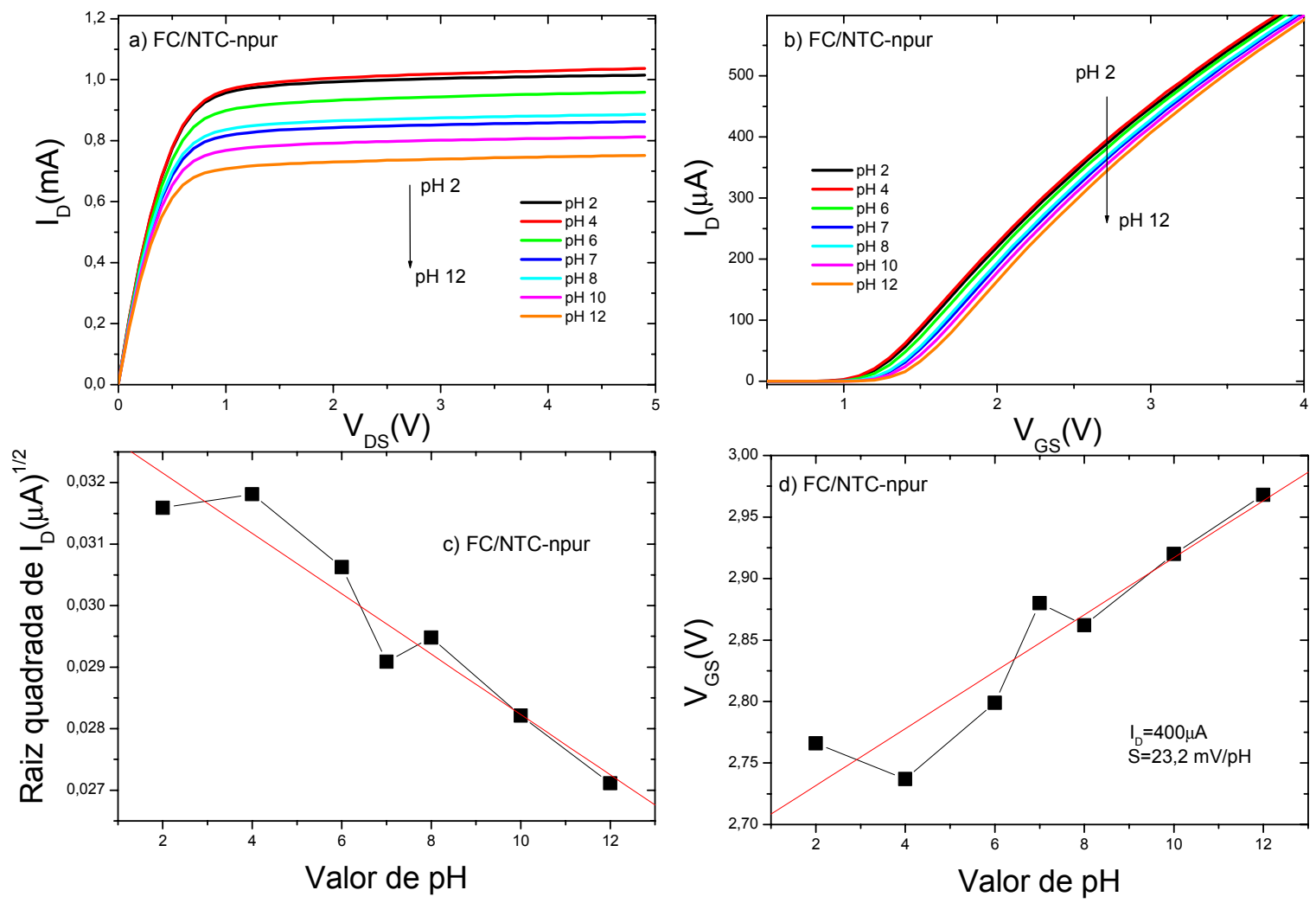

Figura 5.15: Curva da resposta do FC/NTC-npur como EGFET. Na figura é visto o EGFET operando na região de saturação (a) e na direita na região linear (b), com comportamento da raiz quadrada em funçao do $\mathrm{pH}$ (c) e da sensibilidade (d).

A intenção foi verificar a influência da purificação no processo de medida. Observa-se na figura 5.15 que a corrente relacionada aos pHs 2 e 4 estão muito próximas. Como conseqüência desse comportamento, a raiz quadrada da corrente na região saturada não mais se comporta de forma linear tendo alguns pHs não acompanhando o comportamento dos demais como é o caso do $\mathrm{pH} 4$ e 7, que foram os dois pHs que destoaram dos demais. 
Por sua vez, a sensibilidade também não foi linear tendo esses mesmos valores de pHs não acompanhando os demais tendo como valor de $23,2 \mathrm{mV} / \mathrm{pH}$, fazendo uma aproximação linear.

Dessa forma, vemos que a membrana com crescimento de nanotubos de carbono que sofreu purificação, teve um aumento na sensibilidade enquanto que aquela onde não houve purificação, a sensibilidade diminuiu de forma considerável além do fato de não responder linearmente à variação do pH.

A figura 5.16 mostra a estabilidade das correntes de dreno em função do tempo nas amostras FC/NTC-pur e FC/NTC-npur.
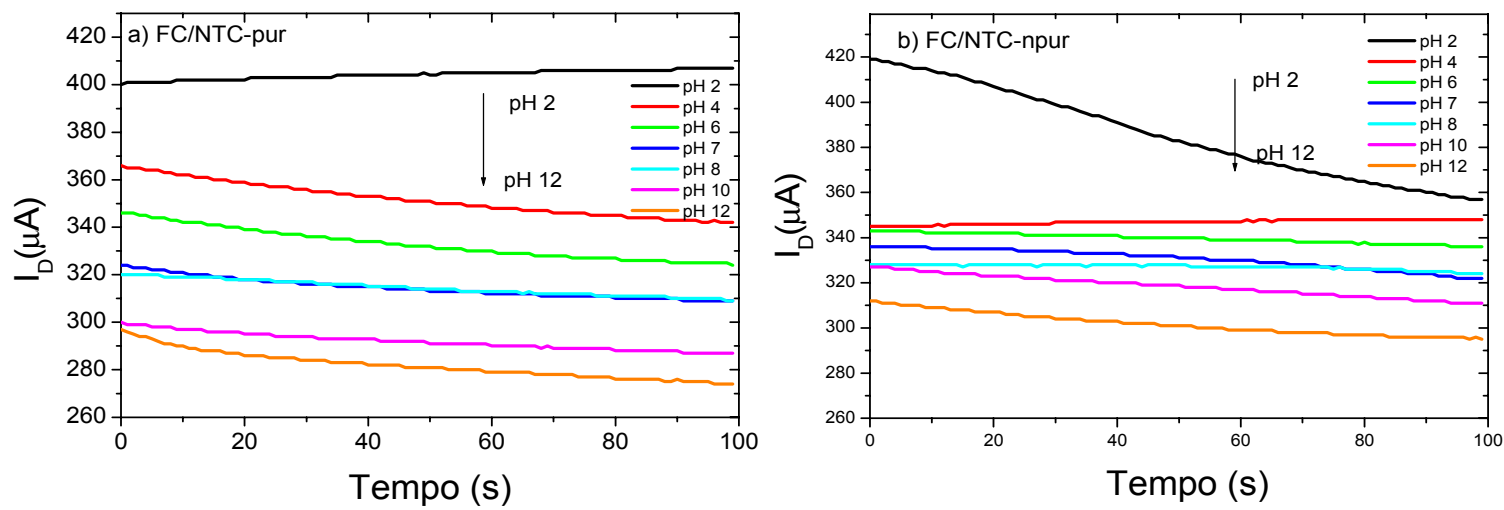

Figura 5.16: Curva da estabilidade do FC/NTC-pur (a) e do FC/NTC-npur (b)como EGFET.

A figura 5.16, permite observar que no inicio, há sobreposição de correntes nas duas amostras, FC/NTC-pur e FC/NTC-npur. Porém com o passar do tempo, as correntes de dreno da amostra FC/NTC-pur se separam e praticamente se estabilizam, enquanto que na amostra FC/NTC-npur, elas pouco se separam, o que contribui a para baixa sensibilidade. Note que em ambas amostras fica difícil a diferenciação dos pHs 7 e 8. 
Essa característica leva a crer que as "impurezas" presentes nas membranas, como os catalisadores, competem com sítios de ligação quando na medida de $\mathrm{pH}$, o que por outro lado, faz-nos perceber que as membranas purificadas, ou seja, livres desses catalisadores, possivelmente, exibem uma maior quantidade de sítios de ligação efetivos, como por exemplo os próprios nanotubos.

\subsection{2-A influência da polianilina}

Foram recobertas com polianilinas as fibras do feltro de carbono. Esses recobrimentos ocorreram também nas membranas com crescimento de nanotubos tanto aquelas purificadas quanto não purificadas. O recobrimento ocorreu, como dito anteriormente, pelo método químico e em dois estados: protonado e deprotonado.

Na figura 5.17 observa-se o comportamento da corrente em função da variação do $\mathrm{pH}$ na membrana FC/NTC-pur/Pani-pro, notando que na região saturada há uma boa separação da corrente em função do pH, exceto os pHs 10 e 12 que não corresponderam ao esperado.

Esse comportamento pode ser visto na figura 5.17-c, onde mostra a raiz

quadrada em função da variação de pH. Na região linear, figura 5.17-b, houve a separação das correntes em função da variação do pH, porém, os pHs 10 e 12 também não variaram seguindo os demais, o que pode ser visto na figura 5.17-d quando se calcula a sensibilidade, que está em torno de $34,1 \mathrm{mV} / \mathrm{pH}$. 
Observa-se que quando se recobre as fibras de feltro de carbono com polianilina, melhora-se a linearidade da raiz quadrada da corrente de dreno em função do $\mathrm{pH}$, assim como a variação da sensibilidade. Porém essa mudança não foi suficiente para aumentar a sensibilidade. Aumentou, com relação a amostra FC/NTC-npur, mas ainda é pouco quando comparado com a amostra FC/NTC-pur.
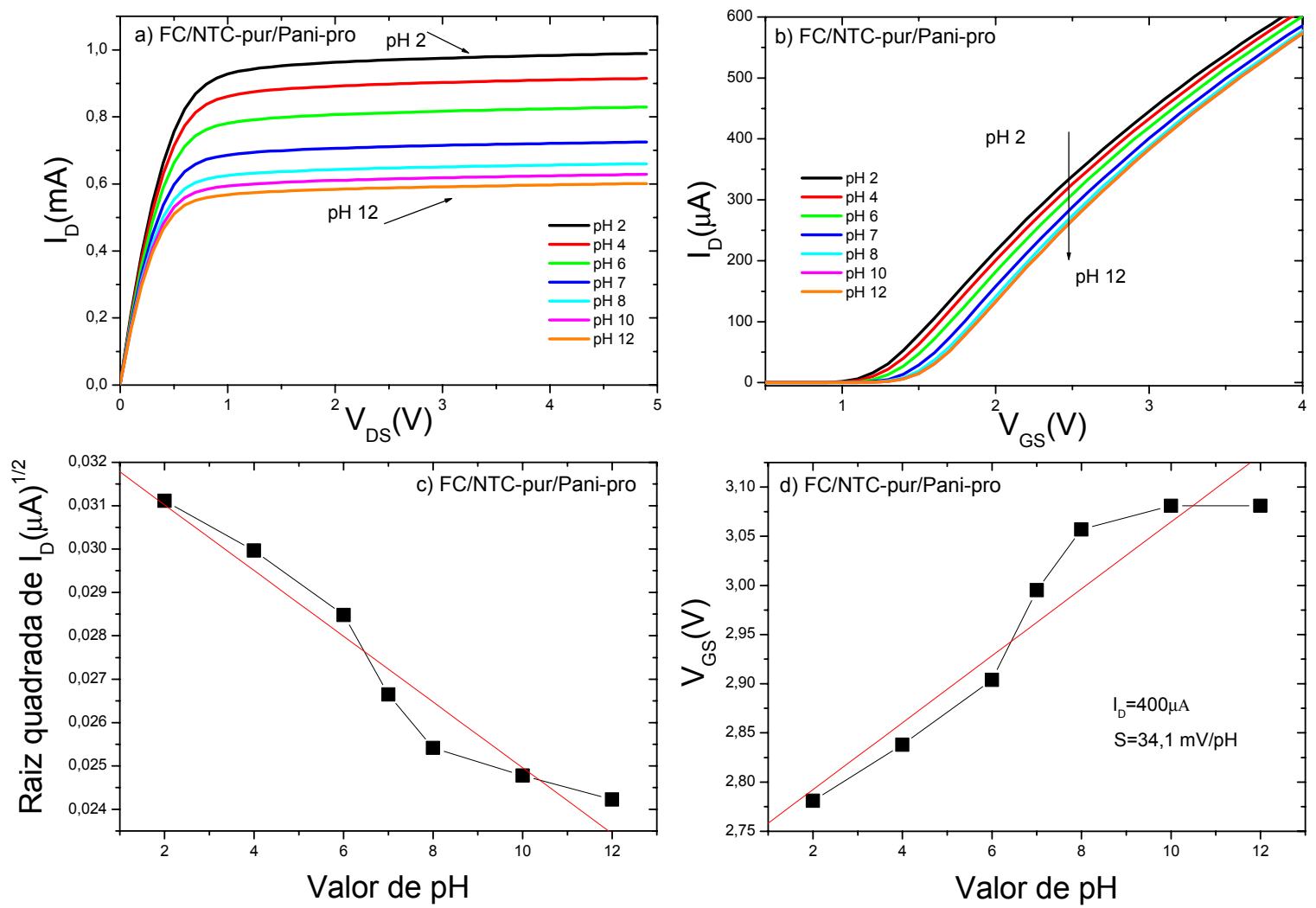

Figura 5.17: Curva da resposta do FC/NTC-pur/Pani-pro como EGFET. Na figura é visto o EGFET operando na região de saturação (a) e na direita na região linear (b), com comportamento da raiz quadrada em funçao do $\mathrm{pH}$ (c) e da sensibilidade (d).

A figura 5.18, mostra o comportamento da amostra FC/NTC-npur quando se recobre esse material com a polianilina. 
A polianilina no estado deprotonado, FC/NTC-pur/Pani-depro, teve um comportamento melhor do que aquela no estado protonado, FC/NTC-pur/Pani-pro. Esse comportamento pode ser observado na região saturada e não saturada, vistos na figura 5.18-a e 5.18-b.
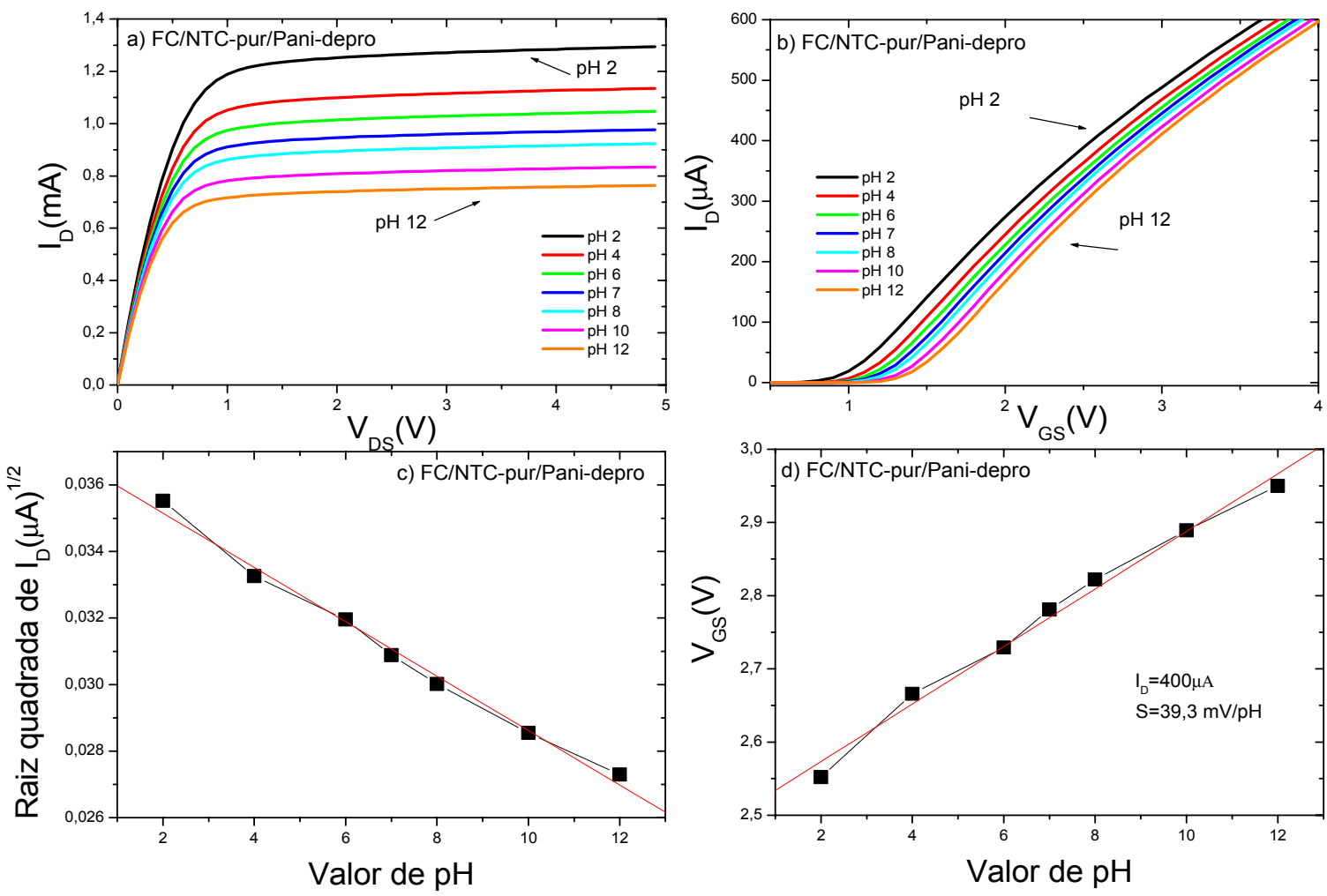

Figura 5.18: Curva da resposta do FC/NTC-pur/Pani-depro como EGFET. Na figura é visto o EGFET operando na região de saturação (a) e na direita na região linear (b), com comportamento da raiz quadrada em funçao do $\mathrm{pH}$ (c) e da sensibilidade (d).

A partir dos dados obtidos desta figura, verificamos que a raiz quadrada da corrente varia linearmente com o $\mathrm{pH}$, figura 5.18-c, resultado melhor do que aquele no estado protonado, e que a sensibilidade, figura 5.18-d, apesar de ser 
baixa é melhor, e se comporta de forma linear em todos os pHs em torno de 39,3 $\mathrm{mV} / \mathrm{pH}$.

O comportamento das correntes de dreno com o tempo, pode ser visto na figura 5.19. Nessa figura, observa que, começa e termina sem grandes oscilações, com separações entre as correntes. Esse comportamento mostra que tanto a amostra FC/NTC-pur/Pani-pro é mais estável que a FC/NTC-pur/Pani-depro, entretanto, essa variação é acompanhada por todos os pHs. Isso é uma boa característica, ou seja, é uniforme a variação, mantendo a separação.
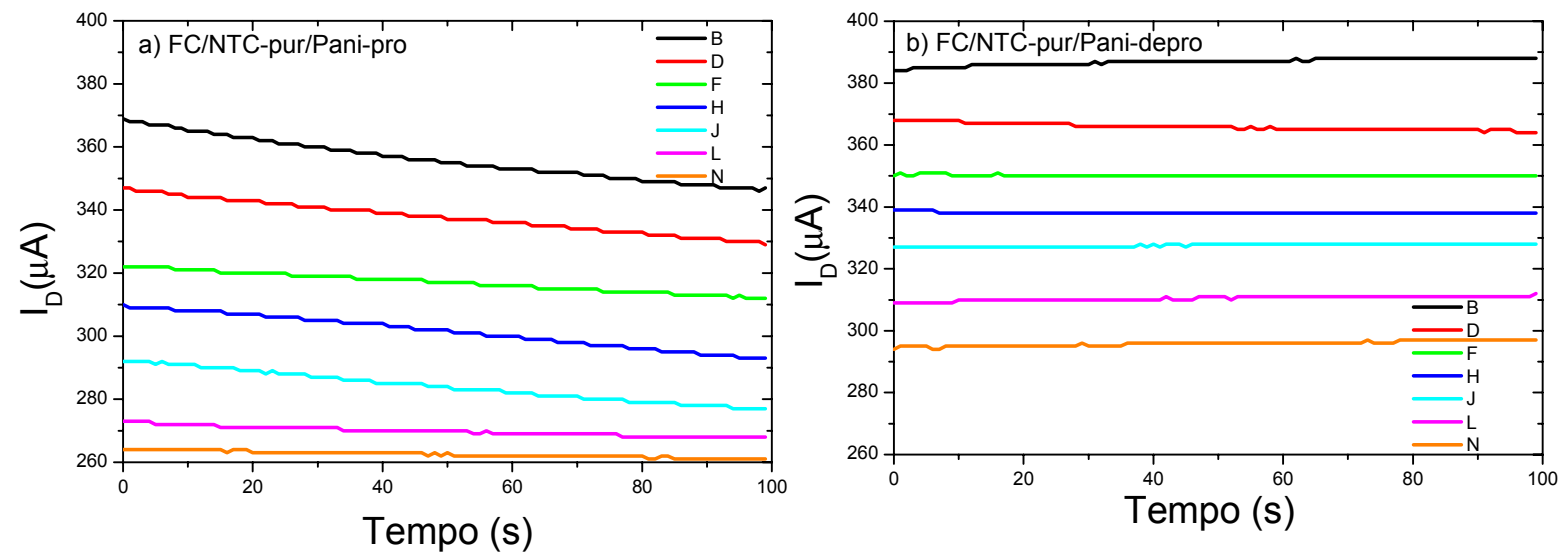

Figura 5.19: Curva da estabilidade do FC/NTC-pur/Pani-pro (a) e do FC/NTC-pur/Panidepro (b)como EGFET.

O mesmo procedimento foi realizado nas membranas onde após o crescimento dos nanotubos, não foram purificadas, FC/NTC-npur/Pani em ambos os estados, protonado e deprotonado.

Na figura 5.20 é visto o comportamento da membrana FC/NTC-npur/Panipro. Observa-se nessa figura que nos pHs 4 e 6, na região de saturação, figura 
5.20-a, houve pouca separação, ou seja, pouca identificação do valor de $\mathrm{pH}$. Comportamento semelhante é observado na região de não saturação, figura 5.20b, com um fator agravante que não houve separação suficiente nos pHs básicos. Com os dados da figura 5.20-b, calculamos a sensibilidade e o comportamento da raiz quadrada da corrente em função da variação do $\mathrm{pH}$, o que pode ser visto na figura $5.20-c$ e 5.20-d.
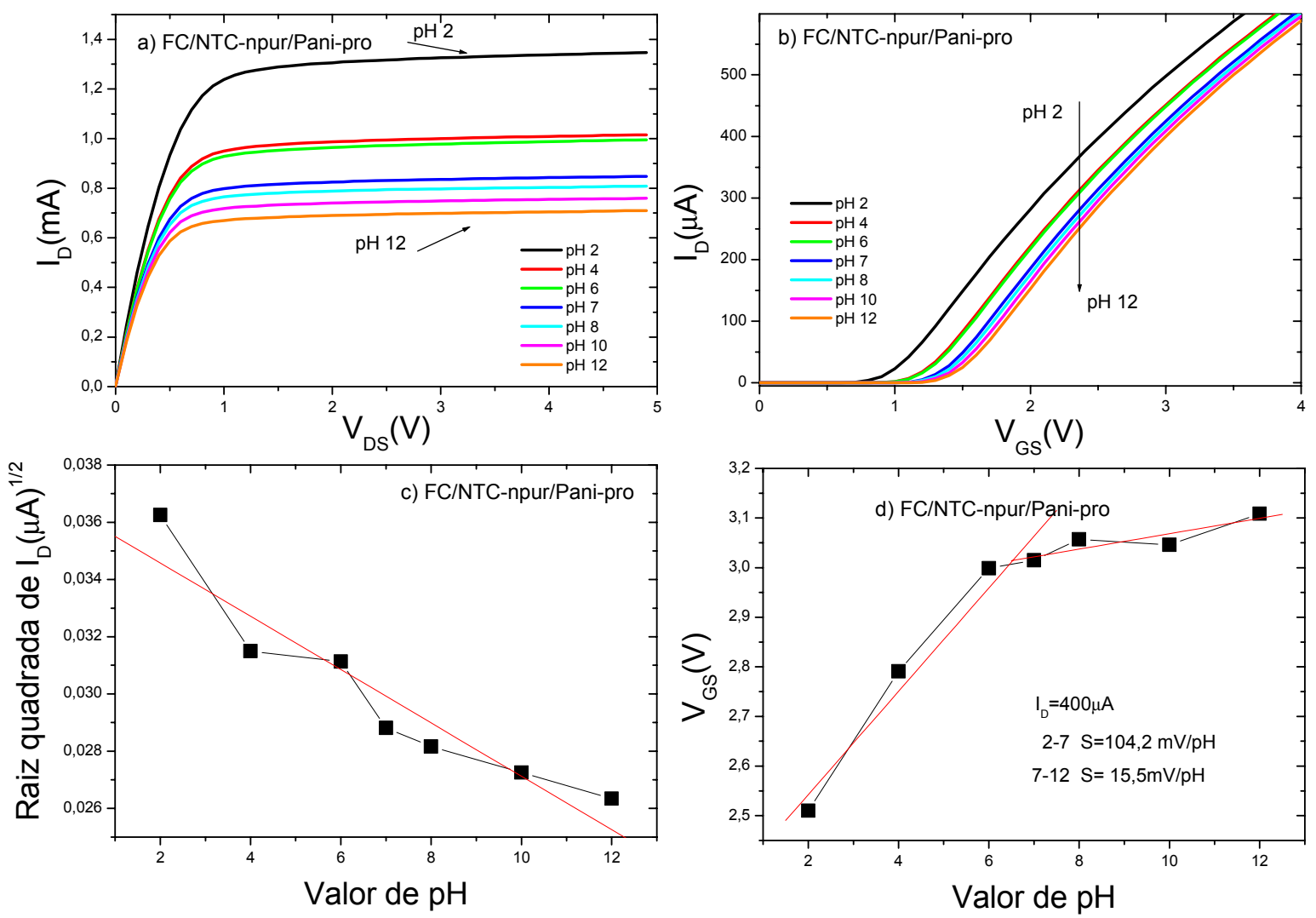

Figura 5.20: Curva da resposta do FC/NTC-npur/Pani-pro como EGFET. Na figura é visto o EGFET operando na região de saturação (a) e na direita na região linear (b), com comportamento da raiz quadrada em funçao do $\mathrm{pH}$ (c) e da sensibilidade (d). 
Observa-se na figura 5.20, que a raiz quadrada da corrente não se comporta de forma linear com relação a variação do $\mathrm{pH}$, o que mostra que a separação entre as curvas, ou seja, separação dos pHs na região de não saturação não é uniforme.

A sensibilidade por sua vez, apresenta comportamento separado em duas partes. Entre os pHs 2 a 7, soluções ácidas, a linearidade obtida, ou seja a sensibilidade, foi da ordem de $104,2 \mathrm{mV} / \mathrm{pH}$, enquanto que entre os pHs 7 a 12 , soluções básicas, a sensibilidade foi da ordem de $15,5 \mathrm{mV} / \mathrm{pH}$.

Por sua vez, a membrana FC/NTC-npur/Pani-depro também não apresentou um bom desempenho como membrana sensível a íons, visto que não conseguiu separar os pHs 6,7 e 8. A figura 5.21 mostra o comportamento dessa membrana.

A figura 5.21-d mostra o comportamento da raiz quadrada da corrente e a sensibilidade, figura 5.21-d, com os dados obtidos da figura anterior. Nessa figura, fica evidente que os pHs centrais estão praticamente sobrepostos, mostrando um comportamento não linear da raiz quadrada da corrente em função da variação do $\mathrm{pH}$, região de saturação e que a sensibilidade apresenta como a membrana anterior, ou seja, a PANi no estado protonado, dois comportamentos diferentes, um na solução ácida e outro na básica. Entre os pHs 2 a 7, solução ácida, a sensibilidade ficou em torno de 45,3 mV/pH enquanto que na solução básica, entre os pHs 7 a 12, a sensibilidade foi da ordem de $20,3 \mathrm{mV} / \mathrm{pH}$.

A estabilidade da corrente com o tempo nas amostras FC/NTC-npur/Panipro e FC/NTC-npur/Pani-depro, podem ser vistos na figura 5.22. 

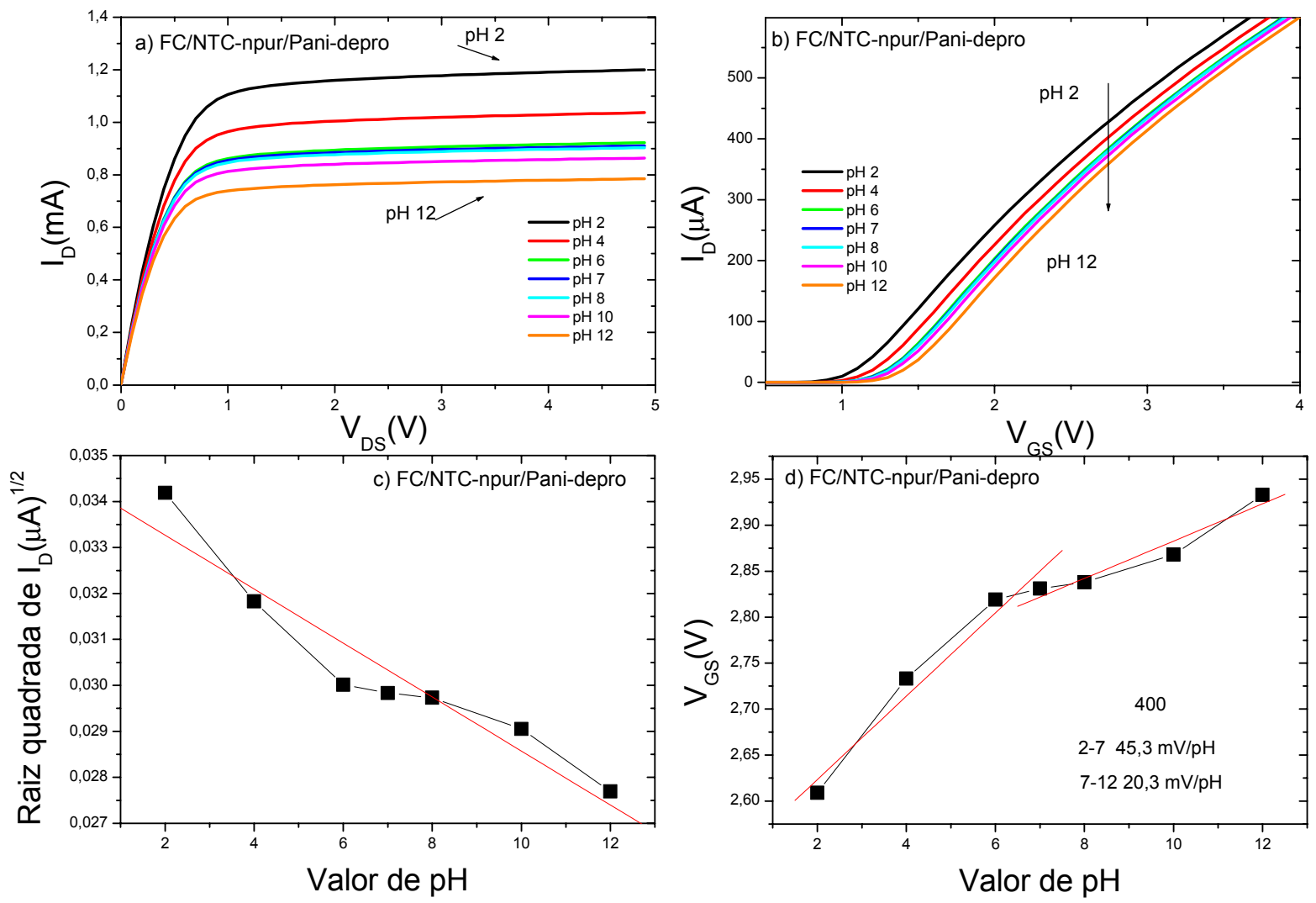

Figura 5.21: Curva da resposta do FC/NTC-npur/Pani-depro como EGFET. Na figura é visto o EGFET operando na região de saturação (a) e na direita na região linear (b), com comportamento da raiz quadrada em funçao do $\mathrm{pH}$ (c) e da sensibilidade (d).
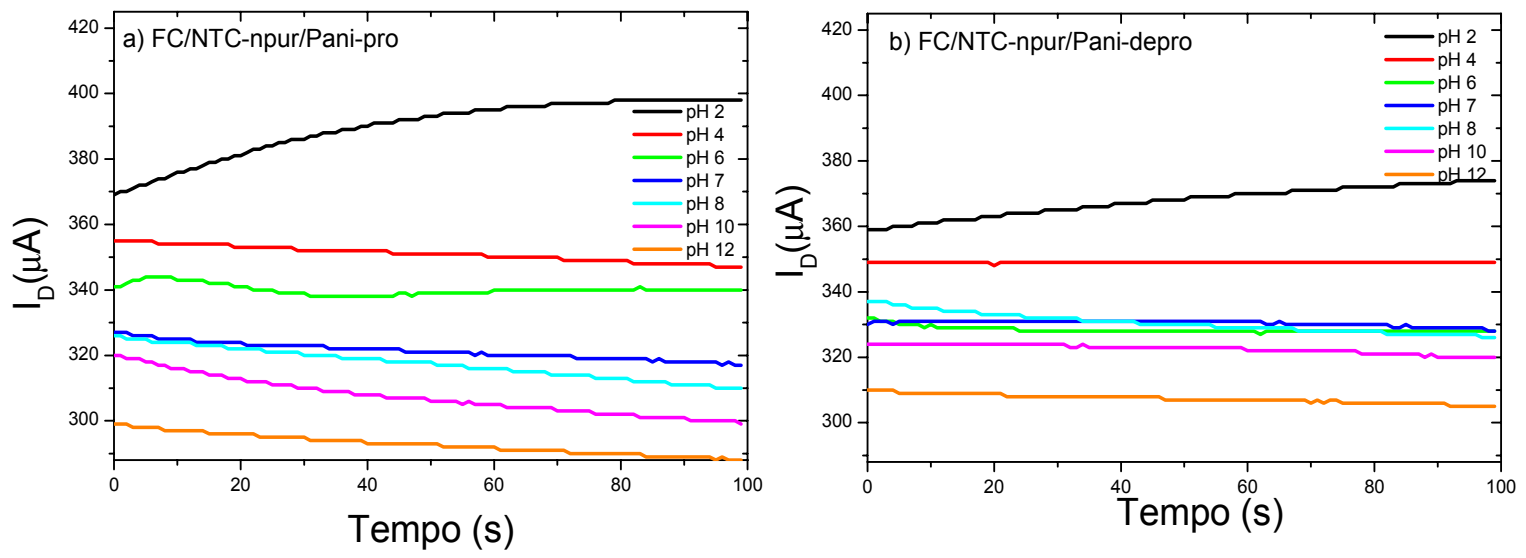

Figura 5.22: Curva da estabilidade do FC/NTC-npur/Pani-pro (a) e do FC/NTC-npur/Panidepro (b)como EGFET. 
Como pode ser visto na figura, as correntes de dreno começam separadas e terminam ainda mais separadas. Na amostra FC/NTC-npur/Pani-pro, a corrente tende a ser menos estável que na outra amostra, FC/NTC-npur/Pani-depro. Mesmo essa separação e essa estabilidade não foram suficientes para garantir uma sensibilidade e linearidade desejada.

Na figura 5.23, podem ser vistas as curvas da amostra FC/Pani-pro.
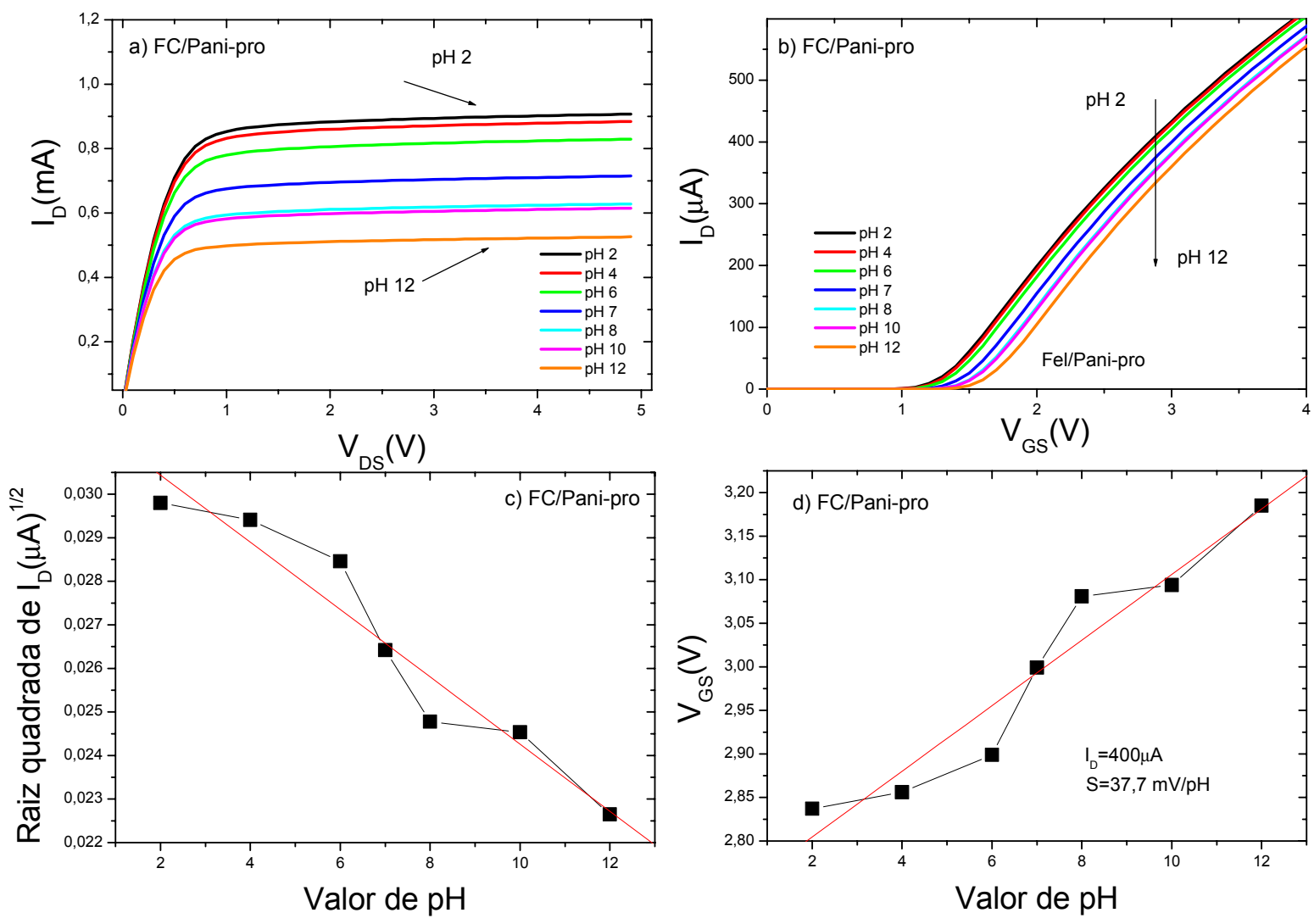

Figura 5.23: Curva da resposta do FC/Pani-pro como EGFET. Na figura é visto o EGFET operando na região de saturação (a) e na direita na região linear (b), com comportamento da raiz quadrada em funçao do $\mathrm{pH}$ (c) e da sensibilidade (d). 
Pode-se observar nessa figura que as correntes de dreno são separadas quando opera-se na região de saturação e de não saturação, figura 5.23-a e 5.23b. No que diz respeito à linearidade, tanto a linearidade da raiz quadrada da corrente de dreno em função do $\mathrm{pH}$, figura 5.23-c, quanto à sensibilidade, figura 5.23-d, apresentam alguns desvios. A sensibilidade nesse dispositivo foi de 37,7 $\mathrm{mV} / \mathrm{pH}$, ou seja, uma baixa linearidade.

A polianilina na sua forma deprotonada junto com o feltro também foi analisada, e as curvas correspondentes desse dispositivo podem se vistas na figura 5.24.
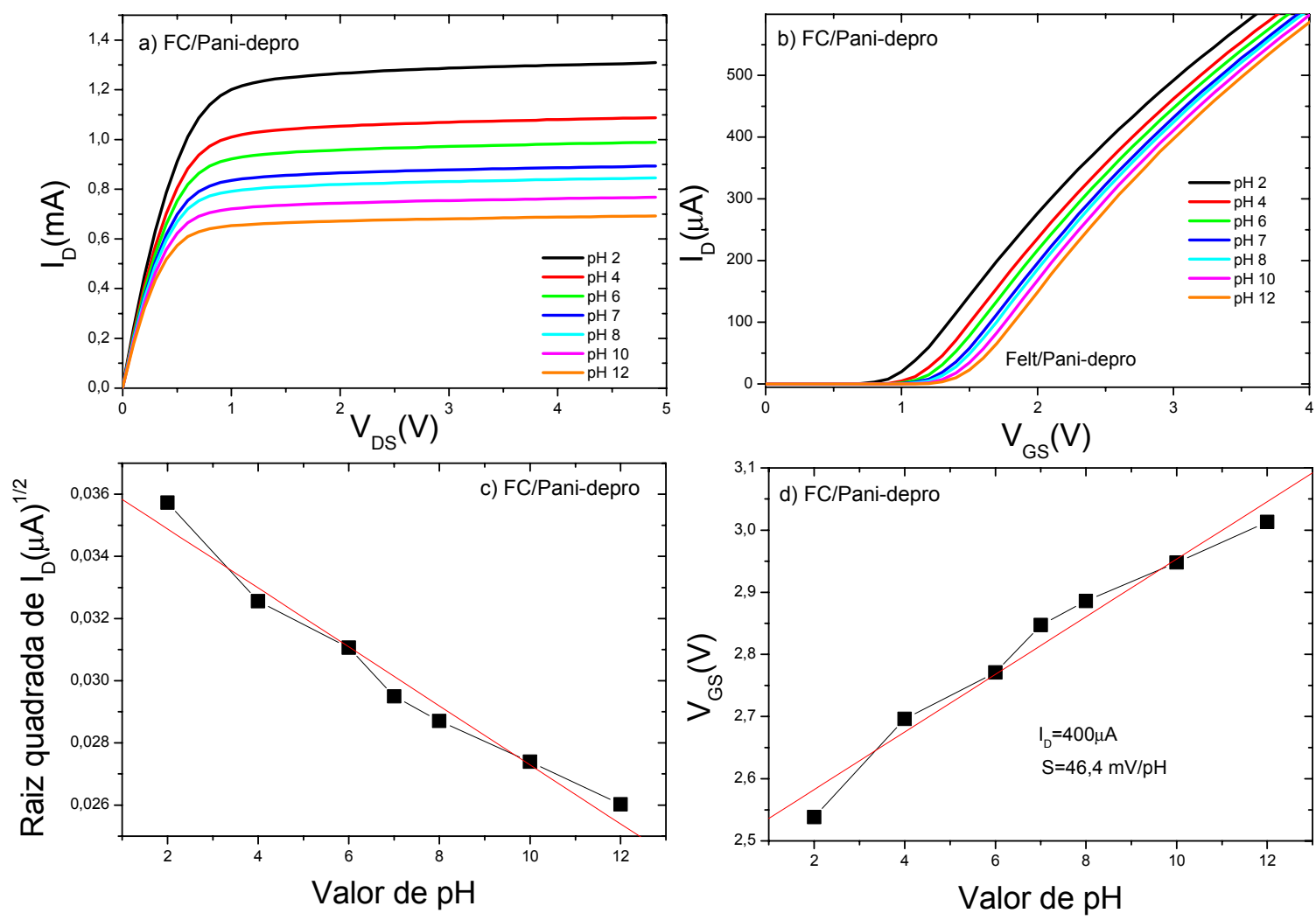

Figura 5.24: Curva da resposta do FC/Pani-depro como EGFET. Na figura é visto o EGFET operando na região de saturação (a) e na direita na região linear (b), com comportamento da raiz quadrada em funçao do $\mathrm{pH}$ (c) e da sensibilidade (d). 
Observa-se pela figura 5.24, que há separação de curvas tanto na região saturada, figura 5.24-a, quanto na região não saturada, figura 5.24-b. Há uma linearidade da raiz quadrada da corrente de dreno em função do $\mathrm{pH}$ assim como a curva que mostra a sensibilidade, figuras 5.24-c e 5.24-d, respectivamente.

A estabilidade da corrente de dreno em função do tempo, foi analisada para as duas amostras FC/Pani-pro e FC/Pani-depro, mostradas na figura 5.25.
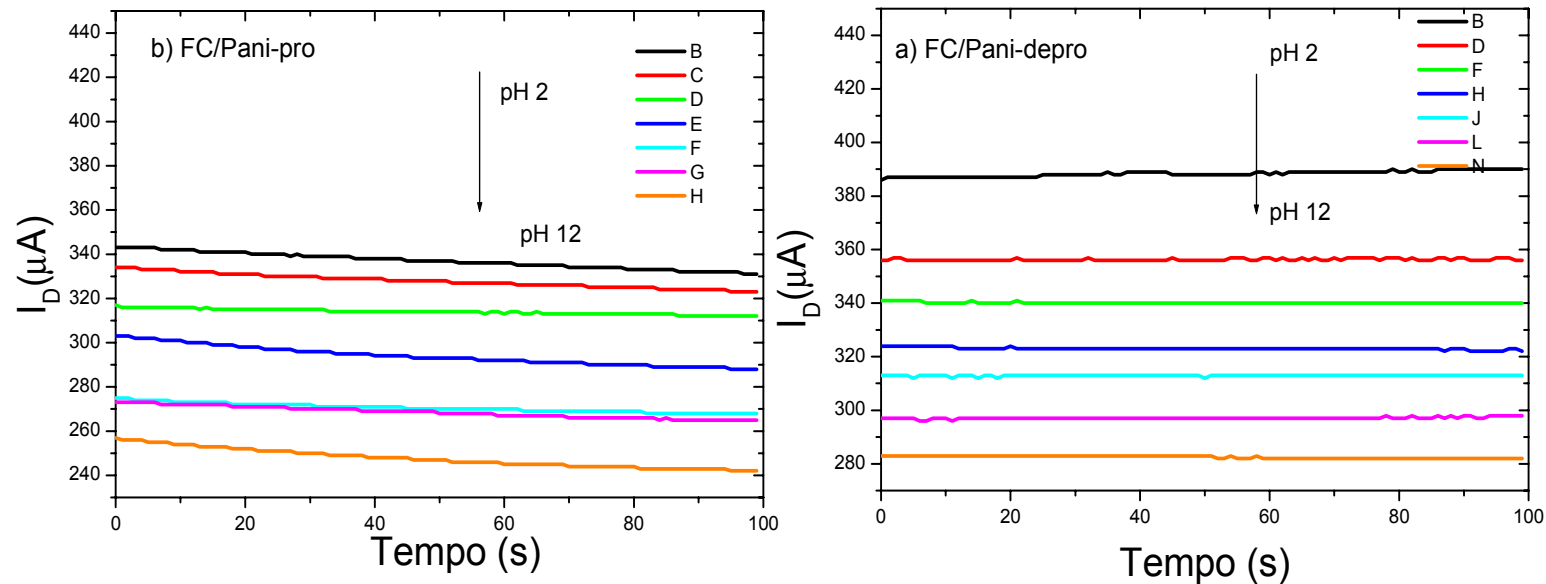

Figura 5.25: Curva da estabilidade do FC/Pani-depro (a) e do FC/Pani-pro (b)como EGFET.

$\mathrm{Na}$ figura 5.25, pode ser observado, que a amostra FC/Pani-depro, separa as correntes de dreno em função do tempo, mantendo uma ótima estabilidade, enquanto que a amostra FC/Pani-pro, não consegue separar as correntes de dreno, referente aos pHs 8 e 10, mas tem também boa estabilidade.

A polianilina tanto no seu estado protonado quanto no estado deprotonado, não apresentou uma boa solução para dispositivo sensível a $\mathrm{H}^{+}$da forma como foi recoberto nas fibras do feltro. Pode ser que quando a Pani recobre o feltro ou o 
feltro/nanotubos, ela impeça que muitos sítios se liguem nos íons a serem medidos e isso prejudicaria a adsorção e conseqüentemente a detecção.

Analisando todos os resultados, podemos fazer um resumo do que foi observado, na tabela abaixo.

Tabela 5.1: Desempenho dos dispositivos em relação a sua constituição.

\begin{tabular}{|c|c|c|}
\hline & Material & Sensibilidade \\
\hline & FC & $65,5 \mathrm{mV} / \mathrm{pH}$ \\
\hline \multirow{2}{*}{$\begin{array}{l}\text { Influência dos } \\
\text { nanotubos FC }\end{array}$} & FC/NTC-pur & $67,7 \mathrm{mV} / \mathrm{pH}$ \\
\hline & FC/NTC-npur & $23,2 \mathrm{mV} / \mathrm{pH}$ (pouca linearidade) \\
\hline \multirow{2}{*}{$\begin{array}{l}\text { Influência da Pani } \\
\text { nos FC/NTC-pur }\end{array}$} & FC/NTC-pur/Pani-pro & $34,1 \mathrm{mV} / \mathrm{pH} \quad$ (pouca linearidade) \\
\hline & FC/NTC-pur/Pani-depro & $39,3 \mathrm{mV} / \mathrm{pH}$ \\
\hline \multirow{2}{*}{$\begin{array}{l}\text { Influência da Pani } \\
\text { nos FC/NTC-npur }\end{array}$} & FC/NTC-npur/Pani-pro & $\begin{array}{ll}104,2 \mathrm{mV} / \mathrm{pH} & (\mathrm{pH} \text { de } 2-7) \\
15,5 \mathrm{mV} / \mathrm{pH} & (\mathrm{pH} \text { de } 7-12)\end{array}$ \\
\hline & FC/NTC-npur/Pani-depro & $\begin{array}{ll}45,3 \mathrm{mV} / \mathrm{pH} & (\mathrm{pH} \text { de } 2-7) \\
20,3 \mathrm{mV} / \mathrm{pH} & (\mathrm{pH} \text { de } 2-7)\end{array}$ \\
\hline \multirow{2}{*}{$\begin{array}{c}\text { Influência da Pani } \\
\text { nos FC }\end{array}$} & FC/Pani-pro & $37,7 \mathrm{mV} / \mathrm{pH}$ \\
\hline & FC/Pani-depro & $46,4 \mathrm{mV} / \mathrm{pH}$ \\
\hline
\end{tabular}

Quando se mede apenas com o feltro, tem-se uma boa separação de das correntes de dreno; a intensidade da corrente de dreno na região de saturação é alta; a raiz quadrada da corrente de dreno varia de forma linear com o $\mathrm{pH}$; e a sensibilidade também é linear e alta de $65,47 \mathrm{mV} / \mathrm{pH}$. 
Quando se introduz os NTC na forma purificada, notamos que há separação de curvas, porém, as intensidades diminuem; a variação da raiz quadrada da corrente de dreno não é muito linear; a sensibilidade por sua vez e linear e maior, de $67,7 \mathrm{mV} / \mathrm{pH}$.

Quando introduz os NTC sem purificação, notamos que há sobreposição de correntes de dreno; a raiz quadrada da corrente de dreno deixa de ser linear; assim como a sensibilidade, que diminui para $23,2 \mathrm{mV} / \mathrm{pH}$. Assim, o papel da purificação dos NTC, segundo nossos testes preliminares, é fundamental.

Quando se introduz a Pani no seu estado protonado na conjunto FC/NTCpur, notamos que há separação de correntes de dreno, que já havia antes; a raiz quadrada da corrente de dreno varia de forma linear, pouco melhor do que sem a introdução a Pani; a sensibilidade é praticamente linear, como antes da introdução Pani; e o valor da sensibilidade foi $34,1 \mathrm{mV} / \mathrm{pH}$, bem menor do que antes da introdução da Pani.

Quando se introduz a Pani no seu estado deprotonado no conjutno FC/NTC-pur, esse conjunto apresenta praticamente as mesmas características quando a Pani-pro foi introduzida, sem muita diferença.

Quando se introduz a Pani no seu estado protonado no conjunto FC/NTCnpur, não há muita diferença da amostra sem a Pani. A maior diferença está no aparecimento de comportamentos diferentes. Do $\mathrm{pH} 2$ até $\mathrm{pH} 7$ e outro do $\mathrm{pH} 7$ até $\mathrm{pH} 12$.

Quando se introduz a Pani no seu estado deprotonado no conjunto FC/NTC-npur, o conjunto apresenta o mesmo comportamento daquele quando da 
introdução da Pani no estado protonado. Aparecendo dois comportamentos distintos. Uma para soluções ácidas e outro para soluções básicas.

Quando se introduz a Pani no estado protonado no feltro puro, o resultado é pior do que antes da introdução. A linearidade fica prejudicada e diminui a sensibilidade.

Por sua vez, quando se introduz a Pani no estado deprotonado, no feltro puro, o resultado é melhor do que a amostra com a Pani no estado protonado. Há separação das correntes de dreno e elas são lineares, e a sensibilidade aumentou, porém ainda é menor que a sensibilidade do feltro puro. A Pani também diminui as oscilações da corrente de dreno, tornando as amostras mais estáveis.

O comportamento, quando se coloca os NTC, é dominado por esses. Os nanotubos purificados responderam melhor do que aqueles sem purificar.

Duas hipóteses para tentar explicar o comportamento. Primeira hipótese: os catalisadores atrapalham as medidas, impedido que os íons se liguem nos feltros e também nos NTC; segunda hipótese, com a purificação, o uso de ácidos faz com que crie sítios de ligação, que de certa forma seria como que uma funcionalização, facilitando a interação dos íons com os feltros e NTC.

\section{6-Conclusão}

Nesse capitulo, foram apresentados os resultados preliminares como membranas seletivas de íons de $\mathrm{H}^{+}$a partir do FC e FC com nanotubos e polianilina. 
Segundo os dados desse capítulo, podemos chegar a algumas conclusões. O feltro puro é um bom sensor e ainda pode ser usado como substrato para outros materiais. Quando se coloca nanotubos de carbono nas fibras do feltro, as membranas purificadas (FC/NTC-pur) são melhores do que aquelas que não foram purificadas (FC/NTC-npur). A membrana FC/NTC-pur melhorou a sensibilidade do dispositivo. Essa sensibilidade foi de $67,7 \mathrm{mV} / \mathrm{pH}$, não conseguida por nenhum material ainda. Quando se recobre os feltro com a Pani, seja com feltros puros quanto com feltros/nanotubos, a Pani no estado deprotonado responde melhor do no estado protonado. O feltro puro é mais estável no tempo que o feltro em combinação com qualquer outro material.

Foi constatado que o feltro tem um potencial para ser utilizado como membrana seletiva. Vale lembrar que as características dos feltros variam em função de alguns parâmetros. As propriedades micro-estruturais dos feltros são fortemente afetadas pela temperatura de produção, que influencia, por sua vez, o crescimento e nucleação de outros materiais em sua superfície. Somando-se a isso, a temperatura de produção influencia a propriedade elétrica, porque há um aumento da orientação preferencial das camadas de grafites das fibras na direção axial quando produzido em alta temperatura.

Uma das dificuldades apresentadas por outros materiais, como apresentado nos capítulos anteriores, é o isolamento do substrato para que esse não interfira nas medidas. Uma das saídas para esse problema específico, foi a utilização de substratos isolantes, ou pouco condutores.

Nesse caso, isso não é problema, pois o feltro, que serve como substrato para outros materiais, também já é a própria membrana seletiva. A incorporação 
dos nanotubos em suas fibras, foi uma alternativa. Os resultados apresentados responderam de forma um pouco tímida ao esperado, pois com a introdução de nanotubos em suas fibras, acredita-se, que aumentou o número de sítios que poderiam servir para adsorção do íon a ser medido e com isso a sensibilidade seria maior.

A sensibilidade foi maior na membrana Felt/Ntc-pur, porém o aumento foi mínimo.

Vimos, também, que os materiais necessários para o crescimento dos nanotubos, precisam ser purificados, já que estes interferem nos resultados, diminuindo e muito, a sensibilidade como a membrana Felt/Ntc-npur.

Com a introdução da polianilina, não houve mudanças significativas nas sensibilidades.

Em algumas amostras, a membrana teve um comportamento diferente entre a solução ácida e a solução básica. Isso faz com que o comportamento não ficasse linear e a sensibilidade ficasse prejudicada. 


\section{6}

\section{Conclusão}

Ao longo do texto, durante o desenvolvimento do trabalho, apresentamos o projeto, a fabricação e a caracterização de dispositivos para serem utilizados como sensores de $\mathrm{pH}$, utilizando o princípio de efeito de campo. O primeiro dispositivo desenvolvido, como membrana seletiva, foi com base no óxido de manganês. O segundo dispositivo foi através da utilização dos nanotubos de carbono como membrana seletiva e por último, o feltro de carbono, que além de servir como membrana seletiva, serviu também como substrato para os nanotubos de carbono e a polianilina.

Esse trabalho esteve focado no desenvolvimento do EGFET a partir do óxido de manganês, nanotubos de carbono e feltro de carbono. Buscou-se utilizar técnicas e métodos de produção de filmes finos, com características de baixo custo quando comparados a métodos tradicionais de preparação de filmes finos. Além disso, como sensor de íons, o EGFET tem a vantagem de evitar etapas de 
construção, que estariam relacionadas com a produção do ISFET - que seriam dispendiosas -, dessa forma, fazendo o uso de um MOSFET comercial.

Na primeira parte utilizou-se o óxido de manganês produzido pelo método hidrotérmico. Esse método mostrou-se eficiente e barato na produção de nanomateriais. Tentou-se a produção de filmes finos com três concentrações, 1g/l, $2 \mathrm{~g} / \mathrm{l}$ e $3 \mathrm{~g} / \mathrm{l}$; e com duas temperaturas diferentes de deposição, $80^{\circ} \mathrm{C}$ e $100^{\circ} \mathrm{C}$ e em dois substratos, vidro liso e rugoso, através da técnica de spray-pyrolysis. Os filmes com concentrações de $1 \mathrm{~g} / \mathrm{l}$ e $3 \mathrm{~g} / \mathrm{l}$ não responderam de forma satisfatória. $\mathrm{O}$ primeiro devido à má formação do filme, pouca espessura e pobre homogeneidade. O segundo, o 3g/l, com pouca adesão ao substrato, soltando no ato da medida. Apenas os filmes produzidos com concentração de $2 \mathrm{~g} / \mathrm{l}$ e com temperatura de deposição de $80^{\circ} \mathrm{C}$, foram aqueles que responderam a variação do $\mathrm{pH}$. Desses filmes, o depositado no substrato de vidro rugoso, teve uma sensibilidade de 50,1 mV/pH, com pouca distinção dos $\mathrm{pHs} 10$ e 12 . O filme depositado sobre o vidro liso, teve uma sensibilidade de $75 \mathrm{mV} / \mathrm{pH}$, com pouca distinção dos pHs 6 e 7, porém com valor acima das sensibilidades registradas por muitos óxidos, mostrando ser um material promissor e alternativo, entretanto, necessitando de mais estudos.

A segunda parte surgiu com continuidade da primeira por utilizar uma outra nanoestrutura, os nanotubos de carbono. Os nanotubos foram crescidos pelo método de CVD e os filmes finos depositados também por spray-pyrolysis, em concentrações de $1 \mathrm{~g} / \mathrm{l}$ e $3 \mathrm{~g} / \mathrm{l}$, temperaturas de deposição de $80^{\circ}$ e $100^{\circ} \mathrm{C}$, em substratos de vidro liso e rugoso. Os filmes depositados com concentração de 1g/l não responderam de forma satisfatória. Uma hipótese, seria a má qualidade dos 
filmes formados. Os filmes que apresentaram uma boa sensibilidade em toda faixa de $\mathrm{pH}$ foram aqueles depositados: a $80^{\circ} \mathrm{C}$, em substrato rugoso com concentração de $3 \mathrm{~g} / \mathrm{l}$, com sensibilidade de $51,6 \mathrm{mV} / \mathrm{pH}$; e a $100^{\circ} \mathrm{C}$, em substrato liso, também com 3g/l, com sensibilidade de $53,1 \mathrm{mV} / \mathrm{pH}$. Esses filmes apresentam sensibilidades muito boas comparadas a alguns materiais como $\mathrm{SnO}_{2}$ e a-BCxNy, com sensibilidades de $50 \mathrm{mV} / \mathrm{pH}$ e $46 \mathrm{mV} / \mathrm{pH}$, respectivamente, ambos produzidos por sputtering, alem do fato de que apresentam possibilidades para serem usados como biossensores.

Por fim, na terceira parte, foi apresentado a utilização dos feltros de carbono, a base da PAN, como membrana seletiva e também como substrato para os nanotubos de carbono e a polianilina. Os feltros apresentaram uma alta sensibilidade, de $65,47 \mathrm{mV} / \mathrm{pH}$, com linearidade em toda faixa de $\mathrm{pH}$ com estabilidade da corrente de dreno, apresentando-se como alternativa como membrana seletiva. Em suas fibras, foram crescidos nanotubos de carbono. Uma parte dessas membranas foi purificada e a outra ficou sem purificação. A influência dos nanotubos foi que aquela parte que não foi purificada, prejudicou a sensibilidade, diminuindo-a, enquanto que, a parte que foi purificada, teve um ligeiro aumento na sensibilidade, sendo de $67,7 \mathrm{mV} / \mathrm{pH}$. Houve o recobrimento do feltro puro e do feltro com nanotubos, com a polianilina. Por sua vez, quando se introduz a Pani, a estabilidade das correntes aumenta. A introdução da Pani no estado deprotonado, no feltro puro, teve melhor resultado do que a amostra com a Pani no estado protonado. A melhor sensibilidade obtida com a Pani presente foi de $46,4 \mathrm{mV} / \mathrm{pH}$, que não é tão ruim assim, mas inferior a sensibilidade do feltro puro e do feltro com nanotubos de carbono com purificação. 
Com isso, podemos chegar a algumas conclusões. Os melhores materiais que observados nesse trabalho foi o óxido de manganês, com uma ótima sensibilidade, porém, necessita de otimização do processo de produção da membrana, ou seja, produção do óxido e do filme fino para se ter reprodutibilidade; e o outro material é o feltro.

O feltro puro, por sua vez, se apresenta como um bom sensor e ainda com possibilidade para ser usado como substrato para outros materiais. Pode-se produzir, relativamente, em grande quantidade e toda parte dessa produção, tem comportamento semelhante. A introdução dos nanotubos é valida. Porém, a complexidade da produção e purificação dos nanotubos, pelos dados iniciais que temos, não compensa, porque a sensibilidade aumentou pouco, com relação ao feltro puro. Outro fato é que o feltro puro é mais estável no tempo que o feltro em combinação com qualquer outro material.

Desde o inicio do trabalho foram empreendidos esforços para a fabricação de dispositivos alternativos como sensores de íons e potenciais biossensores. Muito trabalho e tempo foram gastos no desenvolvimento de procedimentos e metodologias para produzir dispositivos EGFET como sensores de $\mathrm{pH}$. Procedimentos estes, importantes para o estudo do EGFET, uma vez que eles são uma alternativa a dispositivos similares com alto custo de produção (ISFET). Estudos de preparação de composição com outros materiais, permitiram obter interessantes resultados sobre a influência de algumas nanoparticulas e polímeros, como sensores de $\mathrm{pH}$.

O conhecimento, bem como o controle da modificação das propriedades dos materiais nanoestruturados relacionados à sua dimensão e composição, é 
muito importante como base para o desenvolvimento de futuras aplicações tecnológicas. Assim, percebe-se que este campo de pesquisa se apresenta tão promissor, que a velocidade em que novas descobertas acontecem, o desafio para os pesquisadores da área é tão grande quanto os avanços.

Vale lembrar que esses materiais necessitam sim, de mais estudos como membrana seletiva, mas abre-se uma variedade de aplicações como materiais sensíveis a outros íons e também em biossensores. Essa foi uma etapa inicial de estudos desses materiais. Outros experimentos podem e devem ser realizados para a melhor compreensão do comportamento desses materiais como membranas seletivas. A pesquisa constante e diversificada levará a um melhor entendimento já que a investigação procederia de uma forma sistemática dos fatores que afetam ou podem afetar o funcionamento do dispositivo. Outro fato é que não foi possível encontrar um modelo convincente para explicar o fato da sensibilidade ter sido maior do que o esperado segundo o comportamento nernstiano.

O importante, em meio a tantas dúvidas e incertezas, é a certeza de que o conhecimento é dinâmico e as pesquisas, por isso, acontecem. Onde está o homem, estão todas as coisas. A procura do conhecimento a favor do ser humano é uma delas, seja em que tempo, espaço e área forem. A contribuição foi feita. 


\section{7}

\section{Referências Bibliográficas}

[1] J.R.Stetter, W. R. P., S. Yao. Sensor, chemical sensor, electrochemical sensors, and ECS. Journal of the Electrochemical Society, v.150, n.2. 2003, pS11-S16.

[2] Kolmokov, A; Moskovits, M; Chemical sensing and catalysis by one-dimensional metaloxide nanoestructures; Annual Review of Materials Research, 34, 2004, p.151-180.

[3] Lowinsohn, D., Bertotti, M.; Sensores eletroquimicos: Considerações sobre mecanismos de funcionamento e aplicações no monitoramento de espécies químicas em ambientes microscópios; Química Nova, v. 29, n.6, 2006, p.1318

[4] Thevenot, D. R., et al; Eletrochemical biosensors: recommended definitions and classification; Biosensor and Bioeletronics, 16 , 2001, p.121

[5] Bergveld, P.; The future of biosensor; Sensor and Actuator A, 56, 1996, p.65-73.

[6] Rosatto, S. S., et al.; Biossensores amperométricos para determinação de compostos fenólicos em amostras de interesse ambiental; Química Nova, v.24, n.1, 2001, p.77-86

[7] Chaubey, A., Malhota, B. D.; Mediated biosensors; Biosensor and Bioeletronics, 17, 2002, p. 441-456.

[8] Malhotra, B. D., Chaubey, A.; Biosensors for clinical diagnostics industry; Sensors and Actuators B, 63, 2003, 1-1.

[9] Bergveld, P.; Thirty years of isfetology what hjappened in the past 30 years and what may happen in the next 30 years; Sensor and Actuators B, 88, 2003, 1

[10] Shöning, M, J., Poghossian, A.; recent advances in biologically sensitive field-effect transistor, Analyst , 127, 2002, p.1137-1151.. 
[11] Yuqing, M., et al.; Ion sensitive field effect transducer-based biosensor; Biotechnology Advances, 21, 2003, p-527-534

[12] Yuqing, M., et al.; New technology for the detection of $\mathrm{pH}$; J. Biochem. Biophys. Methods, 63, 2005, p.1-9.

[13] Dzyadevych, S.V.; et al.; Enzyme biosensors based on ion-selective field-effect transistor; Analytica Chimica Acta, 568, 2006, p.248-258.

[14] Carvalho, R.,; Kubota.; SPR- uma nova ferramenta para biossensores; Quimica Nova, v.26, n.1, 2003, p.97-104.

[15] Wang, J.Q., J.C. Chou, T.P. Sun, S.K. Hsiung, and G.B. Hsiung, pH-based potentiometrical flow injection biosensor for urea. Sensors and Actuators B-Chemical,. 91(1-3), 2003, p. 5-10.

[16] Chen, J.C., J.C. Chou, T.P. Sun, and S.K. Hsiung, Portable urea biosensor based on the extended-gate field effect transistor. Sensors and Actuators B-Chemical, 91(1-3), 2003, p. 180-186.

[17] Luo, X.L., J.J. Xu, W. Zhao, and H.Y. Chen, Ascorbic acid sensor based on ionsensitive field-effect transistor modified with MnO2 nanoparticles. Analytica Chimica Acta,. 512(1), 2004, p. 57-61.

[18] Lakard, B., et al.; Potentiometric miniaturized pH sensors based on polypyrrole films; Sensors and Actuartors B, 122, 2007, 101-108.

[19] Korostynska, O, et al.; Review Paper: Materials and techniques for in vivo pH monitoring; IEEE Sensor Journal, v.8, n.1, 2008, 20-28.

[20] Fernandes, J.C.B., L.T. Kubota, and G.D. Neto, Ion-selective electrodes: Historical, mechanism of response, selectivity and concept review. Quimica Nova, 24, 1, 2001, p. 120-130.

[21] Torres, K.Y.C., P.C. Marzal, L.T. Kubota, and E. Bakker, Recent advances and new perspectives of ion-selective electrodes. Quimica Nova, 29,5, 2006, p. 1094-1100.

[22] M. F. M. Fernandes, C. A. L. F. Um panorama da nanotecnologia no Brasil (e seus macro-desafios). Quimica Nova, v.31, n.8. 2008, p. 2205-2213

[23] Araki, K. Estratégia supramolecular para a nanotecnologia. Quimica Nova, v.30, n.6. 2007, 1484-1490.

[24] Rao, C.N.R., G.U. Kulkarni, P.J. Thomas, and P.P. Edwards, Size-dependent chemistry: Properties of nanocrystals. Chemistry-a European Journal, 8,1, 2002, p.29-35.

[25] Choi, S.M. and H. Awaji, Nanocomposites - a new material design concept. Science and Technology of Advanced Materials, 6, 1, 2005, p. 2-10.

[26] Zarbin, A. J. G. Química de (nano)materiais. Quimica Nova, v.30, n.6. 2007, p. 14691479.. 
[27] Toma, H. E. Interfaces e organizações da pesquisa no Brasil: da química à nanotecnologia. Quimica Nova, v.28. 2005.

[28] Maciel, A.P., E. Longo, and E.R. Leite, Nanostructured tin dioxide: Synthesis and growth of nanocrystals and nanoribbons. Quimica Nova, 26, 6. 2003, p. 855-862.

[29] Wang, X., et al.; A perfect carbon nanotubos with two closed ends; Nanoscience and Nanotechnology, 2, 1, 2002, p. 33-35.

[30] Jiao, J. and S. Seraphin, Single-walled tubes and encapsulated nanoparticles: comparison of structural properties of carbon nanoclusters prepared by three different methods. Journal of Physics and Chemistry of Solids, 61, 7, 2000, p.1055-1067.

[31] Raghu, T., R. Sundaresan, P. Ramakrishnan, and T.R.R. Mohan, Synthesis of nanocrystalline copper-tungsten alloys by mechanical alloying. Materials Science and Engineering a-Structural Materials Properties Microstructure and Processing, 304, 2001, p. 438-441.

[32] lijima, S., Helical Microtubules of Graphitic Carbon. Nature, 354, 1991, p. 56-58

[33] Herbst, M.H., M.L.F. Macedo, and A.M. Rocco, Technology of carbon nanotubes: Trends and perspectives of a multidisciplinary area. Quimica Nova, 27, 6, 2004, p.986-992

[34] Souza, A.G. and S.B. Fagan, Functionalization of carbon nanotubes. Quimica Nova, 30, 7, 2007, p.1695-1703.

[35] Hierlemann, A., O. Brand, C. Hagleitner, and H. Baltes, Microfabrication techniques for chemical/biosensors. Proceedings of the leee, 91, 2003, p.839-863.

[36] Li, C., E.T. Thostenson, and T.W. Chou, Sensors and actuators based on carbon nanotubes and their composites: A review. Composites Science and Technology, 68, 6, 2008, p.1227-1249.

[37] Gooding, J.J., Nanostructuring electrodes with carbon nanotubes: A review on electrochemistry and applications for sensing. Electrochimica Acta, 50, 15, 2005, p.30493060

[38] Sharma, P. and P. Ahuja, Recent advances in carbon nanotube-based electronics. Materials Research Bulletin, 43, 10, 2008, p.2517-2526.

[39] J. Ruzicka, The seventies - golden age for ion selective electrodes Journal of Chemical Education 74, 2, 1997, p. 167.

[40] G.J. Moody, R.B. Oke and J.D.R. Thomas . Calcium-sensitive electrode based on a liquid ion exchanger in a Poly(Vinyl-Chloride) Matrix Analyst 95, 1136, 1970, p. 910.

[41] David Goldhaber-Gordon, E. A. Overview of nanoelectronic devices. Proceedings of The IEEE, v.85, n.4. 1997, 521-540.

[42] Bakker, E. Electrochemical sensors. Analytical Chemistry, v.76, n.12. 2004. p.32853298 
[43] S. Martinoia, G. M., L. Lorenzelli. Modeling ISFET microsensor and ISFET-based microsytems: a review. Sensors and Actuators B, v.105. 2005, p.14-27

[44] Yin, Li-Te., et al.; Glucose ENFET doped with $\mathrm{MnO}_{2}$ powder; Sensor and Actuators $\mathrm{B}$, 76, 2001, p.187-192.

[45] A. Hierlemann, O. B., C. Hagleitner, H. Baltes. Microfabrication techniques for chemical/biosensors. Proceedings of The IEEE, v.91, n.6. 2003.

[46] Li-Lun Chi.; Study on separative structure of EnFET to detect acetylcholine. Sensors and Actuators B, v.71. 2000, p.68-72

[47] S. Park, H. B., T. D. Chung. Electrochemical non-enzymatic glucose sensors. Analytica Chimica Acta, v.556. 2006, p.46-57

[48] Dong-Sun Kim, E. A. An extended gate FET-based biosensor integrated with a Si microfluidic channel for detection of protein complexes. Sensors and Actuators B, v.117. 2006. p.488-494.

[49] Shinwari, M.W., M.J. Deen, and D. Landheer, Study of the electrolyte-insulatorsemiconductor field-effect transistor (EISFET) with applications in biosensor design. Microelectronics Reliability, 47, 12, 2007, p.2025-2057.

[50] Buck, R.; Electrochemistry of ion-selective electrodes; Sensors and Actuators, 1, 1981, p.197-260.

[51] C.D. Fung, P. W. C., H. C.Wen. A generalized theory of an electrolyte-isulatorsemicondutor field-effect transistor. IEEE Transactions on electron devices, v.33. 1986, p.8-18.

[52] Resende, S. M.; A Física de materiais e dispositivos eletrônicos, Editora da Universidade Federal de Pernambuco - Recife, 1996

[53] Smith, C.; Microeletronic circuits, 2007.

[54] Bergveld, P., Development of an Ion-Sensitive Solid-State Device for Neurophysiological Measurements. IEEE Transactions on Biomedical Engineering, Bm17,1, 1970p. 70-\&

[55] Bergveld, P., Development, Operation, and Application of Ion-Sensitive Field-Effect Transistor as a Tool for Electrophysiology. IEEE Transactions on Biomedical Engineering, Bm19, 5, 1972 p. 342-

[56] Matsuo, T. and K.D. Wise, Integrated Field-Effect Electrode for Biopotential Recording. leee Transactions on Biomedical Engineering.. Bm21, 6, 1974,p. 485-487.

[58] Niu, M.N.; et al.; Effect of two types os surfaces sites on the characteristics of $\mathrm{Si}_{3} \mathrm{~N}_{4}$ gate pH-ISFET; Sensors and Actuators B, 37, 1996, 13-17

[59] Bobro, P. V.; Tarantov, Y. A.; Chemical sensitive of an ISFET with $\mathrm{Ta}_{2} \mathrm{O}_{5}$ membrane in strong acid and alkaline solutions, Sensors and Actuators B, 3, 1991, 75f-81. 
[60] Jung-Chuan Chou, P.-K. K., Zhi-Jie Chen. $\mathrm{SnO}_{2}$ separative structure extended gate $\mathrm{H}^{+}$-ion sensitive field effect transistor by the sol-gel technology and the readout circuit developed by source follower. Japanese Journal of Applied Physics, v.42, n.11. 2003, $6790-6794$

[61]. Li-Lun Chi, E. A. Study on extended gate field effect transistor with tin oxide sensing membrane. Materials Chemistry and Physics, v.63. 2000, p.19-23

[62] Li-Te Yin, et al.;Study of indium tin oxide thin film for separative extended gate ISFET. Materials Chemistry and Physics, v.70. 2001, p.12-16

[63] .Chou, J.C, Chiang, J.L.; Study of the amorphous tungsten trioxide ion-sensitive field effect transistor, Sensors and Actuators B, 66, 2000, p.106-108

[64] Shiun-Sheng Jan, et al, Characteristics of the hydrogen ion-sensitive field effect transistor with sol-gel-derived lead titanate gate, Analytica Chimica Acta, 469, 2002, p.205216

[65] Shiun-Sheng Jan, et al A. Preparation and properties of lead titanate gate ionsensitive field-effect transistors by the sol-gel method. Japanese Journal of Applied Physics, v.41. 2002, p.942-948

[66] Van Hal, R.E.; et al.; A general model to describe the eletrostatic potencial at electrolyte oxide interfaces, Advances in Colloid and Interfaces Science, 69, 1996. p.31-62

[67] Jung-Lung Chiang, Y.-C. C., Jung-Chuan Chou. Simulation and experimental study of the $\mathrm{pH}$-sensing property for AIN thin films. Jpn.J. Appl. Phys., v.40. 2001, p.5900-5904

[68] Jung-Lung Chiang, J.-C. C., Ying-Chung Chen. Study on ligth and temperature properties of AIN pH-ion-sensitive field-effect transistor devices. Japanese Journal of Applied Physics, v.44, n.7A. 2005, p.4831

[69] Li-Te Yin, E. A. Separate structure extended gate $\mathrm{H}^{+}$ion sensitive field effect transistor on a glass substrate. Sensors and Actuators B, v.71. 2000, p.106-111

[70] Yuang-Lung Chin, E. A. Titanium nitride membrane application to extended gate field effect transistor pH sensor using VLSI technology. Japanese Journal of Applied Physics, v.40. 2001, p6311-6315.

[71] C.L. Li, E. A. Amorphous boron carbon nitride as a $\mathrm{pH}$ sensor. Applied Physics Letters, v.84, n.14. 2004

[72] Hsu, Jung-Fu.; et al.; Silicon nanowires as pH sensors, Japanase Journal of Applied Physics, v. 44, 2005, p.2626-2629

[73] Batista, P.D, Mulato, M.; ZnO extended-gate field-effect transistor as $\mathrm{pH}$ sensor, Applied Physics Letter, 87, 2005, 143508

[74] Bousse, L. Bergveld, P.; On The Impedance of the silicon dioxide/electrolyte interface; J.Electroanal chem., 152, 1983, 25-39 
[75] Yates, D.E.; et al; J. Chem. Soc. Fraday Trans, 1, 1974

[76] Guozhong Cao, D. L. Template-based synthesis of nanorod, nanowire, and nanotubos arrays. Advances in Colloid and Interface Science, v.136. 2008,p45-64.

[77] Xu, Tao., et al.; Modification of nanostructured materials for biomedical applications, Materials Science and Engineering C,27, 2006, p579-594

[78] Dai, R.; et al.; Novel nanoestructures of functional oxides synthesized by thermal evaporation, Ad. Funct. Mater, 13, n.1, 2003, p.9-23

[79] Zhang, W.X., Z.H. Yang, Y. Liu, S.P. Tang, X.Z. Han, and M. Chen, Controlled synthesis of Mn3O4 nanocrystallites and MnOOH nanorods by a solvothermal method. Journal of Crystal Growth, 263, 2004, p. 394-399.

[80] Zhang, Y.C., T. Qiao, X.Y. Hu, and W.D. Zhou, Simple hydrothermal preparation of gamma-MnOOH nanowires and their low-temperature thermal conversion to beta-MnO2 nanowires. Journal of Crystal Growth, 280, 2005, p. 652-657

[81] Li, L.L., Y. Chu, Y. Liu, and L.H. Dong, Synthesis and shape evolution of novel cuniform-like MnO2 in aqueous solution. Materials Letters, 61, 2007, p. 1609-1613.

[82] Zhang, Z.Q. and J. Mu, Hydrothermal synthesis of gamma-MnOOH nanowires and alpha-MnO2 sea urchin-like clusters. Solid State Communications, 141, 2007, p. 427-430.

[83] Luo, X.L., J.J. Xu, W. Zhao, and H.Y. Chen, Ascorbic acid sensor based on ionsensitive field-effect transistor modified with MnO2 nanoparticles. Analytica Chimica Acta, 512, 2004 , p. 57-61.

[84] H.W.Kroto, E. A. C60: Buckminsterfullerene. Nature, v.318. 1985

[85] lijima, S. Helical microtubules of graphitic carbon. Nature, v.354. 1991.

[86] Sumio lijima, T. I. Single-shell carbon nanotubes of 1-nm diameter. Nature, v.363. 1993.

[87] D.S.Bethume, E. A. Cobalt-catalysed growth of carbon nanotubes with single-atomiclayer walls. Nature, v.363. 1993.

[88] Balasubramanian, K., Burghard, M., Biosensor based on carbon nanotubos; Anal Bioanal. Chem., 385, 2006, 452

[89] Pumera, M., S. Sanchez, I. Ichinose, and J. Tang, Electrochemical nanobiosensors. Sensors and Actuators B-Chemical,123, 2007, p. 1195-1205.

[90] Sobhi Daniel, E. A. A review of DNA functionalized/grafited carbon nanotubes and their characterization. Sensors and Actuators B, v.122. 2007, p.679-682.

[91] Yan-Li Liu, E. A. Gas sensing properties of tin dioxide coated onto multi-walled carbon nanotubes. Thin Solid Films, v.497. 2006, p355-360. 
[92] E.C. Almeida, A. V. D., J.M. Rosolen, V. J. Trava-Airoldi, N.G. Ferreira. Structural and voltammetric studies at boron-doped diamond electrode grown on carbon felt produced from different temperature. Diamond \& Related Materials v.14. 2005, p.679-684.

[93] Yan-Xiang Wang, Q. W. Evaluation of carbonization tar in making high performance polycrylonitrile-based carbon fibers. Journal of Applied Polymer Science, v.104. 2007, p1255-1259.

[94] S.R.Dhakate, O. P. B. Effect of carbon fiber surface functional groups on the mechanical properties of carbon-carbon composites with HTT. Carbon, v.41. 2003, p11931203.

[95] E.C. Almeida, A. F. A., M.R. Baldan, N.A. Braga, J.M. Rosolen, N.G. Ferreira. Nanocrystalline diamond/carbon felt as a novel composite for electrochemical storage energy in capacitor. Chemical Physics Letters v.438. 2007.

[96]. E.C. Almeida, M. R. B., J.M. Rosolen, N.G. Ferreira. Impedance characteristics of the diamond/carbon fiber electrodes for eletrical double-layer capacitor. Diamond \& Related Materials. 2008.

[97] G.M.Nascimento, E. A. Synthesis and characterization of single-wall-carbonnanotube-doped emeraldine salt and base polyaniline nanocomposites. Journal of Polymer science:Part A:Polymer chemistry, v.43. 2005.

[98] J.M.Rosolen, E. A. Carbon nanotube/felt composite electrodes without polymer binders. Journal of Power Sources, v.162. 2006

[99] L.A.Montoro, C. A. L., J.M.Rosolen, E. Cazzanelli, G. Mariotto. Study of oxigen influence in the production of single-wall carbon nanotubes obtained by arc method using Ni and Y catalyst. Diamond \& Related Materials, v.12. 2003.

[100] T.Jeevananda, S., S. Seetharamu, S. Saravanan, L. D'souza. Syntesis and characterization of poly (aniline-co-acrylonitrile) using organic benzoyl peroxide by inverted emulsion method. Synthetic Metals, v.140. 2004.

[101] Chiang, C.K., et al.; Electrical conductivity in doped polyacetylene, Phys. Rev. Lett., 39, 17, 1977, p.1098-1101

[102] Shirakawa, H., et al.; Synthesis of electrically conducting organic polymers: Halogem derivatives of polyacetylene;. J. Chem. Soc. Chem. Commum, 16, 1977, p.578-580

[103] Pron, A.; Rannou. P.; Processible conjugated polymers: from organic semicondutctors to organic metals and superconductors, Progress in Polymer Science, 27, 2002, p.135-190.

[104] Oliveira, M., Cossielo, R, Atvars, T; Akcelrud, L., Dispositivos poliméricos eletroluminescentes, Qumica Nova, v.29, n.2, 2006, p.277-286

[105] Mattoso, L.H.; Polianilinas: Sínteses, estrutura e propriedades; Química Nova, 14 1996, p. 388-399; 
[106] Travain, S.; Bianchi, R., Colella, Enia., Andrade, Adnei.; Dispositivos Flexíveis de Monitoramento de pH e de deflexão mecânica à base de polianilina,.Polímeros: Ciências e Tecnologia, v.17, n.4, 2007, p.334-338

[107] Shirakawa, H., et al.; Synthesis of electrically conducting organic polymers: Halogem derivatives of polyacetylene;. J. Chem. Soc. Chem. Commum, 16, 1977, p.578-580

[108] Hegger, A.J., Semiconducting and metallic polymers: The fourth generationof polymeric materials, Synth, Met., 125, 1, 2002, p.23-42

[109] Zoppi, R. A, Paoli, M.A., Aplicações tecnológicas de polímeros condutores: perspectivas atuais. Química Nova, 16,. 6, 1993, p.560-569

[110] MacDiarmid, A. G, Epstein, A.J., Polyanilines - A novel class of conducting polymers., J. Faraday Dis. Chem. Soc, 88, 1989, p.317-332

[111] Genies, E. M., Polyaniline: A historical survey., Synth. Met, 36, 2, 1990, p.139-182

[112] Stejskal, J., et al., The genesis of polyaniline nanotubos, Polymer, 47, 2006, p.82538262

[113] Guo, et al., Synthesis of polyaniline/multi-walled carbon nanotube nanocomposites in water/oil microemulsion 